CORVINUS UNIVERSITY OF BUDAPEST

\title{
THE IMPACT OF PATENT PROTECTION ON ENVIRONMENTAL AND GENERAL INNOVATIONS
}

Ph.D. thesis

Supervisor: Dr. Gyula Zilahy

\section{Gergely Szücs}


DOI: $10.14267 /$ phd.2015020 


\section{Gergely Szücs \\ 1118 Budapest \\ Beregszász út 81.}




\section{Department of Environmental Economics and} Technology

Supervisor:

Dr. Gyula Zilahy

Associate Professor

(C) Gergely Szücs 
CORVINUS UNIVERSITY OF BUDAPEST

Doctoral School of Management and Business Administration

\title{
THE IMPACT OF PATENT PROTECTION ON ENVIRONMENTAL AND GENERAL INNOVATIONS
}

\author{
Ph.D. thesis
}

Gergely Szúcs

Budapest, 2014 
DOI: $10.14267 /$ phd.2015020 


\section{Table of Contents}

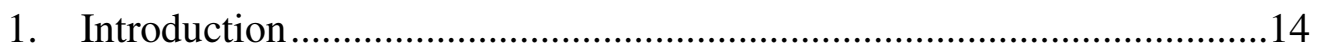

2. Theoretical overview - Innovation and intellectual property ....................17

2.1. The concept and significance of innovation..........................................17

2.2. The types of innovation, innovation strategies ...................................21

2.3. The concept and significance of environmental innovation .................27

2.4. The types of environmental innovation, environmental

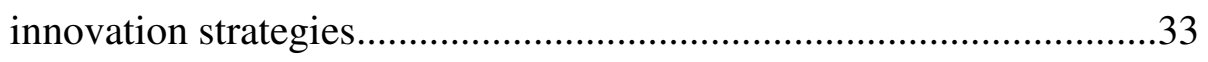

2.5. The concept, significance and types of intellectual property ................41

2.6. The alternative approaches of the utilization of intellectual property...44

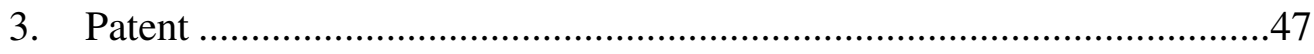

3.1. The concept and characteristics of patent ……………………….........47

3.2. Theories related to patent .................................................................50

3.3. The significance and alternatives of patents ......................................5

3.4. The fundamental directions of patent research ....................................64

3.4.1. Patent propensity and the value of patents .....................................65

3.4.2. The strategic application of patents................................................79

3.4.3. Patent infringement trials ............................................................... 89

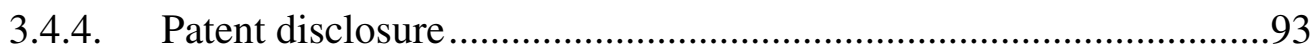

3.4.5. Patents and environmental innovations ...........................................94

3.4.6. The effect of patents on innovation ...............................................99

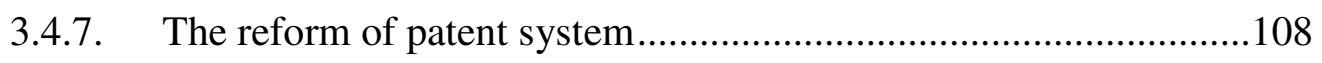

4. The situation of innovation in Hungary .................................................112

5. Empirical research of the patenting activity of innovative firms............132

5.1. Research questions .........................................................................132

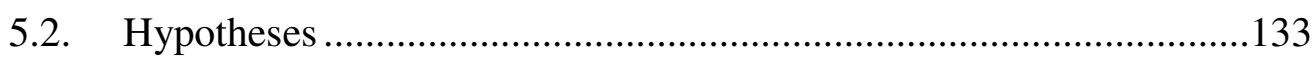

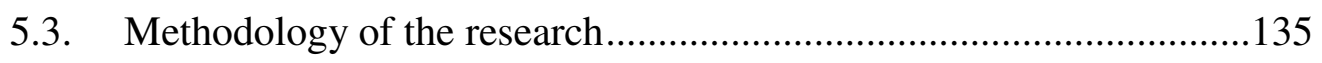

5.4. Survey and sample characteristics .....................................................145

5.5. Basic characteristics of the sample …………………………….......149

5.6. Impact of patent protection on innovations........................................154

5.6.1. Innovation in the absence of the patent system ...............................155

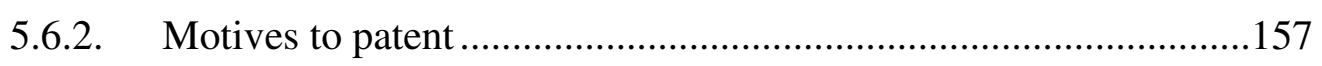




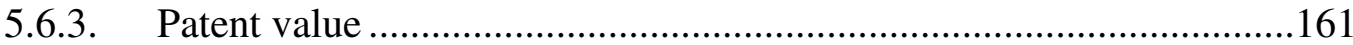

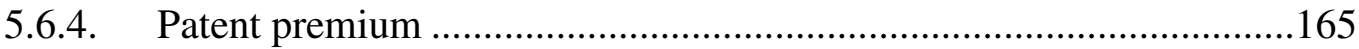

5.6.5. Effective protection time (industry specialties) ................................167

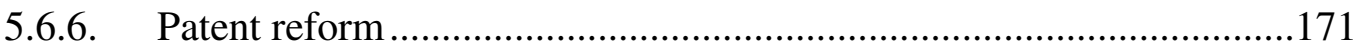

6. Examination of the research hypotheses ...............................................174

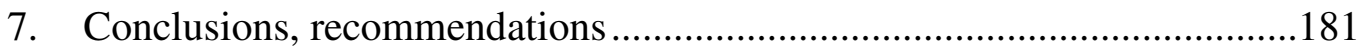

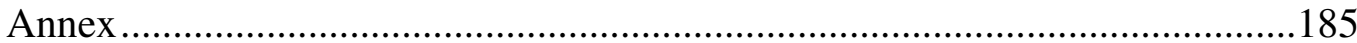

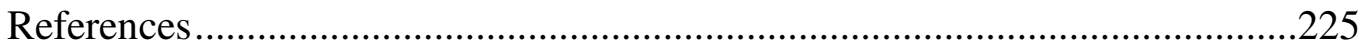

The author's own publications related to the topic ...........................................251 


\section{List of Tables}

Table 1.: The forms of protection of intellectual products ...............................43

Table 2.: The significance of tools for the protection of innovation .................61

Table 3.: Machinery industry suppliers, as a source and user of pollution

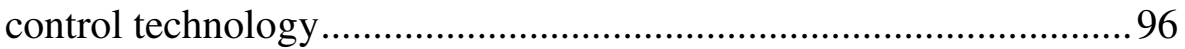

Table 4.: The ratio of innovation, which would not have been developed or introduced in the market in the lack of patent protection

Table 5.: Studies examining the connection between patents and innovations

Table 6.: Hungary's „Global Innovation Index 2013” rankings

Table 7.: R\&D expenditures of enterprises in Hungary 2012, according to main branches 


\section{List of Figures}

Figure 1.: The cycle of innovation 20

Figure 2.: The development and changing rate of generations of a product family. 23

Figure 3.: Environmental innovation as a special case of innovation 27

Figure 4.: The stages of environmental development ..................................... 34

Figure 5.: Different directions of environmental protection ............................ 36

Figure 6.: The categories of intellectual property protection.......................... 42

Figure 7.: The classification of the advantages of patents .............................. 56

Figure 8.: Reasons for not patenting innovations ............................................. 60

Figure 9.: The connection between R\&D and patenting.................................66

Figure 10.: The change of patent propensity in time ..................................... 70

Figure 11.: The connection between patent propensity and firm size ............. 72

Figure 12.: The distribution of the values of patents (EUR) ........................... 75

Figure 13.: The reasons for patenting of product innovations ......................... 82

Figure 14.: The reasons for patenting of product innovations ......................... 82

Figure 15.: The significance of motivations to patent ................................... 83

Figure 16.: Patent infringement trials of patents related to smart phones

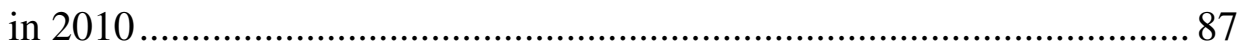

Figure 17.: U.S. patent lawsuits filed in District Courts ................................ 89

Figure 18.: Growth rate of claimed priorities patenting for the selected clean energy technologies 98

Figure 19.: Aggregate profits from patents and aggregate litigation costs for U.S. public firms 103

Figure 20.: Number of triadic patents families and trademarks registered abroad per 1 million people between 2007 and 2009; OECD and G20 countries

Figure 21.: The innovation performance of EU member states ..................... 114

Figure 22.: EU Member state growth performance ...................................... 114

Figure 23.: Domestic patent applications of Hungarian applicants ............... 116

Figure 24.: Patent applications of Hungarian applicants .............................. 117

Figure 25.: The development of R\&D expenditures in Hungary 2000-

$2012(\mathrm{GDP} \%)$ 
Figure 26.: Volume index of investments in Hungary

Figure 27.: Number of companies implementing environmental innovation between 2006 and 2008

Figure 28.: Ratio of companies implementing technological innovation broken down according to number categories

Figure 29.: Applications for the Hungarian Innovation Grand Prize recognised as innovations 1992-2013.

Figure 30.: Industrial breakdown of the population (patented innovations applied for the HIGP 2002-2013)

Figure 31.: Ratio of Hungarian Innovation Grand Prize award categories between 2002-2013: patented innovations and all innovations.

Figure 32.: Industrial breakdown of the population and the sample.

Figure 33.: Ratio of award categories within the population and the sample

Figure 34.: Position of respondents within the company \& relation to the patent.

Figure 35.: Size distribution of the companies in the sample by employee number in the year of the innovation

Figure 36.: Size distribution of the companies in the sample by sales volume (Million HUF) in the year of applying for the HIGP ....

Figure 37.: Ratio of firm size categories of the PatVal II Hun database and of the sample based on employee number

Figure 38.: Distribution of the types of studied environmental innovations

Figure 39.: Importance of patenting motivations on a 1-5 scale.

Figure 40.: Differences in motivations to patent in PatVal II Hun, PatVal

II and the sample

Figure 41.: Motivations to patent in case of environmental and non environmental innovations

Figure 42.: Distribution of the value of patents in the sample (values in EUR)

Figure 43.: The share of the legal protection within the patent value (\%)...... 165

Figure 44.: Decrease in the value of the innovation in the absence of patent protection but in the presence of other methods (\%) 
Figure 45.: Distribution of effective lifetime of innovations after eliminating two companies with values of 60 year and 100 year........... 167

Figure 46.: Distribution of the effective lifetime of innovations (values in years)

Figure 47.: Distribution of difference in years between effective and normal lifetime of innovations after eliminating one company with a value of 30 year

Figure 48.: Average normal and effective innovation lifetime in years in selected industries. 169

Figure 49.: Distribution of opinion of firms about possible reforms 172

Figure 50.: Differences in motivations to patent in PatVal II and the sample..... 


\section{Acknowledgements}

I would like to express my gratitude first of all to my current supervisor Gyula Zilahy for his continued support and guidance over the last two years, as well as to my previous supervisor Sándor Kerekes who inspired me to join the Ph.D. program and guided me through the hard times of selecting a research topic and writing the draft-thesis. I also owe special thanks to Anna Széchy who supported me during these years with both professional and friendly advice. While working on the dissertation I received a lot of valuable advice from Ágnes Zsóka, Gábor Harangozó, György Pataki and József Bisztriczky. I would like to thank dr. Gábor Németh and Dorottya Simon who helped a lot in the finalisation of the questionnaire and to the students who interviewed the companies, especially Kristóf Zékány.

Heartfelt thanks are due to my wife and two children for their support when working on my thesis from time to time, and apologies for me not being fully able to devote myself to them. 


\section{Introduction}

Patents similar to the ones we have today were created in the 18th century, first in England in 1718. Later, patent systems were established in almost all countries. The TRIPS Convention ${ }^{1}$ in 1995 ensured that patent protection exists in case of all WTO member states (Hall and Harhoff, 2012). The philosophy behind setting up patents and other types of intellectual property protection was based on the belief that monopoly is able to stimulate innovation. Until the last decades this belief was widely accepted. From the middle of the 20th century more and more researchers have warned that further empirical studies are needed to assess the effects of the patent protection on innovative activity in the modern economy. Since then several researchers have studied this topic, and research activity has accelerated in the last decades.

Still today, the most important and current question of the research of patents is whether the existence of the patent system enhances innovation and ultimately social utility. Regarding this topic, a number of studies try to analyze, what reforms of the patent system could aid the positive effects and hinder the negative ones. There are only few studies that are able to give at least a partial answer to these questions. The main reasons for this are the huge variance between the specific innovations, and the sometimes large-scale externality effects which are hard to assess. So, the studies which are usually based on large scale representative surveys fail to give universal findings.

The effect of the patent system on environmental innovations is a much less researched topic. Still, this field is worth studying as environmental innovations have several unique attributes which could alter the patent system's effect on them. The main reasons for this are the double-externality effect, the different attitude of the companies towards these kinds of innovations and the greater need for their efficient diffusion.

The two main goals of my research are the contribution to the more thorough understanding of the advantages and disadvantages of the patent system for

\footnotetext{
${ }^{1}$ Trade-related Aspects of Intellectual Property Rights
} 
innovative companies, and the study of the diversity of these effects in the special case of environmental innovations. In the latter case I also apply an approach different from most studies, as I study environmental innovations not only in the environmental sector, but in all industries. I study the above in the special case of Hungary.

The relevance of this topic is underpinned by the current scientific debate around patents. Patents have constituted a part of economy for several hundred years and until the last decades, their efficiency in promoting innovation was not seriously questioned. After this, views considering dominant theories too simplifying, too abstract compared to reality and old fashioned have emerged. A number of newer and re-current theories doubt that patents in their current form are useful enough for society. Numerous empirical surveys have been carried out in the topic, but it is hard to see completely clearly because the measurement of the effects of patents is problematic. The innovative activity constituting the base for patents is hard to examine since it depends on a large number of factors. Thus, general conclusions about the effects of patents on innovation can be drawn only with limitations.

Empirical research has already been done on the effects of patents on environmental industries and technologies. Only few studies about the effect of patents on environmental innovations in the non-environmental sector have been carried out until today. The significance of this is that environmental innovations have further characteristics compared to general innovations, due to their positive effects on the environment or less negative ones compared to alternatives. This is why the effects of patents in case of environmental and general innovations are different. The research is able to contribute to the already existing knowledge base by examining the connection between patents and innovations from the aspect of environmental innovations, too. This examination is important because of the key role of environmental innovations are playing in achieving sustainability. Furthermore, it can be also interesting to understand which potential changes of the patent system would foster environmental innovations.

During the research of patents there have been few empirical studies, which could concretely measure the effects of patents on innovations and social 
welfare. The reason behind this is that the studies in literature are mostly based on large sample representative surveys. It is hard to draw general conclusions from this, due to the significant differences between innovations. The more detailed examination planned in the research can contribute to the existing knowledge with more in-depth knowledge about the topic, and can promote the adjustment of the patent system considering environmental innovations to a larger degree.

The thesis is built up the following way: in the theoretical part, first innovations and environmental innovations are defined, their significance, types and possible innovation strategies are introduced. This is followed by the presentation of the concept, significance, form of protection and alternative utilization opportunities of intellectual property. The most emphasized theoretical part of the thesis is the introduction of patents and the summary of the main research results on their significance in the induction of innovation. I will also pay attention to the studies carried out in the field of innovations with environmental effects. Furthermore, a detailed overview of the wide spectrum, often contradictory opinions about the institution of patent system and the proposed reform will be provided. Since I plan to examine Hungarian companies, it is also important to get to know the context of the research. This is why the role of innovation in Hungary, the current trends and potentials in innovation activities will be presented. In the empirical part I present the hypotheses and the methodology of the research and introduce the results. Finally the thesis ends with the examination of the research questions, conclusions and recommendations. 


\section{Theoretical overview - Innovation and intellectual property}

To be able to examine the connection between patenting and innovation it is first indispensable to present the theoretical background and the scientific concepts related to the topic. In the next subchapters I will describe innovations, especially environmental innovations and intellectual property. In the next sections I will describe the notion of innovation, especially environmental innovations and intellectual property.

\subsection{The concept and significance of innovation}

The concept of innovation was created and introduced to economics by Schumpeter in the first half of the 20th century. Schumpeter considered economics as being in constant change because of technological development, while enterprises competing with each other through their innovative activity, just like in the area of prices. According to Schumpeter, innovation is the successful introduction of an invention to the market, which is a new combination of factors (Schumpeter, 1980. p. 111.). He identified five types of innovation:

1. The production of new goods not yet known by the consumers or a new quality of certain goods.

2. The introduction of a new method of production not yet known in the given industry, which should definitely not be based on new scientific discovery, and which can also be a new commercial procedure related to a certain good.

3. A new distributional opportunity, which can mean the opening of a market where the given industry of the given country has not yet been introduced, whether this market existed before or not.

4. The conquest of new sources of supply for raw materials or semi-finished products, whether this source of supply existed before, was not taken into consideration or was not considered appropriate or had to be established first. 
5. The establishment of a new organization - e.g. the establishment of monopoly through the formation of trusts - or its abolishment. (Schumpeter, 1980. p. 111.)

The definition widespread in the scientific literature of innovation published in the so-called Oslo manual is based on the definition of Schumpeter. According to this, 'innovation is an implementation of a new or significantly improved product (good or service), or process, a new marketing method, or a new organizational method in business practices, workplace organization or external relations' (OECD, 2005, p. 46.). This definition differentiates between four types of innovation:

1. Product innovation: the introduction of a product or service, which - in relation to its features and function - is new or significantly renewed. This contains the detailed technical descriptions related to development, the components and materials, the built-in software, the user friendly feature or other functional characteristics.

2. Process innovation: the implementation of a new or significantly renewed production or transportation method. It covers the significant changes arising in technology, apparatus and/or softwares.

3. Marketing innovation: the application of new marketing methods resulting in significant changes in product planning, packaging, the introduction of products to the market, marketing of products or pricing.

4. Organizational innovation: the implementation of new organizational methods in the business practice of the company, the organization of work or external relations.

The definition of Drucker (1985, p.42.) is based on an approach different from the ones mentioned above. According to this innovation is "whatever changes the wealth-producing potential of already existing resources.' According to this interpretation innovation forms the basis of an enterprise, while the definition does not contain any restrictions related to the novelty feature of innovation. 
It is widely accepted that innovation is one of the main driving forces of competitiveness and economic development (see e.g. Pakucs (2003), Pitti (2008), Losoncz (2008), Inzelt (2011), Guellec et al. (2001)).

In modern economies, knowledge, research and innovation play important roles. For continuous innovation it is necessary to gain and preserve the knowledge of a given area. In modern knowledge based economies the two main permanent competitive advantages of companies are their ability to innovate and to adapt the innovations of others (Lengyel, 2001).

Due to the key role of innovation in competitiveness, numerous countries and companies strive for the fostering of innovation. One of the most important influencing factors of innovation is the research and development activity of enterprises, however, innovation also depends on numerous other factors, e.g. the level of education, consultancy, infrastructure or the availability of financial resources, industrial legal protection and incubational opportunities (Balogh, 2012).

According to Iványi and Hoffer (2010, p. 47.) research and development is the essence of innovative activity. However, innovation is not a one-time activity, it consists of numerous sub-processes. To ensure that the results of research and development activities appear in new applications, further innovative activities are also necessary: planning, engineering, launch of production, marketing or e.g. license purchase. Innovation can also be grasped through $\mathrm{R} \& \mathrm{D}$ expenses, however innovation is more than this in both intellectual and material expenditures (Iványi and Hoffer, 2010). 
Figure 1.: The cycle of innovation

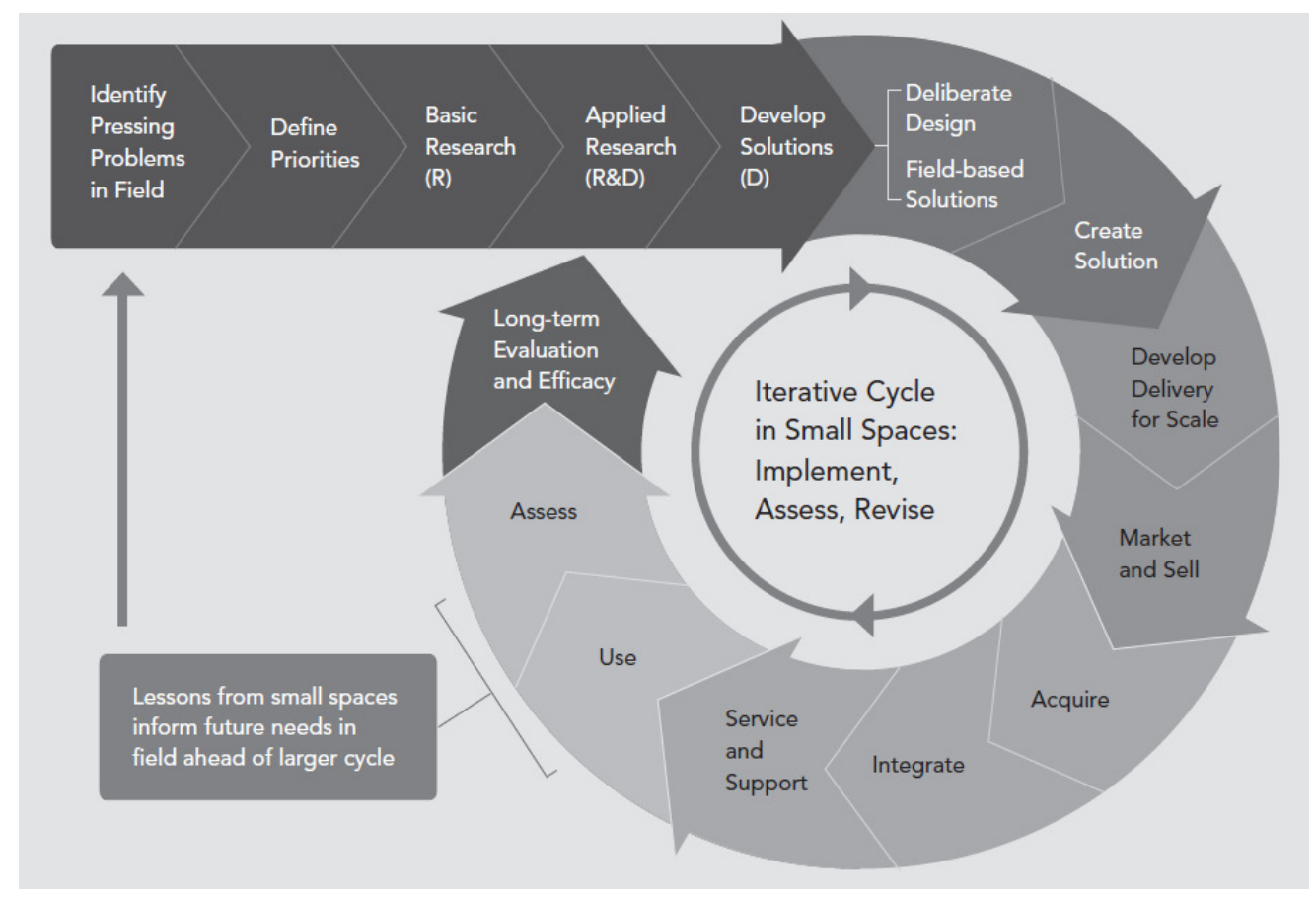

Source: Smith and Petersen, 2011

According to Hoffer and Katona (2012), the activities of innovation beyond $\mathrm{R} \& \mathrm{D}$ are necessary for the application of innovative technologies and methods, their transmission to the market and integration, as Figure 1 also shows. According to Smith and Petersen (2011) the innovation process starts with identifying problems and defining priorities. After the R\&D activity, there are several steps through which the innovation transforms into a product, reaches the market, is used, and finally the results of the whole process are assessed and evaluated.

Thus innovation can also be considered as the practical application of research results. The significant difference between research and development and the following innovative steps is that the latter requires the investment of much more financial resources. Although the research and development phase implies high risk, but requires much lower expenditure than the following innovative steps (Hoffer and Katona, 2012).

According to Aho et al. (2006), besides the increase in R\&D expenditures the establishment of innovation friendly market and environment are necessary to increase innovation, the resources spent on high-level science, industrial $R \& D$ and scientific-industrial relations should be increased, $R \& D$ 
productivity should be improved and higher mobility is needed regarding human resources, capital and knowledge.

Barysh et al. (2008) also point out that it is not possible to measure innovation only through an R\&D index and higher R\&D expenditure does not imply higher corporate success. It is also important to consider other factors such as sectorial competition, the intensity of competition or the return on R\&D expenditures (Barysh et al. (2008), quotes Némethné Pál (2011)).

The research of Gambardella et al. (2005) expressively describes the connection between $R \& D$ and innovation. According to their result regarding Western-European companies, in case of more than half of the patents in the sample, the innovation was a result of a targeted R\&D activity. In case of $12 \%$ of the patents innovation was an unexpected result of R\&D activity. It case of $34 \%$ of the patents, innovation was realised without substantial R\&D activity.

It is important to highlight that economic advantages (from the point of view of the whole society) based on new technologies originate much more from the diffusion process, i.e. the adaptation of existing technologies, than the narrowly interpreted technical development containing invention and innovation (Bronwyn, 2006, Losoncz, 2008). However this adaptation in most of the cases is not a simple copying, but requires significant creative performance (Osman, 2006).

\subsection{The types of innovation, innovation strategies}

Innovations can be differentiated from numerous aspects, such as the effect of innovation (radical or incremental), the source of innovation (technological opportunity or market need), or the source of knowledge necessary for innovation (inside or outside of the company). The type of the innovation partly depends on the facilities of the company, and partly on its innovation strategy. Innovation strategy determines the company's relation to intellectual property. The next sections introduce the types of innovation and the possible innovation strategies of the company.

The classification according to the effect of innovation is based on the process of technological development, the so-called ' $S$ ' curve model, which 
was created by Tarde (Valente, 1995). According to this, when a new basic technology emerges, usually more alternatives compete to gain a leading position. As time goes by, usually one of these alternatives becomes dominant, widespread and determines the direction of development (Dosi, 1988) ${ }^{2}$. Dominant technology will continuously become more and more efficient until it reaches the limits of its development, and will not be able to fulfil changing consumer needs any more (Kemp et al., 1998). In this case a new basic technology will take over its role, there will be a discontinuity in development and a new $\mathrm{S}$ curve will start. The technical development of the succeeding generations of a given product family also shows a picture similar to the development of basic technologies, as it can be seen on the following figure too. Continuous technical development is built up by the elimination of initial errors of the product, smaller constructional and technological innovations, constructional improvements, which will be implemented in the framework of continuous, incremental innovation. The sharp, radical technical development is enabled by the discovery of such a new constructional or technological principle, which ensures a potentially higher product niveau than the previous version (Iványi and Hoffer, 2010).

${ }^{2}$ It depends on numerous factors, which technology will become a paradigm. Based on experiences not necessarily the best, most efficient alternative will spread in the widest circle. 
Figure 2.: The development and changing rate of generations of a product family

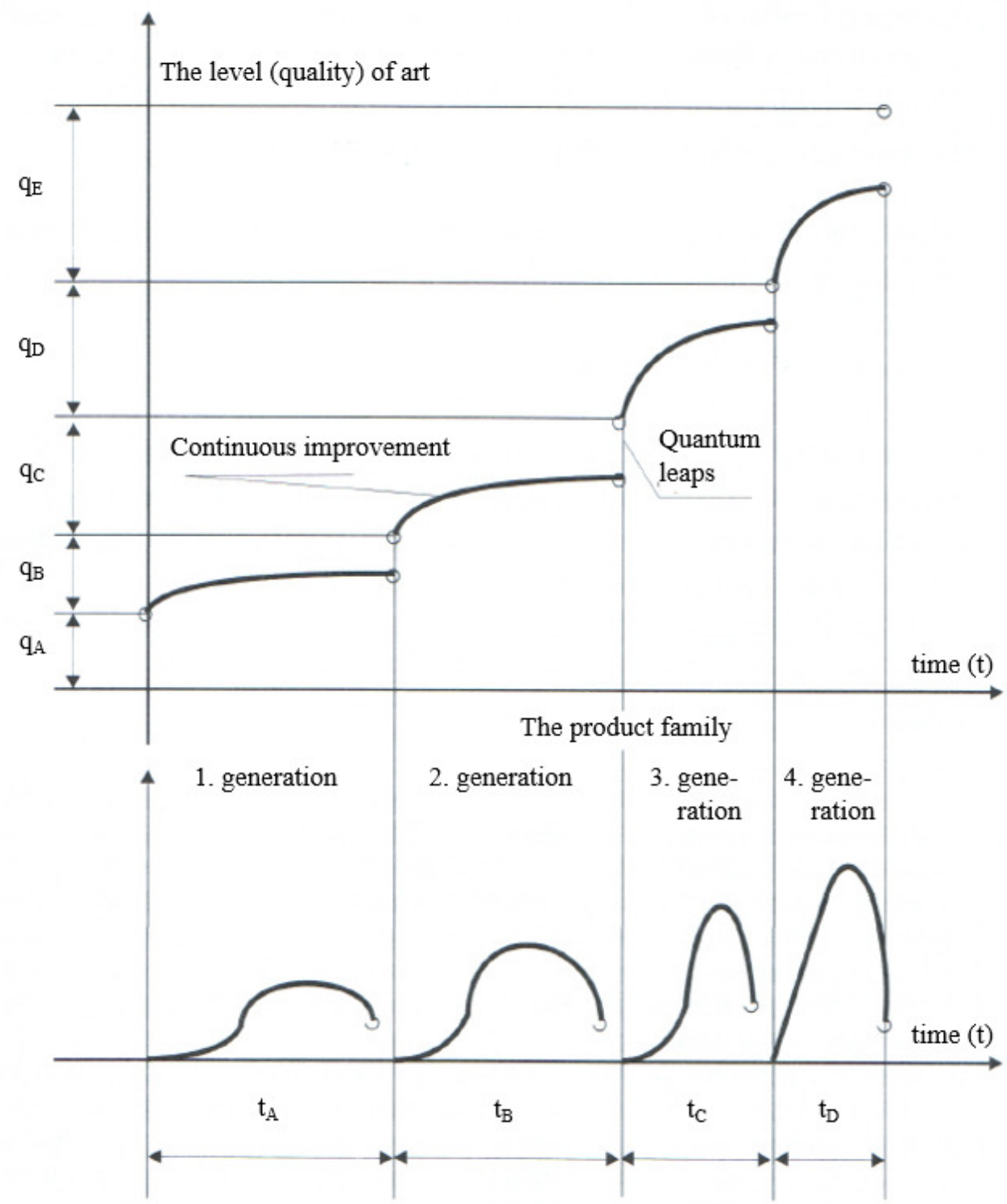

Source: Iványi and Hoffer, 2010, p. 55., quotes Iványi and Hoffer, 2004

The classification according to the source of innovation is based on whether the establishment of innovation was induced by technological opportunity or market demand. The innovation achieved due to technological opportunity is enforced by scientific and technical development, forcing consumers and companies to develop and apply novelties. However, innovative pressure is often felt from the demand side, so the request for novelty can be traced back to market or social need. The appearance of innovation induced by 
technological opportunity requires mainly basic research, while the innovation induced by demand usually needs applied research (Iványi and Hoffer, 2010). According to Dodgson et al. (2008) these two models are not necessarily separated from each other, both sources have an effect on innovative processes. Innovation is more often seen as a phenomenon, where the market and technological processes interact with each other in a complex way. Conscious strategic processes within the company, organizational solutions supporting innovation and the company's innovative network gain ever more importance.

According to Inzelt (2010) depending on the source of knowledge necessary for innovation we differentiate between the closed and open innovation model. As per the closed model dominant until the 1960's, the main characteristic of the innovation process was the knowledge produced within the company and its utilization. In the latter period, external knowledge was incorporated within the frames of open innovative activity. In order to implement innovations, companies tend to cooperate with external partners more and more. These can be suppliers, customers, universities, competitors, etc. The reason for this is that only based on their own resources, companies are even less able to preserve their competitiveness. The operation of research $\&$ development and innovative networks is important in the open innovative system, as they are able to contribute to the establishment of equilibrium between indoor and outof-door R\&D capacities themselves. Indoor capacities are still important during the choice of external $R \& D$ partners, reaching decisions connected to the purchase of new knowledge and technology and the support of the application of the purchased technology. An extreme case of the open innovation model (and the next step in innovative development) is the unlimited, globally open innovation model (Inzelt, 2010).

The theory of globally open innovation is originated from Chesbrough (2006), and differs from open innovation mostly in its innovative approach. Although Chesbrough calls it 'open innovation', from the viewpoint of this thesis and to avoid confusion with the previous theories, 'globally open innovation' is a better name and describes the attributions of the innovation better. According to Chesbrough's definition this is 'the use of purposive 
inflows and outflows of knowledge to accelerate internal innovation and expand the markets for external use of innovation' (Chesbrough, 2006, p. 1.). The joint use of external and internal ideas is recommended for companies during the development of their innovations. The process of globally open innovation creates platforms and systems by uniting internal and external ideas. The strategy of companies is directed towards the establishment of the frameworks of these systems. Companies own numerous patents ensuring their smooth operation, but these patents have only marginal values for them. In the spirit of globally open innovation these patents should be utilized in order to launch promising new activities or such patents have to be obtained by selling unnecessary patents. Globally open innovation is accompanied by the much better utilization of patents and can open new directions of development (Chesbrough, 2012).

Open innovation also brings about new challenges for the institution of intellectual property. While the protection of innovations can be efficiently solved by various ways (e.g. business secret) within a company, numerous studies underpin that in case of innovations established through co-operations with external partners the role of intellectual property is much more emphasized (e.g. Cohen et al., 2000).

In order to handle decisions, processes related to innovation, a conscious innovation strategy is needed, which has to be suitable for the handling of the uncertainty regarding innovation. The ability for responding to unexpected events becomes the key to success. According to Dodgson et al. (2008) the innovation strategy has to handle three basic elements: resources related to innovation, the innovative ability of the company and the innovation processes. The classification of innovation strategies is usually based on how cutting-edge the company is in the areas of innovative activities.

Dodgson et al. (2008) differentiate between the following basic strategies:

1. Proactive innovation strategy: The company strives for the implementation of world class innovation, carries out intensive R\&D activities, is also ready to implement high risk, radical innovations. In case of the application of 
such a strategy the protection of intellectual property can be extremely important.

2. Active innovation strategy: The company strives for the quick following of world class innovations, its $\mathrm{R} \& \mathrm{D}$ activity mostly focuses on applied research, striving for medium risk, especially incremental innovations. The protection of intellectual property compared to the previous strategy is less emphasized, but can be important.

3. Reactive innovation strategy: The company awaits developments, takes over novelties only later. It implements only low risk, incremental developments and purchases the necessary knowledge especially from external sources. The protection of intellectual property is usually not important.

4. Passive innovation strategy: The company does not carry out formalized innovation activities, introduces incremental novelties responding to external pressure only in an ad hoc way, does not take risks in this area. The protection of intellectual property is not important.

Iványi and Hoffer (2010, p. 40-41.) in their classification similar to the above differentiate between the following innovation policies:

1. Proactive technical development policy requires certain lead in the given area. The condition for this is to ensure the critical $R \& D$ potential presuming success and the effective demand enabling return. The proactive development policy promises the implementation of a world class product and the realization of high innovation profit, quick return. The protection of intellectual property in case of this policy can be of utmost significance.

2. Reactive technical development policy can be taken into consideration usually in case of conditions not meeting the critical potential. In this case the development or adaptation of a not necessarily world class, but medium quality, lower price range product and service can be the target. This policy is characterized by lower level $\mathrm{R} \& \mathrm{D}$ expenditures and lower profit. In certain cases the protection of intellectual property can be important.

3. Adaptational technical development policy is the common version of the reactive one. In this case the company takes over or purchases technology in 
the form of intellectual property. The task of the company is restricted to 'localization', the protection of intellectual property is not emphasized.

In certain cases, adaptational development policy enables the sale of a relatively modern product only in the market areas determined by the contract. Its great advantage is that the company is freed from the burdens and risk of capital intensive development, while it also wins time by taking over the ready knowledge material. In case of world class developments it also often happens that certain sub processes are solved by the purchase of intellectual property and there is a strive for the incorporation of own novelties only in case of critical technologies. This is called combined development policy (Iványi and Hoffer, 2010).

\subsection{The concept and significance of environmental innovation}

The concept of environmental innovation does not have such a broadly accepted definition as general innovations. The conceptual framework of environmental innovation is expressively described by Huppes et al. (2008) in the following figure.

Figure 3.: Environmental innovation as a special case of innovation

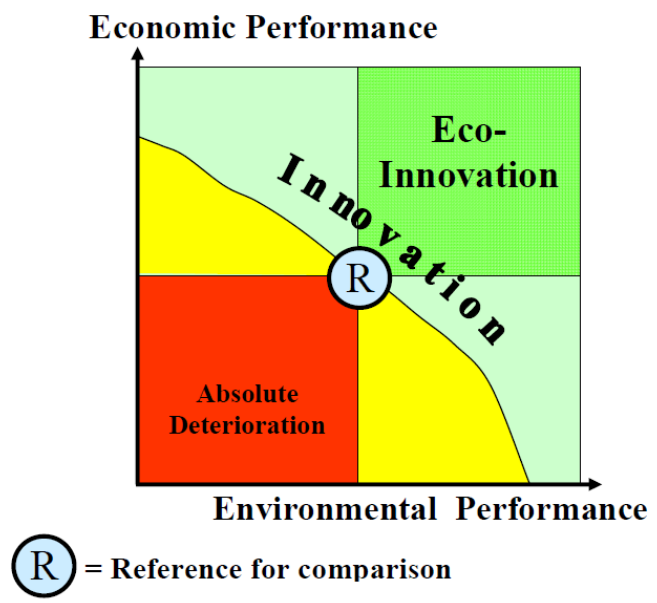

Source: Huppes et al., 2008, p. 4.

Their interpretation is based on the three pillars of sustainable development (environment, society, economy) and according to the principle of strong 
sustainability it does not allow the conversion between any two of the three pillars. Environmental innovation is a change in economic activities improving both economic and environmental performance. According to Huppes et al. (2008) innovations resulting in an improvement of the environmental factor, but negatively effecting economic performance do not qualify as environmental innovations even if the overall effect of the innovation is positive. In the above figure, innovations in the upper right green square are qualified as environmental innovations.

If, according to the principle of weak sustainability, we assume that a certain conversion can be accepted between environmental and economic performance, then the upper section (falling over the line in the figure) of the lower right square as environmental innovation ${ }^{3}$. However, the concept of weak sustainability is difficult to apply in practice. The environmental and economic effect of innovation has to be examined together and conversion between the two has to be enabled. However, the possible exact assessment of all economic and environmental effects and the determination of the conversional ratio can also be problematic.

This is why Kemp and Foxon (2007, p. 4.) defined environmental innovation in a way that it does not necessarily meet the principles of weak sustainability. In their interpretation 'eco-innovation is the production, assimilation or exploitation of a product, production process, service or management or business method that is novel to the organisation (developing or adopting it) and which results, throughout its life cycle, in a reduction of environmental risk, pollution and other negative impacts of resources use (including energy use) compared to relevant alternatives.'

The definition of Kemp and Foxon (2007) in the conceptual framework of Huppes et al. (2008) determines the lower right and the two upper squares. Based on this, the establishment of an environmental innovation doesn't even satisfy the weak sustainability condition, i.e. an economic cost higher than environmental improvement is also possible. Theoretically no one implements

\footnotetext{
3 The principles of strong and weak sustainability are further detailed by Huppes and colleagues (2008), Kerekes (2006) and Kemp and Foxon (2007).
} 
an innovation, which implies an overall loss (taking both environmental and economic factors into account), but practically it can be very difficult to assess all environmental and economic effects of an innovation. It is also hard to decide on what kind of conversion is acceptable between economic and environmental goods. The fact that the benefits and costs of innovation do not necessarily appear at one actor due to the external effects also makes the situation more complicated. It is possible that a company implements an innovation known to imply overall economic loss, but with overall positive direct effects on the firm. This way the role of companies, stakeholders and environmental regulation is also important, since it is their responsibility to influence the value of environmental impact (by voluntary undertakings, influencing market demand, qualifications, limits, quotes, pollution rights etc.), in the end to internalize externalities. In case of optimal conditions, the environmental innovations implemented by companies fulfil the weak sustainability criterion.

It is important to highlight that both above definitions focus on the result of innovation, neither of them requires economic or rather environmental improvement to be a declared ex ante goal of innovation.

In the thesis I use the restricted version of the definition of Kemp and Foxon (2007). According to this, environmental innovation is an original technical innovation, as a result of which the environmental impact of a product or service decreases during its complete life cycle compared to the relevant alternatives, independently from the fact whether it is a primary objective or only a positive side effect.

The choice of definition is underpinned by the following reasons:

- The connection between patents and innovations can be only examined in relation to the original (not adapted) technical innovations.

- Based on the principle of weak sustainability I examine all types of environmental innovations, since this way the end-of-pipe technologies, which usually result extra costs for the company, can also serve as subject for research.

From the point of view of sustainability the definition has more limitations: 
- Based on the above, environmental innovations of firms with negative overall economic and environmental effects can also exist.

- As a result of the rebound effect the decrease in a specific environmental impact of the company does not necessarily imply overall environmental improvement.

- The aggregate of innovations of the firms implying environmental improvement is not necessarily enough for sustainability.

- There is not always a relevant alternative, which can be used as a baseline.

The importance of environmental innovations is well described by the socalled 'Ehrlich-formula'. Based on this the Impact ("I") of mankind on the environment can be described by the following formula: $\mathrm{I}=\mathrm{P}^{*} \mathrm{~A} * \mathrm{~T}$, where „P” stands for population, „A” for affluence describing the economic performance per capita, while „T" for the technology representing the environmental impact related to the production and consumption of products and services (Ehrlich, 1968).

According to the formula, the decrease in the effect of mankind on environment can be achieved by decreasing the values on the right side of the formula. The decrease in population brings up numerous ethical issues. On the other hand, the size of population itself does not underpin that mankind is not sustainable, since the biomass of human race is smaller than that of ants, still ants do not imply global environmental danger (McDonough and Braungart, 2002).

The decrease in welfare can also conflict with basic human rights. The aim of most countries is to increase the welfare of their population. In case of the poorest countries it is completely indispensable from the point of view of long term survival. However, the constructional shift of consumption towards

\footnotetext{
${ }^{4}$ Numerous theses are rooted in the theoretical grounds of the Ehrlich formula. Kocsis (2010) writes about an alternative, happiness based approach, while Bajmóczy and Málovics (2011) about the dinamization of the formula.
} 
smaller environmental impact does not necessarily imply decrease in welfare, should we at least partially switch for supplier economy (Frosch and Gallopoulos, 1989) or should the composition of the consumer basket shift towards the intellectual direction. According to most researchers, this is also necessary for achieving sustainability (e.g. Csutora and Kerekes (2004), Csutora (2008), Ekins (2010)).

Another possible path seems to be the decrease in T factor, i.e. the decrease in environmental impact related to the production and consumption of a product or service. Based on the above this is possible through environmental innovation. The critical significance of environmental innovations to achieve sustainability is a generally accepted view.

The concept of sustainable development was propagated by the Brundtland Report, according to which it is development that meets the needs of the present without compromising the ability of future generations to meet their own needs' (WCED, 1987, p. 37.). The ecological footprint of the Earth's population (Wackernagel and Rees, 2001) today exceeds the biocapacity of the Earth (Global Footprint Network, 2009). The ecological footprint takes global environmental issues into account, which seriously challenge mankind individually ${ }^{5}$. Thus our existence in present form is unsustainable in the long term.

However, the effect of environmental innovations on sustainability is not as obvious as it would follow from the Ehrlich formula. The reasons are the negative side effects of environmental innovations and the rebound effect.

The negative side effects of environmental innovations occur because companies are not able to fully assess all impacts due to uncertainty, the complexity of the processes of biosphere, its batch and systematic operation, novelty and the reflexive feature of change. A significant part of our new modern technological solutions strives for the correction of problems caused by previous innovations (being often not foreseeable) (Beck (2003), Hronszky (2002), quote Bajmócy and Málovics (2011)). Environmental improvement at

\footnotetext{
${ }^{5}$ These are expressively demonstrated by Kiss (2009).
} 
the micro level does not necessarily vanish at the macro level, in certain cases the sum of all positive micro level effects can lead to even higher macro level improvements.

The opportunities hidden in environmental innovations are well described by the fact that the redesign of the product aiming at decreased environmental impact typically abolishes $50-75 \%$ of total environmental impact. The rethinking of a product in an environmentally conscious way, focusing only on the utility of products can even cease the complete environmental impact (Ryan, 2003).

Kerekes and Wetzker (2007) also highlight the unforeseeable effects of innovations. In their opinion, multinational companies are the key to applied research, treasuring their developmental results. For them the basic condition for achieving competitive advantage is to be a leader in innovation. During the implementation of innovation by collecting knowledge they do not only gain a competitive advantage, but can also deal better with the relatively slow legislation, which requires a long time to examine the potential problems caused by the new product or technology. Thus according to Kerekes and Wetzker, under the circumstances prevailing in the developed world, only a new corporate ethical mindset can secure the appropriate environmental conditions, which forces the fulfilment of environmental and social expectations without them appearing in state norms.

According to Bajmóczy and Málovics (2011) innovation is part of a complex economical and technological system. A change occurring due to an environmental innovation can induce further changes beyond direct environmental improvement, as the spillover effects can change the relationship between environment and technology in other indirect ways too. The realization of innovation thus changes status quo. Due to the rebound effect the decrease in the relative price of technology can induce an increase in the volume of production. It can happen that the resulting financial savings from the environmental innovation will be spent on another, more polluting activity. Because of the decrease in the relative price of the technology possibly there will be an additional environmental impact due to previously unknown or not efficient utilization (e.g. escalator driven by electricity). 
Due to these factors the examination of the environmental effects of environmental innovations at the macro level has to be handled carefully.

\subsection{The types of environmental innovation, environmental innovation strategies}

The literature typically differentiates between environmental innovations according to the approach of innovation, which can be complementing, integrated or holistic. Together with the changes in view, the consideration of environmental aspects increasingly affects environmental processes and strategy.

We can talk about conscious environmental innovation since the appearance of environmental management, approximately the 1960's. However, this does not mean that environmental innovations did not exist previously, although to a certain extent in an unconscious way. But the undesirable side effects of economical development raised serious questions about the sustainability of the process. From this moment on we can talk about conscious environmental innovations (Buday-Sántha, 2009).

In the following section I will describe the above types of environmental innovation, the theories constituting their base and the corporate strategies rooted in the different views.

According to Csutora and Kerekes (2004), based on the stages of the

environmental development, we can differentiate between four types of environmental innovation. The appearance of the four types and their transformation into leading paradigm are successive as seen on the figure below. 
Figure 4.: The stages of environmental development

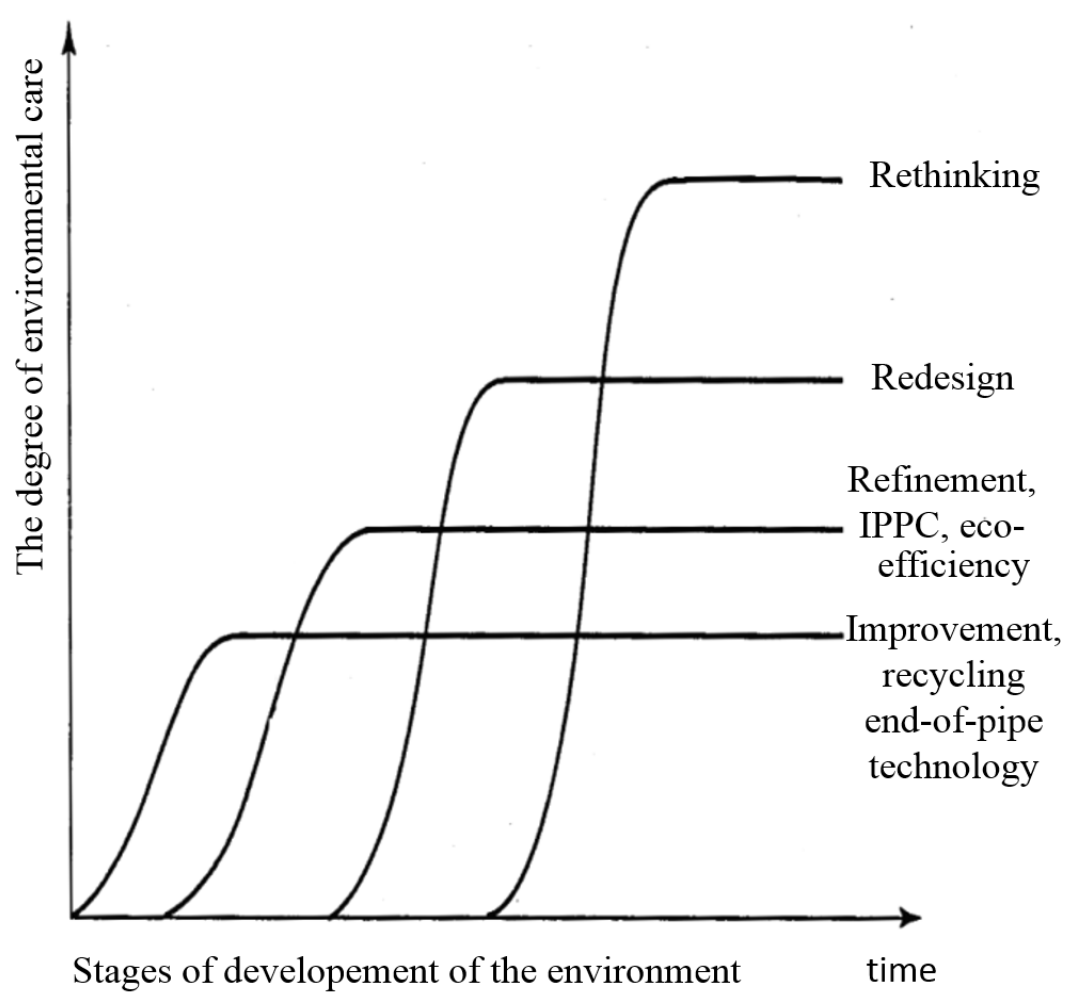

Source: Csutora and Kerekes, 2004, p. 48., quote Hans Schnitzer ERCP '99, Budapest

1. First, the protection against serious environmental damage exclusively served the protection of health and wealth. Typical environmental innovations aimed for the development of complementary, so-called endof-pipe technologies.

2. The second development stage of environmental protection was integrated pollution protection and pollution control. Environmental regulation and the applied environmental innovations are not only directed towards polluting outputs, but also towards changing corporate processes, they also take the usage of raw materials, energy efficiency into consideration.

3. The third stage of development includes the new ways of the fulfilment of present needs. The role of radical environmental innovations on this level is already significant, affecting the key processes of the company. Environmental innovations can for example refer to a switch for service economy or the more widespread usage of ecodesign. Service economicy 
focuses on the utilization of present needs as service instead of purchasing the product.

4. In case of the fourth stage of development the legitimacy of present needs and their sustainability are also questioned. The linear production processes are organised into circles thus minimising or eliminating waste production based on the principles of industrial ecology.

Brezet (1997) differentiates between the following types of environmental innovation, listed in an increasing order according to the integration of environmental innovation into corporate processes and strategy:

- $\quad$ product development

- $\quad$ product redesign

- functional innovation

- $\quad$ system innovation

Product development is aimed at changing certain features of the product. Product redesign already affects a significant part of the characteristics of the product. Functional innovation abstracts from the product, only concentrating on the production of the wished utility, which can correspond to the redesign level of Csutora and Kerekes (2004). The most overwhelming system innovation, corresponding to the rethinking level of Csutora and Kerekes questions if the currently fulfilled needs are necessary in their present form, or they are unnecessary or they can probably be made unnecessary.

Zilahy (2000) recommends a classification similar to that of Csutora and Kerekes by classifying environmental innovations according to their characteristics and their role in achieving sustainability. 
Figure 5.: Different directions of environmental protection

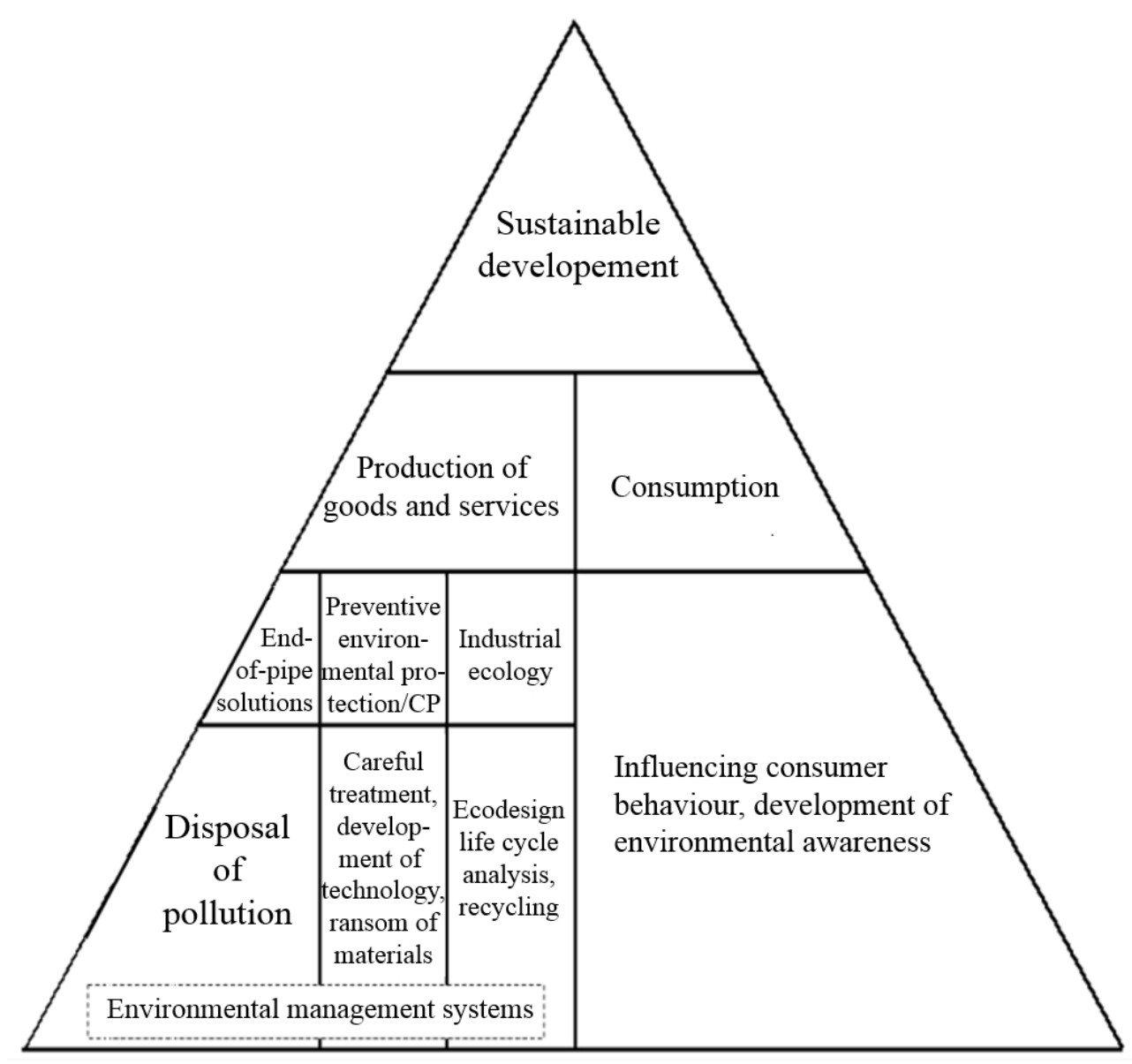

Source: Zilahy, 2000

In the above figure Zilahy (2000) presents the role of two elements of the Ehrlich formula: consumption and technology in a more detailed way in order to achieve sustainable development. Zilahy (2000) applies the classification widely used in literature to group environmental innovations. According to this, the first generation of environmental innovations uses end-of-pipe solutions, the second one preventive solutions (cleaner production) while the third one industrial ecology to enable the reduction of environmental impact necessary for the production of goods and services. We can further specify the figure by taking the environmental burden produced during the complete life cycle of goods and services into consideration. In the next part I will use the classification of Zilahy (2000) to introduce the types of environmental 
innovations, the theories they are based on and the corporate strategies based on individual ways of approach in a more detailed way.

End-of-pipe technologies strive for filtering, localizing pollution without changing the production process or the product, with additional elements. End-of-pipe technologies, although they significantly decrease the quantity of harmful materials reaching the environment, almost always produce additional costs for the companies. This on one hand is the result of the purchase of equipments, on the other hand the result of their continuous cleaning, maintenance. Thus the profit of companies as a result of the application of end-of-pipe technologies continuously decreases.

The general understanding according to which environmental and economic interests conflict with each other and they can be taken into consideration only at the expense of each other, i.e. the environment is a necessary evil the protection of which only increases costs is rooted in this approach (Zilahy, 2000). According to surveys (e.g. Harangozó (2007)), the environmental strategy of most companies simply aims at complying with legal norms. In order to achieve this, most companies apply the simplest 'end-of-pipe' technologies accompanied by the smallest innovation.

The objective of the preventative type of environmental protection is to decrease or abolish harmful emissions and other environmental effects at their sources. This decrease in emissions also diminishes the quantity of resources used at the same time, so pollution prevention contributes to an economic success by improving the efficiency of operations (Zilahy, 2000). Basically we can distinguish between three groups of preventive measures. The first group of measures can be implemented with low costs or even without costs. These measures and the methods leading to their identification and implementation are often called 'good housekeeping' options or 'low hanging fruits'. The second group contains technological modifications, developments requiring higher investments, which usually do not only influence the environmental performance, but also constitute an integral part of environmental processes. The third group is made up of the substitution of applied materials and other resources, which may result in significant savings (Zilahy, 2000). 
Preventive environmental projects often result economic returns. The possibility of parallel improvement of the companies' environmental performance and profitability was first raised by Porter and van der Linde (1995), and became widely known as the 'double-dividend' theory. According to this theory, a stringent environmental regulation fosters companies to realise efficiency gains during the production which can counterbalance the costs of the fulfilment of the regulations. This theory has been criticized many times (e.g.: by Walley and Whitehead (1994), Palmer et al. (1995)). The critics state that it is not always possible to decrease environmental impact with projects producing financial return. In my opinion, environmental innovation does not necessarily imply short term, easily quantifiable advantages either, but through better social perception it can indirectly result in higher profit. As of today there is a theoretical agreement in the fact that sustainability is a competitive factor (Porter and Kramer (2007), Kerekes and Wetzker (2007), Chikán (2009), quotes Ransburg (2011)).

The notion of prevention is also central to the approach of Cleaner Production. Preventive aspect appears in the cleaner production approach, too. As per the definition of the United Nations Environment Programme (UNEP) 'cleaner production is the continuous application of an integrated preventive environmental strategy applied to processes, products and services. It embodies the more efficient use of natural resources and thereby minimizes waste and pollution as well as risks to human health and safety' (WBCSD, 1998, p. 3.).

- 'For processes, cleaner Production includes conserving raw materials and energy, eliminating the use of toxic raw materials and reducing the quantity and toxicity of all emissions and wastes.

- For products, it involves reducing the negative effects of the product throughout its life-cycle, from the extraction of the raw materials right through to the product's ultimate disposal.

- For services, the strategy focuses on incorporating environmental concerns.' (WBCSD, 1998, p. 3.) 
The theory of eco-efficiency initiated by the Word Business Council for Sustainable Development (WBCSD) and aiming at the more efficient utilization of environmental resources focuses on the savings achievable by the preventive approach. 'Eco-efficiency is reached by the delivery of competitively priced goods and services that satisfy human needs and bring quality of life, while progressively reducing ecological impacts and resource intensity throughout the life cycle, to a level at least in line with the earth's estimated carrying capacity' (WBCSD, 1996, p. 4.).

The 'Factor 4' concept of Weizsäcker et al. (1995) is based on the concept of eco-efficiency. According to this in order to achieve sustainability, the increase in welfare has to be accompanied by the decrease in environmental impact. The authors imagine this by increasing the efficiency of raw material consumption to a great extent. The reality of radical saving is also introduced through 50 case studies.

Industrial ecology, the conceptual framework serving sustainable development constitutes the integrity of the principles of preventive environment and system approach. This strives for the transformation of the traditional, linear material and energy flows into closed and cyclic system similar to that to be found in environment. As in the environment, also in industrial systems waste production has to be avoided, since the cheapest and best way of environmental protection is prevention. During energy consumption, industrial ecology strives for achieving the maximization of efficiency. It enables primary material consumption only for initiating the operation of the system and assumes zero waste emission. As per the law of conservation (1st law of thermodynamics) in case of waste production (since regarding material flows the Earth can be considered a closed system), after certain time, lack of raw material would occur (Csutora and Kerekes, 2004).

The technological repertoire of environmental innovations aiming at industrial ecology differs from innovations aiming at cleaner production to a smaller extent, still the approach and final objective of innovation significantly differ from each other. Since in case of cleaner production the objective is at most avoiding or decreasing harmful emissions, in case of 
industrial ecology the cradle-to-cradle approach (Braungart et al., 2007) and the organization of linear processes into cyclic processes is determinant.

The concept of eco-effectiveness roots from the grounds of industrial ecology and cradle-to-cradle approach. While eco-efficiency aims at the decrease in harmful emissions, eco-effectiveness strives for the production of products and services with social, economic and environmental advantages. Eco-effectiveness focuses on the development of products and industrial systems, which during their successive life cycles preserve of improve the quality, productivity of resources (Braungart et al., 2007). The theory of ecoeffectiveness expresses the environmental impact of products and services in absolute unit, which in optimal case either does not exist or the condition of the environment even improves. Thus the theory contrary to eco-efficiency meets the criteria of sustainability. According to Harangozó (2007) the environmental impact of the studied companies decreasing due to eco-efficient innovations in most cases was overcompensated by the increase in production volume. It is important to highlight though that it does not necessary mean a lack of environmental improvement on the macro level. It depends on whether this increase occurred at the expense of more polluting competitors or possible less polluting alternatives.

End-of-pipe technologies, the currently prevailing preventive measures and innovations aiming at industrial ecologies do not exclude the application of the others, but in the given case the implementation of the most appropriate solution has to be the objective. In certain cases we have to aim at the decrease in the production of harmful emissions, in other cases the utilization of the already produced waste as raw material is practical. Should the above methods not be applicable due to certain reasons, then the end-of-pipe solutions can also come into the picture.

The type of implemented environmental innovations and the innovative strategy influence the relation of the company to intellectual property to a huge extent. As per the above it is obvious that environmental innovations also have characteristics different from general innovations. This - together with the utmost significance of environmental innovations in achieving 
sustainability - makes the separate examination of intellectual property on environmental innovations reasonable.

\subsection{The concept, significance and types of intellectual property}

According to the Hungarian Intellectual Property Office, 'intellectual property refers to a legal entitlement which attaches to intellectual creations. It is comparable to private property. Intellectual property right arises from the acquisition of industrial property protection or from those steps that serve to keep an intellectual creation secret, or in case of literary and artistic works, it begins with their very creation. Intellectual property can also be considered as a field of law within civil law, the rules of which provide legal protection for the creators or authors of intellectual creations by exclusive economic rights and moral rights.' (HIPO, 2013 p. 1.)

According to Bendzsel (2006) the past period proved that managing intellectual property should become a core competence of successful enterprises. In knowledge based economy the elements of knowledge capital acting as real property have become the most important sources of stock owner value and competitive advantage (Bendzsel, 2006). This is also underpinned by Osman, according to his description, previously tangible fixed assets and capital goods overrepresented intangible assets among the resources of companies. However, as of today this ratio turned round in developed countries. The overwhelming part of the companies' intangible assets is built up by the elements of intellectual property (Osman, 2012).

The classification of rights serving the protection of intellectual property, provided by laws in force is illustrated by Iványi and Hoffer in the figure below. 
Figure 6.: The categories of intellectual property protection

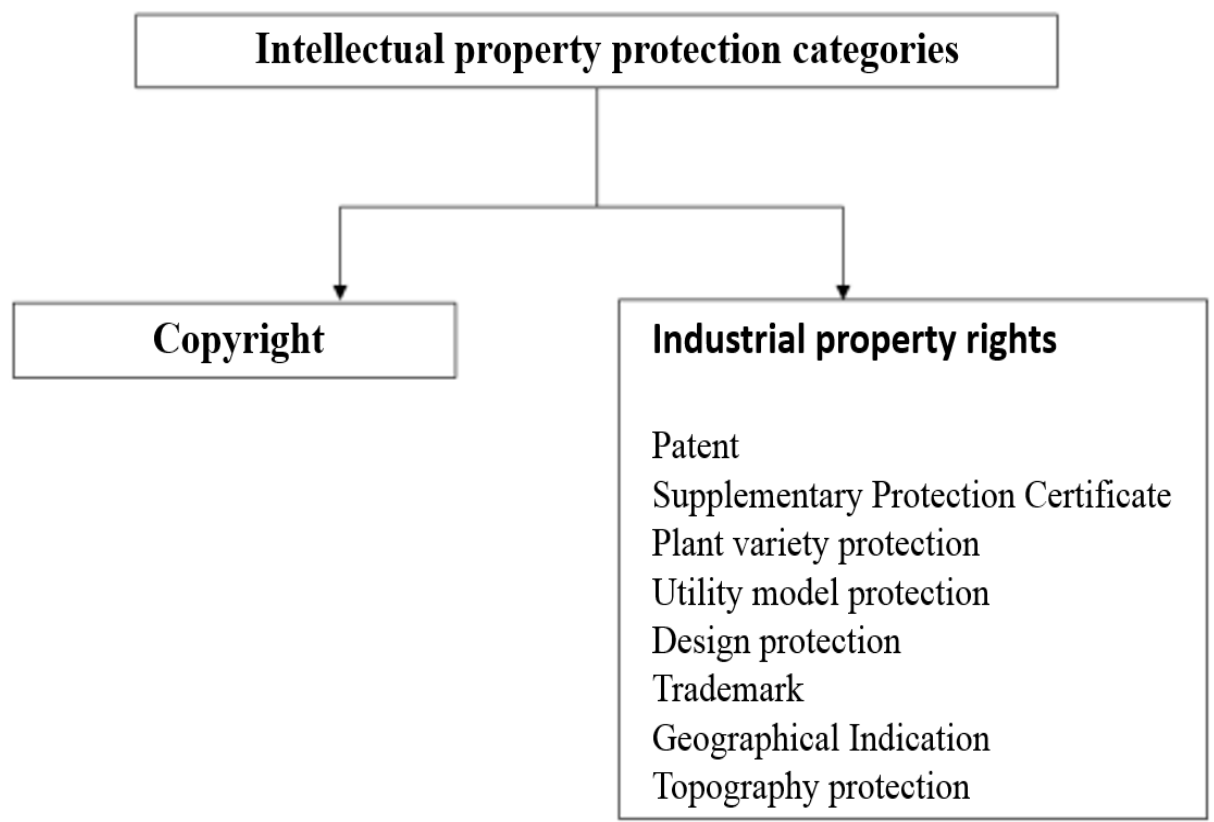

Source: Iványi and Hoffer, 2010, p. 21.

According to Iványi and Hoffer (2010, p. 21-22), based on the laws in force, I will continue with shortly presenting the most important categories of the protection of intellectual property:

Patent means the exclusive right enabled for a technological solution, invention. Eventually it provides a monopoly situation for the one obtaining protection, so not only the costs invested into the development of the invention can be returned, but additional profit can be obtained, too.

Supplementary protection certificate form of legal protection that extends protection conferred by a patent (called "basic patent") in respect of a medicinal or plant protection product.

Plant variety protection ensures the legal protection of improved plant varieties (hybrids, lines, clones etc.).

The utility model protection is a legal protection for the new technical solutions not reaching the level of a patentable invention. By virtue of utility model protection, the owner of the said protection have, as provided for by 
legislation, the exclusive right to exploit the utility model or to license another person to exploit it.

The design protection grants legal protection for the appearance of a product. By means of this protection, the right holder can create or strengthen his position on the market.

Trademark protection enables the identification of individual products and services, their differentiation from each other, the promotion of informing consumers. Industrial property can be considered a specific category, since contrary to e.g. inventions or designs - its moral and property value does not depreciate as time passes by.

As a geographical indication the geographical denotation and origin specification applied for specifying the geographical origin of the product in trade flow can obtain protection.

The subject of copyright protection is the creator of the individual, original work produced in the area of literature, science and arts, the author, to whom the person-related property rights belong. In practice many people already seek for protection for an idea, principle, process, operational method. However, these are not subject to copyright protection. They are affected by the regulations of civil rights, not related to specified intellectual property. In this form, the idea can also constitute a subject of contract.

When choosing the possible form of protection of an intellectual property, the following table of Iványi and Hoffer can provide help. It is important to know that the individual forms of protection can be combined in many cases.

Table 1.: The forms of protection of intellectual products

\begin{tabular}{|l|l|}
\hline \multicolumn{1}{|c|}{ New solution } & \multicolumn{1}{c|}{ Protection opportunity } \\
\hline $\begin{array}{l}\text { Technological type of solution, product, } \\
\text { structure }\end{array}$ & Patent, design protection \\
\hline Technological procedure & Patent \\
\hline $\begin{array}{l}\text { Technological type of solution enabled by } \\
\text { software, computer }\end{array}$ & Patent \\
\hline Organizational solution & Patent only in the USA \\
\hline
\end{tabular}




\begin{tabular}{|l|l|}
\hline $\begin{array}{l}\text { Organizational solution implemented by } \\
\text { software, computer }\end{array}$ & Patent only in the USA \\
\hline Biotechnological invention & Patent \\
\hline Software & $\begin{array}{l}\text { Only its name can be protected by } \\
\text { trademark; its copyright can be } \\
\text { registered in the USA }\end{array}$ \\
\hline Name, company name, logo, indication (can & Trademark \\
also be older) & Design protection \\
\hline Form, esthetical solution, external & Plant variety protection \\
\hline Plant variety & Domain \\
\hline Internet-identifier & Trademark, possibly patent, domain \\
\hline Franchise & $\begin{array}{l}\text { To develop further in the right } \\
\text { direction, at least into a general } \\
\text { 'solution' }\end{array}$ \\
\hline Idea & Not available (to be kept confidential) \\
\hline Know-how &
\end{tabular}

Source: Iványi, and Hoffer, 2010, p. 23.

\subsection{The alternative approaches of the utilization of intellectual property}

The policymaking activities of the state determine intellectual property rights and the methods of their protection. However, numerous actors wish to exploit their intellectual property in a different way. I will now introduce some of these, which can be relevant from the point of view of patents. These, nonexhaustively are the globally open innovation model already introduced in Subchapter 2.2, making innovations public, patent broker activity, prizes and advance market commitments (AMC).

Instead of/besides the own economic utilization of innovations, their sharing has a long tradition. Benjamin Franklin intentionally did not patent his stove, so that he could support its quickest possible diffusion. Röntgen and the Curies referring to public interest also rejected patenting the practical applications of their inventions. IBM freed its portfolio built up by approximately 500 patents in 2005, by making them public (Bendzsel, 2006). 
Recently Tesla has admitted that 'in the spirit of the open source movement, for the advancement of electric vehicle technology ... Tesla will not initiate patent lawsuits against anyone who, in good faith, wants to use our technology.' (Musk, 2014, p. 1.) Tesla's move is not purely altruistic, as they may be able to profit from the faster improving infrastructure for electric vehicles. And by making their technology open source, they can also be a standard in the advent of sustainable transport, making cooperation easier with the major manufacturers. It can also be regarded as a classy marketing move, which can be rather impressive regarding the customers from the software sector, in fond of open source. As a result, the stock price of Tesla has not moved significantly.

Bobrovszky (2008) explains that the previous negative, static approach related to public domain have been substituted by positive, proactive approaches. This public domain is considered an intellectual gold mine, a dominant and dynamically expanding social dimension of intellectual property and its utilization is promoted. The availability, utilization of the public domain has been dramatically increased by Internet. The process has just started, but possibly public domain will restructure the system of intellectual property.

As an initiation of the international organization responsible for sustainable development called WBCSD and IBM, the so-called „Eco-Patent Commons”, a collection of environmental protection related patents in public domain was created, which is available on the website of the organization. According to Hoorebeek and Onzivu (2010) the collection shows that a corporate voluntary initiative is able to influence the role of patents in environmental protection without any governmental or social regulation.

Recently new actors entered the market of patents dealing with the establishment of significant patent portfolio, then its licensing and trade. These companies on one hand help their clients to avoid patent infringement trials, on the other hand they consolidate fragmented patent property rights related to individual technological solutions. The judgment of patent broker activity has so far been ambiguous. According to Myhrvold (2010) the inventional capital, following the pattern of risk capital, constitutes the future 
of innovations. It can generate a social market space, where the individual companies can find the patents important to them at a common place and they do not have to be afraid of patent infringement, either. As per the right diminishment of the risk originated from the purchase of the individual patents such companies can be financed by institutional investors, which would invest this money into the development of new, promising investments. The seriousness of the conception is shown by the fact that recently the firm called Intellectual Ventures has been able to collect a source of more than 5 billion USD for such purposes, and clients of the RPX Corporation of similar activity include e.g. Cisco, Google, Nokia, Samsung, etc.

According to Vardi (2011) these companies will be unable to live up to the expectations and they will end up living of patent infringement trials initiated by them.

Kremer and Williams (2010) argue that Prizes, like the one offered by the $\mathrm{X}$-Prize Foundation, have been successful in promoting innovation, but they especially targeted demonstration projects. Brunt et al. (2012) analyse historical prizes in England between 1839-1939, where patents were also available. They find that prizes contributed to the significant increase of innovation activity. Similarly, Nicholas (2013a) finds that in Japan prizes spurred innovation activity and the diffusion of technology.

Advance Market Commitments are similar to prizes but gives rewards for the usage of a product. These can be for instance vaccines for neglected diseases in poor countries. In an AMC sponsors ex ante guarantee a price for a specified number of vaccines provided for the required population, conditional to the development of a suitable product. In 2009, Italy, the United Kingdom, Canada, Norway, Russia, and the Bill and Melinda Gates Foundation announced a $\$ 1.5$ billion AMC for a pneumococcus vaccine suitable for children in poor countries (Kremer and Williams, 2012). 


\section{Patent}

The central topic of the thesis is the examination of patents, so I will provide a detailed introduction to their concept, characteristics and the fundamental directions of their research. I will take an economics perspective, focusing on the research examining the effects of patents on innovation and its social utility. Based on this there are several topics in the research of patents that are only introduced. The most significant of them is the jurisprudential research related to the topic of patents and patenting. From the economics research ones, such as the effect of patent fees on patenting, the impacts of fundamental patenting principles of universities (e.g. the effect of the Bayh-Dole Act in the USA), the analysis of the economic and ethical influences of the differences between individual countries in certain industries (e.g. software, biotechnology) and the (potential) effects of the institution of patenting in developing countries, etc. will also only briefly be introduced.

\subsection{The concept and characteristics of patent}

As per the description of the Hungarian Intellectual Property Office 'a patent ensures legal protection of inventions by granting a better position to the owner of invention compared with that of rivals in the market of products and technology. The owner of the invention has an exclusive right to exploit the solution of invention, but the period and the territorial validity of patent protection are not unlimited. The patent protection is valid up to 20 years started from the day when the patent application was filed and solely in the countries in relation of which the protection was granted' (HIPO, 2014, p. 1.).

Pakucs and Papanek (2006, p. 162-166.) introduce the characteristics of patenting and patents, summarizing the legal regulation and practice in force. I will describe these basically based on their work:

The invention is new, if it has not become public anywhere in the world, and there is an inventive step which is not obvious for an expert of the specific topic. The scope of the patent protection is determined by the claims defined by the one asking for protection in the patent application. This scope is of high importance, it can specify whether infringement occurred against the patent. 
The claims have to be made up by a subject and a descriptive part; the two parts are merged in one sentence. The known characteristics mandatorily necessary for the implementation of the invention can be found in the subject matter of the main claim. The characterizing part of the main claim also contains mandatory, but so far unknown, new characteristics. The use of subclaims is not mandatory, they provide a withdrawal opportunity for the protection of a possibly restricted invention. The protection is granted after a longer process: novelty research and examination dating back to the day of application. For the maintenance of the patent, annual maintenance fees have to be paid.

The inventor is the person who created the invention. Creation can only be carried out by humans, so the inventor is always a natural person. In case of more inventors we talk about fellow inventors, their authorship ratios have to be specified in case of Hungarian patent applications. The patentee has an exclusive right to utilize the invention and can give permission to someone else to utilize it. Based on the exclusive right for utilization the patentee can act against anybody who in the framework of economic activity, without his permission

- $\quad$ produces, uses, places the product constituting the subject of the invention on the market or recommends its placing onto the market, or holds the product on stock for this reason or brings it in the country;

- uses the procedure constituting the subject of invention or - although knows about it and according to the circumstances it is obvious that the procedure cannot be used without the permission of the patentee - offers the procedure for use for someone else;

- produces, uses, places the product produced directly through the procedure constituting the subject for invention on the market, recommends it for placing on the market or holds it on stock for this reason or brings it into the country.

Patent is valid for the countries determined in the application. For making a foreign application only limited time (1-1.5 years) is available after the domestic application. In case of those patents that are assumed to protect a 
product or procedure that is also successful abroad, it is worth making an application abroad, too. There are three possible ways of it: direct national application, PCT application and European Patent application.

Direct national application can be made towards any foreign country. This is the primarily recommended way, if we want to get a patent for only one or a few countries or if we talk about a country not being a member of the PCT (Patent Cooperation Treaty) to be mentioned later or the European Patent Convention. After the application we receive the same treatment as the citizens of the given state.

With the help of the patent application made in the frames of PCT, protection can be achieved in each member country of the treaty, and most countries on Earth are members of this treaty. PCT's patent application procedure separates the appearance of higher patent costs from the initial phase of development and from the first day of protection in time (the delay can be two and a half years). So PCT patent application is the most common application form abroad.

Should we wish to gain protection in the member countries of the European Patent Convention (which are almost identical with the member states of the European Union), it is worth making a European patent application. This is a regional patent becoming only valid if the protection is verified in at least one member state. Patent will be valid only in the specified countries.

When some people wish to utilize their invention not (only) themselves, they can transfer it for utilization for a certain price, this is called license. In the framework of a contractual license the patentee and the holder of the patent claim can delegate the utilization right of the invention, while the licensee is obliged to pay fee. Retreat from the contractual license according to the competition law does not mean abuse of dominant position. However, the holder is obliged to give permission for utilization in certain situations (stipulated by the law).

According to the theory of disclosure, in return for the exclusive rights, within 18 months after the patent application, its complete text has to be published. For the society it provides knowledge, which otherwise would be 
kept in secret or would be published only later. Patent documentation is the largest storehouse of technological-economic information, due to its almost 75 million elements, and its content of more than $80 \%$ not appearing anywhere else (Bendzsel, 2006).

\subsection{Theories related to patent}

The word 'patent' originates from the Latin word 'patere' (being open), which meant a patent received from government to practice art (Menell, 1999). The first patents were not patents in the current sense, their objective was not the protection against copying, but the monopoly related to one product (Hall and Harhoff, 2012). One of the first patents related to technology was obtained by Brunelleschi in 1421 for a ship planned for marble transportation (Prager, 1946, quote Hall and Harhoff (2012)). The first patent law was created by the Senate of Venice in 1474 (Menell, 1999).

Patent in its current interpretation was created in the 18th century, first in England in 1718. Later, patent systems were established in almost all countries. The TRIPS Convention ${ }^{6}$ in 1995 ensured that patent protection exists in case of all WTO member states (Hall and Harhoff, 2012).

The philosophy of intellectual property protection is based on the fact that monopoly is able to stimulate innovation. Most early theories were interested in whether it was necessary for the state to protect intellectual property. After this, attention was rather turned towards the establishment of concrete rules and institutions.

Adam Smith admitted that in order to promote innovation and trade limited monopolies are necessary (while he found monopolist dominance usually disadvantageous). Jeremy Bentham $(1839$, p. 71.) similarly saw the establishment of protection of intellectual property necessary. He explained in details that the innovators and those copying innovations face different fix costs: 'that which one man has invented, all the world can imitate. Without the assistance of the laws, the inventor would almost always be driven out of the

\footnotetext{
${ }^{6}$ Trade-related Aspects of Intellectual Property Rights
} 
market by his rival, who finds himself, without any expense, in possession of a discovery which has costed the inventor much time and expense, would be able to deprive him of all his deserved advantages, by selling at a lower price.' John Stuart Mill (1862) also concluded that patent monopolies are fair. According to him, a temporary exclusive privilege is better than a general government fee, since this way the reward of the inventor is proportional to the benefit of the invention's consumers (Menell, 1999).

Pigou (1924) discovers the problem of public goods in case of intellectual property. According to him, the objective of patent protection is to bring marginal net private product and marginal net social product closer to each other. Clark (1927) verified this statement, noting that a system not enabling for inventors the disposal of their inventions leads to competition, where the inventors rather wait for each other than getting ahead of each other in establishing further developments (Menell, 1999).

The subsequent theories of patent protection, overwhelmingly based on empirical research are much more controversial. However, based on the consensus outlined in previous years it can be stated that most researchers are not satisfied with the current operation of the patent system. Without detailed knowledge on the topic it is also observable that some parts of the patent system do not function adequately, it is just enough to think of the recent infringement trials and the legal judgements in these cases ${ }^{7}$. According to the opinion of Boldrin and Levine (2009) intellectual property rights really played an important role earlier, which was also underpinned by numerous studies (e.g. North, 1981). The huge efficiency improvement of the industrial revolution could largely take place because of the protection of the rights of inventors, who this way could benefit from the profits of their inventions. Compared to the badly functioning European contractual relations from before the 17th century (which could be easily influenced or even neglected by the royals and aristocrats), the establishment of temporary, but well-defined

\footnotetext{
7 This is explained by Hanula (2012) in a more detailed way.
} 
monopolies meant a really huge step. However, nowadays the protection of intellectual property is already less useful for society than the well-defined property right appearing in competitive environment. The former really means more income for innovators, but at the same time increases the costs of subsequent innovations: all monopolists have to be paid, who own property rights in existing innovations.

It is obvious that in its current form the patent system is only limitedly able to meet the needs of certain industries (e.g. biotechnology, information technology), while especially in the pharmaceutical and chemical industry it seems to fulfil its fundamental function. As I already wrote in the introduction, the assessment of all social effects related to patents is possible at most in concrete, well-defined cases. This makes the objective judgment of the patent system extremely difficult. This is why it could happen that we are still waiting for the real reform of patent system and possibly in the end representatives of certain industries will force it, because of the unsustainability of the situation.

The already mentioned theories related to patents, established in the 20th and 21 st centuries are described below.

The economics of oligopoly and imperfect competition show a picture more sceptic than earlier theories about the protection of intellectual property right and questions whether it is really necessary for the stimulation of inventive activity. According to Plant (1934) numerous inventions are spontaneous so they also happen without patent protection. Further he states that first-mover advantage, market imperfections and other factors provide sufficient motives for inventors to create and market their inventions even without intellectual property rights. Plant concludes that patent protection leads to excessive research and development (R\&D) investments, which although results in patentable inventions, but lavishly diverts resources from other alternatives (Menell, 1999).

After examining literature, Machlup (1958, p. 80.) does not fundamentally see the benefit of patent protection justified, so he encourages further research. He states that 'if we did not have a patent system it would be irresponsible ... 
to recommend instituting one. But since we have had a patent system for a long time, it would be irresponsible, on the basis of our present knowledge, to recommend abolishing it.'

Numerous researchers have questioned if the approach considering intellectual property as public good is correct. According to the opinion of Demsetz $(1969,1970)$ strong intellectual property rights are necessary, and the efficient allocation of resources has to be a task of the market through Coase type of agreements. In the opinion of Hirshleifer (1971) innovators can also achieve a fair return without the protection of intellectual property, if they have the right to speculate about stock price changes occurring on capital markets before the publication of information (Menell, 1999).

From the 1960's economists drew ever more attention to the question how intellectual property rights should be developed to promote innovative activity the best possible way. Nordhaus (1969) pointed out that in case of the optimal period of patent protection, innovative stimulators are equal to the monopoly's deadweight loss. He pointed out that the longer the patent's optimal lifetime is, the smaller the given product's demand-price elasticity is, so the social benefit occurring from the invention is smaller, compared to research-development costs and the number of inventions is more sensitive to the research \& development expenditures (Menell, 1999).

The static models of intellectual property assumed that inventors carried out their research independently, in forms of non-competitive projects, but the real innovative environment is dynamic. Different investors (and firms) often competed for being number ones, which results in patenting competition. Barzel (1968) proved that the competition of inventors for patents allocates more than optimal resources for innovations. However, the monopolist patent inventor - since he does not have to be afraid of competition - is likely to induce less than optimal innovation. Gilbert and Newberry (1982) enwidened Barzel's basic model: the authors pointed out that for patentees the patenting of new technologies acts as a stimulator for the maintenance of monopolist power, the objective is to prevent potential competitors from entering the market. The literature of rival competition highlights two general aspects of patent competition. According to the aspect of imperfect competition, 
multiplies costs rise through parallel research costs and decentralized research programmes. While research \& development efforts increase the probability of the invention's development and obtaining the patent, the firm decreases the probability of its competitors to achieve the same invention (Menell, 1999). However, it leads to excessive research \& development investments, which is an ever increasing problem nowadays ${ }^{8}$. According to the efficient competition aspect, patent competition is useful, since it stimulates investment activity, speeds up investment rate and so forces continuous progress (Menell, 1999).

Most of the static models assumed that the result of innovation is an end product or process that cannot be improved further. However as time passed by it has been proved that most innovations are not only outputs, but also inputs of further innovations (Menell, 1999). The model of Bessen and Maskin (2006) (certainly with limitations) proved that in case of a one-off innovation, total social effect of patents is positive. In the extreme case when all innovations are built upon each other, the social effect of patents is negative. In this latter case, sometimes the original innovator can gain extra profit even without patents due to the additional positive effects of further developments.

Palmer $(1989,1990)$ brings up liberal reasons emphasizing the efficiency of competition against intellectual property rights. According to the opinion of Barlow (1994) intellectual property rights threaten the free flow of ideas through Internet (Menell, 1999).

The liberal theory of Boldrin and Levine (2009) based on numerous empirical examinations also emphasizes that the patent system should be abolished and efficient allocation of resources should be a task of the market. According to them there is neither theoretical, nor empirical proof that the abolishment of patents would slow down technological development. Contrarily, it would mean a decrease in transactional costs, so the adverse

\footnotetext{
${ }^{8}$ In the European Union the amount of resources wasted due to parallel research, repeated inventions became five times bigger by 2000 compared to 1990 , which amounted to about 100 billion euros in 2000 (Palugyai, 2004).
} 
utilization of patent system would be abolished (e.g. rent-seeking ${ }^{9}$, defensive patenting and the corresponding giant legal costs).

Bessen and Meurer (2008) highlight that intellectual property and the property related to tangible goods (which operates well according to them) are different from each other in numerous aspects. The right of utilization of tangible assets can be relatively well defined, contrary to intellectual property rights. However, an invention can be used by more people at the same time and more people can claim ownership, too. Independently from each other, the given technology can even be used by more people at the same time, still only one person can own it. A substantial difference that the right of the licensee that of being able to exclude others from the application of the invention is not identical to being able to apply that himself. Should someone possess an invention, still he cannot apply it if parts of it have already been patented by someone else.

The role of patents was perceived positively by most researchers in the 1719th centuries. However, the patent system in its current form can even less comply with the challenges of the 20 th and especially the 21 st century. The first critical publication was published more than 80 years ago. Despite the ever stronger negative voices, the patent protection was substantially strengthened until the end of the 20th century. However, by the 21 st century problems became even more evident. As a response to this, the reform of the patent system was initiated in more countries. In the USA, the patent system was reformed in 2011, but according to researchers further, even more radical reforms are necessary. In Europe there is a hope for improvement thanks to the introduction of the single patent system planned for 2015 .

\subsection{The significance and alternatives of patents}

In the below figure Frietsch (2010) demonstrates the possible components of patent values excellently from a positive aspect. He shows the utility of

\footnotetext{
${ }^{9}$ Lőrincz (2007) describes rent-seeking and its significance in a more detailed way.
} 
patents in relation to the inventor and society on the vertical axis. On the horizontal axis the advantages of patents are presented by breaking them down according to economic, strategic and technological advantages. From the 15 elements shown in the figure there are numerous, which also represent advantage for all stakeholders not demonstrated in the figure, for example in the solution for social problems. However, patents can also have numerous advantages, which represent disadvantage for competitors or the society, like for example the blocking or postponing of the competitors' innovative activities. It can be observed that the disadvantageous activity for external stakeholders mostly occurs in case of the strategic utilization of patents. Should patent protection altogether mean advantage for the inventor, then most probably he will use it, without taking net social effect in consideration.

Figure 7.: The classification of the advantages of patents

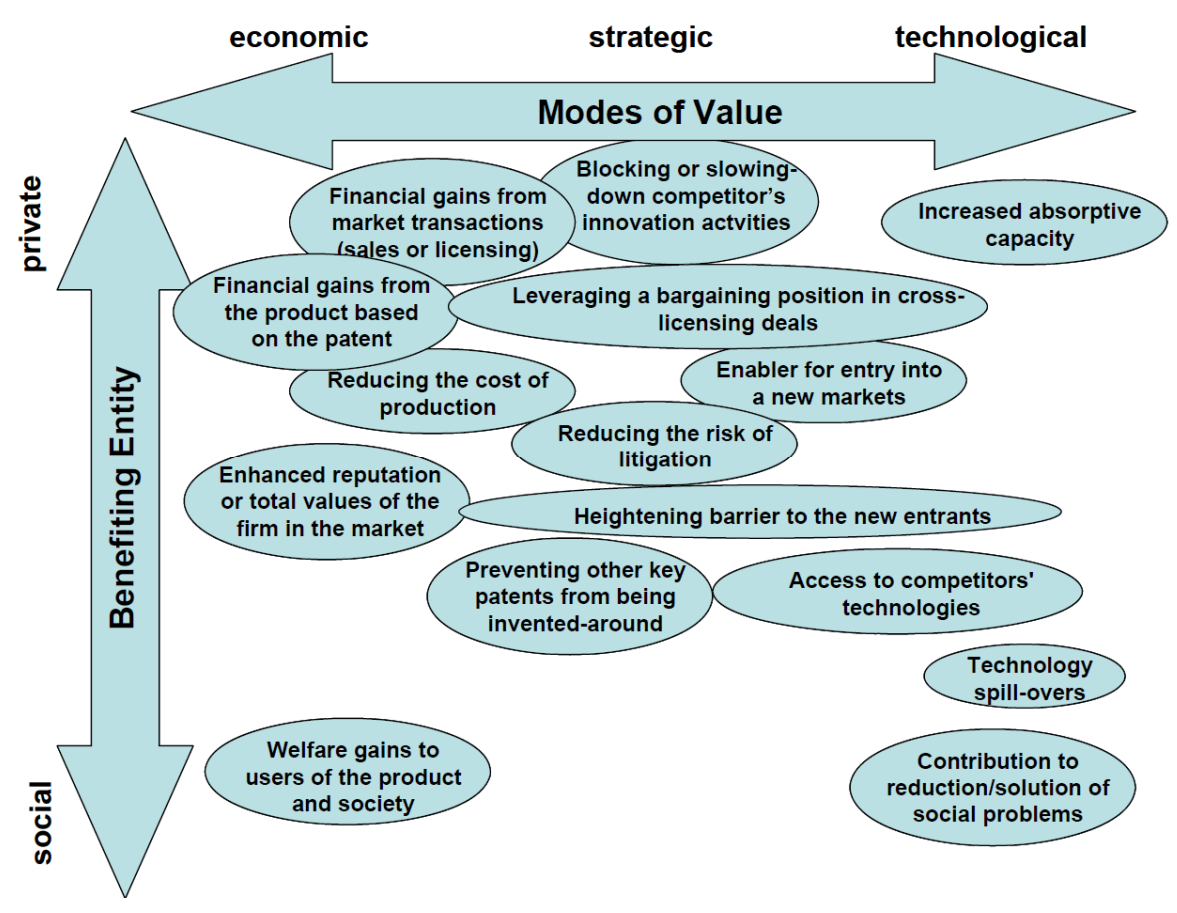

Source: Frietsch et al., 2010, p. 10.

The social effect of patent system is the sum of numerous positive and negative effects. According to Mazzoleni and Nelson (1998) patent system has the following potential advantages:

- it stimulates innovative activity; 
- promotes the implementation and commercialisation of innovations and (especially should the innovator not possess the necessary abilities or motivation);

- promotes the disclosure of innovations (which can enhance the diffusion of innovation and the activities of those dealing with similar innovation);

- sometimes patents enable orderly development of broad prospects (a 'controlling' patent can define the main directions for development and enable the more efficient utilization of resources).

The potential disadvantages, social costs of patent system can be the following:

- a price temporarily higher and quantity lower than socially optimal;

- in certain cases a monopoly even existing after the end of patent protection;

- in certain cases restriction of competition and the appearance of potential new market entrants;

- possible slowing down of follow-up innovations (based on the original);

- resources wasted during parallel research due to patent competition;

- costs, resources related to patenting;

- trials and trial-risk due to the possible infringement of patents of others.

The cost for operation of patent institution system can be a further social cost.

A significant part of modern technological innovations is patented. Based on empirical studies its quantity depends on numerous external factors. According to researchers in developed countries, the ratio of patented technological innovations in the complete economy can be around 20-50\% (Cohen et al. (2000), Arundel and Kabla (1998), Kleinknecht and van der Panne (2009)). Besides the fact that the more expensive inventions are more likely to be patented (Moser, 2007), this quite transparently shows that patents provide serious advantage for innovators.

According to Cohen et al. (2000), the belief in the positive effect of patents on innovation led to the strengthening of patent protection in the 1980's and 
1990's in the USA, EU and Japan. In the USA due to a law from 1982, patent protection became stronger and more integrated. Since the beginning of the 1980's the circle of those things and inventors being entitled for patent protection has been widened (e.g. new forms of life, state laboratories, etc.). Since then the patenting ratio of innovations, the ratio of claimant successes in law infringement trials, and the number of law infringement actions have all increased significantly (Kortum and Lerner 1999, Lanjouw and Lerner 1997). Thus patenting activity increased to a significant extent, in the USA the number of patent applications grew from 104,000 in 1980 to 357,000 by 2004 . The cause of further growth is that the number of patent claims has also significantly increased. Bessen and Meurer (2008) contribute a huge part of the growth to the strengthening of patent protection. However, according to Danguy et al. (2010) this growth was to a huge extent contributed to the fact that contrary to earlier, inventors patent their inventions ever more globally, also in the USA. It is also important to highlight the growing importance of China, where the total yearly number of granted patents surpassed the USA in 2011 (Nicholas, 2013b).

According to Mansfield (1986) patent propensity was continuously increasing earlier too, although at a smaller rate. In his research he examined randomly chosen 100 firms of 12 industries, with a revenue of at least 25 million USD in the USA between 1981 and 1983. In case of half of the participant companies patent propensity was unchanged between the end of the 1960's and the beginning of the 1980's, while the others rather reported about growth. Here the main stimulator of growth was not legal change, but the change in the product structure of firms. The more and more sophisticated products were certainly patented by companies to a higher ratio. According to Mansfield, other factors leading towards the direction of increase in patent propensity were the intensification of competition, a bigger routine gained in patenting and the technological development making imitation of the product easier.

In another research Mansfield et al. (1981) examined 48 product innovations. They pointed out that in general the total cost of imitating the innovation and placing it on the market (from the imitation of innovation, through the avoidance of the possible patent until generating benefit) is $65 \%$ of the 
original, while the time needed is $70 \%$ of that. The deviation of the sample was significant, in half of the cases the cost of copying was either under $40 \%$ or above $90 \%$. Certainly innovation could not always be imitated, since other factors can also play a role (e.g. the well-introduced brand), but 4 years after introduction $60 \%$ of the sample's patented innovations were copied. Patent in general makes imitation more expensive, the median additional imitation cost was $11 \%$, in contrast to $6 \%$ in case of not patented products. In the case of two products, patenting even would also have decreased the time and cost of imitation, since the inventor was able to keep certain elements of the invention secret, which he otherwise should have published during patenting. Patenting made imitation the most expensive in case of ethical pharmaceutical manufacturing. This explains those results of the survey that patenting in this industry plays a more important role. Median cost increase in this industry was $30 \%$, compared to $10 \%$ of chemical industry and $7-7 \%$ of electronics and machinery. The expected effects of patenting and so patent propensity significantly differ in these industries.

Certain protection of their inventions is a natural interest of inventors, but it cannot only happen through patent protection. Moser (2007) studied more than 7000 innovations of 4 British and American world's fairs between 1851 and 1915. She showed that the effectiveness of business secret plays a decisive role in reaching a patenting decision. Keeping the invention secret is possible with small risk in industries, where it is difficult to reconstruct innovations based on observable elements, but implies high risks where it is not the case. Contrary to business secret, patent protection is a more universally applicable solution. She found that technological novelties helping the reconstruction of innovation, promote patent propensity. A good example for this is that due to the discovery of the periodical system, chemical patent propensity increased to a significant extent both in time and compared to other industries.

In the survey of Cohen et al. (2000), which examined the R\&D department of approximately 1500 USA companies active in the field of machinery, firms had to answer the question what was the reason behind not patenting the latest such product. The following answers could be given: 1. underpinning the novelty of information is problematic; 2. they did not want to publish essential 
information (that could be used by competitors); 3 . costs related to patenting; 4 . the cost of protecting patent in court; 5. patent can be easily invented around.

The results of the survey can be seen in the figure below. According to this, ease of inventing around and publishing substantial information are the most important arguments for the neglection of patent protection.

Figure 8.: Reasons for not patenting innovations

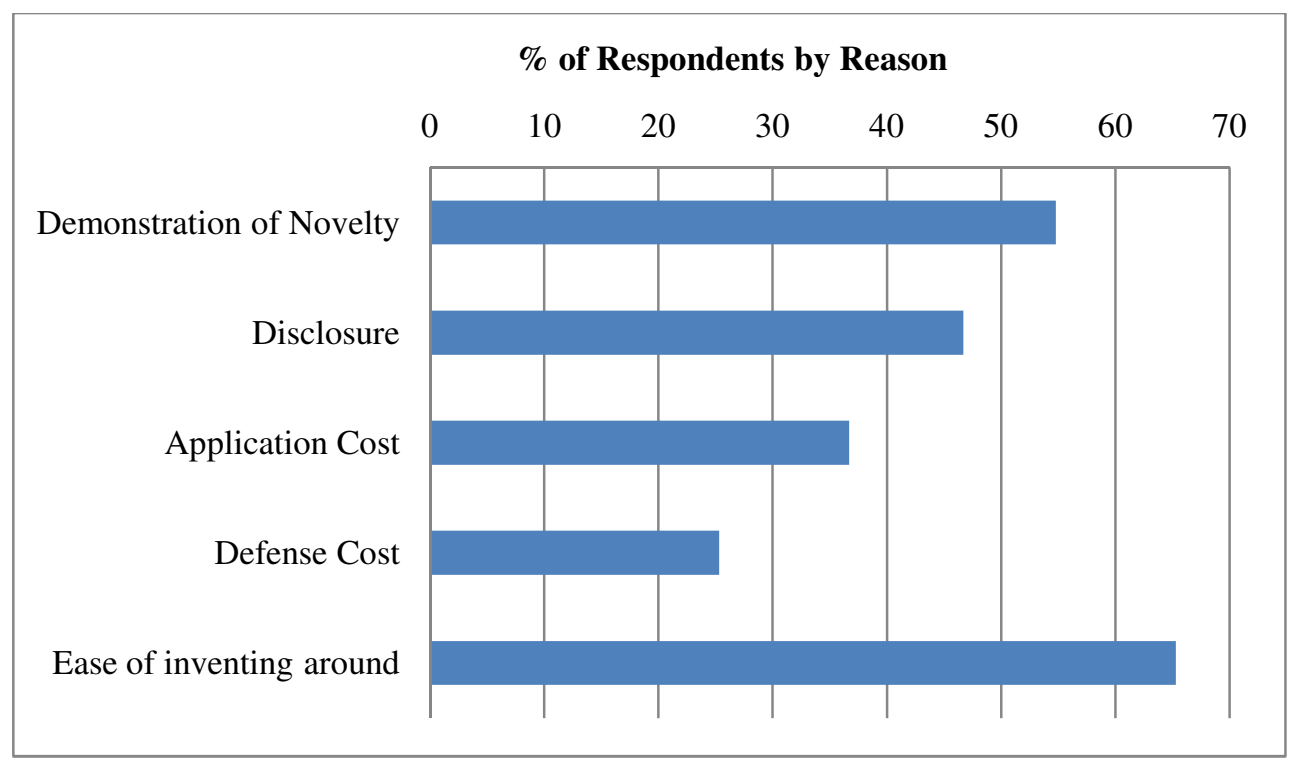

Source: Cohen et al., 2000, p. 46.

This is also underpinned by the previously shown research of Mansfield et al. (1981), where they invented around $60 \%$ of the patented innovations in their sample.

Besides the reasons to be found in the questionnaire of Cohen et al. (2000) uncertainty and the expected economic lifetime of the invention can also play a role in the neglection of patenting. In case of new technologies (microelectronics, biotechnology) there is a common uncertainty, so the inventor often keeps the discovery secret (Basberg, 1987). The value of the patent depends on for what time period it provides exclusive rights for production and marketing. Although the internationally accepted patent term is 20 years, effective protection is much shorter, since even 5-10 years can pass by until the innovation protected by the patent enters the market. Thus the patent term exploitable after entering the market significantly decreases. In 
such a case the institution of complementary patent protection can enable the expansion of the original patent term of 20 years. If the expected lifetime of the product is much longer, then it is not worth patenting it, since during the patenting process the description of the invention can become public, and after the expiry of patent protection anybody can freely manufacture, distribute the product. In these cases the inventor better keep the invention secret (Basberg, 1987). A good example for this is Zwack Unicum.

Should the lifetime of the product be much shorter than the time of patent protection, it is still worth keeping the discovery secret, because there is a chance that the invention becomes obsolete even before the patent will be granted (Basberg, 1987).

Blind et al. (2006) examined more than 500 German firms with significant patenting activities in 1999. The firms had to specify the significance of 11 different protection strategies, the answers can be found in the table below. It is not surprising that according to the sample containing firms active in patenting the role of patents is extremely important, still the most important tool for the protection of innovation is time advantage.

Table 2.: The significance of tools for the protection of innovation

\begin{tabular}{|lc|}
\hline $\begin{array}{l}\text { Importance of protection instruments (share of companies giving } \\
\text { high or very high importance) }\end{array}$ \\
\hline & Significance \\
\hline Lead time advantage & 0,88 \\
Patent strategies abroad & 0,79 \\
Domestic patent strategies & 0,72 \\
Exclusive relations to customers & 0,66 \\
Trademarks & 0,58 \\
Secrecy & 0,58 \\
Supplier contracts & 0,51 \\
Long term contracts with workforce & 0,44 \\
Utility patent & 0,24 \\
Copyright & 0,15 \\
Design patent & 0,11 \\
\hline
\end{tabular}

Source: Blind et al., 2006, p. 661. 
The 11 strategies were classified in three groups with the help of cluster analysis, which shows the possible innovation protection strategies of firms.

- $\quad$ patent protection: domestic and foreign patents

- other formal rights: trademark, utility model protection, design, copyright

- $\quad$ informal or contract-based: measures aiming at the long term retaining of employees, business secret, advantage in time compared to competitors, exclusive customer relations, contracts with suppliers

In their survey, Levin et al. (1987) raised the specific question, by which methods firms ensure the return of their innovations besides patents. Based on the answers effective tools were the exploiting of advantage in time, quick advancement in the learning curve (restriction of net cost), complementary sales and service abilities and business secret. Many companies applied more of these tools.

For the protection of innovations, firms mentioned one more method, namely defensive publication. This can be used when they feel that they cannot obtain the patent for innovation, but there is a chance that someone else can get it. By publishing part of the innovation (and keeping other parts secret) the firm can at least avoid that others will patent it and he cannot use it freely (Cohen et al., 2000).

Similarly Cohen et al. (2000) find that besides patent protection, firms can ensure their profit originated from innovations in more ways. These are business secret, time advantage, complementary marketing and manufacturing abilities. Firms find business secret and time advantage the most important. In most industries the role of patents is less emphasized. Based on their results besides industrial differences there are also significant differences between product and process innovations. In case of product innovations a higher ratio of respondents found patenting an efficient tool for protection $(35 \%)$, than in case of process innovations (23\%). The detailed results of the research can be found in Annex 1.

According to Cohen et al. (2000) the optimal way of protection of innovation also depends on the stage of the innovation process. In the first stage of 
innovation firms mostly build on business secret, but afterwards they can try to preserve their competitive advantage through patents, aggressive marketing, advantage in time or the combination of these. They can also apply different methods at the same time, should the innovation consist of more separate elements. In chemical industry in certain cases patent protection is provided for certain parts of innovation, while other elements are kept secret (Arora, 1997). The sales, service and manufacturing capabilities of certain firms, their coherence and advantage in time together underpin the reasons of Teece (1986) that the value of the patent hugely depends on what abilities the utilizing firm has.

During the factor analysis of methods three different strategies can be distinguished. The first includes complementary capacities and time advantage, the second includes legal tools (including patents), while the third one is business secret. Firms cannot really choose the strategy, it is very much determined by external factors. These can be for example existing technology, the complexity of the product, specific features of innovation, characteristics of production process (e.g. in case of complex, capital intensive products focused on continuous production, manufacturing capacities can gain an important role), furthermore the feature and intensity of market competition (e.g. the relative importance of price and the application of the most modern technology). Generally it can be said that process innovations are harder to observe for external parties, so it is easier to keep them confidential, this is why patents in their case are less efficient than in case of product innovations (Cohen et al., 2000).

The results of the research of Brouwer and Kleinknecht (1999) also underpin the above. Their research is based on two databases. One of them is the survey containing the data of manufacturing firms from the year 1988 in the Netherlands. The other one is the Community Innovation Survey (CIS) containing the data of 1992. In case of the 1992 research, approximately 2000 firms provided data, while in case of firms answering both surveys the sample consists of 1300 elements and is representative for the firms active in machinery industry, employing at least 10 people. Compared to the other studies, the sample also contained firms of much smaller size. Based on their 
results, approximately half of the firms do not find patents useful at all during their protection from imitators. The most important mechanism in their case is time advantage compared to competitors. A further result of their research also coincides with the above, according to this in case of process innovations patents are somewhat less significant. The detailed results of Brouwer and Kleinknecht's research (1999) can be found in Annex 2.

However, examining only the large companies we can obtain much different results. Among large companies in case of more industries the efficiency of patents is the best (pharmaceutical industry, perfume manufacturing, rubber and wood chemicals, tubes and valves, oil industry machinery, gearboxes and other car components). Above this, although not being the most efficient method, its value is minimum $50 \%$ in case of organic chemical industry, wire and cable production, turbines and generators, motors and industrial control devices and medical devices (Cohen et al., 2000).

Summarizing the above we can conclude that patents have gained ever more significance in the last decades. Patent protection has a huge significance in the protection of innovations despite the fact that companies typically rather keep their inventions confidential or rely on their time advantage. The efficiency of patent protection significantly depends on the industry of the innovation, whether we talk about process or product innovation and the size of the firm. Inventors not patenting their innovation are mostly afraid from the imitators inventing around the patent and would like to avoid the disclosure of their innovations.

\subsection{The fundamental directions of patent research}

Patent research focuses on numerous areas. As already mentioned in the beginning of the chapter, I primarily focus on those economic studies examining the effects of patent protection on innovation and its social utility. I will continue with the detailed introduction of the following research topics below:

- Patent propensity and the value of patents,

- The strategic application of patents, 
- Patent infringement trials,

- Patent disclosure,

- Patents and environmental innovations,

- The effect of patents on innovation,

- The reform of patent system.

The review of these research areas is indispensable when answering research questions. Through them we can get insight into the relation between the patent system and innovations; the examination of the social utility of patent system and the reform proposals is directed towards increasing social utility.

\subsubsection{Patent propensity and the value of patents}

The concept of patent propensity was created by Scherer (1965, quote Arundel and Kabla (1998)), he used it for describing the relation between the number of patents and $R \& D$ expenditures. This index is difficult to use in practice and the productivity of $\mathrm{R} \& \mathrm{D}$ activity can also influence the end result. This is why Mansfield (1986) defines patent propensity as the patented part of patentable innovations. Certainly this interpretation also has its own constraints. Ács and Audretch (1998, quote Arundel and Kabla (1998)) pointed out that the number of patents related to innovation is not constant but depending on the industry can vary between $0.6-49$ on average.

According to Danguy et al. (2010) the patent propensity used in Mansfield's interpretation should be broken down into two parts. Based on the figure below one of them is compliance propensity, while the other one is strategic propensity. The former tries to map whether in case of the given innovation patent protection was used, while the latter models how many patent requests were handed in for the protection of the given innovation. Reitzig (2004) examined 614 requests handed in to EPO (European Patent Office). Based on this one innovation is tried to be protected by approximately five corresponding patents on average. 
Figure 9.: The connection between $\mathrm{R} \& \mathrm{D}$ and patenting

\begin{tabular}{|c|c|c|c|c|c|c|}
\hline $\begin{array}{l}\text { Research } \\
\text { input }\end{array}$ & research $>$ & Inven- & appropriability & $\begin{array}{c}\text { Patent } \\
\mathrm{Y} / \mathrm{N}\end{array}$ & strategic & How \\
\hline
\end{tabular}

Source: Danguy et al., 2010, p. 172.

The concept of Danguy et al. is without doubts positive, but is difficult to use in practice. From now on we will use the definition of Mansfield, similarly to most researchers in literature.

Moser (2007) examined more than 7000 innovations of 4 British and American World's Fairs between 1851 and 1915. A World's Fair as source of data has more advantages: 1. it contains both patented and non-patented innovations; 2. numerous industries and countries are being represented; 3 . the significance of individual innovations was examined by a professional committee and it was put together accordingly. Moser found that at this time inventors patented only a small ratio of their inventions. In $185111 \%$ of British innovations, while $15 \%$ of USA ones. This means that a decisive part of these inventions was protected in some other way. It is important to note that patent propensity shows huge diversity in different industries. 0-5\% of chemical innovations (USA and British ones), while 40-30\% of machinery innovations got patented (USA and British ones). By 1915 the ratio of chemical industry patents grew to $18 \%$ in the USA, most likely due to the discovery of the periodic system.

The research of Moser (2007) is based on the examination of a stage relatively early in time. Since then the patent and economic system has gone through quite significant changes. She also points out that patent propensity must have significantly increased since then, especially in case of chemical industry. However it is evident that mostly the innovative industry effects patent propensity. Moser (2007) also identified further factors, which have an influential force. The high value of innovation (the prize-winning inventions are patented to a higher ratio in 7 out of 10 industries), the low cost of patenting and the central geographical location of the inventor (city or country) also lead towards the increase in patent propensity, but their effect is small compared to the industrial effect. 
In another research Fontana et al. (2010) examined the 'R\&D 100 Awards' of the Research and Development newspaper between 1963 and 2005. The database here also has the main advantage of containing both patented and non-patented inventions. It is important to highlight that winning the prize is based on the opinion of experts, so it mostly includes valuable innovation. Similarly to Moser, they also found a low patenting ratio slightly below $10 \%$. However this survey (as the authors themselves also highlight) significantly overrepresents high-tech type of technologies and the inventing activities of formalized R\&D laboratories. These partly cannot be patented and based on other studies they have a relatively lower patent propensity.

Kleinknecht and van der Panne (2009, quotes de Rassenfosse 2010) examined the patenting of new products published in commercial newspapers in the Netherlands. On average $35 \%$ of these got patented. In this sample SMEs are likely to be found in a more representative form, since typically rather small enterprises communicate through commercial newspapers and presentations.

In the following I will present the results of studies, in case of which patent propensity is determined by the questioning of firms, which worsens the reliability of surveys. This is matched by the fact that numerous such studies were carried out and the results scatter in a real range.

The research of Mansfield (1986) covers 12 industries. In the 5 industries where patents are considered to be important, more than $80 \%$ of innovations were patented, and even in those 7 industries where they are less important, at least $60 \%$.

The survey of the European Patent Office (EPO (1994), quote Arundel and Kabla (1998)) covers those firms employing less than 1000 employees, which in the examined period filed for patent applications. $50 \%$ of the respondent 1006 firms filed for patent applications for more than half of their patentable innovations.

The firms manufacturing machinery taking part in the survey of Cohen et al. (2000) filed for patent application for $49 \%$ of their product innovations and $31 \%$ of their process innovations between 1991 and 1993. 
Arundel and Kabla (1998) carried out research based on two databases. In 1993 the 500 greatest European R\&D industrial firms were examined except for France, while in France 2622 companies with more than 50 employees were asked. It is important to highlight that in their research they examined patent application propensity, the ratio of actually approved patents in reality is lower than this. In 1992 EPO rejected 32\% of patent applications, while the USA patent office $37 \%$ of them or the inventor withdrew them. The ratio of rejection and withdrawal is different in the individual European countries, which can also influence the end result of the research. According to the results of Arundel and Kabla the ratio of patented product innovations is $35.9 \%$, while that of process innovations is $24.8 \%$ reflected to all companies, weighted by the turnover of firms. Without weighting, patent protection was requested in case of $33.0 \%$ of product innovations and $20.1 \%$ of process innovations. Industrial differences are also significant here, in the pharmaceutical industry patent application was filed for in case of $79.2 \%$ of product innovations, this is followed by chemical industry $(57.3 \%)$ and machinery $(52.4 \%)$. Contrary to this, in textile and clothing industry this ratio is only $8.1 \%$ and in case of metal raw materials also only $14.6 \%$. If only the data of the first, European survey were examined, which mostly contained larger firms, then higher patent propensity was found (in case of product innovations $43.6 \%$, in case of process innovations $25.9 \%$ ). In the sample containing European companies the timetable of the R\&D department for 5 activities was also examined. By using these data the patent propensities of individual firms were also calculated, weighting them by turnover patent propensity was obtained, which exceeded $50 \%$ in case of only four sectors. It is surprising that product innovations are emphasized also in process-driven industries such as oil refinery, food and tobacco industry. Thus in case of product innovations, patents play a more important role than business secret. The detailed data of the research of Arundel and Kabla can be found in Annex 3.

De Rassenfosse (2010) examined 772, relatively larger firms with patent application at EPO. The firms represented in the research patented 54\% of their innovations on average. 
Based on this, patent propensity is significantly lower than in the research of Mansfield (1986) and slightly lower than in that of Cohen et al. (2000). The main reason for this can be that the research of Mansfield (1986) is not based on a completely equivalent sample as the other two analyses. The analysis of Mansfield is of narrower range (100) and is related to larger companies (firms of at least 25 million USD turnover). As I will later describe in a more detailed way, size significantly influences patent propensity. Besides this the following reasons can contribute to the ratio being lower in Europe than in the USA:

- higher patent costs;

- relatively smaller market size;

- more disadvantageous legal environment (the law of 1982 in the USA strengthened patent rights).

De Rassenfosse (2010) also draws attention to the importance of the country of the innovation that influences the patent propensity as per his calculations approximately two times as high as firm specific and industrial effects.

Furthermore, Cohen et al. (2000) identified more factors, which can also influence patent propensity. The companies also selling their products for American or Japanese markets (and likely to be exposed to higher competition) patent their product innovations to a higher ratio. Patent propensity is influenced by product license revenue only on a $10 \%$ significance level, while the R\&D intensity of individual firms has no effect on patent propensity. In case of process innovations selling on the above mentioned foreign markets has a much less positive effect on patenting. By filtering the common effect of the other factors it was found that in case of process innovations the industry influences patent propensity only to a limited extent.

Hottenrott and Lopes Bento (2012) examined the patent activities of firms taking part in innovative cooperation in the Fleming part of Belgium between 2000 and 2009. According to their results, innovative cooperation positively influences patent propensity.

During their research, Brouwer and Kleinknecht (1999) found that firms signing R\&D cooperational agreement are more likely to patent and file for 
more patent applications. The innovative output of companies (e.g. turnover originated from the sale of innovative products) also systematically relates to patent activity.

Danguy et al. (2010) examined the R\&D and patenting data of 18 industries of 19 countries between 1987 and 2005. Based on their result, patent propensity is higher in industries based on complex technologies and possessing stronger patent protection. During their research they find that the influence of the strategic part of patent propensity in case of industries built on more complex products can be higher. The result of this in their sample can be experienced in case of IT and communications and electrical equipments the strongest. In case of countries with stronger patent protection they also find higher strategic propensity.

Danguy et al. (2010) in their research find that filtering the effects of the increase in $R \& D$ expenditures and research productivity patent propensity in case of primary application does not increase. Contrary to this, in case of more important patent offices more serious growth was experienced. A reason for this can be that although firms did not patent substantially more innovations, but as a result of the globalization effect they strive for recording them in an ever wider circle.

Figure 10.: The change of patent propensity in time

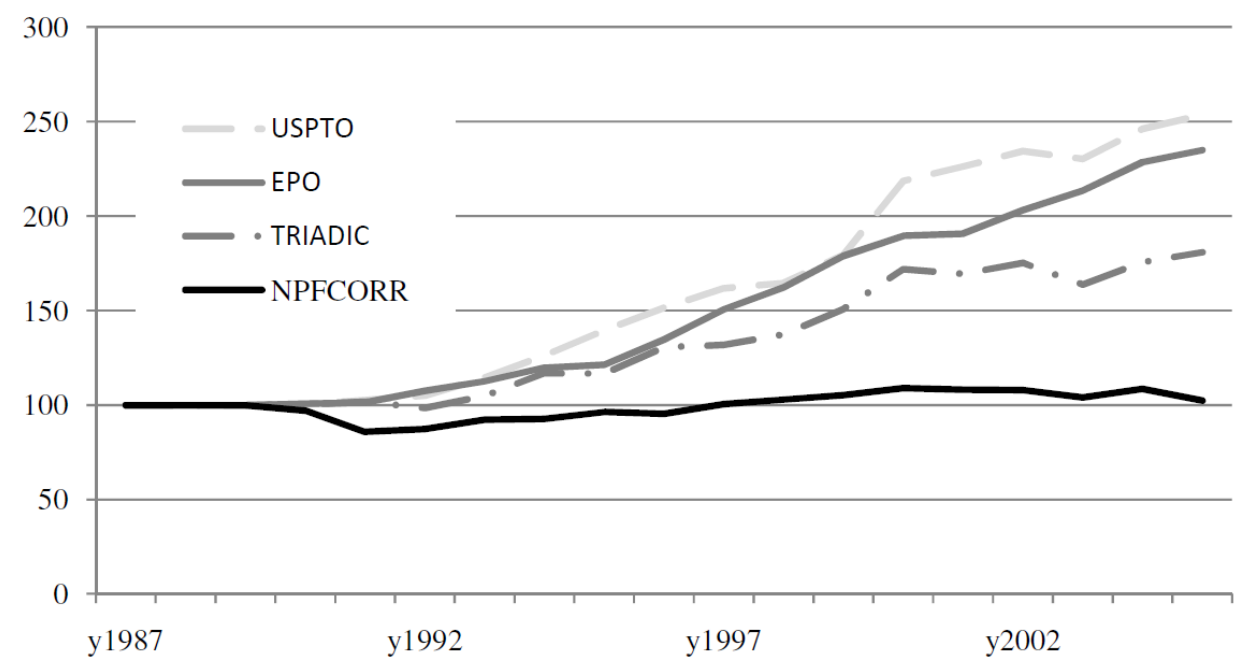

Source: Danguy et al., 2010, p. 188. 
The change of patent propensity in time is demonstrated by the figure above. USPTO shows the primary patents applied in the USA's patent office, TRIADIC those applied jointly in the patent offices of the USA, the EU and Japan, while NPFCORR the primary patents of the inventors of a given country applied around the world.

Patent propensity is not constant at all, it depends on numerous factors. The most influencing factors are the country and industry of the innovation and firm size. Furthermore it is also influenced by a number of other factors, researchers mostly highlight the strength of competition, the type of innovation (product or process innovation) and the importance of the R\&D cooperation between companies, which lead towards the increase in patent propensity. According to numerous studies, the patent propensity of firms has increased in the past decades. As per the opinion of Danguy et al. (2010) this is true mostly in case of the biggest countries and the effect of globalization is significant.

A number of studies aim at the examination of the effect of firm size on patent propensity. This is also important from my research's point of view, this is why it will also be presented in a more detailed way below.

Arundel and Kabla (1998) found that as seen in the figure below, patent propensity increases proportionally to the turnover of the company up to a revenue of 750-1000 million ECUs, and decreases afterwards. In regression models in case of product innovation, the connection is positive and significant in every case. According to them, the reason for decrease is partly of industrial origin, since there are only a few industries where the turnover of firms can be quite high, and they have relatively low patent propensity (e.g. oil industry, metal raw material manufacturing and the manufacturing of other raw materials). Thus the fraction of these firms is over-represented in the highest turnover ranges. Regression models underpin this assumption, by filtering the industrial effect, patent propensity increases together with firm size. A separate analysis was also carried out regarding 95 firms in four technology intensive industries, and similar results were achieved there, too. 
Figure 11.: The connection between patent propensity and firm size

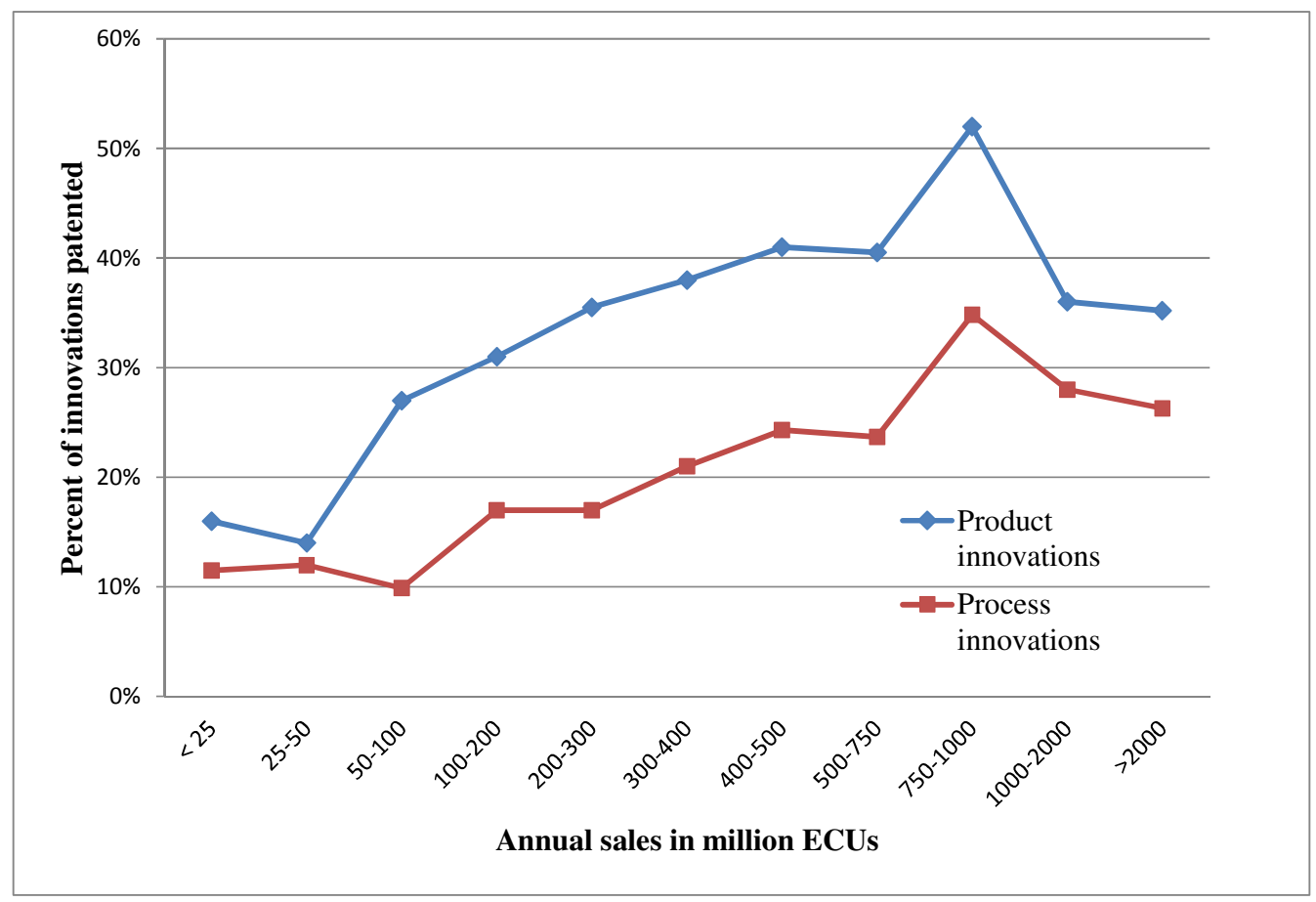

Source: Arundel and Kabla, 1998, p. 134.

According to the results of Arundel and Kabla (1998), research using estimations mostly based on the data of large firms, overestimate patent propensity regarding all firms. This is slightly compensated by the fact that small companies with higher propensity were also left out of the sample. However they think that their results do not alter significantly even if they are related to all firms, since the survey includes most of the turnover and $R \& D$ expenditures of European firms.

Brouwer and Kleinknecht (1999) and de Rassenfosse (2010) reach conclusions similar to the above meaning that the patent propensity of larger companies is higher. The chance of a firm having at least one EPO patent increases to a ratio larger than the number of employees. However, should a firm already own a patent, the number of patent applications will increase in a ratio smaller than firm size (especially due to the existence of smaller size, but extremely innovative firms). According to them, mostly the costs of patenting and the lack of information related to patent system affect smaller companies more sensitively than larger ones. 
Cohen et al. (2000) examined the reasons for the lower patent propensity of firms more in detail. In sync with the results of Lerner (1995) and the above they found that costs related to patents divert smaller companies from the application of patent protection. Based on their results, both the costs related to patenting and the non-patenting due to possibly relatively large patent trial costs, significantly depend on company size. Larger companies are able to spread these costs to their product portfolios more. Although according to their surveys, in most industries patent protection is not the dominant type of protection for product innovations, although in case of large companies it is one of the most important tools in more industries.

Blind et al. (2006) identified further reasons to verify the higher patent propensity of larger firms. Based on their results there is an almost linear connection between firm size and the existence of corporate patent department. Almost all larger companies have their own patent agents and engineers. These do not only help the work of R\&D department passively and by request, but they often actively take part in projects, strive for uncovering patent potential already at the early stage and draw the attention of developers to these opportunities.

De Rassenfosse (2010) slightly contradicts this by finding that the chance of having a patent agent within the firm increases proportionally to firm size, but does not influence patent propensity.

Besides the above, Blind et al. (2006) conclude that only taking the traditional application methods of patent protection (protection of innovation, prevention of imitation) into consideration, firm size does not influence patent propensity significantly. However, in case of strategic motivations it typically does have an effect. Obviously, patenting in order to lay down the foundations of reputation is a more attractive option for smaller firms (1-249 employees). Contrary to middle-sized firms, the smaller and largest firms (more than 2000 employees) rather strive for license revenues, improving their patent bargain and exchange position. Finally as firm size increases, they much rather apply patents for the motivation of employees and measurement of performance. Regarding this latter only the largest firms differ significantly from the others. So, small and large firms contribute a higher significance to motivations for 
patenting than mid-sized ones. However, it is important to highlight that Blind et al. only examined those firms, which were already engaged in patenting activities.

Mäkinen (2007) carried out a research of approximately 800 Finnish product innovations. In case of the smallest, start-up companies his results underpin the relatively higher role of patents, while in case of mid-sized companies their lower patent propensity. Patent propensity as a function of firm size is $U$ shaped.

Thus there is no general answer to the question what ratio of innovations is patented, since it depends on numerous factors. Generally in case of developed countries patent propensity can reach a value of approximately 20$50 \%$.

The requirement of patentability is met by numerous inventions, which can be hardly or not at all utilizable. The fact that firms patent such a high ratio of their innovations projects that most patents are of low value. There are a number of methods applied for the evaluation of patents in literature. It is important to differentiate between the value of innovation protected by patent and the value of patent protection. The value of patented innovations can be reflected by patent references, how many previous patents the patent marks as predecessors and how many refer to it. The value of companies in the stock market and its change can also well describe the value of patented innovations. In case of less valuable patents the renewal rate of the patent can reflect the value ${ }^{10}$ well. Additionally certainly the individual evaluation of patents and the direct interviewing of companies can also be of use.

Scherer and Harhoff (2000) examined 8 data series related to firms and universities. Based on their results, the distribution of patent values is lognormal and strongly skewed. Depending on the observed sample the most valuable $10 \%$ of innovation contributes to $48 \%-93 \%$ of returns. In their

\footnotetext{
${ }^{10}$ This method is based on the fact that for maintaining the patent the patentee gradually has to pay an increasing annual fee.
} 
sample with the highest number of elements they examined those German patents, whose patent application took place in 1977 and the patent was continuously renewed, until the expiry of the patent in 1995. Thus in this sample the more valuable patents are over-represented from the beginning. Based on their results in this concrete sample the most valuable decile of patents contributes to $84 \%$ of the total value of patents.

Gambardella et al. (2008) examined the value of European patents based on the data of approximately 9000 European patentees between 1993 and 1997 . Their result fits with the above, as it can also be seen in the figure below, the distribution of values follows a lognormal pattern.

Figure 12.: The distribution of the values of patents (EUR)

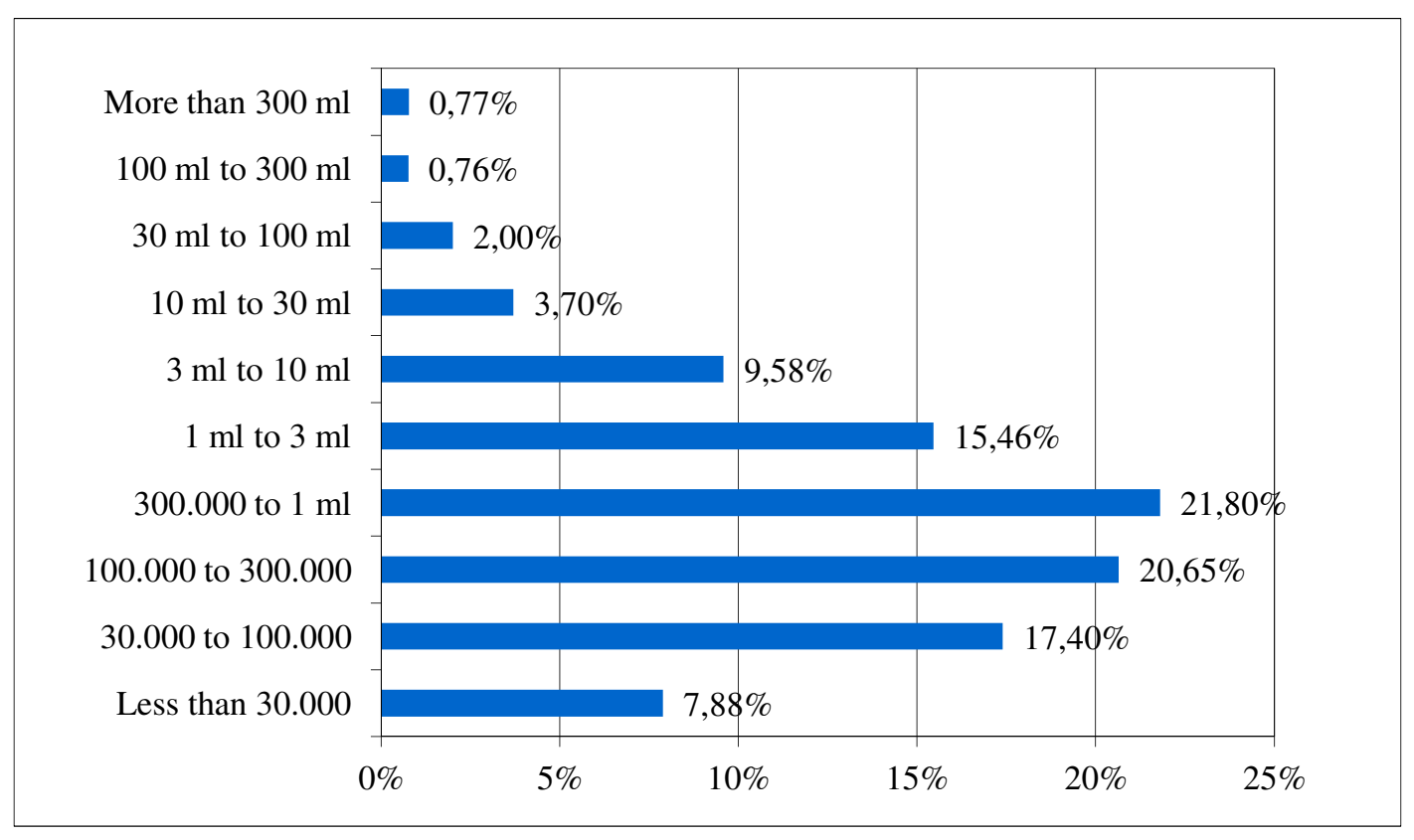

Source: Gambardella et al., 2008, p. 45

Giuri et al. (2007) analysing the same data find that the most valuable $10 \%$ of patents contribute to approximately $90 \%$ of the value. There are numerous mid-value patents, the value of which falls between 300 thousand and 10 million Euros, so it is worth taking them into consideration. According to Friesch et al. (2010) this is one of the reasons why it is not worth dealing only with the most valuable patents. A further reason is that the most valuable patents almost exclusively relate to the radical innovations of large companies and the innovations of successful start-up enterprises. This is why 
concentrating solely on them is not suitable for the examination of incremental innovations and SMEs.

Gambardella et al. (2005) showed that the value of patent portfolios relating to one innovation or one family of innovations increases largely because of the number of related patented inventions. The increase in the average value of the patents is less important.

Gambardella et al. (2010) studied more than 22 thousand patent applications between 2003 and 2005 in 20 European countries, USA and Japan. They show that a bigger inventive step of an innovation increases patent value. Inventive step is positively related to the better educational background of inventors and depends also on the size of the inventor team and the resources deployed. The inventive step in case of commercial organizations is lower than in the case of other type of organizations. Inventive step decreases even with firm size, mainly because of the increasing patent propensity.

Based on the examination of the patents of USA firms between 1985 and 1991 Bessen (2008) concludes that the patents of larger companies are much more valuable than those of smaller firms. In his opinion, it can show the deficiencies of the technology-trade market. He emphasizes that the value of the patent is not a concrete number, but hugely depends on who the owner of the patent is.

Gambardella et al. (2011) studied the determinants of the value of patents. They found that the experience and education of the inventor, the man-months invested in the research are important factors of the patent value.

Kani and Motohashi (2012) based on the examination of Japanese patents find that the license of numerous patents could not be sold contrary to the intention of the owner. They also blame the deficiency of the technology-trade market for this.

Gambardella et al. (2007) who also worked from the database used by Giuri et al. (2007) reach similar conclusions, too. Based on their research, the most important determinant of the licensing of patents is firm size. The value and subject matter of the patent have smaller influence. These latter factors typically rather influence the intention of licensing. Similarly to the above, the 
reason is said to be the high transaction costs of the technology-trade market. Given the $48 \%$ value of larger companies, the $22 \%$ patent renewal rate of individual applicants and the $25 \%$ value of small firms show that there are huge opportunities in the establishment of a more efficient market.

Based on the results of Bessen (2006), the values of patents of smaller patent applicants are lower. In his opinion, in addition to the previously described effect this can be partly caused by the individual, private applicants registered among small applicants. Individual applicants do not necessarily patent their inventions due to economic reasons, but because of vanity or the sake of increasing their reputation.

The special situation of individual applicants is also pointed out by Gambardella et al. (2005), based on the data of approximately 9000 European patentees between 1993 and 1997. Their results meet the opinion of Bessen (2006) since for the individual applicants not the benefit of patent protection, but proving the technical implementability of the invention is the most important factor. This is followed by prestige and in case of employee invention, corporate compensation. The benefit of the invention, the arising career opportunities are less important, while they find the performance increase of innovation for the company the least important. These are quite interesting results, which are worth considering by companies.

The concept of patent premium shows what additional value patenting provides besides the value of the patented innovation. For this, the patent's value has to be broken down into value of innovation and patenting value compared to the next best alternative (Jensen et al., 2009). The value of patenting has to be determined in money or as a ratio of the total value. This latter concept is patent premium (Arora et al., 2008).

Schankerman (1998) examined the applications of the French Patent Office between 1969 and 1982 and their renewals between 1970 and 1987. In his opinion inventors could also be made interested by subvention instead of patents. According to his calculations, $15-35 \%$ of the R\&D cost would be enough for this. It is important to highlight that Schankerman did not calculate 
the patent premium of the innovation, but the equivalent subsidy rate (ratio of patent premium and $R \& D$ cost).

The empirical research of Arora et al. (2008) is based on the data of R\&D institutions between 1991 and 1993. They find that patent premium is the highest in case of medical devices, slightly above $100 \%$. Its value is around $100 \%$ in the biotechnological and pharmaceutical industry, too. In further industries the value is typically between $40 \%-60 \%$. It is the lowest in case of food and tobacco products, where it is $28 \%$.

In their empirical research Jensen et al. (2009) examined Australian patent applications between 1986 and 2005. Based on their estimations, the value of patent premium is around 50\%. No significant differences between individual industries were found.

By examining the value of equivalent subsidy rate, Bessen (2006) found a result significantly different from the other studies, in Europe the equivalent subsidy rate is around $0.9 \%$, while in the USA around $2 \%$. According to Bessen, the reason for the difference between the EU and the USA is the larger, single market. Despite the low equivalent subsidy rate, due to their significant value, patents produce a benefit not negligible for their owners at all.

The main difference between Bessen (2006) and other studies is that he calculates with a significantly different patents/\$million $R \& D$ rate. Bessen (2006) calculates with an average 0.31 patents $\$$ million $\mathrm{R} \$ \mathrm{D}$, while Schankerman (1998) calculates with an average of 9.7 patents/\$million. This difference can mainly be attributed to the differing method for calculating R\&D. While Schankerman (1998) calculates with national level R\&D, Bessen (2006) calculates with the R\&D of public companies, where it is better measured because of the stricter regulations than in other non-pubic and typically smaller firms. The sample of Schankerman uses data from almost all French patent applications between 1969-1982, while Bessen uses data of US patenting public firms between 1985-1991. The significant difference of the size of the companies could well also have contributed to the significantly different results. According to Bessen (2006), previous studies systematically 
significantly underestimate $R \& D$ expenditures, this is the reason for the difference. A possible further reason is that in case of numerous questionnaire surveys many patentees cannot separate patent premium from the value of innovation adequately.

Despite this, such a low value of patent premium or equivalent subsidy rate as Bessen (2006) estimates is not considered to be real, especially taking the relatively significant patent propensity into consideration. In my opinion, this result has to be underpinned by other studies, too. Anyway, such surprisingly low value of patent premium can show that for companies the significance of patent protection regarding most of their innovations is not critical.

\subsubsection{The strategic application of patents}

In the past decades the use of the patent system from strategic consideration has become widespread. More studies dealt with changing the patent strategy. According to Hall and Ziedonis (2001) modern intellectual property right management can also change the significance of patents. The significance of intellectual property right management increased, its borders were expanded and it became part of the corporate strategy. The newer strategic motivations related to patenting can be quite various. However, a common feature is that patenting (despite the significance of the protection of innovation) partly becomes independent from the technological necessity of the protection of innovation, from ensuring the return of own R\&D investments (Blind et al. 2006).

Blind et al. (2006) describe that the number of patent applications in the past decades significantly increased in more European countries, the USA and also in Japan. However additionally, R\&D expenditures only slightly rose. According to them, it can have more reasons, one of them being the improvement in the efficiency of $R \& D$ procedure or its better differentiation, thus having more patents for unit R\&D expenditure. A further reason can be spreading the circle of patentable innovations (e.g. biotechnology, software). The third option is that as mentioned in the previous paragraph patent strategies changed, became more complex and overwhelming. 
According to Danguy et al. (2010) increase was significantly caused by globalization, but based on the research presented next, the spread in strategic motivations for patenting can also be obviously captured.

The traditional motivation of patenting is the protection of own innovations from imitation. However, the role of strategic motivation aimed at blocking competitors is also significant. This can have two types: either offensive or defensive. Offensive blockade is when firms patent in order to prevent their competitors to use innovations in the application areas relevant for the firm even though they may not be interested in utilizing those patents. In case of defensive blockade firms patent in order to prevent their own technological room to manoeuvre being reduced by others (Arundel and Patel (2003), Kingston (2001), quote Blind et al. (2006)). This also includes that a firm tries to avoid other firms' initiating patent infringement trials against him by obtaining patents (Arundel et al. (1995), Cohen et al. (2000)). Further strategic motivations of patenting can be the evaluation of the performance of $R \& D$ personnel, the improvement of bargaining position, international market expansion, improvement of reputation, necessity due to the patenting activities of competitors and setting of own innovation as general standard (Blind and Thumm (2004) quote Blind et al. (2006)).

Blind et al. (2006) examined the significance of individual motivations to patent. They compared the results of six studies. In all cases, the traditional motivation to patent was the most important, so the patent system is still suitable for fulfilling its original role. The most widespread types of strategic motivations are offensive and defensive blockade and the improvement in bargaining position. The detailed results of the research can be found in Annex 5 .

Arundel et al. (1995) examined the firms of three European countries (Italy, Great Britain, Germany). In these countries the most important types of strategic motivation are the improvement of bargaining position and the prevention of patent infringement trials. The sequence of motivations in case of product and process innovations is unchanged, but all motivations are more important in case of the former. The significance of strategic motivations increases not only with firm size, but also with R\&D intensity. Industry also 
influences the significance of individual strategies. In case of IT and telecommunications industries the most important ones before traditional motivation are the improvement in bargaining position and avoiding trials.

Duguet and Kabla (1998) examined 299 French companies of 12 industries. According to their results, the traditional motivation of patenting is of utmost significance. Among strategic motivations the most outstanding ones are defensive blockade and the improvement in bargaining position, these were mentioned by firms in $62 \%$ of the cases. The role of other motivational factors is substantially smaller $(28 \%-18 \%)$.

In the 2003 survey of OECD firms were asked about changes in their motivations in the last 10 years. Most firms start feeling that due to the increasing patenting activities of market actors they will also need to increase their patenting activities (Roberts (1999), quote Blind et al. 2006). This can be one of the reasons why in case of research intensive large companies patent activities become more and more independent from $R \& D$ activities. The motivations of firms, although to a smaller extent, also increased in the areas of improving their bargaining positions and motivations of defensive blockade (Blind et al., 2006).

Cohen et al. (2000) also measured what motivations of firms influence the patenting of their innovations. Their results are shown by the two figures below. In case of them the most important reason was also avoiding the imitation of innovation, with the second most important motivation being the blocking of connected innovations of competitors ${ }^{11}$. Based on the results of the research, there are significant differences between the motivations to patent in case of industries based on simpler products (e.g. chemical industry) and industries based on complex products (e.g. telecommunications). Such simpler products can be for example new medicines or chemicals, since they are typically composed of relatively few patentable elements. In their case the strategic objective of patenting is mostly blocking their competitors. In industries built upon complex products, e.g. telecommunications firms often

\footnotetext{
11 We differentiate between two types of connected innovations: they can be either substituting or complimentary.
} 
do not possess the patents for all important elements. Here even a patent related to one subelement of the product can stop its market entry. This is why the companies rather strive for agreement, they use patents for the improvement of their negotiating positions.

Figure 13.: The reasons for patenting of product innovations

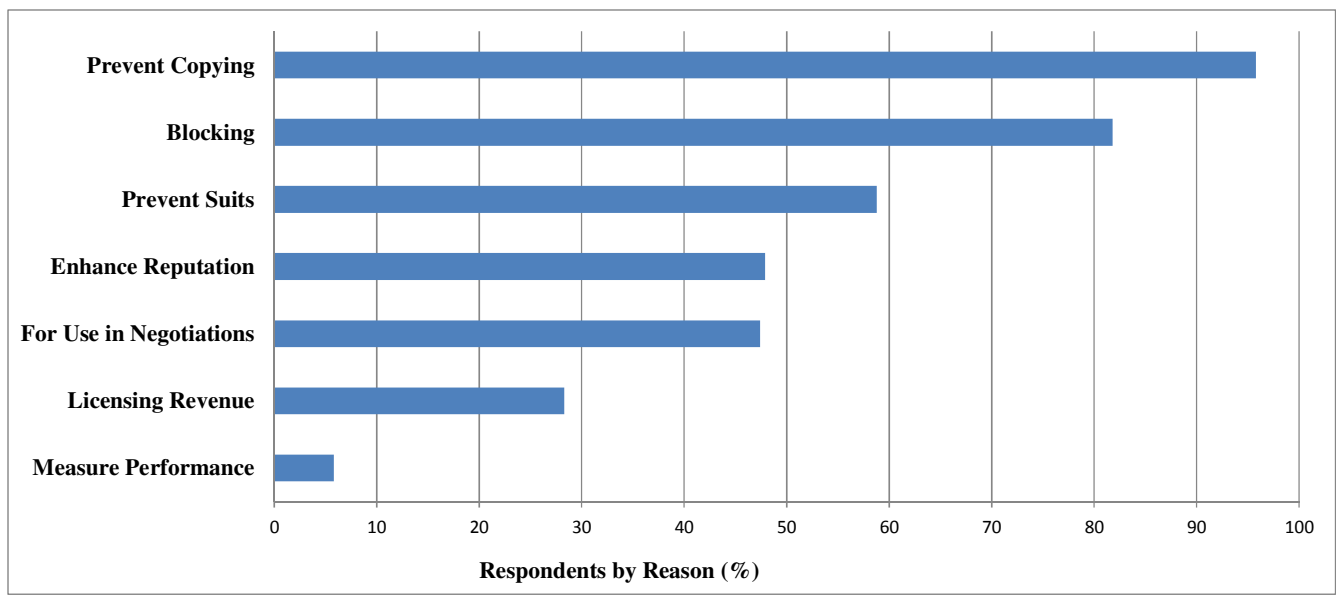

Source: Cohen et al., 2000, p. 48.

Figure 14.: The reasons for patenting of product innovations

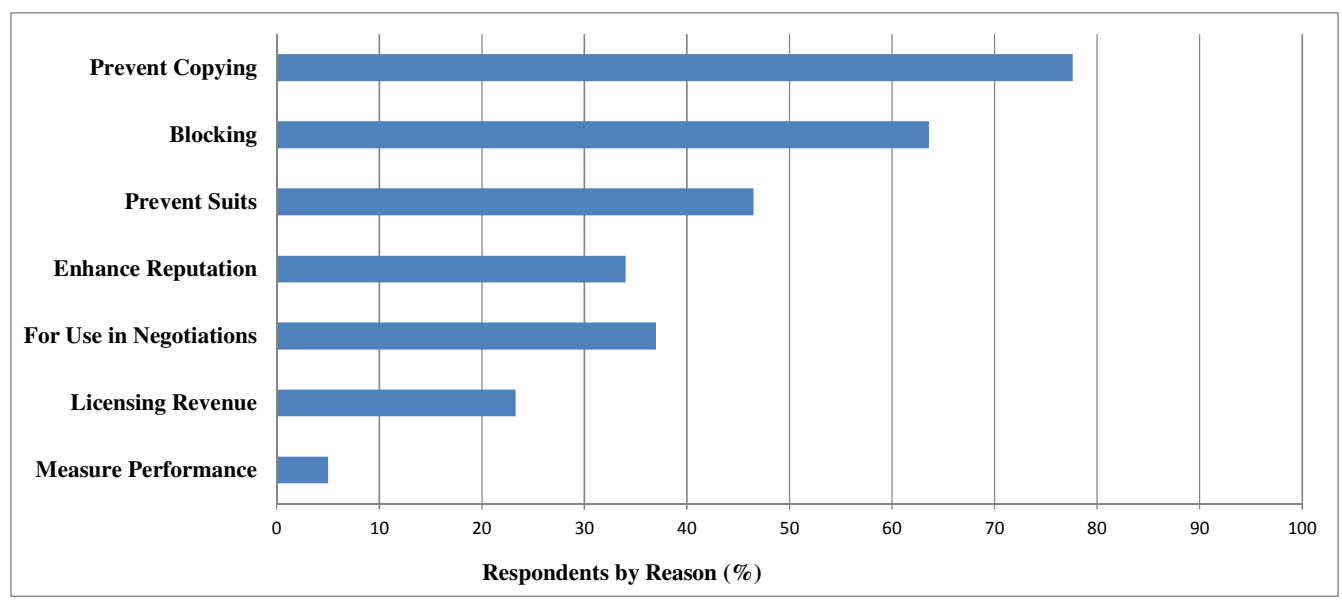

Source: Cohen et al., 2000, p. 49.

Blind et al. (2006) examined the importance of more motivations to patent, in their own survey. In sync with the results of the other researchers they found that the most important one is the traditional motivation to patent. The most widespread strategic reasons were securing European and national 
markets and defensive blockade. During the factor analysis of motivational factors, five motivational groups were identified. These were the following:

- Protection: protection against copying, securing national, European and international markets;

- Blocking: blocking of competitors both in defensive and offensive ways;

- Reputation: improving reputation, increasing goodwill;

- Exchange: improvement of cooperational position, better access to capital market, improving bargaining position, license revenue;

- Motivation: motivation of employees.

Figure 15.: The significance of motivations to patent

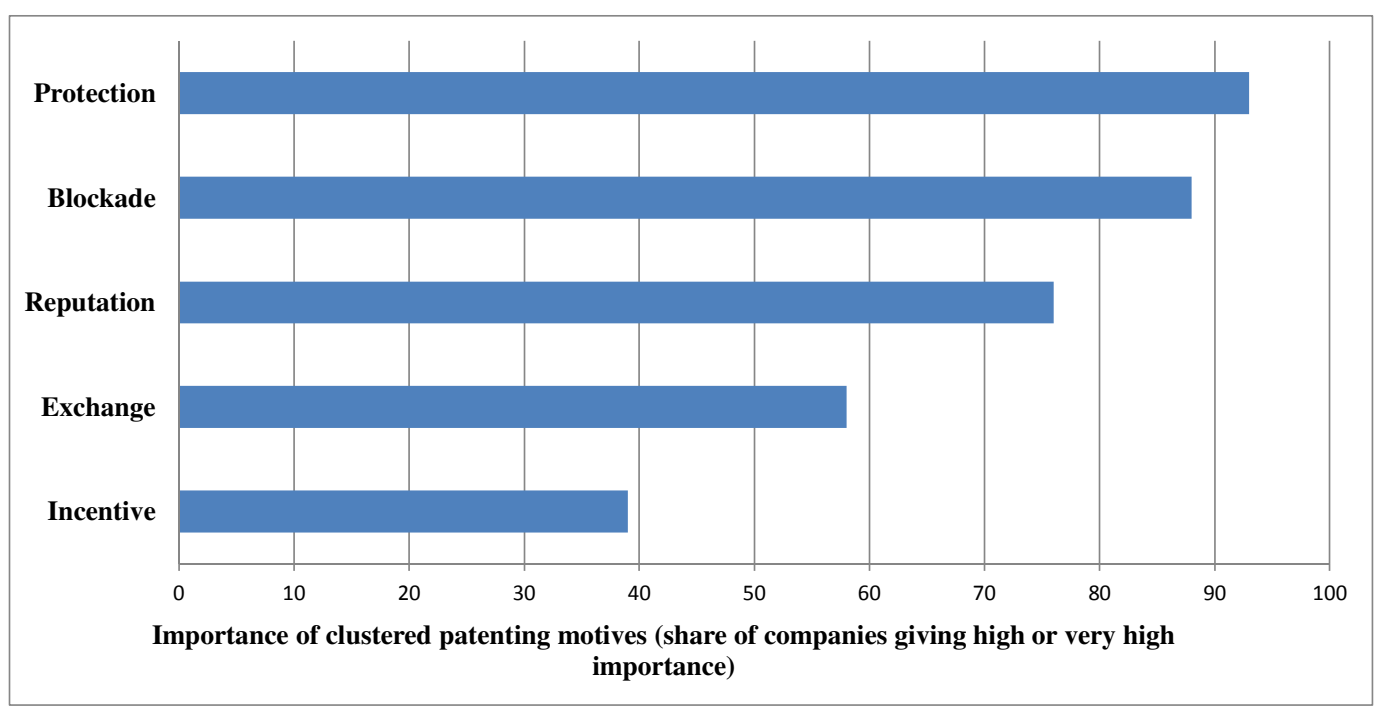

Source: Blind et al. (2006), p. 664.

Regarding industries, significant difference was found only in a few cases, thus this result does not underpin the existence of differences in motivations to patent between industries based on complex and simpler products. This can be a consequence of the fact that this research distorts towards larger companies and only those firms already having patent applications were taken into consideration.

Blind et al. (2006) also examined the factors influencing the individual motivations to patent. They found that the perceived intensity of competition hugely influenced traditional motivations to patenting and blocking, while it 
did not have a significant effect on other strategic motivations. The frequency of interactions between firms only has a significant effect on the exchange motivation, which shows that patents really have an important role in the bargaining procedure between firms. The R\&D intensity of firms does not influence traditional motivations to patent and blocking, however it has a positive effect on the other three types of motivation. Companies being active in common patenting contribute a more important overall role to patents and all motivations. In case of patent searches firms also got to know about the most modern technologies, and although the frequency of these searches does not influence the traditional motivation to patent, it increases reputation, motivation and exchange motivations. In case of companies attaching too high significance to trademarks, protection and reputation motivations are also more significant. As it was already presented in the previous chapter, firm size also influences the significance of strategic motivations. Based on European patent data, Giuri et al. (2007) also verified that the significance of motivation for blocking increased proportionally with the growth in firm size, to a huge extent.

In their research Gambardella et al. (2005) examined the lack of practical utilization of patents. According to them, this occasionally does not only depend on the low utility of innovation, the patentee's having insufficient competencies or the imperfection of the technology-trade market. Numerous so-called 'sleeping patents' are simply not utilized, which is mostly typical of larger companies. Finally a number of patents are not intended to be utilized, they serve strategic objectives. Based on their research, $36 \%$ of patents are not utilized. Since their sample mostly consists of more valuable patents, this ratio can be higher in relation to all companies.

Frietsch et al. (2010) pointed out that among the European patents not used, there is a substantially higher ratio of those referring to blocking or crosslicense agreement due to strategic reasons. This underpins the conclusions of Gambardella et al. (2005).

Gambardella et al. (2010) in another research finds that the share of unused patents increases with firm size. This is less than $30 \%$ in the case of SMEs (with less than 250 employees) and is over $50 \%$ in the case of the biggest 
firms (with over 5,000 employees).Overall the share of unused patents is 43\%, $27 \%$ of which are unused because of strategic motivations.

Next to the firm size several factors affect the commercialization of patents. The lack of complementary assets and if inventions are not the target achievement of a $R \& D$ project both increase the probability that the patent will be unused. Also, patents with a lower inventive step are more likely to be used for strategic purposes. The role of competitors is dual from this aspect. First, intensive competition motives firms to rely more on strategic motivations such as blocking patents. On the other hand competition reduces the ratio of sleeping patents (Gamberdella et al., 2010).

It is visible that besides protection against imitation, firms much rather use their patents for strategic objectives, too. Among these objectives there are ones, which are likely to be overall useful for society. These are for example the increase in reputation, motivation of employees or promotion of capital injection. However, other motivations aim at restricting the playing field for competitors. It is a question whether the social loss accompanying the obvious restriction of competition of these utilization methods can be overcompensated by the corresponding advantages.

The strategic application of patents is accompanied by further phenomena, whose judgment in literature is rather negative.

In the world of patents those actors putting together a significant patent portfolio, but trying to gain benefits from suing market actors instead of their actual utilization, play a specific role. The slightly ironic name of these actors in literature and media is 'patent trolls'. Eisenberg (2011) highlights that recently, a number of actions were taken to make the strategies of these actors more difficult. However, in the opinion of Chien (2011) they still have enough motivation and undermine the normal operation of the patent system.

Especially in case of industries built upon simpler products, the patenting of numerous substituting, complimentary innovations is possible. In these cases in order to protect its patented central innovation, the firm can also patent them, so that the opportunities of competitors are narrowed in advance. In literature this is also called 'patent fence'. Substituting innovations can be 
improved or modified versions of the central innovation, but this is not a requirement and neither is for the firm to place them on the market. In the 1940's for example du Pont patented more than 200 substituting products of Nylon in order to protect its central innovation (Hounshell and Smith (1988), quote Cohen et al. (2000)). The research of Motohashi (2008) in Japan for example proved the existence of patent fences in chemical industry empirically, too.

During the examination of European patents, Reitzig (2004) found that in industries built upon complex products the so-called 'patent thickets' are forums for trading complimentary technologies. According to Cohen et al. (2000) patents in such cases function as some kinds of currencies. The extended patent portfolios are also used for scaring potential new entrants away, should they not possess the right quantity and quality of patents. Patent thickets enable insiders' rent seeking. In the 1980-1990's, Texas Instruments for example used its patents existing in semi conductor manufacturing without their actual utilization, for only benefitting from the profit of semi conductor manufacturing companies. The research of Blind et al. (2006) proved the above empirically too, based on their results the firms patenting to the highest extent, deal with avoiding patent infringement trials and improving their bargaining position less than expected. Lampe and Moser (2012) studies the effect of patent pools on innovation under the New Deal in 20 industries. They find a $16 \%$ decline in patenting in response to the creation of a pool. Most of the decline can be attributed to technology fields where competing firms combined patents for substitute technologies. This suggests that unregulated pools hinder innovation by weakening competition among innovators.

A current example for patent thickets is smartphone technology. According to the estimation of the stock report of RPX Corporation (engaged in patent broker activities) from 2011 (RPX, 2011), approximately 250.000 patents relate only to smart phone technologies, which is also underpinned by Chien (2011). Masnick (2010) demonstrated the trials existing among individual market actors in the figure below (which at first sight might be quite surprising). 
Figure 16.: Patent infringement trials of patents related to smart phones in 2010

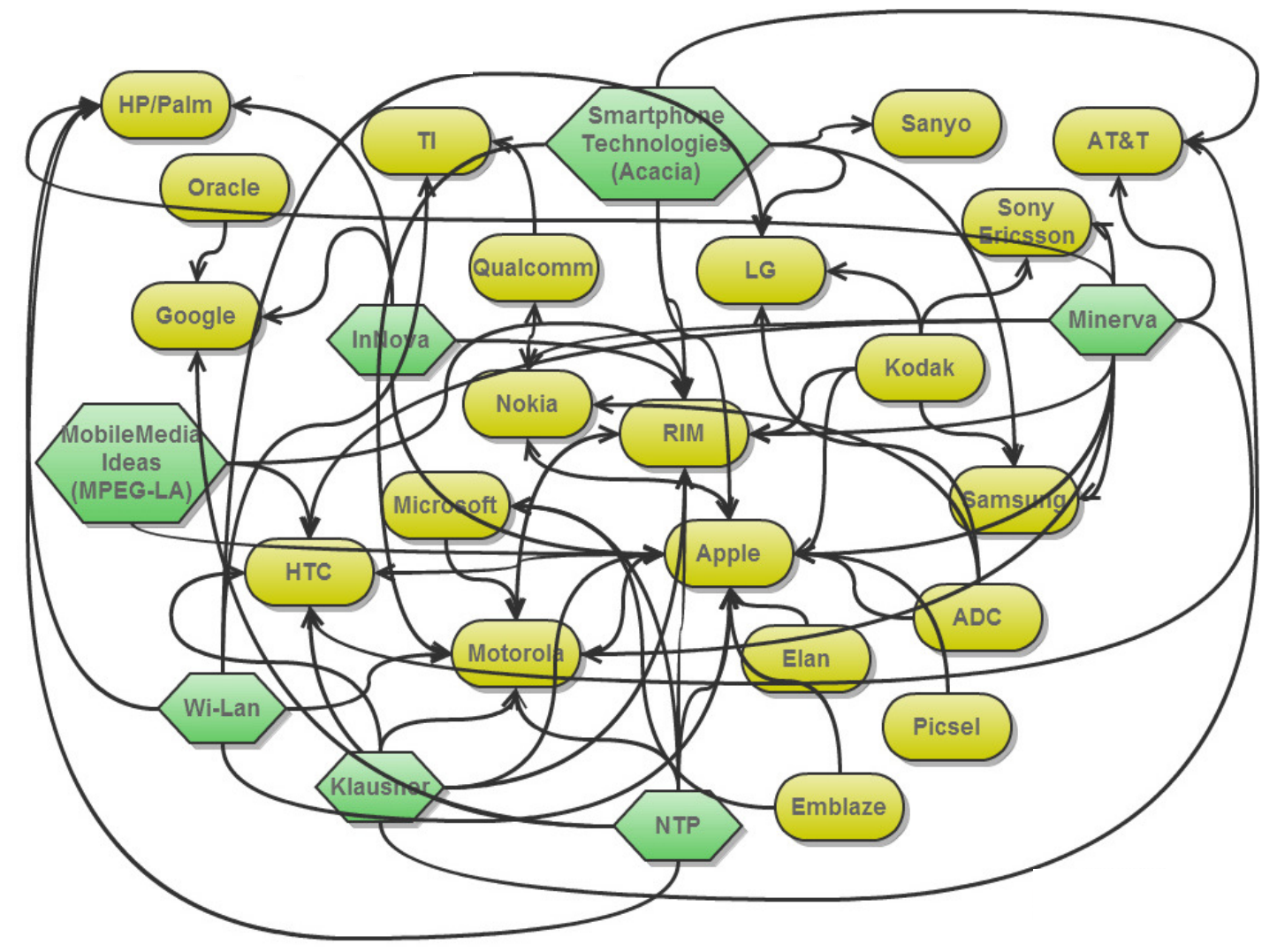

Source: Masnick, 2010

However, patent thickets do not decrease social utility in every case. In their empirical model, Galasso and Schankerman (2010) examined the connection between patent infringement trials and patent thickets based on their database built upon patent infringement trials between 1975 and 2000. They found that in their opinion, patent thickets promoted the actors affected in trials to reach quick agreement and thus technological development. The importance of patent thickets is also emphasized by Merges and Nelson (1990), Scotchmer (1991), Heller and Eisenberg (1998). In their opinion should too many firms possess patents for certain parts of technology, market entry can also fall through. Disadvantages arising from fragmentedness can be cumulated license fees, the different evaluations related to the values of certain patents and the arising differences in views, and the significant transaction costs. By 
restricting the number of new entrants, the chances for agreement and the market utilization of innovation grow (Cohen et al., 2000).

It is obvious that patent thickets possess a number of characteristics, which influence their social utility in positive and negative direction. It depends on the individual features of these thickets what direction their sum has, but most researchers think that eventually they decrease social utility. The higher fix costs related to the more and more widespread defensive strategic use of patents can also decrease the social utility of patents (von Hippel (1988), quote Cohen et al. (2000)). Patent fences are also capable of restricting competition, should complete technological areas be walled-up by them (Arora, 1997). Additionally, fences do not only exclude innovations substituting central innovations, but also those built upon original innovation (Turner (1998), quote Cohen et al. (2000)).

According to Cohen et al. (2000) in those industries built upon complex products where the non-cooperative strategic innovation is widespread and where cross-license agreements are common, other worries can also arise. Firms in these industries primarily apply the advantage of the first market entrant, business secret and complimentary abilities for the protection of innovations, but they also take advantage of patents to a huge extent. The competition aiming at building patent portfolios can be accompanied by patenting higher than socially optimal (typical prisoner's dilemma) and so unnecessarily increases the cost of innovation. On the other hand, part of these patents implies hardly any benefit from the social point of view. A further problem can arise if only a limited circle of companies with huge patent portfolio can gain access to the technology of competitors, since in this case patents make the entry of new firms on the market more difficult. Contrary to patent thickets in this case the patent protects not a monopolist, but oligopolists. The weight of the above statements is underpinned by the research of Blind et al. (2006). According to them a huge shift towards industries built upon complex products can be experienced, so strategic motivations in the whole economy increase the costs of innovation. As per Cohen et al. (2000), patent portfolio competition also has advantages. The participants patent a higher part of their innovations, since they cannot risk 
withdrawal from the industry or not being able to apply their own innovation. However, with more published innovations, the R\&D activities of competitors can be much more coherent, which might increase the speed of innovation.

The total social effect of the above described strategic motivations of patents is not necessarily positive. It is a general view that such utilization of the patent system decreases competition, increases the cost of new firms' entering the market and affects especially SME's in a negative way.

\subsubsection{Patent infringement trials}

Patent infringement trials have a critical role in the adequate operation of the patent system. I will continue with showing how the legal structure constituting a base for these trials influences the innovation activity of companies.

Bessen and Meurer (2008) point out that the number of patent infringement trials initiated in the USA sharply increased from the beginning of the 1990's, as it can also be seen in the figure below. In their opinion this is a sign that patent system does not function adequately.

Figure 17.: U.S. patent lawsuits filed in District Courts

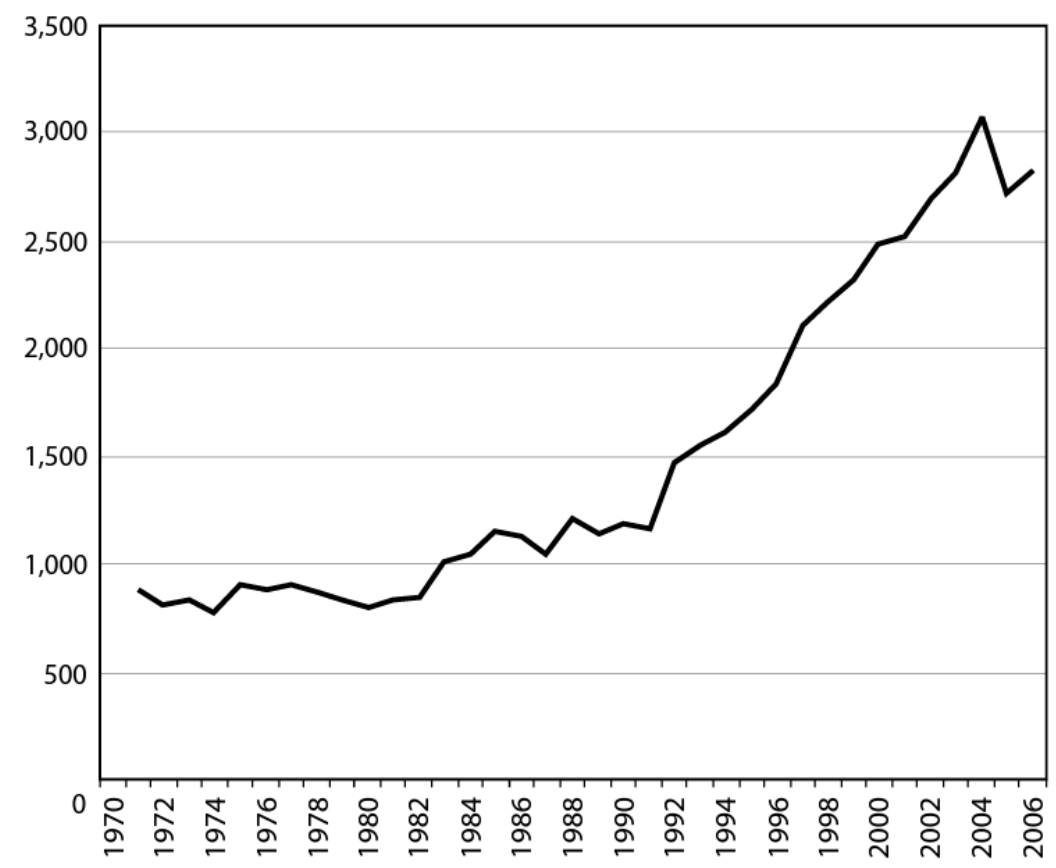


Source: Bessen and Meurer, 2008, p. 122, quote: Administrative Office of the U.S. Courts; John L. Turner

According to Bessen and Meurer (2008), due to their current legal structure, patents are not able to fulfil their previous role in promoting innovation for more reasons. The technological borders marked by patent claims are not obvious, which is further worsened by the blurred wording of claims. The number of patents affecting one technology can be sometimes extremely high and the claims of patents relate to a too wide technological area.

In the opinion of Lanjouw and Schankerman (2004) the reasons for increase in the number of patent infringement trials is the increase in general patent activities and the shift towards industries with higher trial risk. The number of patents between 1978 and 1999 increased by 71\%, but in pharmaceutical industry, biotechnology and in case of medical devices it nearly tripled, while in case of computers it quadrupled. Filtering the effects of this increase the number of patent infringement trials did not increase in any industries in the related period. The opinion of Lanjouw and Schankerman underpins that the problem brought up by Bessen and Meurer (2008) is caused on one hand by the significant increase in the number of patents, on the other hand in case of certain industries the inadequate functioning of the patent system.

According to Lemley (2008) firms are aware of the importance of the industrial property right examination preceding innovation, which significantly decreases the chance of patent infringement trials. However, the examination implies significant costs and the precise overview of the literature consisting of more thousand elements in each case is often not possible. This is why in certain industries firms usually do not carry out industrial property right examinations before starting research. Furthermore, should there an infringed patent exist, then in case of a later patent infringements trial they would receive better treatment, if they can prove that they were not aware of this. According to Lemley (2008), neglecting the patents of others can be an optimal strategy for companies even knowing about the infringement, since these trials are initiated only in case of $1-2 \%$ of the patents and imply 
significant costs. Lemley (2008) highlights that it does not relate to pharmaceutical industry, where in his opinion harmonic conditions prevail.

According to Bessen and Meurer (2008), in certain industries innovators can expect enormous trial risk. Beyond the advantages of patenting, inventors have to take the costs arising from their possible patent infringements with even larger weight taken into consideration. In their opinion, in order to improve the situation the borders of patents should definitely be clarified and the patents relating to a given technology should be made obvious. This would enable companies to be able to judge with low cost and high security whether their activity infringed the patent of others. This would lead to a radical decrease in legal costs, which would make companies interested in innovation.

Senftleben (2010) argues the freedom of 'fair use', according to him the regulation of intellectual property should be flexible. In his opinion, the exceptions not infringing exclusive rights should not be precisely listed, worded and defined, but the referee exercising power in the trial should decide what can be accepted as 'fair use' in the given case. This can promote the coherence of innovations, the overwhelming protection of intellectual property rights can be partly avoided and so their social cost can decrease. It can be especially useful, if more types of protection can be obtained for the given intellectual property (e.g. patent and copyright jointly). Beckerman-Rodau (2010) also highlights that the previously sharp limit between forms of protection of intellectual property has gradually disappeared due to legal changes, so the different forms of protection of intellectual property can often be applied together, too. Although the individual forms of protection would not injure the free flow of ideas that much, together they already increasingly endanger their free use.

Based on the description of Lanjouw and Schankerman (2004), in case of patent infringement trials there are two main possibilities for agreement, without including the court. The first is the licensing of intellectual property, the second one being common agreement. The threat of patent trial is the highest motivation for agreement between the parties. Chances of agreement are higher if the connection between parties is more frequent, since in this case the optimal strategy is cooperation. This favours companies with larger 
portfolio, since it decreases the probability of a trial. Thus the risk of trial is much higher in case of patents, where the owner has a smaller patent portfolio. However, the end result of trials is completely independent from the size of firms, which shows that even smaller firms can efficiently represent their interests in court. It is important to note that after the start, but before the closing of the trial, even before the first trial, in case of $95 \%$ of suits parties reach an agreement, so firms do not face significant legal expenses. Unfortunately small companies take part in trials more and more often, and in their suits the court does not act quicker than in other cases either, although their legal expenses proportionally are extremely significant. This undermines the motivation of smaller firms for carrying out $R \& D$ activities. The research of Lerner (1995) underpins that small firms avoid those R\&D areas where larger firms are more likely to sue them. This phenomenon can also be observed according to Cohen et al. (2000). In case of certain industries with higher trial risk, the patent strategy of companies is rather built upon legal knowledge instead of technological knowledge. This implies unproportionally higher costs for smaller firms.

According to Lanjouw and Schankerman (2004) because of the above there is an ever higher agreement among experts about the fact that the increased trial risk accompanied by fragmented patent rights and strategic patenting eventually prevents firms from carrying out efficient R\&D activities.

Eisenberg (2011) has a different opinion. According to him, trial risk is contrarily low, since the imperatives of patent infringement trials are high costs, and due to the tightening of USA laws it has decreased significantly in the past period. Chien (2011) has a similar opinion, she sees especially the suing of the cooperating partner problematic. According to her, due to the accelerating technological development, for example in the information technological industry, it is ever harder to acquire exclusive rights for an innovation.

Based on literature it can be seen that firm size significantly influences the relation towards patent infringement trials. In case of larger companies, the fact of infringement will almost definitely become known, so they can expect significant costs. In case of smaller firms, patent infringement is more likely to 
be kept hidden. Additionally, since their patents are basically less valuable and the trial costs are higher, even in case the infringement becomes known there might not be any proceedings instituted against them. It is not true for smaller firms owning especially valuable patents, they are very likely to face the lawyers of large firms, which does not necessarily promote innovation activities.

\subsubsection{Patent disclosure}

According to the classic theories of patents, the disclosure of substantial information needed for achieving patent protection significantly promotes the innovative activities of competitors and thus contributes to technological development. This is why many researchers tried to determine the significance of patent disclosure.

Hall and Harhoff (2012) overviewed the literature of the social effect of patent disclosure and concluded that according to most authors it has a huge impact on the diffusion of innovations. In the opinion of Hall and Harhoff this is not underpinned enough in the empirical way. According to the authors, in case of products reaching the market the characteristics of innovation can be examined without disclosure, too. Moreover, the patenting of an innovation whose disclosure could be very useful for a third party, is less probable. These innovations are protected by their owners rather in alternative ways. In case of their more valuable patents firms strive for leaving out information of key importance from their disclosure, which further decreases the utility of disclosure, and they try to describe innovation by such complicated legal expressions, which do not even help experts seriously, either. This disclosure can be useful in only a few cases. However, disclosures are well used in industries, where products only reach the market in a late stage of development (e.g. pharmaceutical industry). Disclosure can also be useful in case of parallel research aimed at the development of one innovation, as it can promote the decrease in the amount of unnecessary expenditures.

In their research Gambardella et al. (2010) quantified the amount of positive effects of patent disclosures, with 2.7 hours in the case of telecommunications 
and 99.8 hours in case of organic chemicals. They also find that in industries where important inventions are patented, inventors read patent disclosures more and find relevant information. Therefore in such industries patents are unlikely to cause cost increases for follow-up inventions, according to this study. Their result underpins the theory of Hall and Harhoff (2012). Seemingly most companies, although restrictedly, but utilize the information from patent disclosures. In the pharmaceutical and chemical industry it is more significant, but still not critical. In most industries patent disclosures mean only 6-12 hours of work saving for competitors. This value is the highest in organic chemical industry, 36 hours.

Nagaoka and Walsh (2009, quote Hall and Harhoff, 2012) show that the utilization of information from disclosure is higher in case of Japanese firms. Despite the above, Fromer (2009) finds the role of patent disclosure important, recognizing that the current practice requires serious reform in more areas.

\subsubsection{Patents and environmental innovations}

Only a few researchers examined the role that intellectual property protection plays and can play in achieving sustainability. For sustainable development, environmental innovations transforming the existing systems to have a much lower or zero environmental effect, are definitely necessary.

Menell (1999) showed that intellectual property protection has a huge significance in the development of network externalities. One of its methods is to influence industrial standards, and later inventors are able to deviate from this only via high costs. Patents can be also extremely important in markets with firm networks. In these cases the innovator also needs extra motivation, to be able to develop a new, better standard by fighting the inertia of status quo. In his opinion, in these cases stricter requirements will have to be met to achieve patents than under normal market circumstances. This would help the more efficient adaptation of innovation by standardized basic principles.

The topic of patents opening new development directions is extremely interesting. It also significantly influences in which phase of basic research patent protection can be asked for. According to Kitch (1977) in such cases it 
is extremely important to grant an extensive patent, which later can operate as a certain type of standard. It prevents more companies from carrying out research somewhat different from each other. Parallel research can easily be a socially harmful method of allocating $R \& D$ resources, and can possibly lead to high competition, with no firms being able to exploit the new development direction. Merges and Nelson (1990) reached conclusions different from this. According to them an extensive patent granted in an early stage can lead to enormous costs for society, should it restrict the activities of competitors working on alternatives substantially different from each other and probably being more efficient. This can be extremely important from the point of view of environmental innovations, where there are numerous emerging technologies likely to basically influence later sustainability.

According to Menell (1999), under certain circumstances, the ordering of obligatory licensing can be reasonable in order to exploit network externalities more completely. These questions are of utmost significance in case of environmental innovations. As Rennings (2000) describes, in these cases inventors face double externalities. The first one is the social and economic positive external effect of innovation, while the second one is the positive external effect on environment. From the latter, it is usually harder for the inventor to benefit than from the former, thus the number of environmental innovations does not reach the socially optimal level.

According to Mandel (2005), the most efficient system for promoting environmental innovations is for the state to buy such innovations and make them available for everyone. Should the total social benefit constitute a base for the fee paid for the inventor, also including the environmental benefit for society, then the effect of positive externalities would also occur at the inventor. Thus the inventor would be motivated to implement all potential innovations useful for the society according to market logic, built on business bases.

The specification of value in practice certainly would not be easy at all, and the sum paid for innovators would be also extremely high. By the opinion of Mandel these problems can be handled, since the state would not pay more for innovation than its social utility, so the necessary resources can be collected 
via new taxes, too. According to my opinion, its implementation in the near future is not realistic.

As for which industries are likely to be the main sources of environmental innovations, Lanjouw and Mody (1996) find that these technologies are most likely patented in the machinery industry, thus mostly technological suppliers are the main sources for innovation. The innovations of machinery industry constitute the base for around $80 \%$ of patents in decreasing the environmental effects of industrial air pollution, water pollution, oil spills and exploiting alternative (non-fossil) energy sources.

Table 3.: Machinery industry suppliers, as a source and user of pollution control technology

Machinery suppliers, as a source and user of pollution control technology ${ }^{\text {a }}$

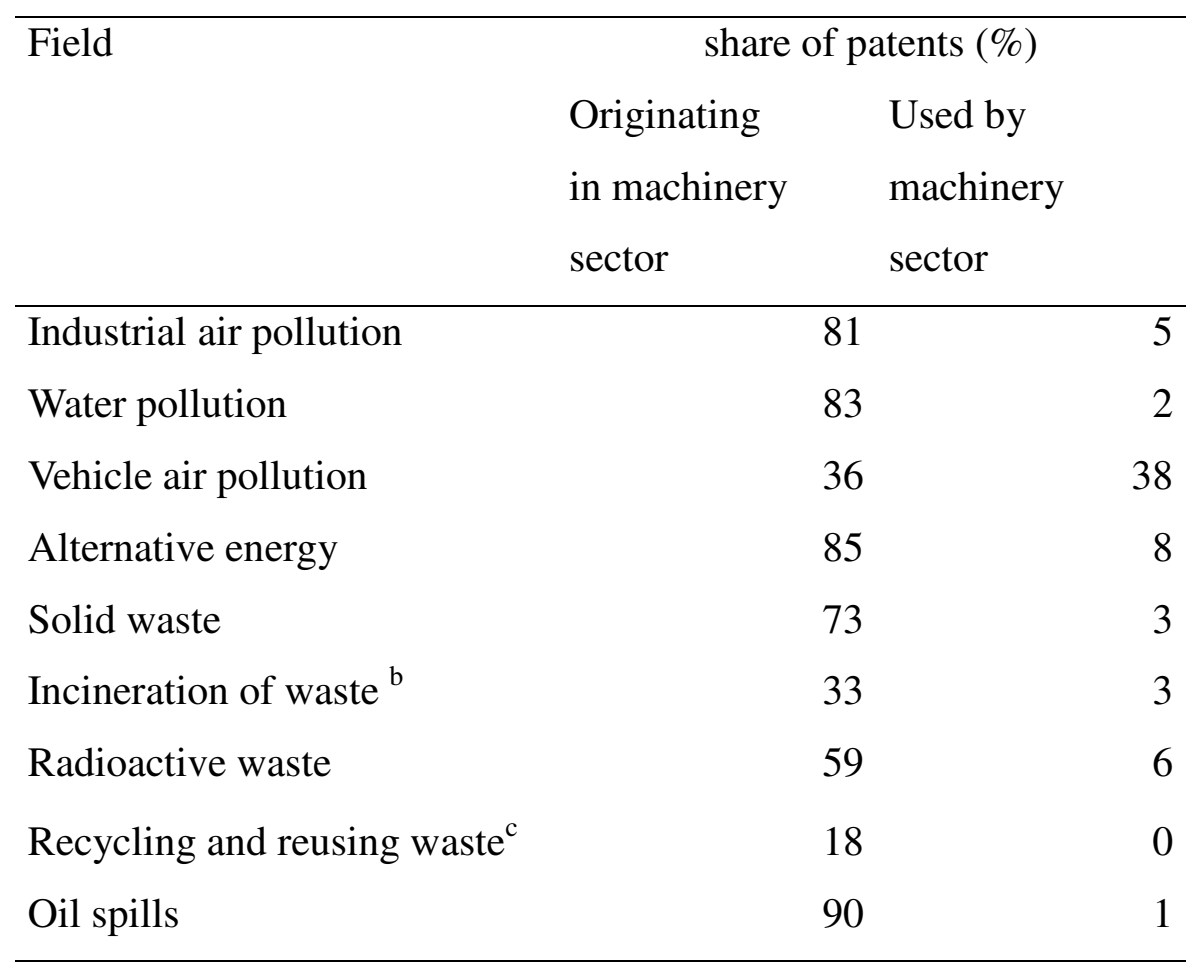

${ }^{\mathrm{a}}$ For details see: Kortum and Putnam (1989)

${ }^{\mathrm{b}} 63 \%$ of patents originates in the fabricated metals industry

${ }^{c} 66 \%$ of patents originate from the food, drinks and tobacco sector Source: Lanjouw and Mody, 1996, p. 554. 
It is important to highlight that the interpretation of Lanjouw and Mody (1996) about environmental innovation is narrower than the definition used in the thesis, focusing only on the environmental sector.

According to Maskus (2010) there are no systematic surveys about the factors driving the invention of environmentally sound technologies. There is limited evidence that most of these inventions occur because of anticipated market demand, relative prices of alternative energy sources, regulatory demands, the costs of investment, and public research subsidies and tax inducements. There is little evidence that patents restrict access to environmentally sound technologies as they are mainly based on mature technologies with numerous substitutes. This can be different in the case of new technologies based on biotechnologies and synthetic fuels, more dependent on patent protection. Maskus (2010) calls for ex ante extensions of patent terms tied to licensing commitments, expedited patent examinations in ESTs, investments in patent transparency and landscaping efforts, and facilitation of voluntary patent pools to promote the development and diffusion of green technologies. These have to be accompanied by broader policy approaches for example raising the costs of using fossil energy.

Sommer et al. (2010) state that intellectual property rights are only one of many tools to generate further investments in environmentally sound technologies. However in their view, diffusion of such technologies may be hindered by the very same exclusive rights. They call for further empirical studies in the topic of the impact of intellectual property rights to energy technologies and other climate relevant sectors and their diffusion into developing countries.

UNEP et al. (2010) emphasise that enhancing technology transfer towards developing countries is an integral part of the global climate change. Patenting rates (patent applications and granted patents) in selected green energy fields have increased by about 20\% yearly between 1997 and 2006, faster traditional energy sources of fossil fuels and nuclear energy. 
Figure 18.: Growth rate of claimed priorities patenting for the selected clean energy technologies

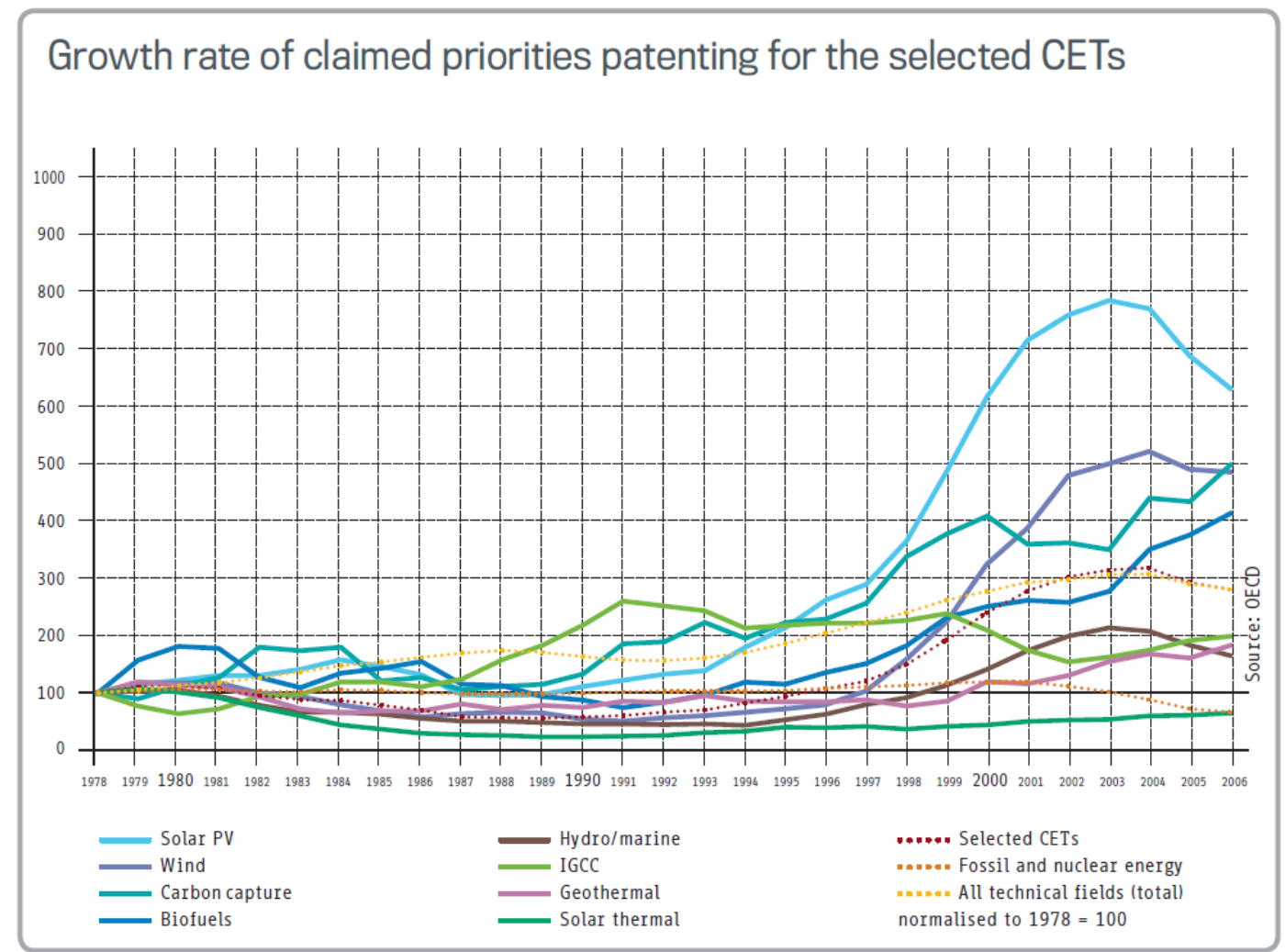

Source: UNEP et al., 2010, p. 5.

They find that more than $80 \%$ of all clean energy patenting originate from just six countries, Japan, the United States, Germany, Korea, France and the United Kingdom. They find that licensing activity to developing countries (mainly China, India and Brazil) is below the average of general licensing activity.

Hall and Helmers (2010) emphasise the role of the "double externality" problem. They think that because of this at least two different policy instruments are needed. R\&D subsidies can enhance the invention of technologies, but are not optimal for spurring their diffusion. The deadweight loss generated by temporary monopolies results in less output than socially desirable, although most of the positive environmental effects arise through diffusion. Patents may not be the preferred policy instrument in this area if they fail to create a competitive market for technology that leads to more 
diffusion than in their absence. So intellectual property may not be the ideal and should not be the only policy instrument to enhance green innovations. The range and variety of such technologies and the need for local adaptation makes patent protection neither available nor useful in some settings.

Based on the scarce evidence, the impact of patents on environmental innovations seems ambiguous, patents may enhance the generation of them, but they may hinder their diffusion. There is a consensus in the literature about the serious lack of empirical studies regarding the role of patents in inducing environmental innovations, and about the utmost significance of environmental innovations justifying research directed at this area.

\subsubsection{The effect of patents on innovation}

There are numerous studies that were not directed at the examination of patent propensity, but approached the topic from another aspect. They tried to quantify the key factor, what ratio of innovations would not be implemented without patent protection.

Taylor and Silberston (1973) carried out an assessment among 27 firms. They found that in pharmaceutical industry $60 \%$, in chemical industry $15 \%$, in electric industry a very low ratio of $R \& D$ depends on the existence of patent protection.

Around half of the innovations in the sample of the research of Mansfield et al. (1981) would not have been introduced in lack of patent protection. Most of these innovations were implemented in the pharmaceutical industry. However, disregarding this, the lack of patent protection would have influenced less than $25 \%$ of innovations. Eventually, although patent protection increases the cost of copying, but with the exception of pharmaceutical industry, in case of at least three-quarters of innovations it is not indispensable. The existence of patent protection is not an essential need for most firms, since it has only a small effect on holding back imitators ${ }^{12}$. Although patent protection generally increases the cost of imitation, not to an

\footnotetext{
${ }^{12}$ In case of approximately half of the innovations it delayed their copying by at most a few months.
} 
extent that it would significantly prevent imitators from entering the market. However, in case of around 15\% of innovations, patent protection had a serious effect, it postponed the entry of imitators in the market by at least 4 years. This is why contrary to the general viewpoint, patent protection in practice often does not mean a monopoly of 20 years for the given innovation.

The research of Mansfield (1986) was based on a questionnaire survey and 25 interviews. He examined what ratio of the innovations patentable between 1981 and 1983 would not have been developed or introduced in the market without patent protection. According to his results the ratio of these innovations was above $30 \%$ only in case of two industries (pharmaceutical and chemical industry). Furthermore in three industries (oil industry, machinery, metalworking industry) it was between $10-20 \%$, while in the remaining seven industries even lower or zero.

Table 4.: The ratio of innovation, which would not have been developed or introduced in the market in the lack of patent protection

The ratio of those innovations developed or introduced in the market, which in the lack of patent protection would not have been developed or introduced in the market. Twelve industries, 1981-83.

\begin{tabular}{|lcc|}
\hline Industry & $\begin{array}{c}\text { Would not have } \\
\text { been introduced in } \\
\text { the market }(\%)\end{array}$ & $\begin{array}{c}\text { Would not have been } \\
\text { developed (\%) }\end{array}$ \\
\hline Pharmaceuticals & 65 & 60 \\
Chemicals & 30 & 38 \\
Petroleum & 18 & 25 \\
Machinery & 15 & 17 \\
Fabricated metal products & 12 & 12 \\
Primary metals & 8 & 1 \\
Electrical equipment & 4 & 11 \\
Instruments & 1 & 1 \\
Office equipment & 0 & 0 \\
Motor vehicles & 0 & 0 \\
Rubber & 0 & 0 \\
Textiles & 0 & 0
\end{tabular}


Source: Mansfield, 1986 p. 175.

In their survey Brouwer and Kleinknecht (1999) identified only 5 out of 19 industries, where at least $30 \%$ of firms found the role of patents of utmost importance or critical importance. Even in case of the pharmaceutical industry having the highest value, the ratio of such companies is only $36 \%$. In general it can be said that companies active in industries with patent propensity higher than average find the role of patents more important. Sectors with huge technological opportunities tend to have higher patent propensity than those with low technological opportunities. The detailed data of the research can be found in Annex 4.

Blind et al. (2006) found that more than $70 \%$ of firms find patents important for the protection of innovation. From this aspect, there are hardly any significant differences between industries, differences have been found only between consumer goods and machinery manufacturing sectors. The choice of sample slightly different from other studies is likely to have a decisive role in their case. As they also note, mostly large companies and mostly industries with higher patent propensity are represented in the sample. Another difference is that only firms with at least three patent applications in 1999 were taken into consideration. This is why their research can cause distortion regarding sectorial differences.

Thus according to certain studies a significant part of the achievements of modern technology are embodied in patents, on the other hand patents are not necessarily needed for a significant part of innovations. The apparent discrepancy can be resolved by the fact that according to Mansfield (1986), although patent protection in most industries is the primary method for protecting innovations, an overwhelming majority of firms applies it in a complimentary way. De Rassenfosse (2010) also reaches a similar conclusion, based on his research more than $70 \%$ of firms' patent innovations even if otherwise they could keep the invention confidential. The reason for this is that the advantages provided by patent protection exceed the costs of patenting. Thus patenting of innovation is rational, even despite the fact that it also had been implemented in the lack of patent protection. 
By my opinion, the examination of the above questions is the most important regarding patents. The implementation of the whole patent system took place in order to motivate those innovators, which would not generate valuable innovations due to imitation. However, based on the above it can be seen that disregarding a few industries, firms request patent protection mostly for innovations, which they also would have implemented anyway. In my opinion these results obviously underpin that the patent system in its current form is not suitable enough for inducing innovations.

Only a few empirical studies were carried out, which examined the effect of the institution of patenting on innovations and social welfare concretely. A reason for this is that studies in literature are mostly based on large sample representative surveys. Due to the significant difference in innovations, it is difficult to reach general conclusions.

Trajtenberg (1990) was able to quantify the social benefit of innovations related to computer tomography equipment. He quantified this by estimating the demand curve, through gathering largely detailed data of the industry.

Bessen and Meurer (2008) also describe that the assessment of social impacts is extremely difficult and the studies trying to quantify this did not lead to reliable results. This is why they examine the motivating power of patent system in case of individual firms. According to their calculations, the result of which can be seen in the figure below, by the end of the 1990's the costs of USA stock companies related to patent system exceed their respective benefits. Thus the patent system directly prevents the innovative activity of firms. Theoretically the social balance of patents can still be positive, but the situation is unsustainable. 
Figure 19.: Aggregate profits from patents and aggregate litigation costs for U.S. public firms
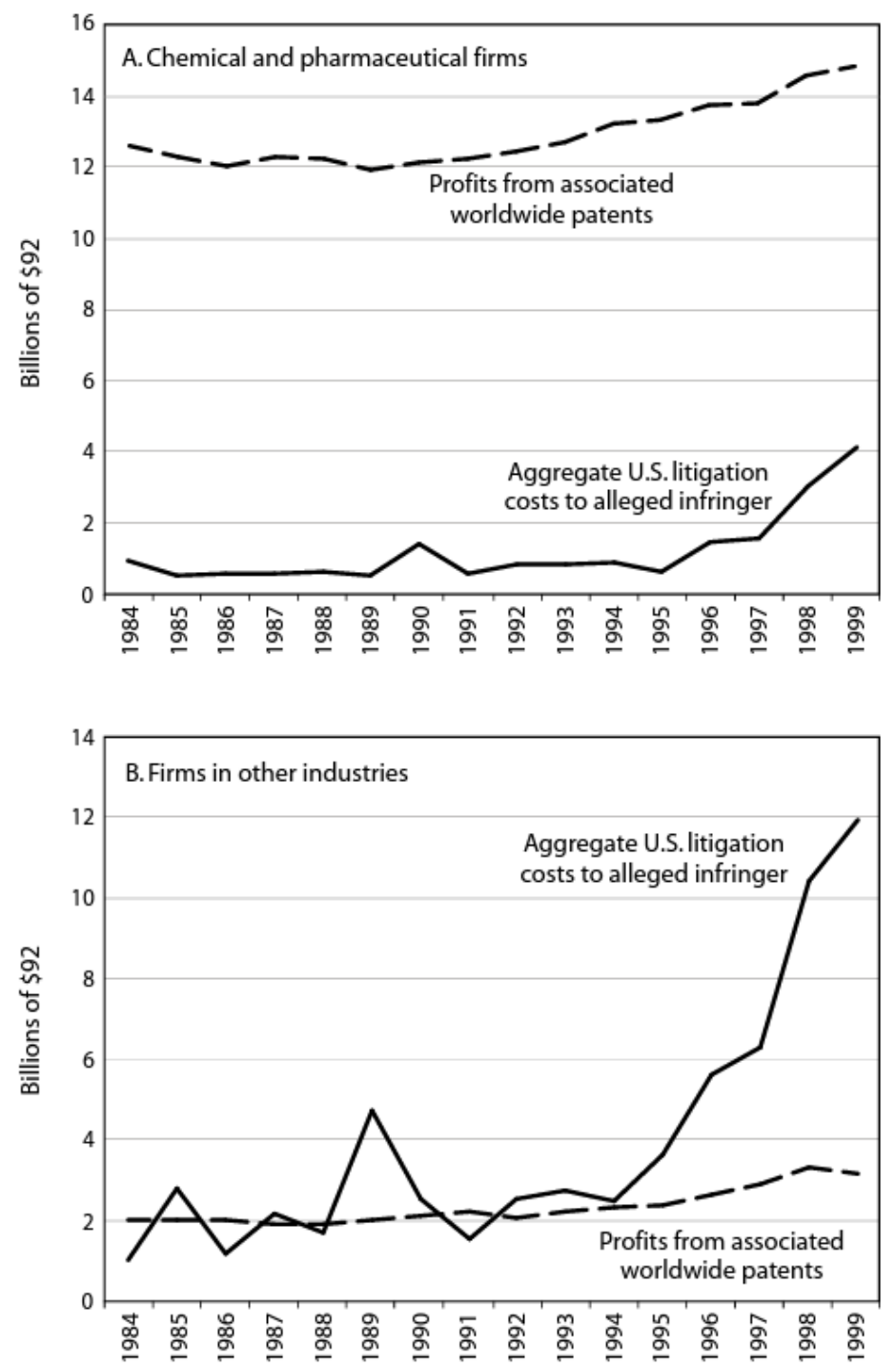

Source: Bessen and Meurer, 2008, p. 15.

It is important to note that the results of Bessen and Meurer (2008) refer to the USA, where the circle of patentable technologies is wider. For example, it is also possible to get software patents, the perception of which in literature is definitely negative. Thus the results of the research cannot necessarily be generalized for the other countries. The authors themselves also highlight the role of pharmaceutical industry, chemical industry and the SME sector, where patents imply the right motivation for innovation. According to their result in the figure above, inventors in chemical and pharmaceutical industries are 
interested in continuing their innovation activities. This does not necessarily mean that the social utility of patents in these industries is positive.

Boldrin and Levine (2009) form radical opinions about patent system. As per their liberal point of view, patents do not promote innovations efficiently, the costs of temporary monopoly hugely exceed its advantages. They mention a few well-known examples to underpin this opinion:

- The steam engine patent of Boulton and Watt is quite likely to have postponed industrial revolution by decades.

- The automobile patent of Selten postponed automobile innovation in the USA approximately the same way.

- The aeroplane patent of the Wright brothers pushed innovative aeroplane industry from the USA into France.

- The English and French patent system forced chemical industry to settle in Germany and Switzerland, where chemical patents that time did not exist or were much weaker.

Boldrine and Levine examined the 23 relevant empirical studies in literature, to be found in the table below. They did not find one, in case of which strengthening intellectual property protection would have obviously increased innovation activities. The strengthening of patent system certainly increased the number of patents, but not that of innovation activities.

Table 5.: Studies examining the connection between patents and innovations

Authors

Arora et al., 2003

Arundel

Baldwin and Hanel

Bessen and Hunt

Branstetter and Sakaribara

Gallini

Hall and Ham

Hall and Zeidonis

Jaffe
Period Country 1990-2002

$$
\text { Various }
$$$$
1993
$$

1980-1996

1988-1998

1980s

1980-1994

1979-1995

Various

USA

Various

Canada

USA

Japan

USA

USA

USA

Various
Industry

Many

Many

Many

Software

Many

Many

Semi-conductor

Semi-conductor

Many 


$\begin{array}{lccc}\text { Kanwar and Evenson } & 1981-1990 & \text { Various } & \text { Aggregate } \\ \text { Kortum and Lerner } & 1980-2000 & \text { USA } & \text { Many } \\ \text { Lanjouw } & 1990 \mathrm{~s} & \text { India } & \text { Pharmaceutical } \\ \text { Lanjouw and Cockburn } & 1975-1996 & \text { India } & \text { Pharmaceutical } \\ \text { Leger } & 1978-2000 & \text { Mexico } & \text { Agriculture } \\ \text { Lerner 2002 } & 1850-2000 & \text { Various } & \text { Many } \\ \text { Lerner 1995 } & 1971-2000 & \text { USA } & \text { Financial } \\ \text { Levine and Saunders } & 1981-2001 & \text { USA } & \text { Software } \\ \text { Licht and Zoz } & 1992 & \text { Germany } & \text { Many } \\ \text { Lo } & \text { Appr. 1986 } & \text { Taiwan } & \text { Many } \\ \text { Mann } & 1900-2002 & \text { USA } & \text { Software } \\ \text { Park } & 1987-1995 & \text { OECD } & \text { Many } \\ \text { Qian } & 1979-1999 & \text { Various } & \text { Pharmaceutical } \\ \text { Sakaribara and Branstatter } & 1988-1995 & \text { Japan } & \text { Many } \\ \text { Scherer and Weisbrod } & 1970 s & \text { Italy } & \text { Pharmaceutical }\end{array}$

Source: Boldrin and Levine, 2009, p. 1003.

There are two studies, which find connection between the strengthening of patent protection and increase in innovation activities the strongest. Kanwar and Evenson (2003) examined the time series data of more countries and identified such factors influencing the subratio of R\&D within GDP as for example the strength of intellectual property rights. Moreover, Lo (2004) examined the effects of the 1986 reform in Taiwan. According to Boldrin and Levine in both cases, in case of countries with weaker patent protection the strengthening of patent system increased foreign investments. However, these investments are implemented at the expense of other countries, so in the opinion of Boldrin and Levine this is a zero-sum game overall, not an increase in global innovation activity.

Mazzoleni and Nelson (1998) point out that most studies hardly focus on the numerous advantages of patent system. The studies are almost exclusively based on the examination of existing firms, among them the larger ones. However, the patent system can significantly help the new actors entering the market, the smaller firms or the institutions operating in a non-corporate 
framework (e.g. universities). In the lack of patents these are not necessarily able to protect their innovations similarly to huge companies, in alternative ways. Often they are also unable to implement their innovations individually. However, possessing a patent these actors are able to co-operate with others or license the innovation more easily, under better conditions, thus the innovation will more probably be utilized. In the lack of patents e.g. in the USA, numerous SMEs active in the biotechnology industry striving for ensuring return or involving capital to their research would not have been established. It is also important to examine the patent system from the point of view that the establishment of an innovation and the market implementation of an invention are not necessarily carried out by the same person. However, taking all these aspects into consideration, Mazzoleni and Nelson do not think that the further strengthening of patent system would have an economic advantage on a global level.

In the opinion of Hall and Harhoff (2012) it is obviously visible that the patent system promotes innovation obviously only in a few industries. Still, patents are widely applied due to their advantages. According to Gambardella and Hall (2006) although the overall role of patents in promoting innovation is not significant, but should a competitor of the company not possess them, then the company would lag behind, should it not apply patent protection. Hall and Harhoff (2012) add that although patents overall do not increase social utility significantly, they imply serious benefits for certain market actors. Although their opinion on the current patent system is basically negative, according to them the social utility of patents cannot be judged obviously as per our current knowledge. In their opinion the slight changes in certain elements of the patent system can also influence social utility to a relatively huge extent. This is why the authors draw attention to the research of international differences and possible reform actions of the patent system.

As of today, patent system is not necessarily advantageous for firms basically taking advantage of the system, either. It is typical especially in complex industries that competitors find the new products of each other almost automatically infringing their own patents (fairly or based on arguable reasons) and ask for compensation in court. In certain cases the value of the 
trial is very large, even threatening the existence of companies. These companies have already invested huge amounts in their patent portfolio and would like to ensure its return. Although large companies successfully push small ones out of the market by patents, but in case of most participants, the fight with each other pulls away more energy and money than the benefit it creates. More and more firms invest huge sums involved in trials and buyouts rather into research and development. This is a typical stalemate, where solution can be expected only through common agreement. In the lack of unity the individual optimal strategy of all actors is to continue taking part in competition. In my opinion it is important to emphasize that the patent propensity of companies is still significant. This can show that especially in numerous industries based on simpler products, for numerous companies it is worth patenting, which is shown by the existence of patent premium. The overall social utility of these patents can certainly be negative.

According to the generally accepted point of view until the 1990's, strong patent system in the long term increases economic growth. This served as a base for the continuous strengthening, expansion of the patent system, in the 1980's and 1990's. However, the results of empirical studies do not typically show that in its present form the protection of intellectual property would imply overall positive effects for society. Patents do have their regular role in protecting innovations, but except for a few industries they are indispensable only in case of a small fraction of innovations. A large percentage of innovations would also be implemented without patents and the establishment of temporary monopolies, so the related social loss would not be needed in all cases. The strategic patent motivations beyond the protection of innovation imply numerous negative side effects, which directly hinder innovation. As conclusion, according to empirical studies and my opinion, the reform of current system, the narrowing of the circle of patentable technologies or the abolishment of patent system would be necessary. 


\subsubsection{The reform of patent system}

The critics written in the literature and the increasing dissatisfaction of companies have been partly echoed. Reforms on patenting system were initiated both in the USA and in the European Union. The modification of the patent law was accepted in the USA in 2011. The USA switched for the European system, according to which the owner of the patent is its earliest applicant (it used to be the first inventor, which did not necessarily promote the application of innovations). The proposal of Jaffe and Lerner (2004) was also included. According to this, before the acquisition and validation of patents, opportunity has to be provided so that before their introduction patents could not only be examined by the patent office, but also by others who might possess more information about the given topic. This was also supported by Kica and Gronendijk (2011), focusing on the new technologies with high uncertainty (e.g. biotechnology). The new law provides opportunity for third persons already during the process of awarding the patent and also later in more occasions to address objections against the patent or application (Venulex, 2011). However, according to several researchers, this will not solve the problems of the institution of patenting, further more radical reforms are needed (Krakovsky, 2012).

In the European Union the establishment of the framework conditions of the single European patent and court is in progress, which would unite the currently fragmented patent institution system, significantly improving its transparency and decreasing its costs. The implementation of the system seems realistic in 2015. According to the research of Galasso and Schankerman (2010) the single European patent court will promote the establishment of European technology license agreements.

A special solution was provided for the reform of the patent system by a referee affected in the patent infringement trial between Apple and the Motorola unit of Google called Richard Posner. He ended the trial by questioning whether patents should be expanded to softwares or most other industries at all (Levine (2012), quotes Hanula (2012)). 
The researchers propose numerous further measures beyond the reforms currently going on.

According to Gallini and Scotchmer (2001) opportunity has to be provided for free use, for those who invented the same invention independently from the owner of the patent and are also able to prove it. This would make the initiation of hostile patent trials much harder, since in this case the bona fide inventor could not be punished so easily.

As per Kingston (2001, quote Boldrin and Levine, 2009) the company should provide obligatory license for patents for the requestors in return for the fee, proportional with $R \& D$ expenditures.

According to Cornelli and Schankerman (1999) and Scotchmer (1999) the renewal of patents should be introduced again, for example in the way that the 20 year long entitlement period would be broken down into more parts and in the end of each stage it should be renewed (Boldrin and Levine, 2009).

According to Mandel (2005) it would be useful for the state to buy the socially extremely useful innovations (e.g. extremely positive environmental effect) and to make these available for everyone free or in return for a certain fee. It is also worth thinking over that the fee would not only be influenced by R\&D expenditure, but probably also by social benefit, thus motivating the inventors active in such field even more.

As per Schankerman (1998) the involvement of inventors could also be achieved by subventions instead of patents. According to Romer (1996, quote Boldrin and Levine, 2009) similarly to patents, subventions have numerous negative effects, thus the circle of those included should be very much narrowed down, for example to the subvention of graduating university students playing a key role in innovation, according to researchers.

Bessen and Meurer (2008) also propose numerous reform measures. In their opinion, patent claims should be made more transparent and it would be necessary for patent offices to give a certificate for a fee, about the innovation not infringing patents. Claims should be precisely worded and granting patents should be restricted. Furthermore, the renewal fee of patents should be 
increased so that by excluding numerous, relatively invaluable patents, the novelty research would be simpler.

A certain ratio of the above proposals can be hardly implemented in practice. It is extremely problematic to determine the value of a given patent or innovation. However it is important to see that there are numerous examples for this in practice (e.g. licenses, transactions, referee practice). Moreover, innovations are so colourful that it is impossible to find an optimal solution, which would provide sufficient stimulation for the implementation of all socially desirable innovations. In this situation it is hard to achieve a change in status quo, but reform proposals should definitely be considered to achieve a social effect that is more positive than the current system.

According to Boldrin and Levine (2009), based on the currently available information in order to increase social welfare, the protection of intellectual property should be gradually abolished. In their opinion, market actors have already collected sufficient legal, economic and business knowledge on how to protect their innovations without patents, too. According to them, based on the studies of the past fifty years there can be little doubt about the harmful effects of patents. The abolishment of these would not be less logical at all than the winding-up of commercial duties and barriers was fifty years ago, which resulted in the significant increase in social welfare as a result of free trade and globalization. The sudden abolishment of patents can really cause significant additional damages, so their gradual reduction in more steps is proposed. The right start for this would be decreasing the term of validity of patents. The opinion of Boldrin and Levine regarding intellectual property rights coincides with that of those economists who think that certain restrictions on trade in special cases would be socially advantageous, but the general abolishment of restrictions on trade is more practical and useful.

According to Boldrin and Levine (2009) although the disadvantages of patents are obvious, no important steps were taken in this matter, since the relatively few beneficiaries of the system continuously and successfully lobbied for status quos. Although there would be ever more winners of abolishment of patents, but the gain individually available for them is relatively little. 
In my opinion, the point of view of Boldrin and Levine is not necessarily the optimal solution, since according to literature, for example in case of pharmaceutical and chemical industry, patents operate more efficiently and the situation is not obvious in case of environmental innovations, either. At least in case of these areas it would be worth examining the social balance of the impacts of patents compared to the relevant innovation-protection alternatives. Should we start moving in the direction of complete abolishment, taking the opinion of Boldrin and Levin into consideration, without retroactive legislation the prevailing of patents is ensured for at least 20 years, and the gradual reduction of the system can also enable the correction of decisions possibly qualified as wrong. 


\section{The situation of innovation in Hungary}

Regarding innovation, Hungary belongs to the group of leading innovators in the world. Based on the Global Innovation Index (GII) ${ }^{13}$ in 2013 Hungary is in 31 st place among the 141 countries participating in the survey. Compared to the neighbouring countries, Hungary is behind Slovenia and the Czech Republic, but ahead of Slovakia and Poland. The strength of Hungarian innovation is the economic utilization of the already obtained knowledge; thus spreading the specific knowledge, new information, their transmission to users and their creative application. As it can also be seen in the figure below, the relative weakness of Hungarian innovation is the creation and protection of new knowledge (Dutta and Lanvin, 2013).

Table 6.: Hungary's „Global Innovation Index 2013” rankings

\begin{tabular}{|l|l|l|l|}
\hline \multicolumn{4}{|c|}{ Global Innovation Index 2013 - Hungary } \\
\hline Indicator & Rank* & Indicator & Rank* \\
\hline Knowledge absorption & 6. (12.) & Innovation linkages & 53. (95.) \\
\hline Knowledge impact & $19 .(12)$. & Knowledge creation & 41. (40.) \\
\hline Knowledge diffusion & $11 .(22)$. & $\begin{array}{l}\text { Creative intangible } \\
\text { assets }\end{array}$ & 96. (111.) \\
\hline Creative goods \& services & $9 .(20)$. & Knowledge workers & 64. (45.) \\
\hline Online creativity & $30 .(26)$. & & \\
\hline
\end{tabular}

*: ranks from the previous year (2012)

Source: HIPO, 2013

The relative domestic weakness of intellectual property rights is also underpinned by the fact that on a worldwide level, Hungary can be found only in a mid-field position of OECD countries, lagging far behind most developed

\footnotetext{
${ }^{13}$ Global Innovation Index is a composite index created by adding together 84 subindices, thus being able to grab innovation performance in a much more complex way.
} 
countries, but surpassing most CEE countries regarding the two most important intellectual property rights, namely patents and trademarks (OECD and USPTO, 2011).

Figure 20.: Number of triadic patents families and trademarks registered abroad per 1 million people between 2007 and 2009; OECD and G20 countries $^{14}$

Patents and trademarks per capita, 2007-09 Average number per million population, OECD and G20 countries

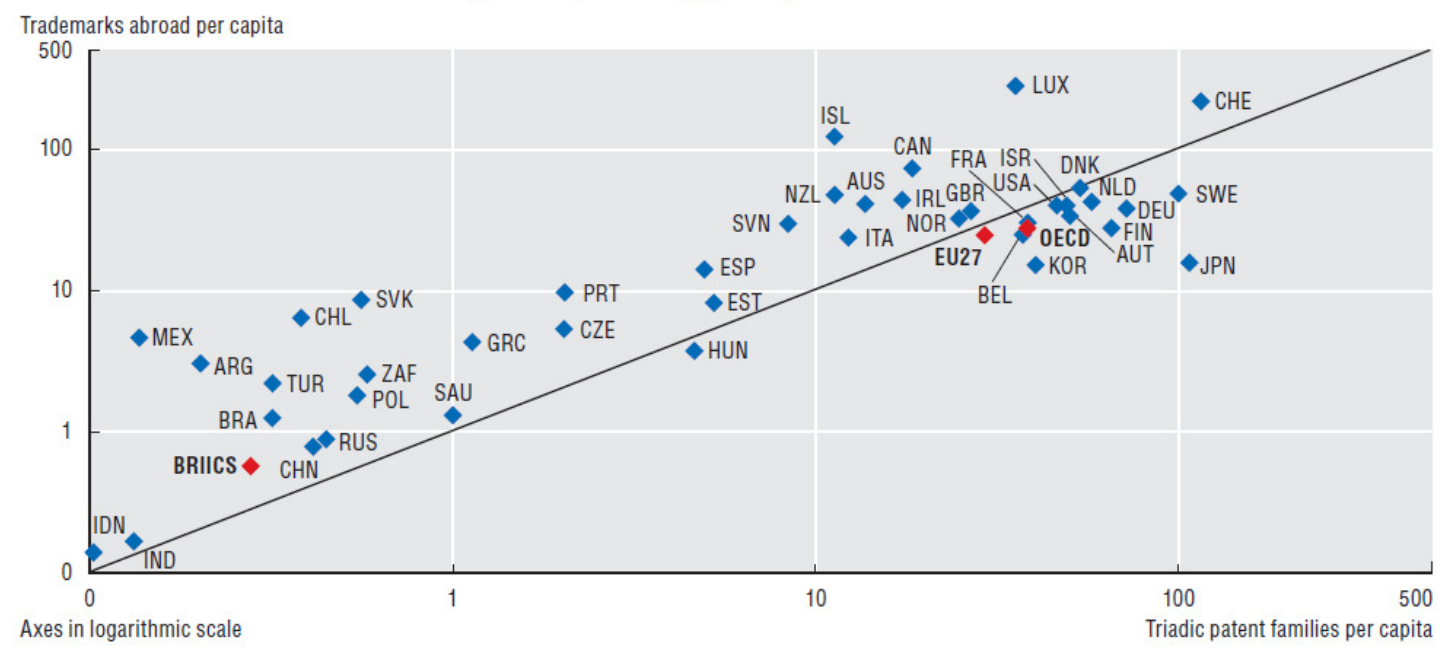

Source: OECD and USPTO, 2011

When comparing Hungary to the other EU countries, including numerous countries which are among the leading innovators of the world, Hungary belongs only to the group of moderate innovators, based on data from 2009 to 2012 (European Commission, 2014). This means that its Summary Innovation Index (SII) ${ }^{15}$ falls between $50 \%$ and $90 \%$ of the average of EU 25 . On the EU level, the most innovative countries are the so-called innovation leaders, they are followed by the innovation followers, then moderate innovators and finally the least innovative ones. As it can also be seen in the figure below, Hungary can be found in the middle among moderate innovators in the EU. Compared to the neighbouring countries, we perform similarly to GII.

\footnotetext{
${ }^{14}$ Triadic patents and trademarks registered abroad are both indicators of more valuable patents and trademarks.

${ }^{15}$ Summary Innovation Index is a composite index created by adding together 25 subindices.
} 
Figure 21.: The innovation performance of EU member states

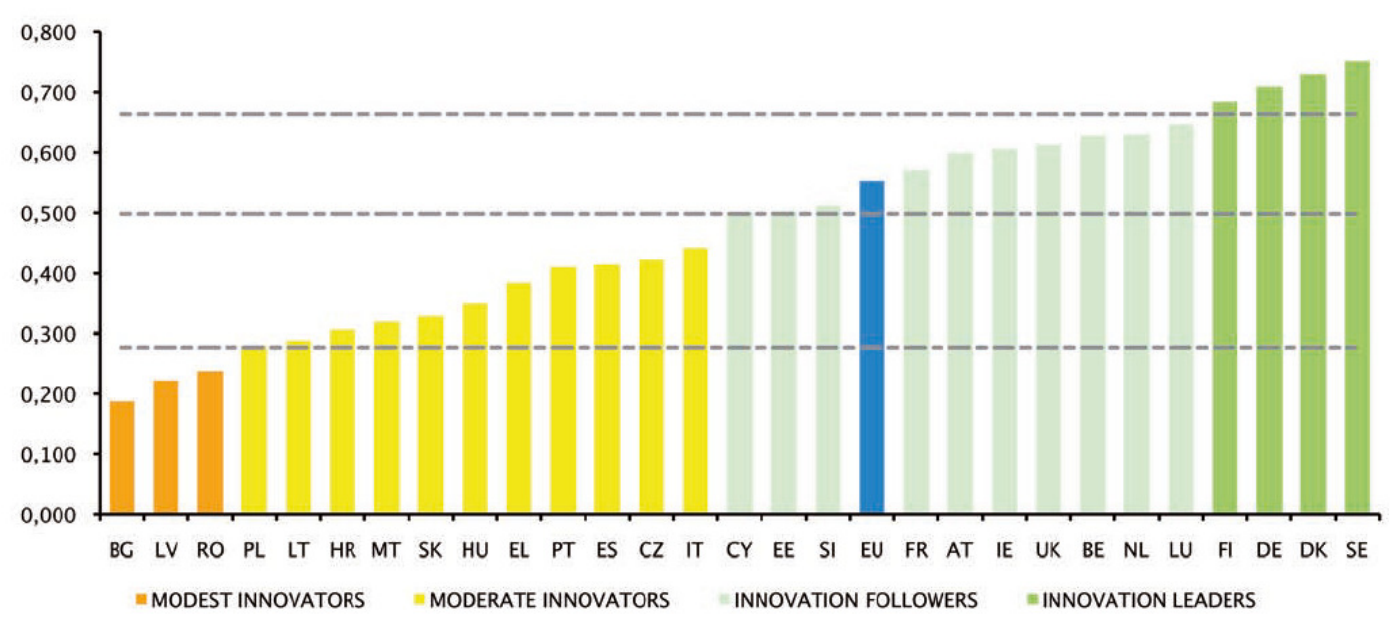

Source: European Commission, 2014, p. 5.

'Hungary performs below the EU average for most indicators, especially for Non-EU doctorate students and Community designs. Relative strengths are observed in License and patent revenues from abroad, International scientific co-publications and Fastgrowing innovative firms' (European Commission, 2014, p. 59.).

Figure 22.: EU Member state growth performance

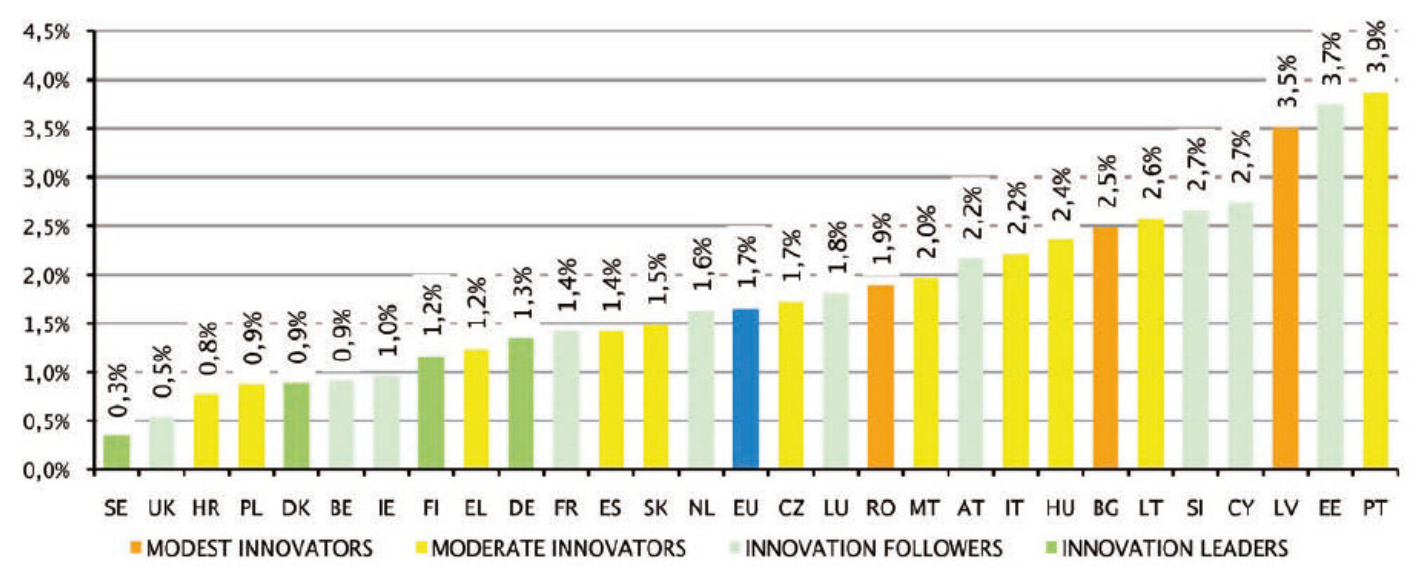

Average annual growth rates of the innovation index have been calculated over an eight-year period (2006-2013) (cf. section 6.2).

Source: European Commission, 2014, p. 23. 
Based on the above figure, the growth rate of SII index in Hungary is located in the first third, compared to countries with similar innovation performance. Compared to the neighbouring countries, the growth rate belongs to the higher ones, and it exceeds the EU average marked by blue line.

Thus worldwide Hungary belongs to the developed countries regarding innovation, but it does not reach the level of the most innovative countries. Hungary is primarily strong at the economic utilization of the already available knowledge, it is weaker at the establishment and protection of new knowledge. Compared to the economic development of the country, the domestic patent activity is low.

The weaker than EU average innovation performance of Hungary can be primarily traced back to historic reasons. In the decades before the transition, the GERD/GDP index (ratio of total research-development expenditure to gross domestic product) in Hungary was fluctuating around the value of 2.5$3 \%$, typical of developed countries. But around the 1990's it fell to the value of approximately $1 \%$, typical of the developing countries (Török, 2006). In Hungary during the transition, $80 \%$ of the industrial R\&D base (industrial research institutions, research firms and company research places) abolished their activities, corporate $R \& D$ expenditures fell to a fraction of the previous value. Even the initial significant volume of foreign working capital flow was unable to meet this (Rakusz, 2008). Similarly to the neighbouring countries affected by the transition, neither R\&D financing, nor the research institutional system was rebuilt in a more modern structure. The R\&D expenditures of the corporate sector were unable to make up for the lost state expenditures, the reasons for these were mainly institutional and organizational ones. New enterprises did not consider R\&D as strategic objective, while the firms of foreign ownership rather took advantage of the services of the foreign research places of their mother companies (Török, 2006). According to Kiss (2004), it can be said that in the 90's Hungarian companies did not primarily search for a source for competitiveness in innovation, but it contributed to the success of competitive companies, especially product development activity. 
As it can also be seen in the figure below, the tendency of domestic patent applications of Hungarian applicant also shows the significant decrease in Hungarian patenting activity after the transition. The following stagnation started in the end of the 1990's can still be experienced nowadays.

Figure 23.: Domestic patent applications of Hungarian applicants

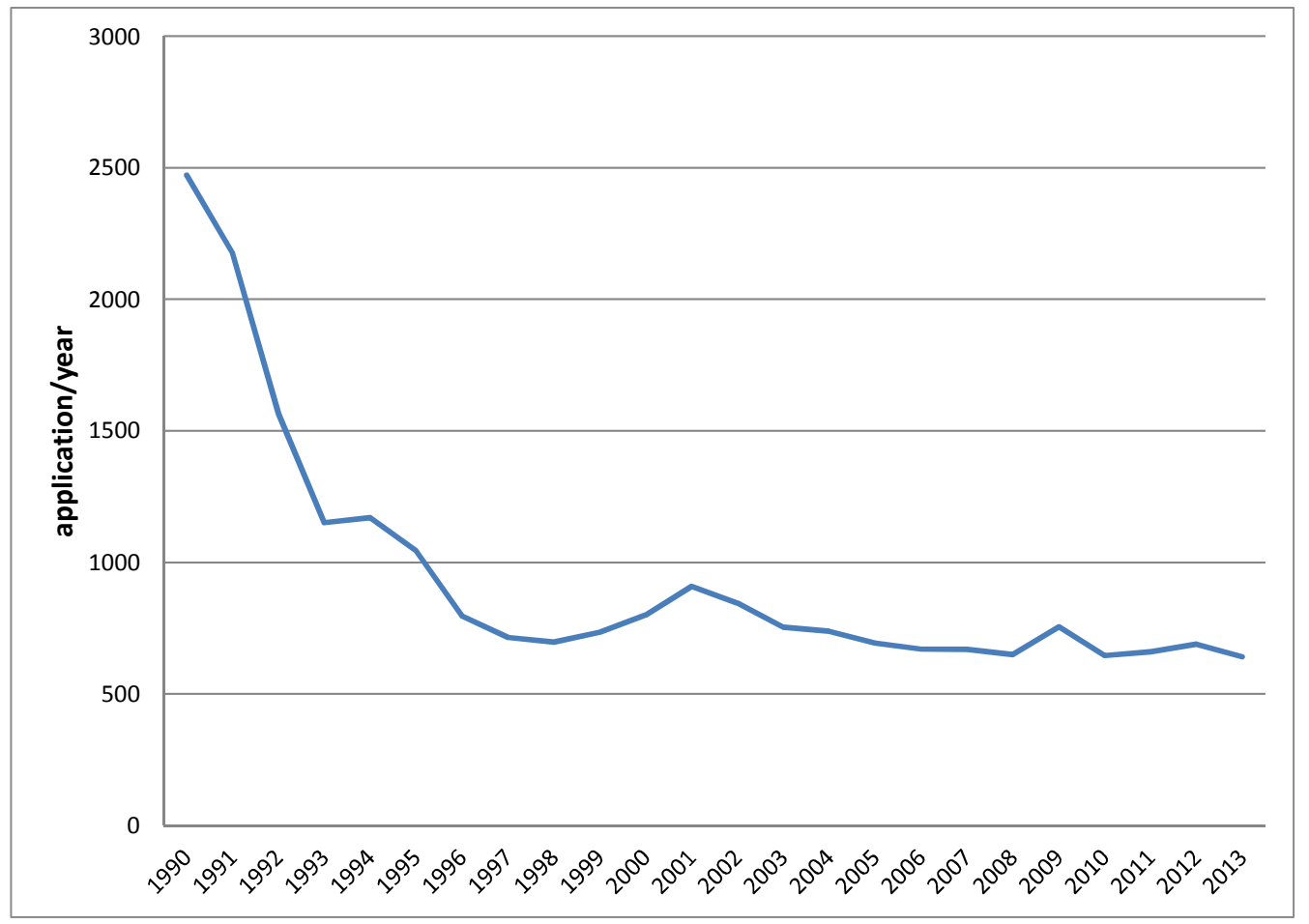

Source: own construction based on the data of HIPO

The number of patent applications reached its low in 2013. 641 domestic patent applications were submitted to HIPO. The low patent activity is in connection with the low intensity of domestic R\&D and innovation activity, the weak industrial property protection consciousness and the ownership structure of domestic companies with $R \& D$ activities dominated by foreigners: these mostly make foreign intellectual property applications.

According to the data of HIPO, the ratio of individual (private person) applicants is very high compared to similar countries, which amounted to 70- 
$80 \%$ in the $2000{ }^{\prime 16}{ }^{16}$. Generally it can be said that among the patent applications of individual applicants only very few are accepted. As a result of the high ratio of individual applicants and the high rejection and withdrawal ratio, in the end only $30-40 \%$ of all domestic patent applications become patented ${ }^{17}$. This is why it can also be worth examining the tendencies of domestic applications of institutional applicants likely to possess more valuable patents (a decisive ratio of them are companies) separately. Their subratio was around $20-25 \%$ in the beginning of the 2000's, but as of today it has increased to $30-35 \%$. Despite the stagnation of the number of all domestic patent applications a moderate increase can be experienced in this segment most likely containing more valuable patents to a higher ratio.

Figure 24.: Patent applications of Hungarian applicants ${ }^{18}$

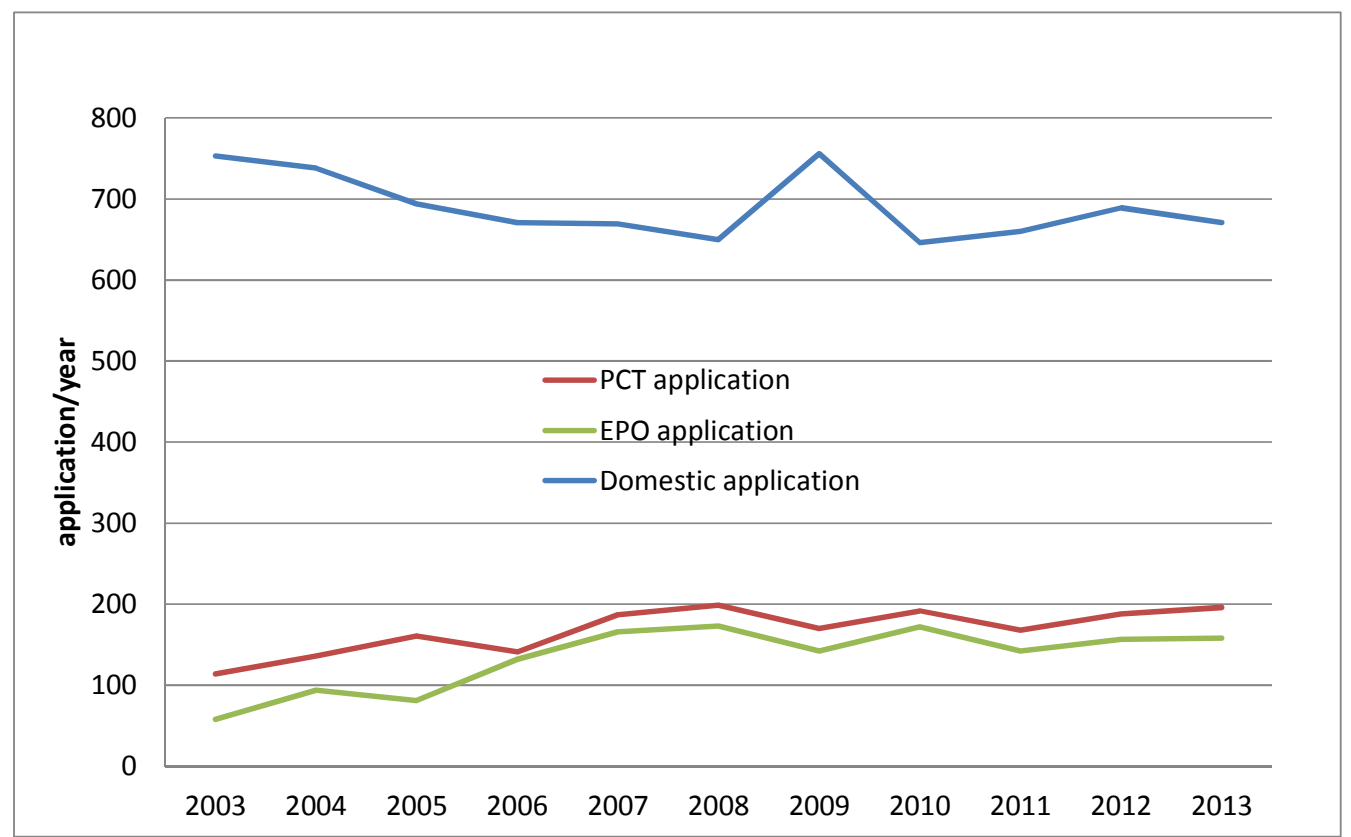

Source: own construction based on the data of HIPO

16 This certainly does not necessarily mean that they would implement the related patents. There are numerous examples where the owner of an enterprise is the patent applicant, while his enterprise utilizes innovation in the frames of a license.

${ }^{17}$ In abroad this ratio fluctuates around 60-70\%, according to Arundel and Kabla (1998).

18 Figures of PCT application and EPO application show the number of applicants with Hungarian address. According to EPO (2014) the number of European Patent Applicants by Country of residence of the applicant from Hungary show a smaller number, 105 in 2012 and 103 in 2013. 
Based on the data of HIPO, in the period between 2003 and 2008, the number of European Patent Office and PCT applications by Hungarian applicants shows a significant increase, as it can also be seen in the figure above. Moreover, due to the high costs, these are typically the more valuable patents of Hungarian applicants. However, after 2008 due to economic recession and the stuck of $R \& D$ subsidies, the number of these applications decreased. It is important to note that this more significant increase experienced between 2003 and 2008 does not necessarily characterize the development in domestic innovation activities precisely. This can be partly caused by the phenomenon described by Danguy et al. (2010), according to which, in case of the more significant patent offices the patent propensity of firms increased recently.

Figure 25.: The development of R\&D expenditures in Hungary 2000-2012 (GDP \%)

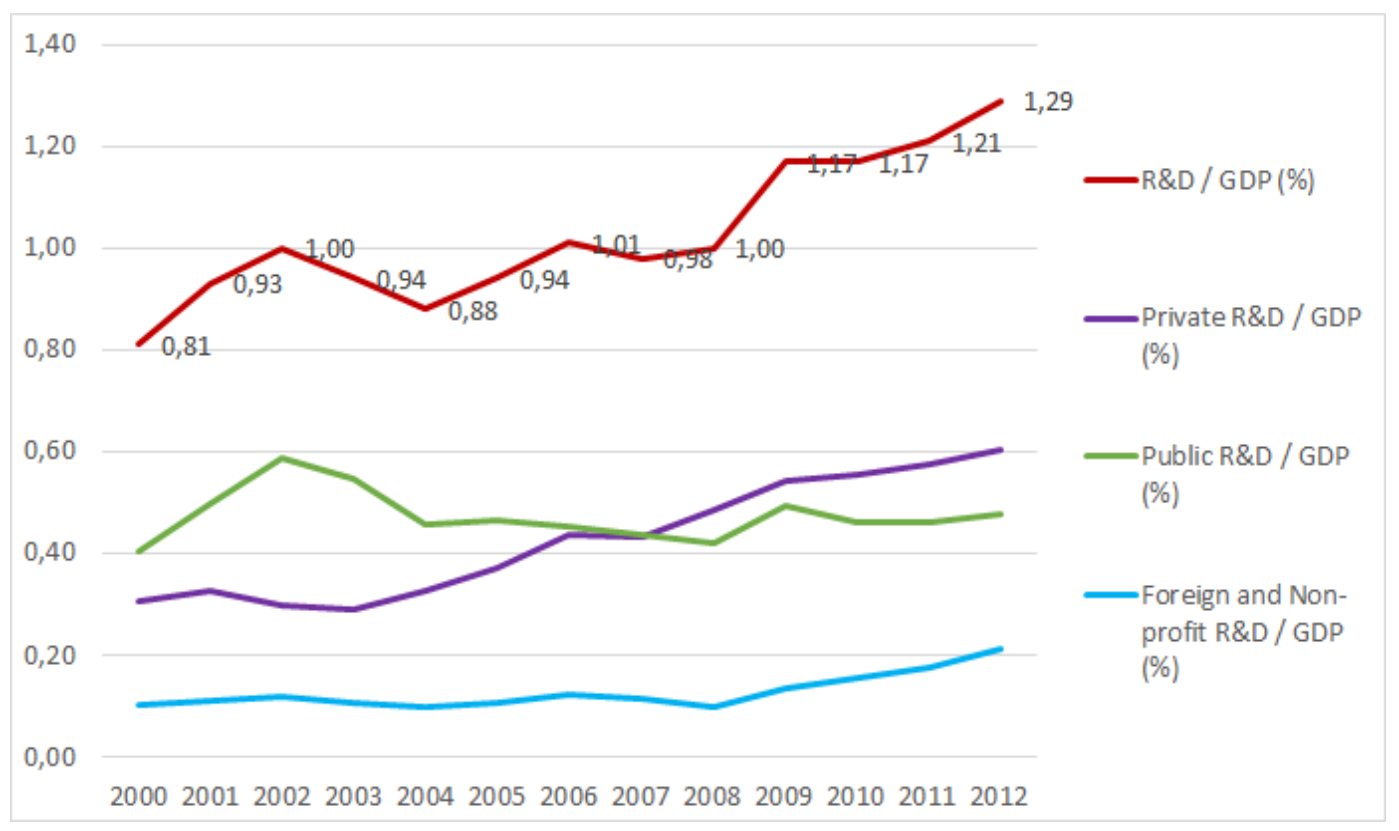

Source: own construction based on the data of $\mathrm{HCSO}(\mathrm{KSH})$

The R\&D expenditures proportional to Hungarian GDP increased in the years of the crisis and exceeded the level of $1 \%$, which in the opinion of Losoncz (2008) is critical because of economies of scale. It is great that the main driving force of growth was the increase in private $R \& D$ expenditures, where the deficit was relatively the most significant. Based on preliminary 
data from HCSO $(\mathrm{KSH}), \mathrm{R} \& \mathrm{D}$ expenditures reached $1.44 \%$ of the GDP in 2013.

The increase in $R \& D$ expenditures does not necessarily contradict to the decrease in the number of patent applications, since their number in Hungary, according to the results of Smahó (2005), correlates with the R\&D expenditures from 2 years earlier the most. Thus from 2012 an increase in the number of corporate patent applications should have been expected. This was not the case, although the numbers of PCT and EPO patent applications have increased to some degree.

The increase in $R \& D$ expenditures in the years of the crisis is slightly surprising considering that since the beginning of the crisis the volume index of investments was continuously decreasing, in 2012 it was on the 2001 level. Such a sharp fall can also undermine the expected growth of the next years. The apparent contradiction can probably be resolved by the fact that the decrease can be contributed to some sectors (e.g. construction industry) and the less innovative companies of smaller size. More companies responded to the crisis by moving forward and increasing their innovation activity. Next to this, the large export oriented firms could progress mostly independently from the domestic situation.

Figure 26.: Volume index of investments in Hungary

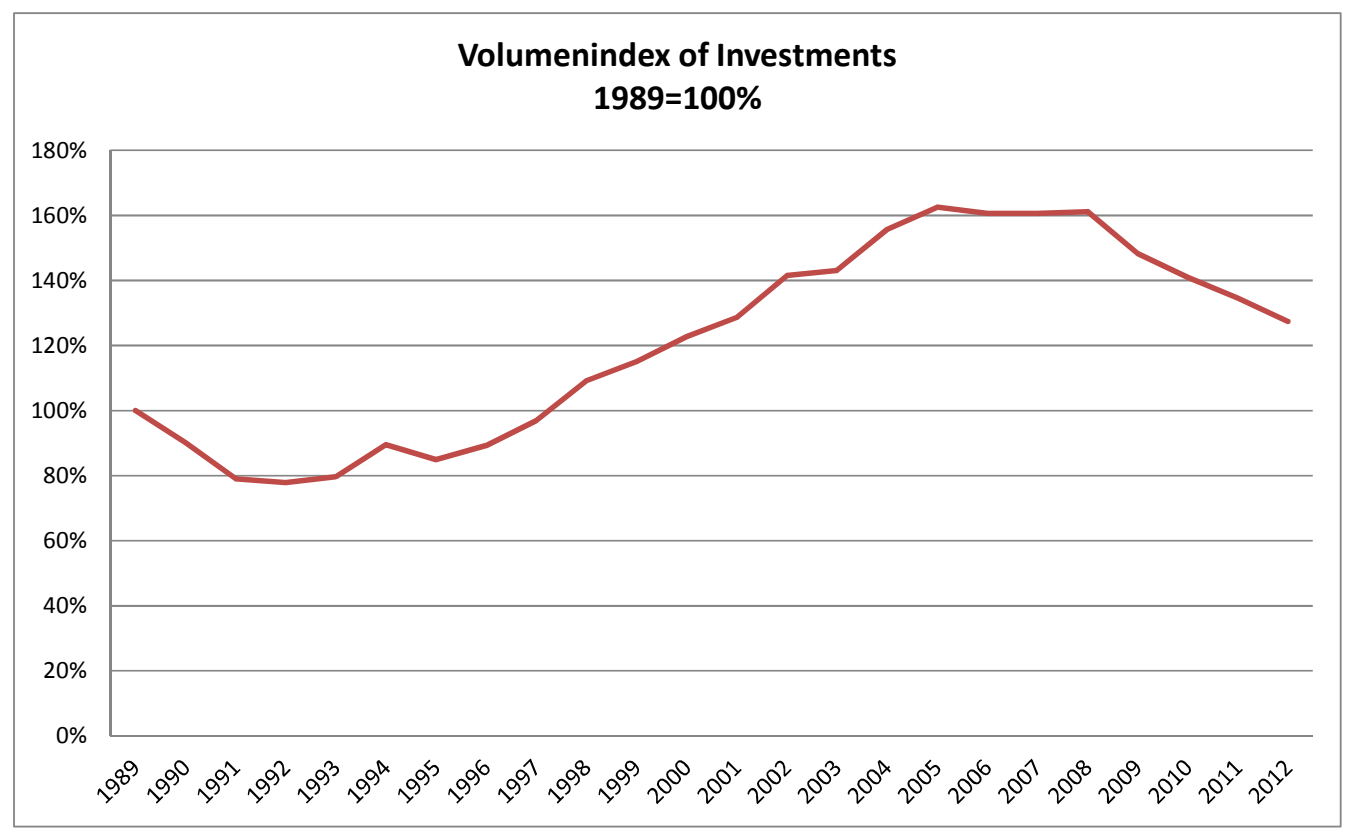

Source: own construction based on the data of HCSO 
Table 7.: R\&D expenditures of enterprises in Hungary 2012, according to main branches

\begin{tabular}{|l|r|r|}
\hline \multicolumn{1}{|c|}{ Industry } & \multicolumn{1}{|c|}{ million HUF } & ratio \\
\hline Chemicals and pharmaceuticals & 64263 & $25 \%$ \\
\hline $\begin{array}{l}\text { Machinery, vehicle, instrument and } \\
\text { device production }\end{array}$ & 60060 & $11 \%$ \\
\hline Other production & 25366 & $13 \%$ \\
\hline $\begin{array}{l}\text { IT services, telecommunication, } \\
\text { transportation, storage }\end{array}$ & 30077 & $12 \%$ \\
\hline Trade, vehicle repair & 28112 & $10 \%$ \\
\hline Other services & 23364 & $\mathbf{1 0 0} \%$ \\
\hline Other & 7429 & $\mathbf{2 3 8 6 7 1}$ \\
\hline Total: & & \\
\hline
\end{tabular}

Source: own construction based on the data of HCSO

Examining the industrial breakdown it is apparent, that pharmaceutical industry contributes a dominant part of $R \& D$ expenditures, which suffered from the crisis to a relatively smaller extent.

The Community Innovation Survey focused on the environmental innovation performance of companies in 2008. Based on the next figure, environmental innovations are mostly directed towards specific energy and material saving. This is not surprising at all, since these two factors imply immediate cost saving for the company. The use of more environmentally friendly materials, the decrease in pollution or the positive effects of recycling can be also indirectly typically well-experienced for the company. The advantages of the product or service occurring at end users and the decrease in corporate $\mathrm{CO} 2$ emission are the least emphasized, since the advantages of these can be noticed by the company only indirectly or not at all. The results are similar in case of all company sizes. In case of the EU average the end result is similar, but here recycling is the most widespread, and the decreased energy consumption of the end user is also more emphasized. 
Figure 27.: Number of companies implementing environmental innovation between 2006 and 2008

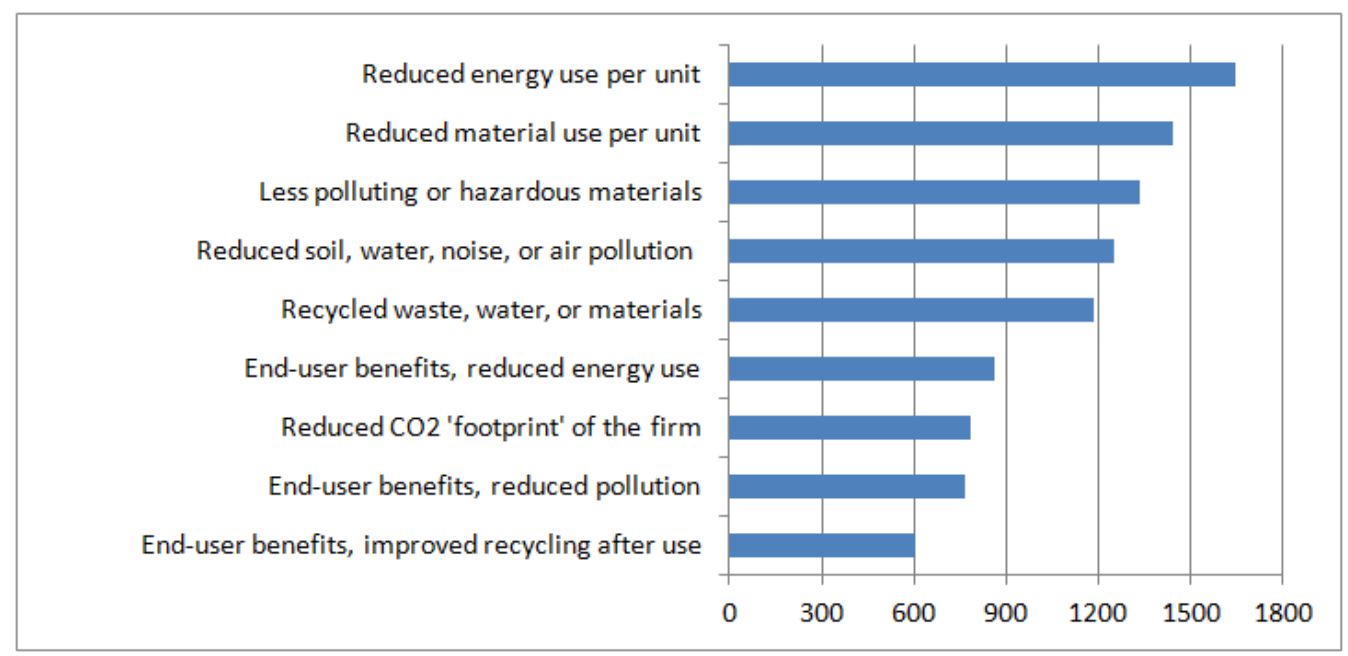

Source: own construction based on the data of Eurostat

According to the CIS survey, the main motivation of the introduction of environmental innovations is the existing or expected administrational regulation. This is followed by voluntary agreements and the existing or expected demand. The least important factors are the subventions that can be called up and the existence of other financial stimulators.

Based on OECD's 2008 innovative country survey, Hungary shows the characteristics of a dual economy. Although the large companies with mainly foreign ownership have a significant economic performance, these are often only loosely connected to the Hungarian SME sector, much more lagging behind from the innovative point of view. Despite a few positive examples mostly there is a lack of innovative middle sized companies. Because of this, the overall innovative performance significantly lags behind opportunities, so Hungary is only restrictedly able to base the further increase in productivity on innovation (OECD, 2009).

The research of Zilahy and Széchy (2010) found that regarding companies in the chemical industry, the more innovative firms in case of general innovations are also more innovative considering environmental innovations. Based on this, general innovation tendencies can also be relevant in case of environmental innovations. 
The difference between large and small companies is well-demonstrated by the number of enterprises implementing technological innovation seen in the figure below and also its change in time. The economic crisis affected small companies the most, so among them the ratio of innovative companies fell by nearly $20 \%$ to $13 \%$ from the already low value of 2006-2008 to the period between 2008-2010. This decrease also overcompensates the moderate increase in other size categories (HCSO, 2012).

Figure 28.: Ratio of companies implementing technological innovation broken down according to number categories

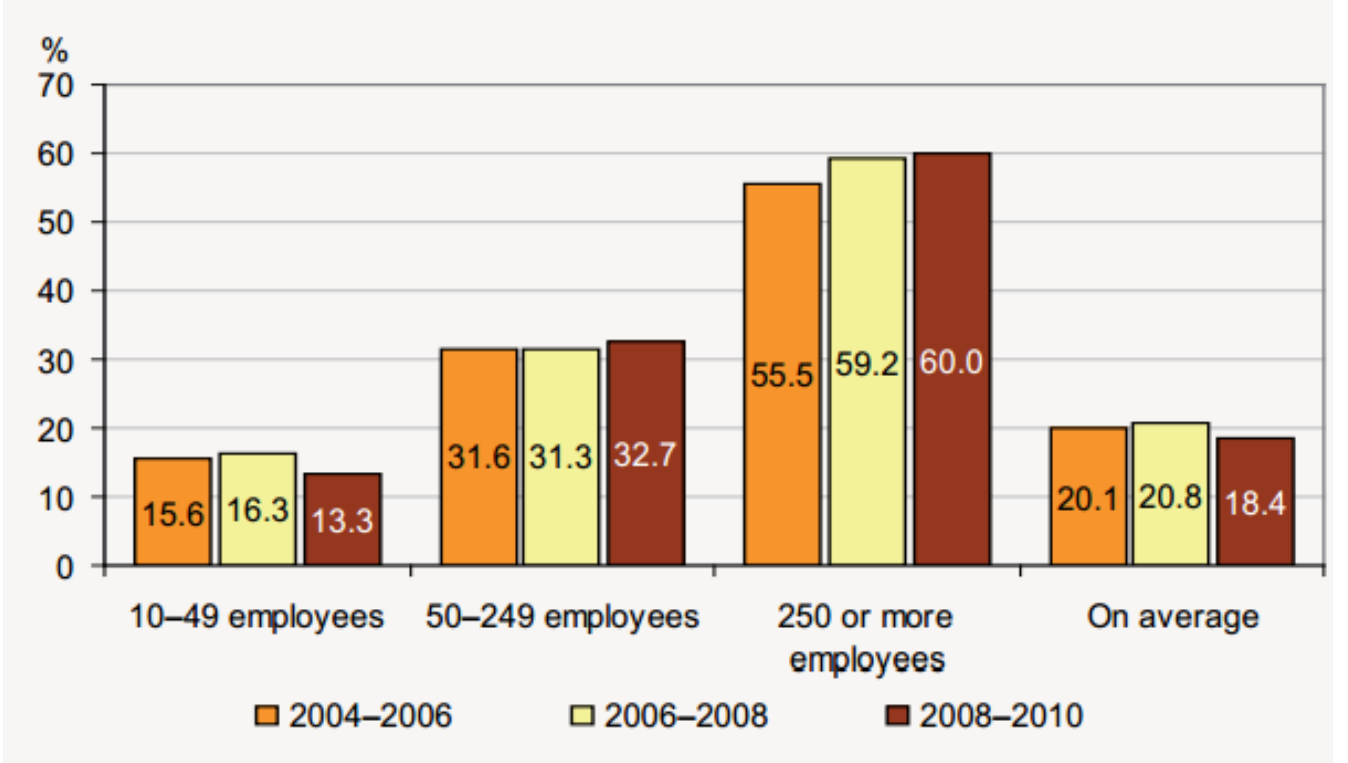

Source: HCSO, 2012, p. 1.

The relative backwardness of small enterprises is also underpinned by the research of Inzelt (2011b), who compared the ratio of domestic innovative companies to that of a few European innovative leader and follower countries with size similar to Hungary. Hungary significantly lags behind in all corporate size categories, but the biggest difference can be experienced in case of small companies. The domestic ratio of $15-16 \%$ is one third of the value of Belgium and Finland, slightly more than one third of the value of Austria and Denmark, and a half of the value of the Netherlands and Norway. In her opinion, such a difference between ratios cannot be explained only by the different industrial structure of Hungarian and foreign small enterprises. 
Bánfi et al. (2012) reached interesting conclusions, too by examining the innovation activities of domestic companies in 2011, according to the opinions of 515 managers (mostly SME). Despite the fact that only a small fraction of Hungarian SMEs introduced new product or procedure, $82.6 \%$ of managers considered themselves innovative. This can be underpinned by two reasons, on one hand smaller developments, improvements are also interpreted as innovation, and on the other hand adaptation is also interpreted as innovation.

The research of Hámori et al. (2012) also shows a similar picture. They examined innovation activities in 2011 based on the answers of 302 companies (overwhelmingly also SMEs). In this research they expressively strived for the examination of incremental developments and adaptations, too. The results of the research are slightly surprising, an overwhelming majority of respondents $(90 \%)$ declared that in the past five years their firms introduced some kind of innovation. The positive results are shaded by the fact that the survey, also based on the description of the authors (e.g. due to the low response rate) shows a picture slightly more optimistic than reality. Innovations not yet known in Hungary were introduced by $67 \%$ of firms in the examined period. Companies typically implemented product innovations, these are followed by process innovations, organizational and marketing innovations.

The negative picture painted about the innovation performance of SME's based on international studies can be slightly shaded by the innovations implemented without substantial R\&D, called barefoot innovations by Szabó (2009). Among these, Szabó presents seven concrete examples. It is also true that Hungarian, especially small size companies often do not precisely report their R\&D expenditures, moreover they are sometimes not even aware of the concept of innovation (Némethné Pál, 2010) ${ }^{19}$. Hoffer and Katona (2012) also

\footnotetext{
${ }^{19}$ Pál Némethné (2010, p. 9.) also illustrates this by an expressive example. The leader of a relatively small brickwork in the countryside during an interview in an environmental protection related topic mentioned that they do not search and innovate, but try to incorporate various agricultural plant residues in the clay of the brick. These burn up during firing, the produced heat causes saving of gas used for firing and the occurring emmission is not included in the firm's $\mathrm{CO} 2$ quota. When she drew attention to the fact that this is innovation and they
} 
share this view. According to them, the innovation activity of enterprises is also not identical with the characteristics underpinned by statistics. The search for and the application of innovative solutions can not be experienced by indices directly, but characterizes the practice of enterprises. According to them, the knowledge and use of innovation and the related concepts is necessary for the leaders of domestic SME's. This can for example also help companies to get access to potential development resources (Hoffer and Katona, 2012). The relatively lower domestic patent activity can be also partly explained by this low consciousness regarding innovation, typical of most SME's.

Although the above described factors slightly improve the not too positive situation told by innovative statistics, but according to the sporadic domestic empirical studies it is obvious that in Hungary, the ratio of innovative small and middle sized enterprises is low even in industries considered to be innovative, as well as in knowledge based sectors (Inzelt, 2011a).

According to Török (2006), innovation activity is not primarily prevented by the lack of funds and human resources, but durable conceptual insecurity, the not appropriate operation of the institutional system and the fact that the domestic political elite is not aware of the significance of innovation ${ }^{20 .}$ Havas (2009) even talks about 'Hungarian paradox'. According to him, all conditions are given for a potentially successful innovation system, still the innovation activity of the country is weak. Although the institutional frameworks are given, their operation is not appropriate. Additionally, Havas marks the lack of

can be proud of it, the answer was: 'we will still keep it secret, otherwise we should have to fill a lot more papers.'

20 Despite the fact that the positive connection between increase in research \& development expenditures and economic growth in case of Hungary was proved empirically. According to the research of Van Ark and Piatkowski (2004), 2.4 percentage point from the annual 3.3 percent expansion of GDP per capita between 1995 and 2001 can be contributed to total factor productivity, where innovation has a significant weight. 
close enough cooperation among companies as the other main reason for paradox.

Even in the opinion of Hámori and Szabó (2010), the biggest problem is the inefficiency of the institutional system. According to them, numerous elements of the market and economic institutions introduced after the transition after Hungary's access to the EU do not function efficiently, part of them only exist as formal framework. They draw attention to the fact that the observable real operational rules of institutions significantly differ from declared rules and a not insignificant part of real interactions take place by leaving or going round 'official' frameworks, often bound with corruption (Hámori and Szabó, 2010, p. 891.). In their opinion this negative impact is more strengthened by the weakness of legal system. According to them, the reason for low innovativity is that the performance of market actors and their achievable profits are not necessarily in sync.

Rakusz (2008) on one hand names the flawy innovation policies as the source of the problem. On the other hand he draws attention to the fact, that although in the area of fundamental research Hungary is relatively strong, in the business utilization of research results we already have weaker results. The reason for this is the low value of corporate $R \& D$ and the bad efficiency of the utilization of public resources. According to him, public resources are not affected adequately by market impulses, there is an insufficient demand for R\&D activity.

Kiss (2009) highlights that R\&D stimulating programmes are not suitable for SME's not dealing with innovation, in their case increasing their technology absorption capacity can be the way to step forward. Thus the company will be able to select the technologies necessary in a more reasonable way and to adapt and further develop them more efficiently. One way to increase technology absorption capacity is to establish institutions and programmes focusing on this. These can be for example technology parks, targeted consultancy, the establishment of clusters or the temporary outsourcing of qualified engineers to firms. Kiss draws attention to the necessity of differentiated innovation support policies. 
Széchy (2012) also draws attention to the fact that during the implementation of their environmental innovations, microenterprises are hardly able to use subventions related to environmentally friendly technologies or to take part in related tenders.

In the opinion of Hámori and Szabó (2012) during the decades of socialism, economic and social system did not compensate innovative people, moreover it blocked their promotion. Thus the heritage of the system is an exclusively anti-entrepreneur social environment.

This is shaded by the opinion of Tamás Sárközy, which he shared in an economic status law lecture in the then-called Budapest University of Economic Sciences in 2000. In his opinion, in the last years of socialism almost everybody was manoeuvring, doing business, income support was also necessary due to the low life standard. According to him, it provided future entrepreneurs with invaluable experiences.

According to Borsi and Bajmóczy (2009), a further reason for the relatively lower innovation activity can be that innovation ability is spacially relatively concentrated in Hungary. On a European level, only Budapest and its suburbs own a modest innovation performance. The innovation ability of university cities and the microregions of their neighbourhood are favourable only compared to the innovation level of the country, and their radiating effects can not be experienced through larger distances. It is a serious issue that almost two-thirds of Hungarian microregions have weak innovation ability even in the Hungarian comparison.

Pitti (2008) examined the reasons for low R\&D expenditures of enterprises and he presented the barrier factors in a detailed way. He found numerous deficiencies regarding the institutional system. Among them the lack of business development strategies, the insufficient stimulating force of economic environment (complicated application mechanisms, decreasing tax subventions, lack of professional support organizations, etc.), the parallel and independent support channels and the regulations and subvention system tailored for large companies are emphasized as barrier factors. Regarding the (co)operation of companies, undercapitalization, atomized feature, the lack of 
cooperation and the spread of lease-work activities constitute the main problems. The observations regarding companies of foreign interest are, that their R\&D activities are not bound to domestic economic activity, the positive effects of domestically accounted $R \& D$ expenditures are typically distributed among more countries.

According to Rakusz (2008), non-innovative companies will not be competitive in the EU. Those ones might be successful, which are supported by a multinational company with its own $R \& D$ base or carry out significant own R\&D activities or have professional relations with scientific institutions. According to Pitti (2008, p. 11.) it is of key importance that the significance of R\&D would be brought to consciousness among companies. Innovative companies are not successful because they realize serious $R \& D$ performance. They spend more than average on $R \& D$ programmes because they have realized than without product and quality improvement, they are unable to preserve their market position.

Inzelt (2011b) examined the activities of 246 selective innovative and noninnovative SME's between 2006 and 2008. Based on her results, among domestic knowledge based enterprises, the role of intellectual property rights can be important. The most widespread intellectual property right is patent, $52 \%$ of firms with intellectual property right own a patent. This is followed by copyright, trademark and utility model. $36 \%$ of innovative companies own patent. Most enterprises established their patents individually, half of these enterprises own only one patent. The enterprises establishing patents with foreign partners typically own 1-4 patents. The largest part of innovative enterprises with patents implemented product innovation, this is followed by process innovation, organizational and marketing innovation are significantly lagging behind. The sample also contained a company owning a patent, but not being innovative. This clearly shows the difference between invention and innovation.

In her research, Széchy (2012) examined the environmental innovation activities of nearly 300 firms from the manufacturing industry in 2010-2011. She explored significant differences between the different types of environmental innovations. While the main objective of preventive type of 
innovations is decreasing costs in an overwhelming ratio of the cases, product innovations are implemented mainly hoping for market advantages. Companies serving end consumers hardly meet any environmental protection needs, this is more typical when the customers are other firms. The products of more favourable environmental impact do not exclusively target environmentally conscious customers, but those who would simply like to spare with their decreased energy consuming, material applying products. According to her suggestion, the role of the state should be to focus on strengthening the consumers and civil organisations.

It is important to draw attention to the fact based on the results of Széchy (2012) (in sync with other studies, e.g. Frondel et al. (2007)), that the largest ratio of environmental innovations is process innovation, while in case of general innovations it is product innovation. This can also be a potential reason for the differences between general and environmental innovations.

The fourth survey of the 'National Competitiveness in Global Economy' was carried out in 2009. In this survey Chikán et al. (2010) collected detailed data about 313 companies in all size segments. Based on their results, in the area of innovation the situation got even worse compared to the unfavourable results of the previous surveys. The ratio of firms introducing new products, technologies decreased. Only 4\% of companies applied for patents abroad between 2005 and 2008, which is a significant fall compared to the $10 \%$ value of the 2004 survey.

This, besides the previously described increase in the number of foreign patent applications shows the concentration of innovativity.

Regarding innovation, an unfavourable result is that among the 18 listed activities of the company, managers found $R \& D$ the least important, which is a serious decrease also compared to the previous surveys. The most important ones were the traditional fundamental functions of operation, such as sales, top management, cost management, marketing (Chikán et al., 2010).

A reason for the apparent fall can be also the timing of the survey, in 2009 economic recession reached its peak and business uncertainty rose to record 
heights. In this situation, most companies postponed R\&D decisions influencing future development directions.

Based on the survey, the biggest obstacle for innovation is still the method of state participation. Although many people mentioned the lack of finance, it is important to highlight that they were fewer than in case of previous surveys (Chikán et al., 2010). Zilahy and Széchy (2010) also highlight that although most firms find the lack of finance the biggest obstacle for environmental innovation activity in case of open questions, the analysis of numerical data does not underpin this. Thus with the lack of further motivations we cannot expect improvement even in case of improving financial conditions.

The fifth, most recent survey of the 'National Competitiveness in Global Economy' was carried out in 2013. In this survey Chikán et al. (2014) collected detailed data about 300 companies in all size segments, with a special focus on SMEs. Similarly to previous results, companies do not consider innovation as an important factor in shaping the economic environment or influencing market trends. They are usually satisfied with the corporate strategy, but these include only moderate plans regarding innovation. The companies hold IT developments as unimportant. There are hardly any responses of the new challenges of the knowledge based economy, the number of educational trainings for employees is very limited. According to Chikán et al. (2014) these are rather dangerous regarding the future development of the Hungarian economy.

There was only a slight change in the ratio of companies considering their current innovation activity as appropriate between 2009 and 2013, but more companies thought that they should make a change in this respect. $70 \%$ of the respondents spend between $2-15 \%$ of their revenue for innovation, and $13 \%$ of them spends more than 20\%. The share of companies introducing new products have stagnated, but it decreased in case of new services between 2009 and 2013. Innovative companies mainly had products and services of better quality than their competitors (Chikán et al., 2014).

The biggest obstacles of innovative activity are the tax system and the costs of innovation, but regulations and lack of own resources are also important. It 
is good that the greatest decrease was in the ratio of companies holding external financial sources as an obstacle of innovation between 2009 and 2013 (Chikán et al., 2014). One reason for this could be that external financial sources were relatively scare in 2009 , because of the high uncertainty in relation with the crisis.

'INVESTING IN THE FUTURE National Research \& Development and Innovation Strategy 2020' (MNE, 2013) was approved by the Ministry of National Economy in 2013, and tried to answer the arising questions. The strategy handles innovation as emphasized economic priority and one of its declared objectives is the establishment of an innovation friendly economic environment. The major statement of the strategy is that Hungary has to be able to reach the critical level of $R \& D$ capacity by seriously concentrating on R\&D\&I. Only this way is it possible to really exploit the possibilities in the EU Horizont 2020 strategy and the associated grants and other available financial resources. The strategy aims for concrete objectives, e.g. the increase of the ratio of R\&D expenditures to GDP to $1.8 \%$ by 2020 , and $3 \%$ by 2030 , connecting thirty bigger research and technology workshops to the world elite and the domestic settlement of thirty new global R\&D centres. Above this, according to the strategy at least a thousand innovative start-up enterprises would receive significant subventions needed for the start, the already settled and settling large global companies would be served by masses of innovative supplier firms with domestic decision making centres, etc. The strategy does not determine priority branches and instead of non-refundable subventions it applies tax rebates to an increasing extent. It is important that they break down the strategy into subobjectives and the significance of interim evaluations is also highlighted. The objective is for the key actors of the innovative system, to strengthen and to dynamize the whole system. This can contribute to the increase in the competitiveness of Hungarian economy and its transformation into sustainable knowledge based economy.

To sum up, the strategy imagines strengthening of the role of innovation according to a realistic, well-planned conception, by setting concrete sub- and final objectives. The main question is, how it will be implemented in practice. 
According to Gál (2013), the analysis behind the strategy is appropriate, but the strategic responses are not all well grounded given the national and international premises. The flow of knowledge and the coordination between the elements of the innovation system do not seem to be ensured. Among several factors he emphasises the role of an institutionally more stable innovation facilitating system to be able to realise the strategy. 


\section{Empirical research of the patenting activity of innovative firms}

\subsection{Research questions}

It is clear from the literature review that the most important and current question of the research of patents is whether the existence of the patent system enhances innovation and ultimately social utility. Regarding this topic, a number of studies try to analyse, what reforms of the patent system could aid the positive effects and hinder the negative ones. There are only few studies that are able to give at least a partial answer to these questions. The main reasons for this are the huge variance between the specific innovations, and the sometimes large-scale externality effects which are hard to assess. The studies which are usually based on large scale representative surveys fail to give universal findings.

The effect of the patent system on environmental innovations is a much less researched topic. Still, this field is worth studying as environmental innovations have several unique attributes which could alter the patent system's effect on them. The main reasons for this are the double-externality effect, the different attitude of the companies towards these kinds of innovations and the greater need for their efficient diffusion.

Two main goals of my research are to contribute to a more thorough understanding of the advantages and disadvantages of the patent system for innovative companies, and to study the diversity of these effects in the special case of environmental innovations. In the latter case I also apply an approach different from most studies, as I study environmental innovations not only in the environmental sector, but in all industries in Hungary. As it was presented in the previous chapter, Hungary is a leading innovator in the world and a moderate innovator in the EU. Hungary has a highly developed patent system, although the significance of patents is lower than the EU average. Results from the study of the case of Hungary can also have relevance for other EU countries. 


\subsection{Hypotheses}

Based on the literature review and the above, I have formulated the following hypotheses:

H1. The realization of patented environmental innovations depends more on the existence of the patent system than in the case of nonenvironmental innovations.

As a result of the "double-externality" effect inventors are even less motivated to generate environmental innovations than non-environmental innovations, so patent protection is more important for them.

H2. The main motivations of patent protection and the importance of these are similar in Hungary and in the European Union, namely: commercial exploitation, protection from imitation, blocking, pure defense (ensuring that the use of a company's own technology is not hindered others), setting of technical standards, improving reputation, licensing.

The major motivations and goals behind creating environmental innovations in Hungary are similar to international innovations, taking all companies, not just the environmental sector. I assume that the effects like similar competencies, decision making mechanisms, regulations of companies override the motivational differences in the country of origin and environmental effect of the innovation.

H3/A. The patent premium (the added value to the innovation by patent protection) is a significant part of the patent value.

Several studies tried to assess the patent premium. According to Arora et al. (2008), and Jensen et al. (2009) this is about 40-60\%. Bessen (2009) however finds a significantly lower patent premium. I plan to analyse this in the case of Hungary. 
H3/B. The value of the patents increases with the size (revenue, employee number) of the innovator.

According to Bessen (2006) and Bessen (2008), the value of patents increases with firm size. The research aims at examining whether this is also true in the case of the most valuable Hungarian patents. Analysis of this topic may have important innovation policy implications.

H4/A. In case of patented innovations, the effective lifetime of the innovation (the period in which the innovation can/could really generate profit) is shorter than the patent protection period granted by law.

Patent protection grants a temporary monopoly of 20 years. In practice however many innovations are imitated sooner and may be squeezed out of the market. Often the life-cycle of the product or process can be shorter than 20 years. Product lifetimes for example in high tech sectors are sometimes only a couple of years. In both of these cases the deadweight loss of the patents ceases to exist. The study of this topic could be important during the analysis of the disadvantages of the patent system and could serve as an input of the proposed patent system reforms.

H4/B. In case of patented innovations, the effective lifetime of the innovation is shorter than the theoretical lifetime of the innovation.

Effective lifetime can be shorter than the theoretical lifetime of the innovation due to several reasons, because of the lapse of patent protection, the imitation of the innovation or the lack of utilization, etc.

\section{H5. Hungarian innovators with patent applications find the reform of} the patent system necessary, in line with the vast majority of researchers.

Most researchers consider the reform of the patent system as a necessity. I think that most of the Hungarian companies have the same opinion, and their quantitative as well as qualitative opinion can serve as a valuable supplement in deciding between the alternatives. 


\subsection{Methodology of the research}

According to Griliches (1990) there is lack of appropriate data to measure innovations and their effects, as innovative activity is hard to measure, its effects are hard to assess and there is no function-like relationship between the inventive input and output.

There are several ways in the literature for the study of innovations:

- Macro-level innovation indices: these can be specific macro-level statistical data like R\&D expenditure, patent applications, composite index using data from several relevant fields, like drivers, barriers and general conditions to innovation or activity based input and output measures. An example for this is the Summary Innovation Index (as described in Chapter 5.), aggregating 25 specific innovation related sub indices.

- Company-level empirical research with surveys or other methods.

- Innovation-level empirical research collecting detailed information to assess the diffusion and effects of innovations.

In case of environmental innovations, gathering relevant data from macrolevel statistics is difficult, as this type of innovation is often realized as a part of or only as a by-product of innovations focusing on other fields.

Company-level surveys or similar methods can serve as a suitable tool for the research of environmental innovations. Data gathered from this type of research is especially useful for micro-level and short-term conclusions. This type of research is most appropriate dealing with well defined and researched topics. Major disadvantages of these types of studies are the subjectivity and relatively high costs. Several biases can arise when we try to aggregate the answers of people with different backgrounds and knowledge about the topic and the specific question. Similar to the research of Némethné Pál (2010) where there were serious bias arising from the fact that companies interpreted the term "innovation" differently.

Only during a thorough study of a specific innovation brings the researcher close enough to experience the complex nature of innovative activity, and is able to make relevant conclusions. This can be achieved by interviews which 
are most appropriate when dealing with less researched and less common areas, and is useful for experimental studies. The disadvantage of this method is that it is difficult to achieve representative industry or macro-level conclusions.

Based on the above benefits and drawbacks of the different methods, the optimal method to test my hypotheses is to gather detailed data about specific innovations. To my knowledge only one such research was done in Hungary, as part of the PatVal II survey. Such a detailed research can complement the existing patent literature, and might influence the patent system to better enhance environmental innovations.

To test the hypotheses, one needs a sample of companies which have invented environmental innovations and are also active in patenting. There are three ways to create such a sample:

- Large scale representative study targeting numerous companies, and identifying relevant companies. The disadvantage of this type of study is the relatively high proportional cost of gathering data from relevant companies. I participated in the research of Széchy (2012), who examined the environmental innovation activities of nearly 300 firms from the manufacturing industry in 2010-2011. One question included in the survey inquired about whether the identified innovation has been patented or not. Although the sample contained about 50 companies owning patents, only 14 environmental innovations have been patented by the companies and only a few revealed plans of future patenting activities. Further analysing the 9 companies owning these 14 patented environmental innovations made it clear, that some of their patents are not of Hungarian origin or not even patented by the company but a supplier from abroad. As a result of this very low rate of patented innovations the survey implemented by Széchy (2012) is not suitable for my purposes.

- It is possible to identify companies with patents considered as environmental innovations. Although patents at the Hungarian Intellectual Property Office are not classified according to 
environmental performance, there are ways to gather information from the detailed description of the patents. In one of my previous research, about 700 patents protecting environmental innovations were identified, with the application time between 1990 and 2006 (Szücs, 2011). Detailed patent descriptions are usually available to approved patents, but not to patent applications. So I only used approved patents, which served well also as a method for sorting out a great number of invaluable patent applications which had never been approved. Since it takes about 3-4 years to approve a patent, the research has to face a substantial lag. As patenting activity significantly decreased from the beginning of the 1990s, most of the patents of environmental innovations found were from the early 1990s. There were about 100 patents of environmental innovations from 2000. These patents included a significant number of patents with marginal value as well as ones which will never be used in practice. I found that the proportion of green patents was rising in the 1993-2000 period (with 3 years' moving average), from $16 \%$ to above $20 \%$ on a $92 \%$ significance level. I also found that it is rather easy to decide whether a patent relates to an environmentally advantageous innovation or not, as most patent descriptions summarize the advantages of the innovation, explicitly stating lowered material usage, lowered energy requirement, less hazardous waste, or more environmental friendly product or process.

- The third way to gather a sample with companies active in environmental innovations and also patenting is to directly search for such companies using publications of awards, newspaper, web, etc. Detailed data can be gathered this way, but this method biases towards bigger companies and more valuable innovations, and is less likely to be representative.

All of the patents at HIPO can be studied and the approved patents of environmental innovations can be sorted out to have a sample. These can be compared with the patent applications of Hungarian applicants at EPO to have a more robust sample likely to contain the most valuable green patents. The 
explanatory power of the research can be further increased with a patent citation based measure, widely regarded as a good proxy of patent value (for example Trajtenberg, 1990). The major disadvantage of this method is that most recent patent applications have to be excluded from the study as the patent approval time is recently 3-4 years. There are some specific industries (for example pharmaceuticals) in which the time lag of approving a patent can be even up to 10 years, so in these industries patent applications of the last 5-7 years of these industries are excluded. With thorough selection, the sample can be representative of the patenting activity in Hungary, not taking the most recent 4-7 years into account. This timelag significantly decreases the relevance of the study, and it is harder to acquire detailed information about more prior inventions. The other major disadvantage of this method is that the sampling can just partly be automatized and high costs arise in case of manual sampling.

The study of an award or contest is an appreciated method in the literature. There are numerous reasons for this. First, it contains independent measures about the value of the innovations which can be rather useful in interpreting results. It contains both patented and unpatented innovations, making a comparison possible. Companies usually apply with their most valuable innovations, making it appropriate for studying innovations with the most important effects. There are usually companies from all size participating, making a comparison possible. This way more detailed data can be found about the innovation. One of the most cited surveys with similar sample is from Moser (2007), who studied more than 7000 innovations of four British and American world fairs between 1851 and 1915, where the significance of individual innovations was examined by a professional committee. Although the time-period studied is long past and the economy is substantially different, she was able to reach several valuable conclusions. In another research, Fontana et al. (2010) examined the 'R\&D 100 Awards' of the Research and Development newspaper between 1963 and 2005. They were also able to gain valuable information from their study, although their sample (as the authors themselves also highlight) significantly overrepresents high-tech type of 
technologies and the inventing activities of formalized R\&D laboratories, which can only partly be patented.

The main drawback of similar studies is that the sample is usually not representative of the innovative activity of the economy. The Fontana et al. (2010) research is unrepresentative of the economy (overrepresenting several industries), while the Moser (2007) research is unrepresentative of the studied economy, and there is also a great time lag Still, the Moser (2007) research is widely cited throughout the literature which means that it is still relevant today.

After the thorough analysis of the advantages and disadvantages of the methods the third method was selected as the most appropriate for the research. The prize chosen is the Hungarian Innovation Grand Prize, awarded each year since 1992 by the Hungarian Association for Innovation. The sample consists of companies, which applied for the Hungarian Innovation Grand Prize between 2002 and 2013 and which also applied for patent protection. Research done on this sample stands out of the bulk of patent research using representative random samples.

Those Hungarian companies can apply for the Hungarian Innovation Grand Prize which realized an innovation of great importance in that year (selling a high quality new product, new process, new service, etc.). The basis of an innovation could be an $R \& D$ result, patent, adaptation of a know-how, technology transfer, etc. The application must include a one page summary which will be published, detailed description about the realization and its market and economic results (extra yearly business result, extra yearly income, increase of market share etc. due to the innovation), and references (expert opinions, opinion of the buyers, photo, video, article, etc.) as well as a statement regarding the truthfulness of the announced data, information and the intellectual property rights as well. A jury evaluates each innovation and decides about the prize. The jury consists of scientists and business professionals invited by the Board of Trustees of the Hungarian Association for Innovation, the head of the jury is the minister for national economy. The evaluation aspects of the Innovation Grand Prize are the achieved extra economic result or extra yearly income and other technological, economic 
advantages, originality, novelty, social utility and the elaboration quality of an application (Hungarian Association for Innovation, 2014).

Application of Innovation Grand Prize as a sample has several advantages:

- companies are likely to apply with their most valuable innovations;

- $\quad$ professional jury decided about the significance of the innovations, which is an independent measure regarding the value of innovations;

- most of the innovations are used in practice, as it is an element of the evaluation;

- $\quad$ one page summary is available about the innovations;

- $\quad$ there are applicants from most industries;

- there are patented and unpatented innovations, so there is the possibility to make comparisons between these groups.

There are also disadvantages of using this sample:

- companies with the most valuable innovations may not apply for this prize due to several reasons (for example: they have no time or resources to prepare the application, they have no information about the prize, they do not want to disclose any information or shed light on their activity, etc.);

- not representative of the Hungarian economy and innovative companies.

In the research I study the period between 2002 and 2013. Regarding the earlier innovations it is quite difficult to gather relevant data from interviews regarding activities performed more than 10 years ago (invention and patent application usually precedes the utilization of the innovation and the application for the prize with 1-5 years). Going further back in time, it is even more difficult to find people with relevant knowledge, due to several reasons. Also the changes in the patent system and in the economy make the study of older innovations less relevant. 
Figure 29.: Applications for the Hungarian Innovation Grand Prize recognised as innovations 1992-2013

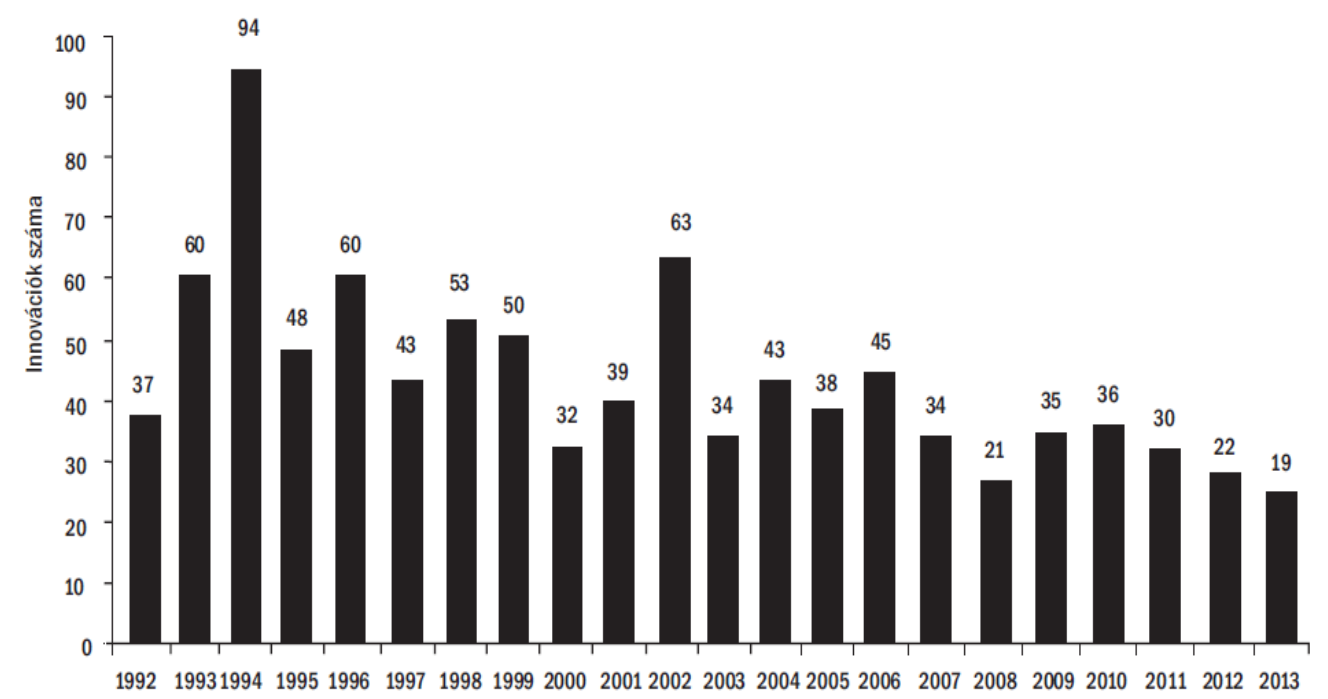

Source: Hungarian Association for Innovation, 2014, p. 36.

The above figure shows that the jury recognised 420 applications for the Innovation Grand Prize as innovation between 2002 and 2013. Studying the summaries of these innovations it can be seen, that 67 of them declares or refers to have applied for at least one patent.

Studying patent applications instead of granted patents has several advantages. Gambardella et al. (2010) have shifted to study patent applications in the PatVal II study instead of patents. According to them, the major advantages of studying patent applications are:

- Applications already serve as strategic instruments

- Companies license the application already and do not wait until the granting of the patent

- Through this method, studying younger patent applications is more appropriate. In case of younger patent applications, often not enough time has lapsed for the patent offices to grant or reject them. Furthermore, there is a better recall among respondents, and the conclusions are more up-to-date. 
Among the advantages noted by Gambardella et al (2010), studying applications in my research can be considered a better method because of the 12 year long period. When studying only granted patents, innovations from the last 3-4 years have to be excluded, and the last 5-7 years in case of industries with longer patent granting times.

There are disadvantages of studying applications. According to Gambardella et al. (2010), these are the following:

- Granted patents are likely to be commercialized more frequently than similar non-granted (pending) applications.

- Some of the applications will be refused or withdrawn.

- Focusing on applications increases heterogeneity in the sample (but has better selectivity).

In case of my research commercialization of innovations with only patent applications is not a major problem, as most of the innovations in the sample are utilized. Innovations with later rejected or withdrawn patents can have smaller value and other different characteristics which can decrease the strength of the conclusions. However many Hungarian patent applications are withdrawn because the innovation seems to have significant value and applicant decides to file an EPO application.

Taking all the above into account, I study patent applications in my research.

After thorough examination of the innovations entered for the Grand Prize with patent applications, about $10 \%$ of these can not be regarded as Hungarian innovations, as neither the patent applicant, nor the inventor is Hungarian. This usually happens in the case of Hungarian subsidiaries of multinational firms. I have thoroughly analysed all of the innovations which applied for the price, their applicants and the main owners of the applicants about possible patent applications at the Hungarian Intellectual Property Office, the EPO and even the USPTO (the latter mainly in search of possible software patents). Next to the aforementioned 67 innovations, a further about 40 innovations were identified which may have related patent applications. In these cases applicants simply did not include the information about patents in the 
summary, or instead of the company the owner of the company is the applicant (and usually the inventor) of the patent. In this latter case the owner usually licenses the patent to his company. During the interviews it turned out that in case of about 40 innovations, they had underlying patent applications. In the end, this meant a population of 90 innovations with patent application.

The testing of my hypotheses, taking into account the attributes of the sample, can be achieved by interviews.

According to Ackroyd and Huges (1992, cited by Lehota, 2001) an interview is a meeting between the researcher and the respondent, where the researcher asks a series of relevant questions with regard to the research topic. The answers of the respondent serve as the basic information which will be analysed later on.

There are several types and classifications of interviews. With respect to the structure of the interview, there are structured, unstructured, and semistructured interviews. Structured interviews are the most formalised ones. Their major goal is to get highly standardised and comparable data. In this form of interview the questions as well as their order are given previously, and the interviewer can not diverge from this. Unstructured interviews are the most informal ones, there are no previously given, standardised questions. This method is appropriate for explorative type of research and gives more freedom for the respondents to talk about things that they think important (Lehota, 2001).

With the use of interviews, more detailed data can be gathered which can complement the relatively smaller sample. The advantages of the interviews are the following:

- To test the hypotheses, interviewees have to answer several questions, through which it is possible to assess innovations and patents in a holistic approach (Yin, 2008).

- Regarding the generalization of the conclusions of such a research it is important to analyse the database from more aspects during the testing of the hypotheses. When it is possible, it is good to have more interviewees questioned about the same topic, to make the results of 
the study more robust (Zivkovic, 2012). In my case it is possible to have partly independent sources of information from the summaries of the innovations, the descriptions of the patents and the valuation of the jury.

- As the number of interviews is relatively large for a few people to manage, it is useful to structure the interviews to make them comparable with each other.

Assuming a response-rate of about 50\%, it seemed realistic to have detailed data of about 40-50 innovations with patent applications. The main problem of the sample and the database is the non-representativeness and the relatively small size. These both mean that conclusions from the research are generalizable only under limited circumstances.

Although the population contains relatively few elements, this is in line with the languid Hungarian patenting activity, which is a structural weakness of the Hungarian economy according to Dutta (2012). The sample size is relatively small mainly because there are only a small number of valuable Hungarian patents. According to Bessen (2008), Scherer and Harhoff (2000), as well as Gambardella et al. (2008), the value distribution of patents is strongly skewed, the most valuable decile giving the $70-90 \%$ of the value of all patents. Between 2002 and 2013 there were about 2500 patent applications from institutional applicants (mainly companies). This can be higher in reality, as in Hungary the ratio of individual applicants is $60-80 \%$, but there are some individual applicants who utilize their patents in the frame of companies. The 2500 patent applications are likely to relate to significantly less innovations, as a lot of valuable innovations are protected by more patents.

It is important to note that although most patent applications regarding the Innovation Prize have been applied for at the HIPO, but not all. In case of several innovations there were more patent applications. Eventually, the population contains at least $3.6 \%$ of Hungarian innovations with patent application, and a high ratio of the really valuable ones. It is also important to see, that in the population most of the innovations are utilized. These patents or applications have the biggest social and environmental effects. Most 
unutilized and marginal value patents have low social and environmental benefits, and the social costs related to the temporary monopoly can be bearable. To be able to form generalizable conclusions, I based the structure of the interviews on a large scale representative study, the PatVal II with more than 22,000 patent applications between 2003 and 2005 in 20 European countries, USA and Japan. About $80 \%$ of the questions of my survey questionnaire originate from this survey. Results of the PatVal II study include data from thousands of European patents, including Hungarian ones. The researchers had a representative sample of 335 patent applications at the EPO with Hungarian inventors. From these they were able to acquire 50 fully and 23 partially filled in questionnaires. From all of the 18 European countries, they were able to acquire 10,107 fully and 3,148 partially filled in questionnaires. Using exactly the same questions it is possible to make comparisons with that study.

If the results are in line with the results of the PatVal II or PatVal II Hungary surveys, it makes the conclusions more robust (see Yin, 1994, cited by Zivkovic, 2012). Based on these, the population is suitable for making general comments in several topics with respect to innovations with patent applications in Hungary. It has to be taken into account that the population is biased towards more valuable innovations. In case of some research themes the results from Hungary are valid in more general context with limitations.

\subsection{Survey and sample characteristics}

A structured interview survey was implemented in order to examine the relationships and to test the hypotheses presented above. The survey was carried out with the participation of applicants for the Hungarian Innovation Grand Prize. The database built can be used for researching further hypotheses and can supplement the PatVal II survey. I was able to acquire the Hungarian version of the PatVal II survey to ensure as much compatibility as possible. It is important to note, that during the PatVal II survey researchers have surveyed inventors, while I surveyed companies. There were a couple of 
highly personal questions in the PatVal II study, like the motivations of the inventor to invent, and the remuneration of the inventor. I have decided to replace these with questions that are important in verifying my hypotheses. These mainly included questions about the environmental effect of the innovations, innovation activity in the absence of the patent system, patent premium, effective patent protection time and possible reforms.

Before the survey was undertaken, in order to ensure that the questionnaire is fully understandable and would reveal meaningful and relevant information, the following experts helped to refine the questionnaire of the interviews:

- dr. László Antos, Chief Secretary of the Hungarian Association for Innovation

- dr. Gábor Németh, Director of the Hungarian Intellectual Property Office

- Dorottya Simon, Hungarian Intellectual Property Office

The questionnaire consists of six main parts: after questions concerning the general features of the patents and of the companies comes the main sections about the process of invention, the value and utilization of the patent, and finally characteristics of the patents and a few questions about the inventors (the questionnaire can be found in Annex 6).

The questionnaire was administered through personal and telephone interviews by students of the Corvinus University of Budapest. Telephone interviews were used mainly in case of companies not based in Budapest. The reason for this is that the personal kind of the interview can be preserved, but there are no further costs (time and money) required to visit single companies in single relatively remote locations. The use of face-to-face and telephone interviewers provided considerable advantages since a large number of companies was surveyed without compromising on the benefits of personal contact. This way it was possible to include several open-ended questions, acquire several valuable personal opinions and benefit from a relatively high response rate. Efforts were made to ensure the high quality of interviewing and the identical interpretation of the questions through a thorough coaching of interviewers. The survey was conducted between April and June 2014. 
The interviewers tried to contact all 80 companies with 104 possibly relevant innovations. From these innovations 14 were not patented or were not considered as Hungarian innovations hence 73 companies with 90 relevant innovations emerged as final population. This means an average 1.23 innovations with patent application per company in the population. Actually there are a handful of highly innovative companies with several innovations, like big pharmaceutical companies, and the majority of the companies having one innovation with patent applications entered for the grand prize.

It is important to note, that the population is not representative of the innovative performance of Hungarian economy, but is representative of the Hungarian patenting activity with limitations. The population overrepresents industries with greater patent propensity, such as pharmaceuticals, chemistry, manufacturing of medical devices and instruments, etc. The population underrepresents industries with lower patent propensity, such as information technology, food processing, public utilities, etc.

Figure 30.: Industrial breakdown of the population (patented innovations applied for the HIGP 2002-2013)

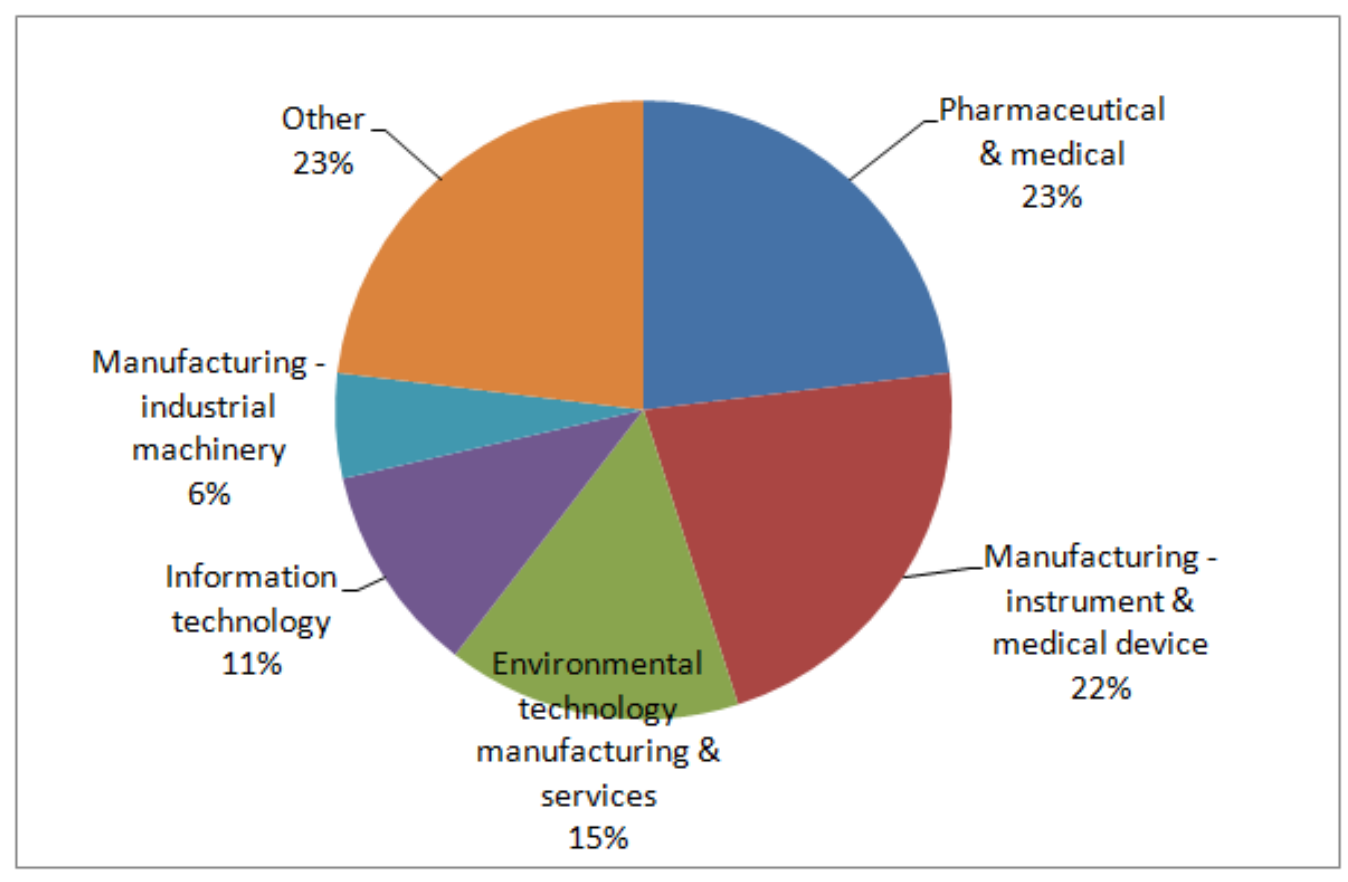

In the industrial breakdown, I have created an industrial category for illustration purposes, namely environmental technology manufacturing \& 
services. Companies in this category are environmental service providers and environmental machinery or instrument manufacturers. Regarding the other industries I do not use the standard industrial classification of the relevant sectors, rather tried to express the types of companies dominant in the specific sub-groups. Comparing the industrial breakdown of the population to Table 7. about the Hungarian corporate R\&D, several observations can be made. The ratio of the pharmaceutical companies in national level $R \& D$ is higher than their ratio of the innovations due to high $\mathrm{R} \& \mathrm{D}$ costs related to the development of pharmaceutical products. The other substantial difference is in the manufacturing of vehicles. While the $R \& D$ expenditure in this sector accounts for a large proportion of the whole, there are no such innovations in the population. The major factor behind this can be that these firms are subsidiaries of multinational companies and the patents are applied for in their home countries by the parent company, with foreign inventors leading the research.

From the 420 innovations applied, 90 (21\%) had underlying patent protection or application. This ratio can not be regarded as patent propensity, because the majority of the innovations were not patentable. Reasons for this were usually the lack of novelty and that sometimes they were not patentable technological innovations like most information technology innovations. Apart from the non-patentable innovations, we see a high patent propensity.

In line with the literature, it seems that more valuable innovations are protected by patents in a higher ratio. Prize winner innovations are far more likely to be patented, as it can be seen on the following figure, although this can partly be attributed to the high patent propensity of the highest value pharmaceutical innovations. 
Figure 31.: Ratio of Hungarian Innovation Grand Prize award categories between 2002-2013: patented innovations and all innovations

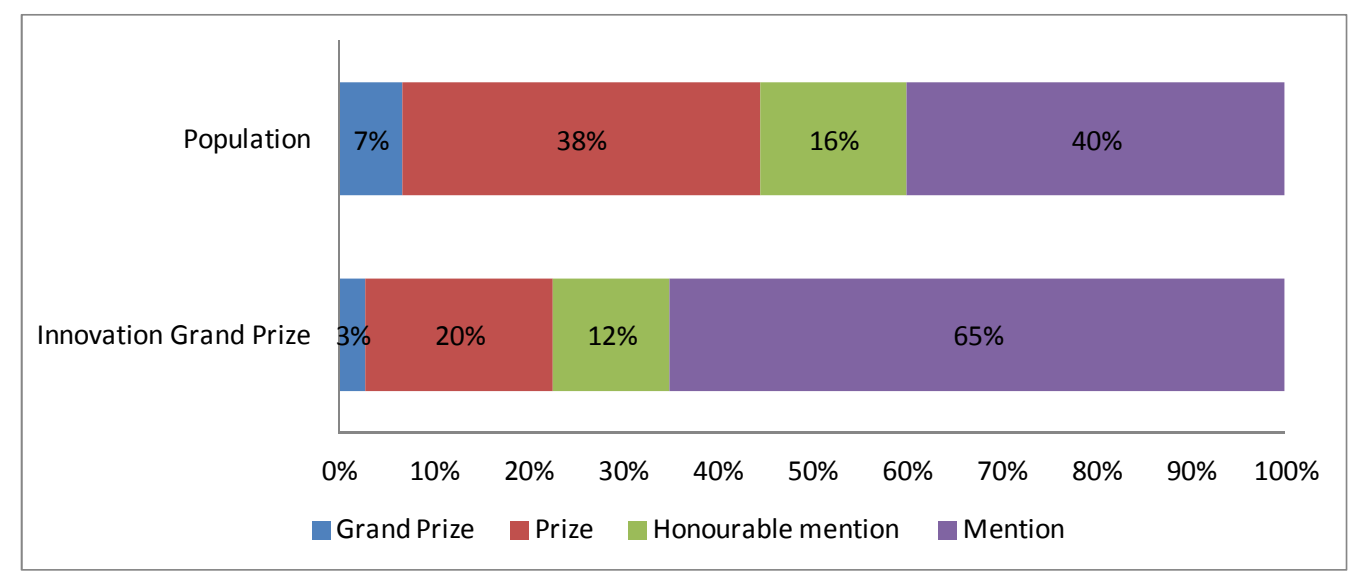

The geographical breakdown of the population shows that $59 \%$ of the innovations with patent applications are from companies based in Budapest, which is somewhat higher than the $47 \%$ of their ratio in case of all innovations. This shows the Budapest centeredness of the innovation activity.

\subsection{Basic characteristics of the sample}

From the 90 innovations with patent applications, 39 interviews could be made, which means a response rate of $43 \%$. The sectorial breakdown of the population and of the sample is shown in the figure below. The sectorial distribution of the sample is similar to the population. Sectors such as Manufacturing - instrument \& medical device, manufacturing - industrial machinery are somewhat overrepresented, pharmaceutical \& medical and environmental technology manufacturing \& services are underrepresented. This fact has to be taken into account during the interpretations of the results. 
Figure 32.: Industrial breakdown of the population and the sample

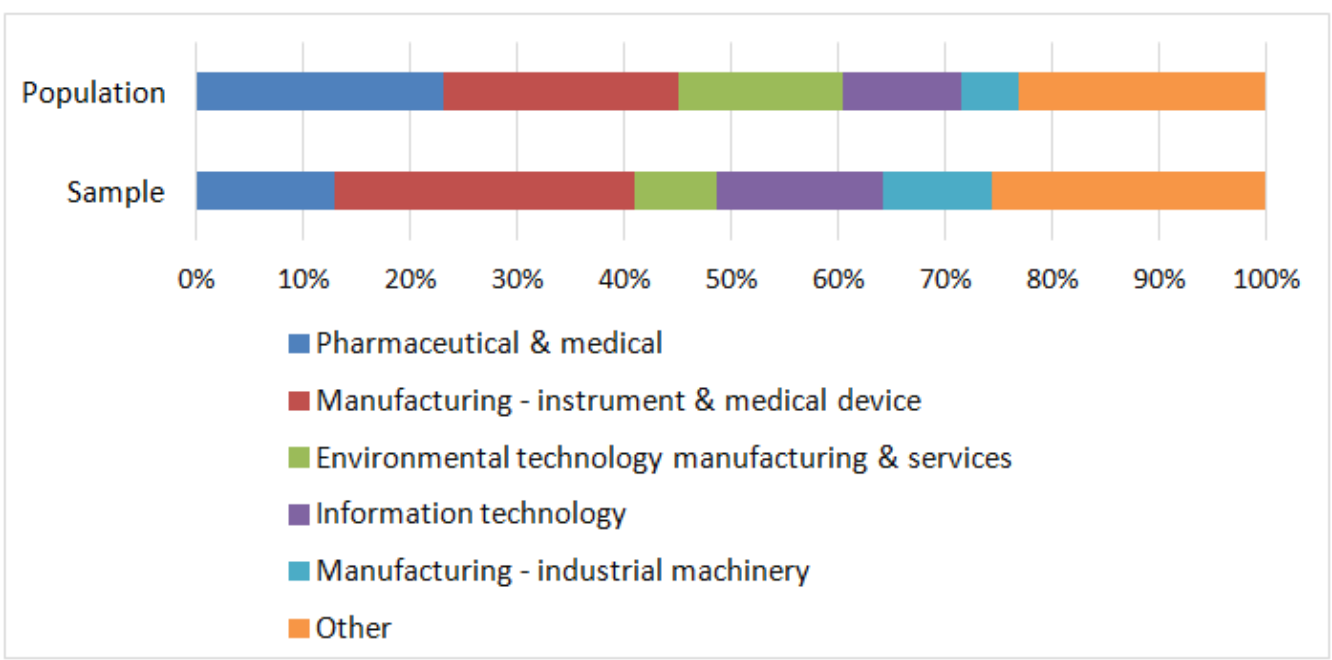

In the sample most of the innovations are related to companies, although there are one belonging to a private individual and one to a university.

Figure 33.: Ratio of award categories within the population and the sample

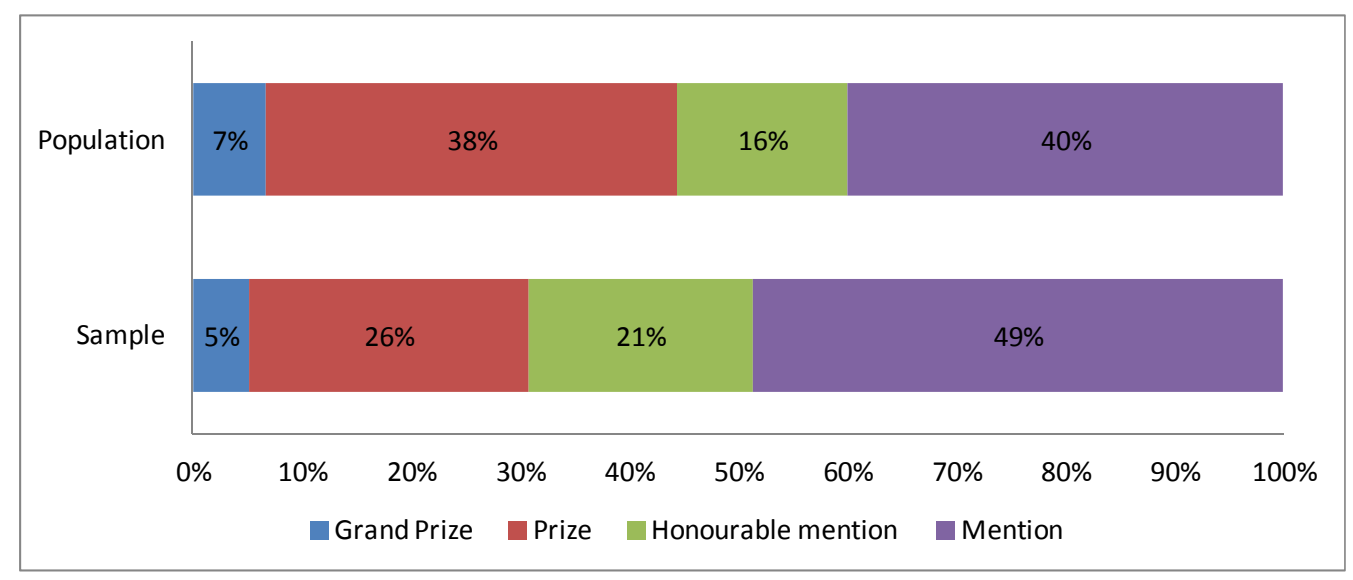

The distribution of the sample is somewhat different from the population, more valuable innovations are underrepresented, and less valuable innovations are overrepresented.

Concerning the identity of the respondents, it was an important aim to survey people who were adequately familiar with the invention. As it can be seen in the figure below, in $43 \%$ of the cases the interview was made with the inventor, in further $44 \%$ of the cases it was made with the CEO or with the head of production or engineering. Other respondents included people working for the company in various positions with relevant knowledge (patent 
attorney, $\mathrm{R} \& \mathrm{D}$ employee, $\mathrm{CEO}$ assistant responsible for patents, manager from non-production and non-R\&D division).

Figure 34.: Position of respondents within the company \& relation to the patent

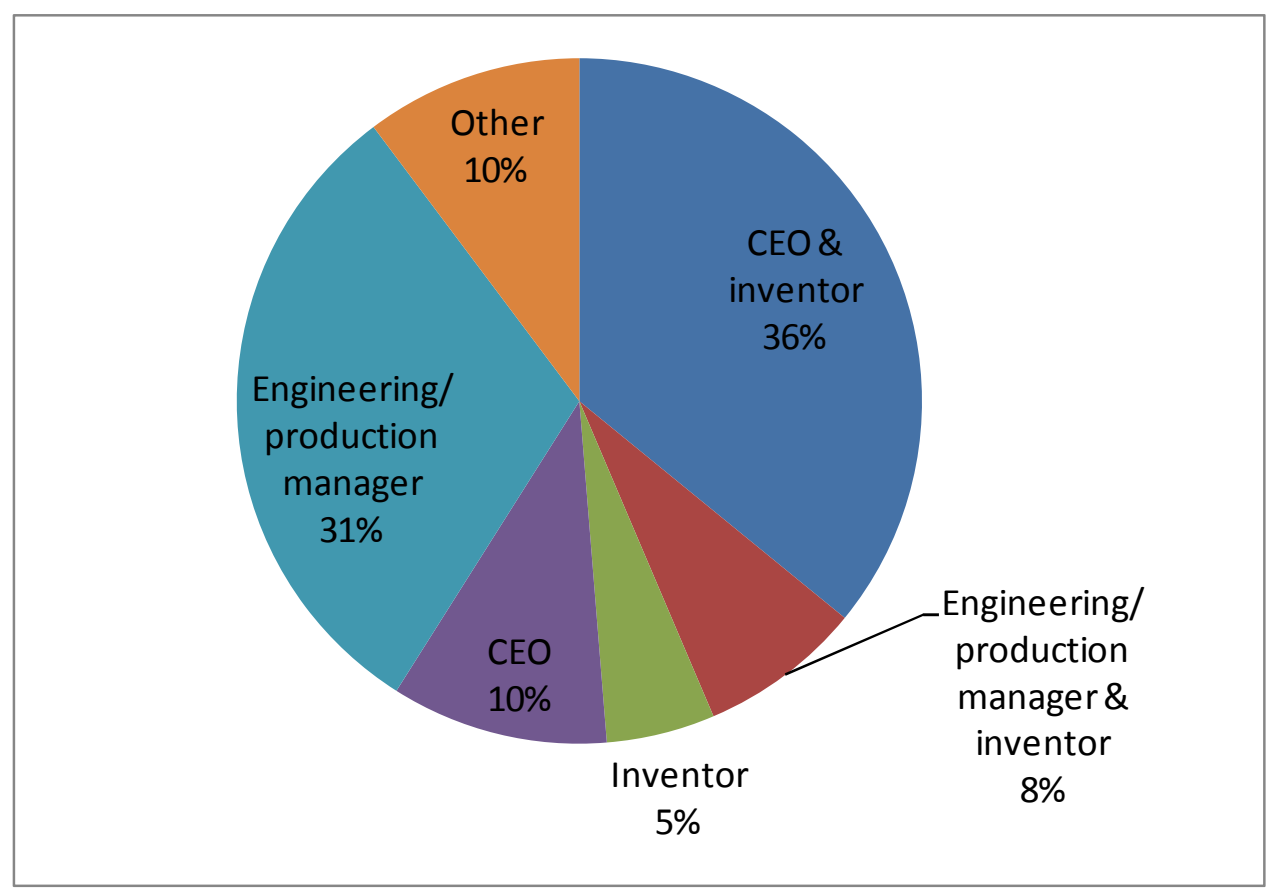

Figure 35.: Size distribution of the companies in the sample by employee number in the year of the innovation

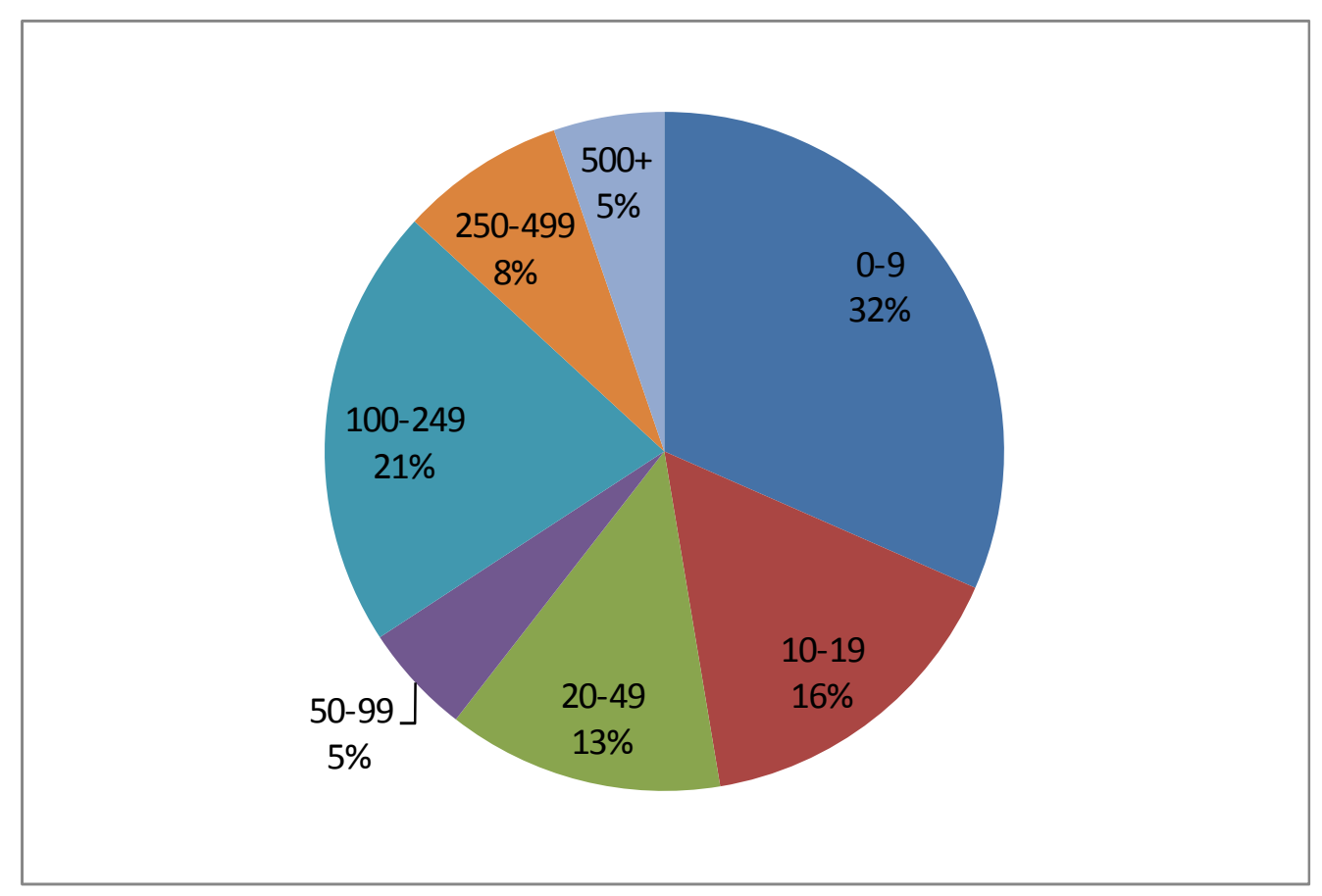


Size distribution categories were created according to the PatVal II study to enable better comparison. The size distribution shows that about $33 \%$ of the innovations were created by companies with less than 10 employees. More than half of the innovations from companies of this size were from spin-off firms. There are relatively few companies with 500+ employees.

Figure 36.: Size distribution of the companies in the sample by sales volume (Million HUF) in the year of applying for the HIGP

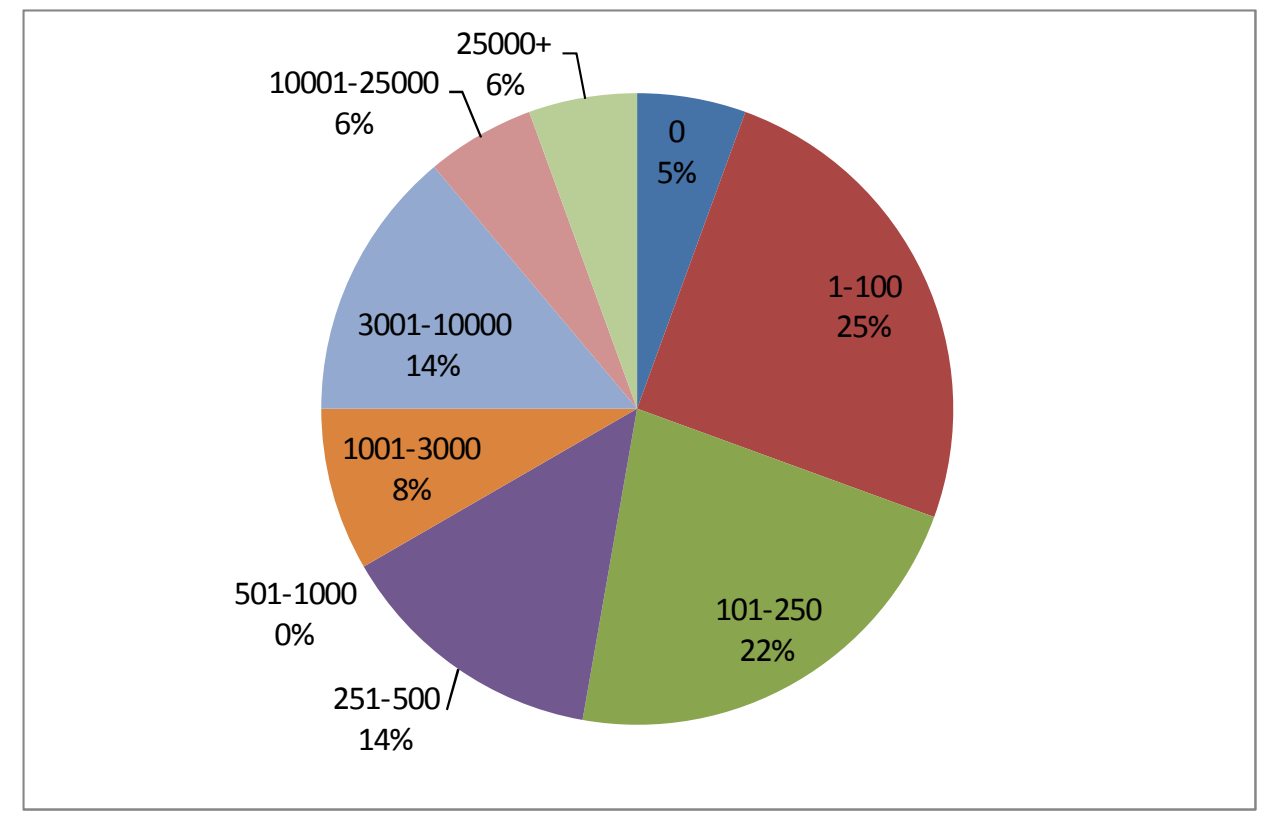

The size distribution by sales volume shows a similar picture, with about half of the companies with surveyed innovations realising a revenue less than HUF 250 Million. Comparing this to the distribution of all Hungarian companies we can see that the size distribution of these companies significantly overrepresents bigger companies. In comparison with the companies with patents from the PatVal II survey the opposite is true. In the PatVal II EU survey, the most significant category is taken by companies with more than 5000 employees (37\% of companies). Companies above 500 employees account for $61 \%$ of the patented innovations studied. Even in the Hungarian part of the PatVal II survey, the average size of the companies is significantly bigger as shown in the figure below. 
Figure 37.: Ratio of firm size categories of the PatVal II Hun database and of the sample based on employee number

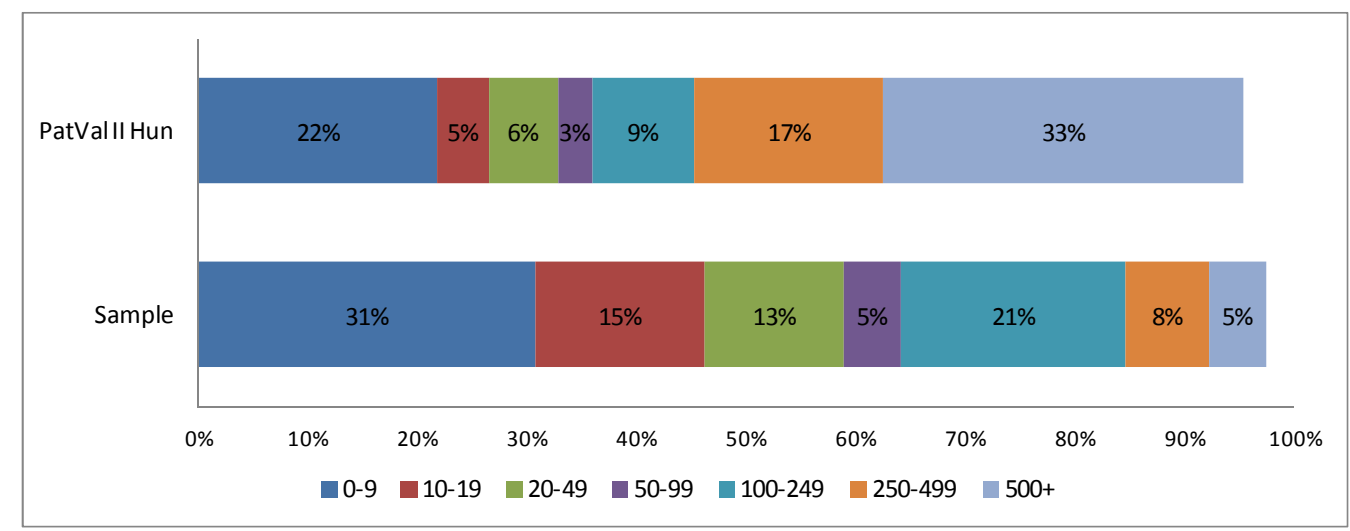

This makes the comparison with the PatVal II survey significantly less reliable. This greatly affects future comparisons about phenomena heavily correlated with firm size, such as firm competencies, motivations, knowledge generation sources, etc.

Only $62 \%$ of the cases the applicant of the patent is a company or the parent institution of a spin-off company ${ }^{21}$. In $38 \%$ of the cases the applicant is a private individual, mainly the inventor. This can be very important when classifying Hungarian patents into institutional or individual categories and can explain the very high ratio (70-80\%) of the individual applicants in Hungary. Reasons for this can be the relatively low costs of applying for a patent in Hungary affordable even by private individuals, less risk associated with the potential bankruptcy of the applicant company, and even tax considerations.

In line with previous expectations most patents (74\%) are first applied at the HIPO. Others are mostly applied for the EPO or the German Patent and Trademark Office first.

\footnotetext{
${ }^{21}$ I did not count the two cases, one where directly the inventor has applied for the Grand Prize and the other where the company is an unlimited partnership which is closely related to the inventor.
} 


\subsection{Impact of patent protection on innovations}

$64 \%$ of the studied innovations regarded as environmental innovations, which is a relatively high proportion. Taking into account that companies from the environmental technology \& services represent only $8 \%$ of the studied innovations, this shows that it is extremely important to focus on environmental innovations in other sectors too.

Figure 38.: Distribution of the types of studied environmental innovations

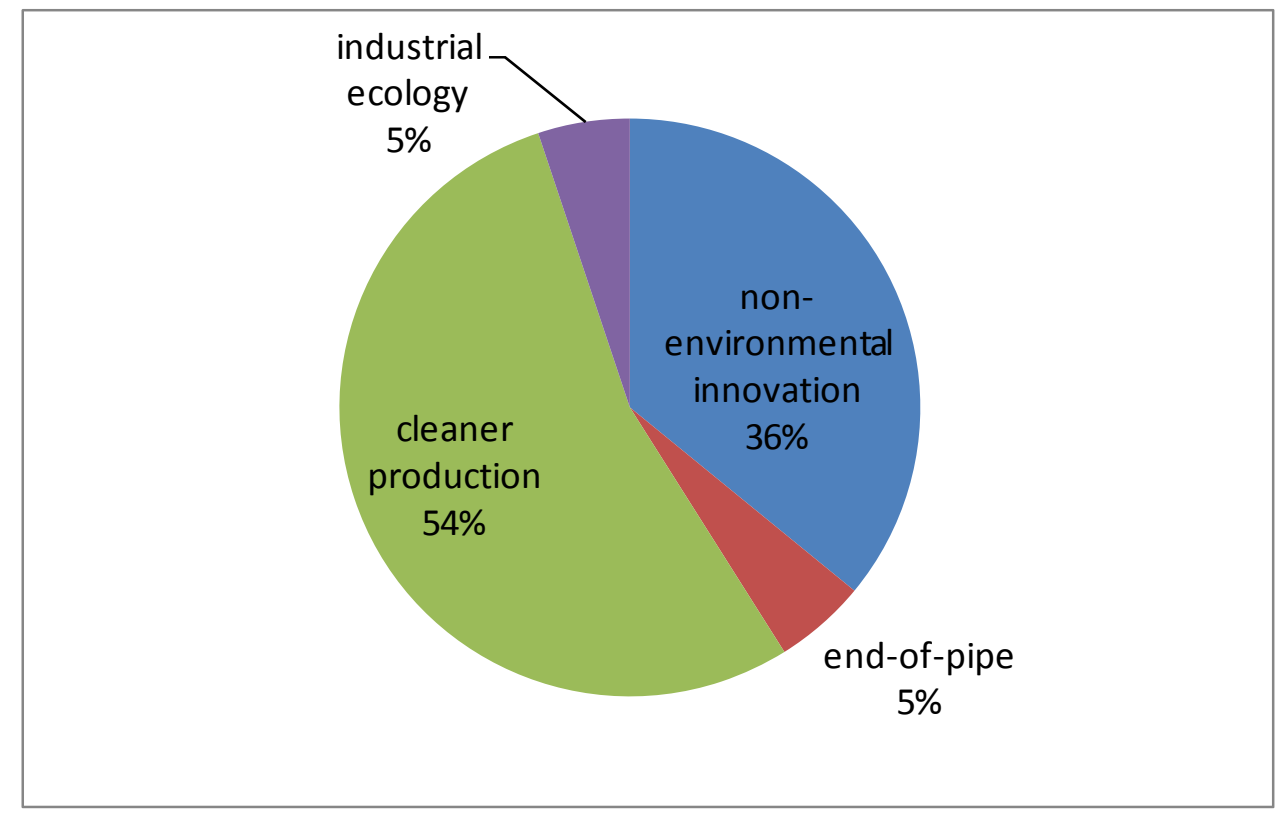

The above figure shows that the majority of the innovations are cleaner production types. There are some innovations which can be considered industrial ecologic type. The aim of these radical innovations is to change the status-quo. The innovations originating from the environmental sector can be classified in the cleaner production and end-of-pipe technologies categories.

According to Sommer et al. (2010) patents may help the invention of environmental innovations, but may hinder their diffusion.

To study this effect there was a question included in the questionnaire about whether the patenting of the innovation helps the diffusion of it. Main reasons for patents not helping diffusion can be classified into two clusters. Respondents from the first cluster focus on the uniqueness of the innovation. 
Answers include "the innovation serves special purposes" and is not useful for other companies and "we only have one customer" and similar. Respondents from the second cluster focus on the scarcity of experts who would benefit from the patent disclosure. Answers include "patenting has no effect on diffusion", "we use it in the production and customers do not care", "there are only about 10 experts in this field who ever notice this patent". Reasons for the patents supporting diffusion were that "patenting gives reputation", "trust" and "is good for marketing purposes". Two respondents claimed that patenting was useful because "imitators had a slightly easier task" and "technology was used in other, non competing fields". Despite the correctly worded question, a number of companies interpreted the question in a way, that whether patenting was useful for their revenue generation or not. Of course this is an obvious point of view of the companies and perhaps they do not even have information about the other companies in foreign countries that may use or profit from their patent. This latter may be an important factor, as in the case of two-thirds of the innovations, the strongest competitors were foreign companies.

\subsubsection{Innovation in the absence of the patent system}

Only $18 \%$ of the respondents stated that they would not have realised the innovation in the absence of the patent system. Most of these companies originate from the pharmaceutical sector, where $60 \%$ of the respondents regarded patent protection necessary. Apart from pharmaceutical companies, only $11 \%$ of the respondents would not have created their innovations in the absence of the patent system. These are in line with the results of other international studies. Most of the respondents were fairly confident about the fact that they would have realized the innovation in the absence of the patent system. One respondent claimed that they would have invented the innovation anyway, but they may have decided to market another innovation then. It shows that patenting is sometimes able to direct R\&D activity, as described by Cohen et al. (2000).

The Chi-Square test of association was used to investigate whether distributions of categorical variables differ from one another. The drawback of 
this method is that the number and the limit of categories influence the results, so if it is applicable, it is worth to make the analysis with multiple versions. As a general rule, the expected frequency count for each cell of the table should be at least 5. In my sample this rule was not satisfied as two cells of the expected frequency count were below 5 (2.6 and 4.4), due the few number of the innovations that depended on the existence of the patent system. This means that the results of the Chi-Square test are not reliable. In this case Fisher's Exact Test should be used. The two-sided test shows a connection on a 61\% significance level. According to Raymond and Rousset (1995) in case of this test the hypothesis can be accepted when the significance is over $50 \%$. So there is connection between the two variables. This fact along with the bar chart shows that environmental innovations are more likely to be realized in the absence of patent protection than non-environmental innovations, which is the opposite of H1. hypothesis. Reason for this can be that industry effects influence the results. Innovations from the pharmaceutical sector depend more on the existence of the patent protection and are environmental innovations in a lower proportion than the rest of innovations in the sample. Hence in the next analysis innovations from the pharmaceutical sector were filtered out. In this case the Fisher's Exact Test using two-sided test shows a total independency of the two variables. This means that the realisation of environmental innovations depends exactly in the same ratio on the existence of the patent protection as non-environmental innovations, not taking the pharmaceutical sector into account. Detailed results of this analysis can be found in Annex 7.

Most of the environmental innovations in the sample are realized by companies from other than the environmental sector. Most of the environmental innovations are cleaner production type, and typically aim for the reduction of material and energy consumption and for the reduction of waste. It seems that the effect of patent protection on cleaner production type environmental innovations is similar to non-environmental innovations. 


\subsubsection{Motives to patent}

There are several advantages of patent protection for companies. According to empirical studies the major motives to patent are the protection from imitation followed by blocking and enhancing reputation. In my study respondents had to rank their motivations to patent on a 1-5 scale, 1 meaning not significant, and 5 meaning very significant. Based on the literature they had to rank the following potential motivations:

- Commercial exploitation (obtain exclusive rights to exploit the invention economically)

- Prevention from imitation (protect present or future inventions by patenting the "findings around")

- Pure defense (ensuring that the use of the own technology is not hindered by third parties)

- Reputation (the patent is one measure for assessing the performance of the researcher/R\&D division)

- Prevention of infringement suits (support of a credible threat, that the organisation can file a suit if it is sued by third parties)

- Blocking patents (avoid that others patent similar inventions)

- Licensing (obtain exclusive rights to license the invention in order to generate licensing revenues)

- Technical standard (Protection of an invention which can be useful as a part of a technical standard)

- Cross-licensing (improve your bargaining position in the trading of your own patent rights in exchange for other firms' patent rights)

The results can be seen on the following chart. 
Figure 39.: Importance of patenting motivations on a 1-5 scale

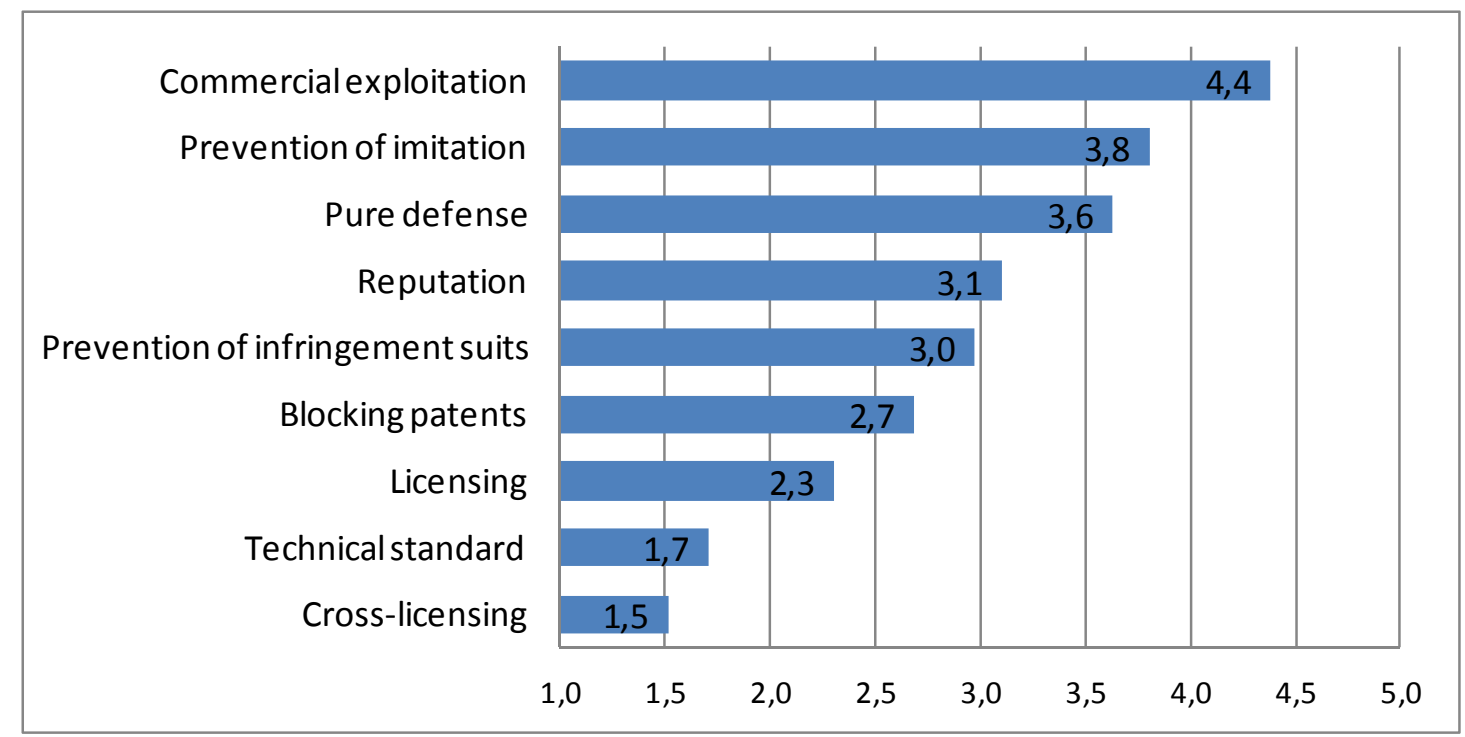

The traditional defensive motivations are the strongest in the sample companies, followed by reputation, blocking and licensing. PatVal II reports less than $30 \%$ of unused patents in case of SMEs and over $50 \%$ of unused patents in case of the biggest (>5000 employee) companies. According to them, these are partly unused on purpose, they serve strategic motives such as blocking or increasing reputation. Frietsch et al. (2010) also concludes that among the European patents not used, there is a substantially higher ratio of those referring to blocking or cross-license agreement due to strategic reasons than in the case of utilized patents.

According to Mazzoleni and Nelson (1998) the patent system can significantly help new actors entering the market and smaller firms as well as institutions operating in a non-corporate framework (e.g. universities). Possessing a patent these actors are able to co-operate with others or license the innovation more easily, under better conditions, thus the innovation will more probably be utilized. This means that licensing is a possibility for mainly smaller companies who are not able or not willing to market their innovations alone. As $95 \%$ of the innovations in the sample are already utilized, based on the above, the blocking, licensing and reputation motivations are expected to be lower than in international surveys studying patenting activity including non-utilized patents, including PatVal II. As strategic motivations are more 
typical of bigger firms, this can cause a further difference when comparing the results with PatVal II. The motivations to patent in PatVal II, PatVal II Hun and in the sample can be seen hereunder.

Figure 40.: Differences in motivations to patent in PatVal II Hun, PatVal II and the sample

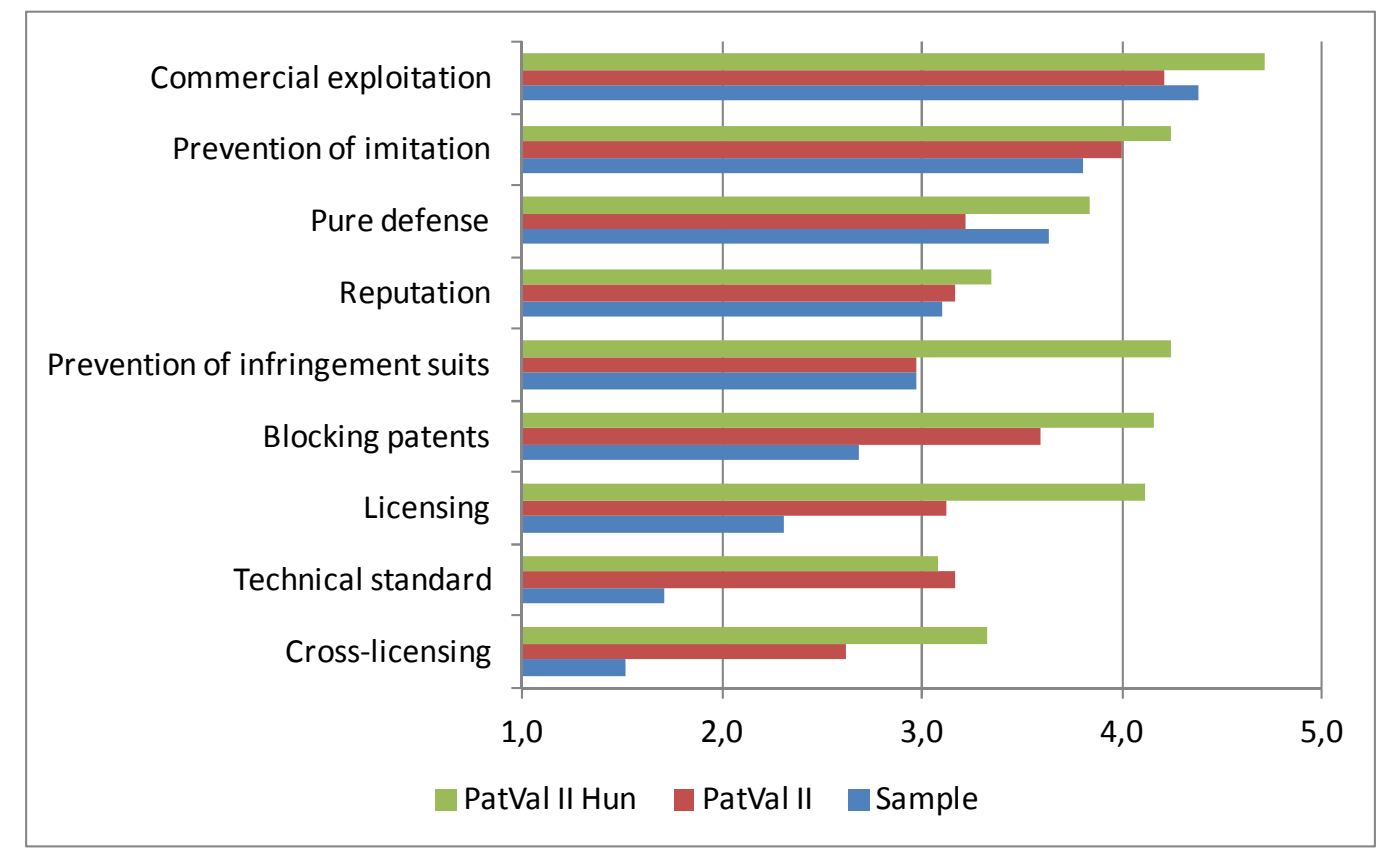

The main difference between the sample and PatVal II is the projected deviation in the significance of blocking patents. There are significant differences in the licensing and technical standard motivations too. As opposed to the expectations there is little difference between the reputation motivations. The rank correlation between PatVal II and the sample is 54\%. This means that knowing the rank of motivations in one study decreases the uncertainty regarding the rank of motivations in the other study. This shows that there is a medium strength connection between the variables. The mean of the motivations in PatVal II (3.3) is somewhat higher than in the sample (2.9).

There are significant differences between PatVal II Hun and the sample. The mean of the motivations in PatVal II Hun is 3.9, which is very high. The two most important motivations, namely commercial exploitation and prevention of imitation are the same. However values received for the prevention of infringement suits, blocking and licensing motivations are significantly higher. 
The rank correlation between the variables is $51 \%$. The rank correlation of PatVal II and PatVal II Hun is 54\%.

In the absence of the more detailed data from the PatVal II study, the difference in the motives of blocking patents can not be further analysed. I assume that they can be mainly attributed to the different sample selection. Furthermore other factors can lay behind the large discrepancy regarding licensing motivations. It is interesting that given the strong motivations for licensing, from the PatVal II EU only about $8 \%$ of the patents were licensed and a further approximately $7 \%$ were planned to be licensed (filtering out those who could not answer the question). This is much higher in the case of PatVal II Hun, 17\% and 14\% respectively. Within the studied innovations it is $11 \%$ and $5 \%$ which is relatively close to the European results. This might mean that Hungarian innovators in my sample are less conscious or motivated about the licensing of their patents, but are not lagging behind in this regard.

There is only a slight difference between environmental and nonenvironmental innovations as it can be seen on the following figure. The rank correlation of these types of innovations is very high, more than $99 \%$.

Figure 41.: Motivations to patent in case of environmental and non environmental innovations

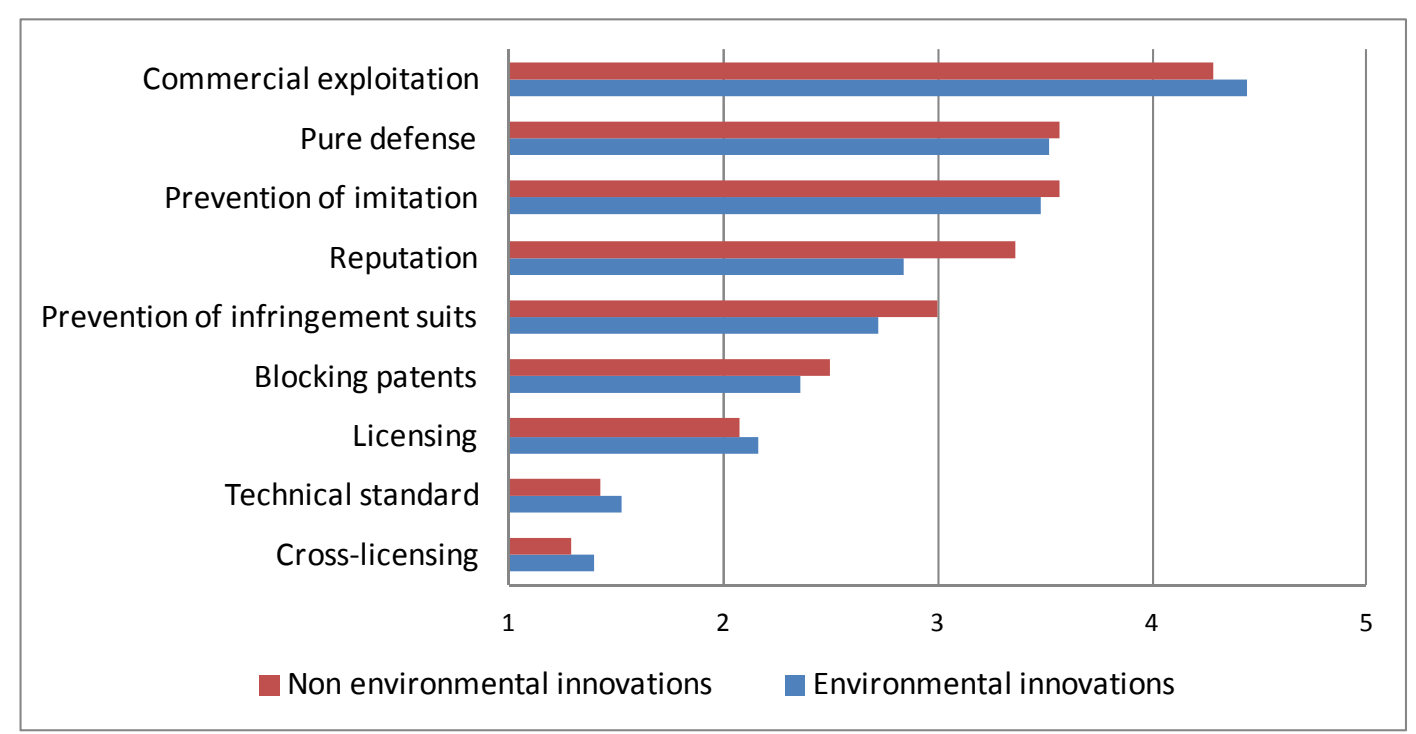




\subsubsection{Patent value}

The distribution of the value of the patents in the sample can be seen on the following figure.

Figure 42.: Distribution of the value of patents in the sample (values in EUR)

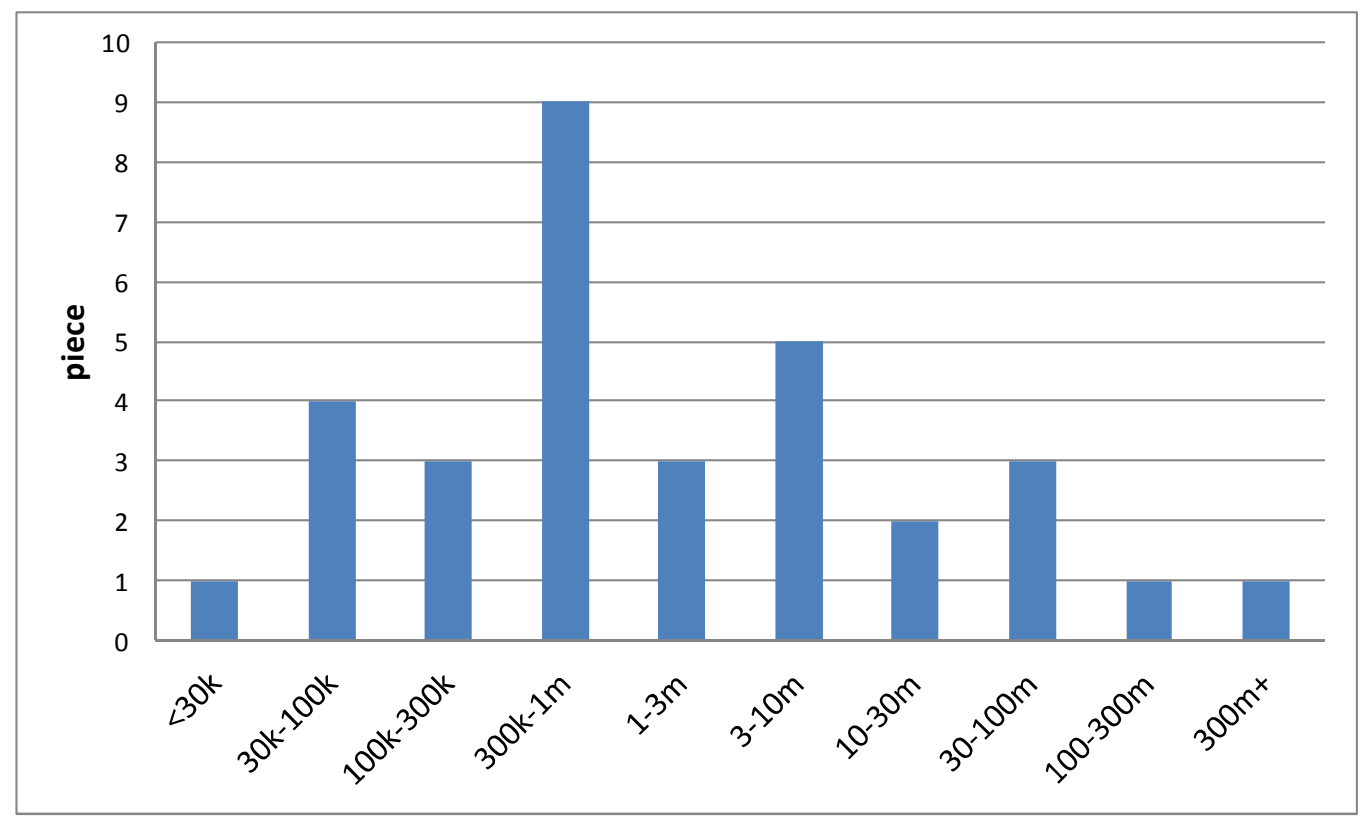

According to the international comparison it is clear that innovations applied for the grand prize are really more valuable than the ones in PatVal II. The median value of the patents in the sample is about EUR 1 Million, while the mode is EUR 0.65 Million. In the case of European patents the median is EUR 0.44 Million, the mode is the same of EUR 0.65 Million. According to this, the median value of the innovations applied for the grand prize worth more than twice the European patents.

According to Gambardella (2008) the value distribution of patents is strongly skewed, the most valuable decile contains $70-90 \%$ of the value of all patents. In research and for the economy it is very important to assess the value of patents or to sort out the most important patents. Because of the large variance of the value of the innovations and as a result of the high number of patents there is no simple way to do this. Based on the literature there are several methods presented in the previous chapters including the assessment of the value growth of a firm on the stock market, assessment based on patent 
counts, R\&D based measures, patent citation measures, calculations based on the renewal rate, survey of innovators, innovation prizes, etc. These are all imperfect measures of the patent value, and sometimes there is such a great uncertainty regarding the value of the patent that a specific value can not even be determined. Perhaps the most accurate method is the survey of innovators, but this method requires relatively high expenditures. Other methods are relatively cheap but are not as accurate as $R \& D$ based measures or can assess the value with a great timelag (for example renewal rate based calculations). There are several examples of studies assessing the value of the patent based on innovation prizes. Only few of these studies assess explicitly how well the prize based measure estimates the value of patents. This is the reason why it is interesting to see how the Grand Prize rank predicts the reported value of the patent.

The Grand Prize rank variable has a relatively small range with 4 possible outcomes (grand prize winner, prize winner, honourable mention and mention). This variable is an ordinary scale variable, while the value of the patent is a nominal variable $\mathrm{e}^{22}$. The connection between these variables can be measured by correlation. Pearson's correlation is 0.45 on a $99 \%$ significance level, while Spearman's and Kendall's correlations are not significant. There were patents with value of above 300 Million EUR. In these cases I have assumed a value of 650 Million EUR. To test the robustness of the result I repeated the correlation tests with a value of 350 Million EUR for the most valuable patents. In this case Pearson's correlation increases slightly to 0.47 , on a $99 \%$ significance level. The other two types of correlations are still not significant. Detailed results of these analyses can be found in Annex 8.

Thus the analyses show that there is significant connection between the grand prize rank and the reported value of the patent, but the rank in the Grand Prize explains only about $20-22 \%$ of the variation of the patent value. This is a fairly weak fit, which reflects the obvious disadvantages of using Grand Prize rank as an indicator of patent value. These can be the following:

22 Originally the patent value is also an ordinary variable, but it can be transformed into a nominal variable by calculating with the average value of the categories. 
- Only one patent can be the winner even if there are several patents of the same value.

- Couple of prizes are given in different categories (for example best industrial innovation, best agricultural innovation, best environmental innovation, etc.) which can overrate a possibly less valuable innovation of that specific category. However not every prices are awarded in every year and one innovation can get more awards.

- The economic advantages of the innovations are a major factor during the assessment, so innovations in their early phase may get rated lower.

- Respondents reported patent value in 2014 (with up-to-date knowledge about the value), while the jury assessed them from 2002-2014. As one respondent from a company with prize winner innovation noted that their innovation had a high potential value, but later on a competitor filed a patent which was superior to it without infringement, leaving the original patent almost worthless.

Further studies should take into account that the disadvantages of the innovation prizes should not be used solely as a proxy for patent value without testing. However it can be useful in assessing the value of the most important patents which can complement one of the greatest disadvantages of valuations based on renewal fees.

Eta test is appropriate for testing the connection between a nominal and a categorical scale variable, with the categorical variable as the independent variable. When studying the connection between environmental innovations and patent value the Eta test can be used, with environmental innovations as independent variable. This shows a connection on a 93\% significance level, the value of Eta is 0.324 , which means that $10 \%$ of the variance is explained. Assuming again 350 Million EUR for the most valuable patents, I find a stronger connection, explaining $14 \%$ of the variance on a $96 \%$ significance level. In both cases environmental innovations prove to be less valuable. One reason for this may be the fact that patents in the instrument and medical 
device manufacturing industry, as well as information technology are relatively more valuable and are relatively less likely to be environmental innovations. Thus the value difference between environmental and non-environmental innovations can be contributed to industry effects. Detailed results of these analyses can be found in Annex 9.

I analysed how firm size predicts the reported value of the patent. Given the two nominal scale variables with a log-normal distribution and a clear direction between them (firm size influences patent value) it is possible to apply a regression model using the logarithm of the two variables. The size of the company can be measured by yearly sales or employee number. Spin off companies should also be filtered out, because they may bias the analysis with non observable variables like the sales and employee number of the parent company or university which can have an effect on patent value.

One of the best fitting regressions was linear regression between the variables of the logarithm of the patent value and the logarithm of the sales after eliminating spin-off companies from the analysis. Still, the regression is only significant on a $93 \%$ level, and there is only a weak explanatory power of $14 \%$. The other regression worth mentioning is the logistic regression between the variables of the logarithm of the patent value and the logarithm of the employee number of companies. In this case the regression is significant at a $94 \%$ level, but the explanatory power is only $13 \%$. The scatterplot of the two variables supports the results, there seems to be a slight positive trend between the variables but the dot's distribution is rather random. The weak explanatory power points to the fact that in line with the literature there are several other factors which can have an effect on the value of patents. Gambardella et al. (2011) for example shows that R\&D costs, the experience and the education of the inventor are all important determinants of patent value. Detailed results of these analyses can be found in Annex 10.

In order to better understand the factors behind the value of a patent multivariate regression can be used. While several studies with more observations use this method to identify significant factors, the methodology and sample size of this current research prohibit the use of such analysis. 


\subsubsection{Patent premium}

Regarding the patent premium there were two questions in the survey. The first question inquired about the share of the patent value, which can be attributed to the legal protection of the innovation. Results can be seen on the figure below.

Figure 43.: The share of the legal protection within the patent value (\%)

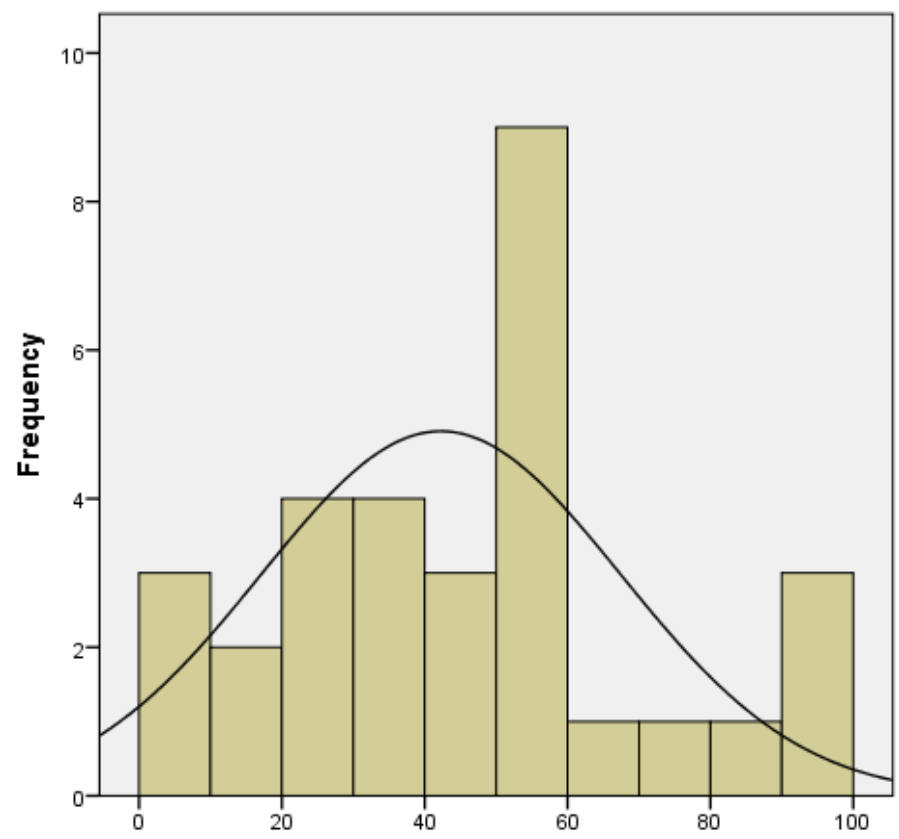

The mean of the variable is $42 \%$, the median is $45 \%$ while the mode is $50 \%$. Standard deviation is $25 \%$, the minimum value is $5 \%$ and the maximum value is $95 \%$.

The second question asked how much the value of the patent would have changed in the absence of patent protection, but in the presence of other methods like trade secret, lead time advantage, complementary capacities, etc. This variable can be interpreted as patent premium as per the definition widely used in the literature. 
Figure 44.: Decrease in the value of the innovation in the absence of patent protection but in the presence of other methods (\%)

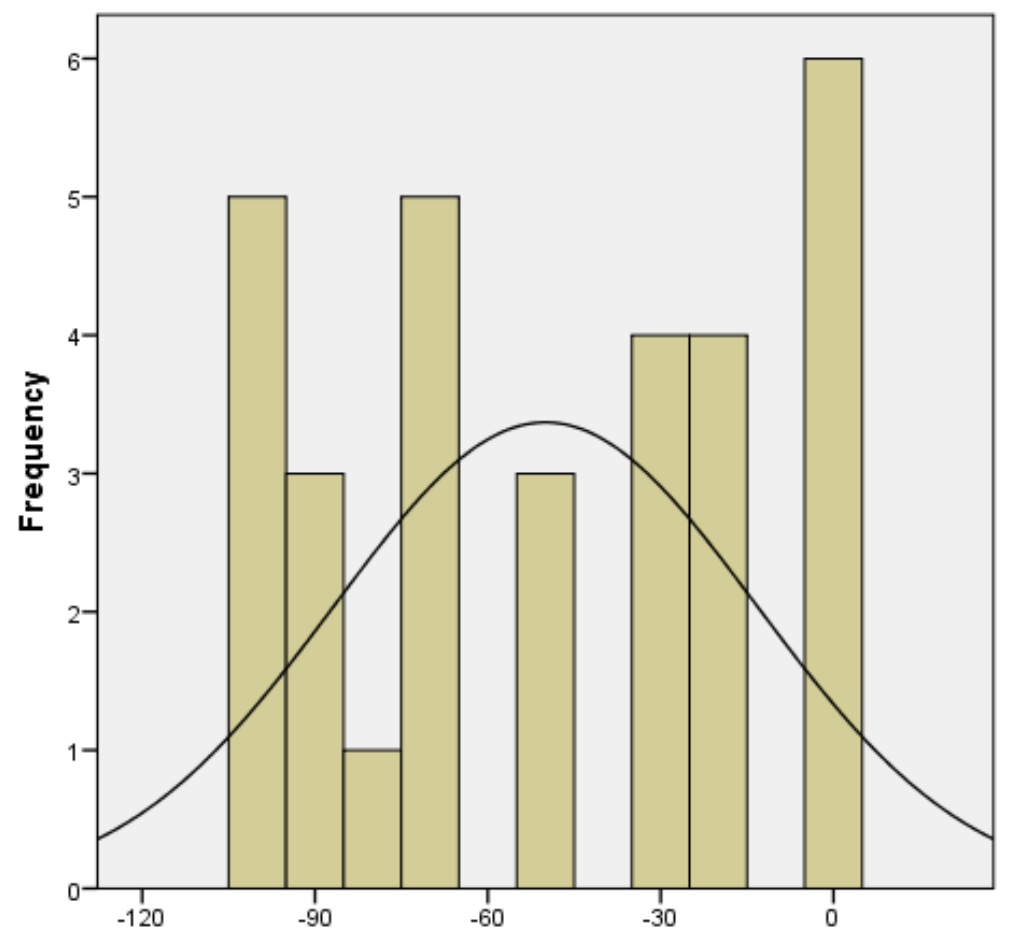

Answers for this question show a much different and more realistic picture. The mean of the variable is $-50 \%$, the median is $-50 \%$ while the mode is $0 \%$. Standard deviation is $37 \%$, the minimum value is $-100 \%$ and the maximum value is $0 \%$. $6(19 \%)$ companies reported that they could have fully replaced patents with alternative protection methods. 5 (16\%) companies reported that their innovations are worthless in the absence of patent protection. There are two distinctly separate groups of companies, one group (with $45 \%$ of the innovations) considers the patent protection as less significant $(>-31 \%)$, the other group (with $45 \%$ of the innovations) considers patent protection as very significant $(<-69 \%)$. According to the literature, industry and the unique characteristics of the innovation determine to which group the innovators belong. This bipolar view of the innovators can give a reason why there is such a great variance between the results of different studies in the literature. In the current sample the ratio of the two groups of innovators is balanced, both the mean and median values are $50 \%$. The standard error of the mean is $6.6 \%$ so the mean is significantly different from $0 \%$. This finding is in line with the literature, with both Arora et al. (2008) and Jensen et al. (2009) arriving to patent premiums of 40 to $60 \%$. 


\subsubsection{Effective protection time (industry specialties)}

Regarding protection time there were two questions: one about the normal lifetime of the innovation (the time until the company could theoretically be able to profit from the innovation before it gets outdated), the other about the effective lifetime of the innovation (the time until the company was or will be able to profit from the innovation in reality). The distribution of the normal and effective lifetime can be seen on the figure below.

Figure 45.: Distribution of effective lifetime of innovations after eliminating two companies with values of 60 year and 100 year

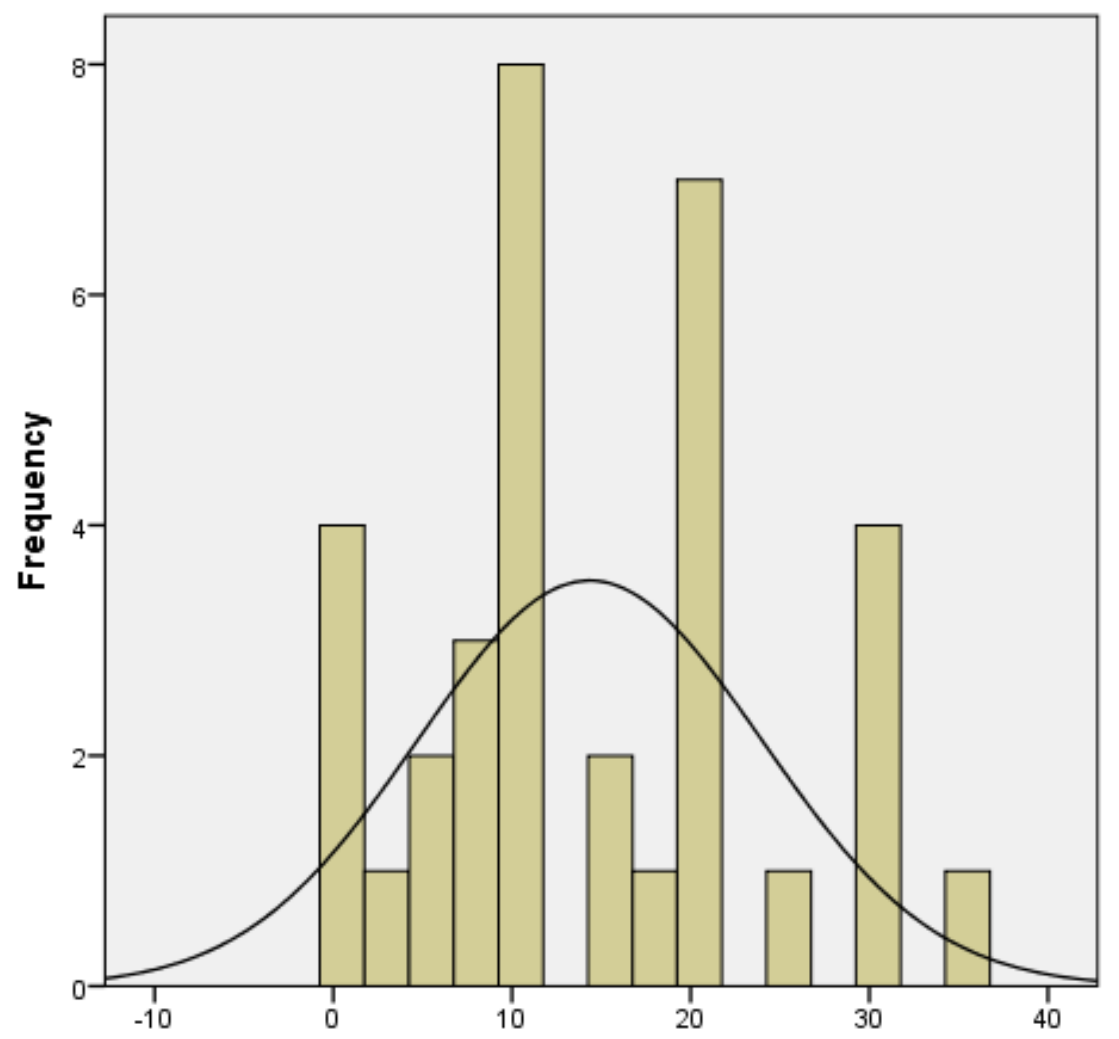


Figure 46.: Distribution of the effective lifetime of innovations (values in years)

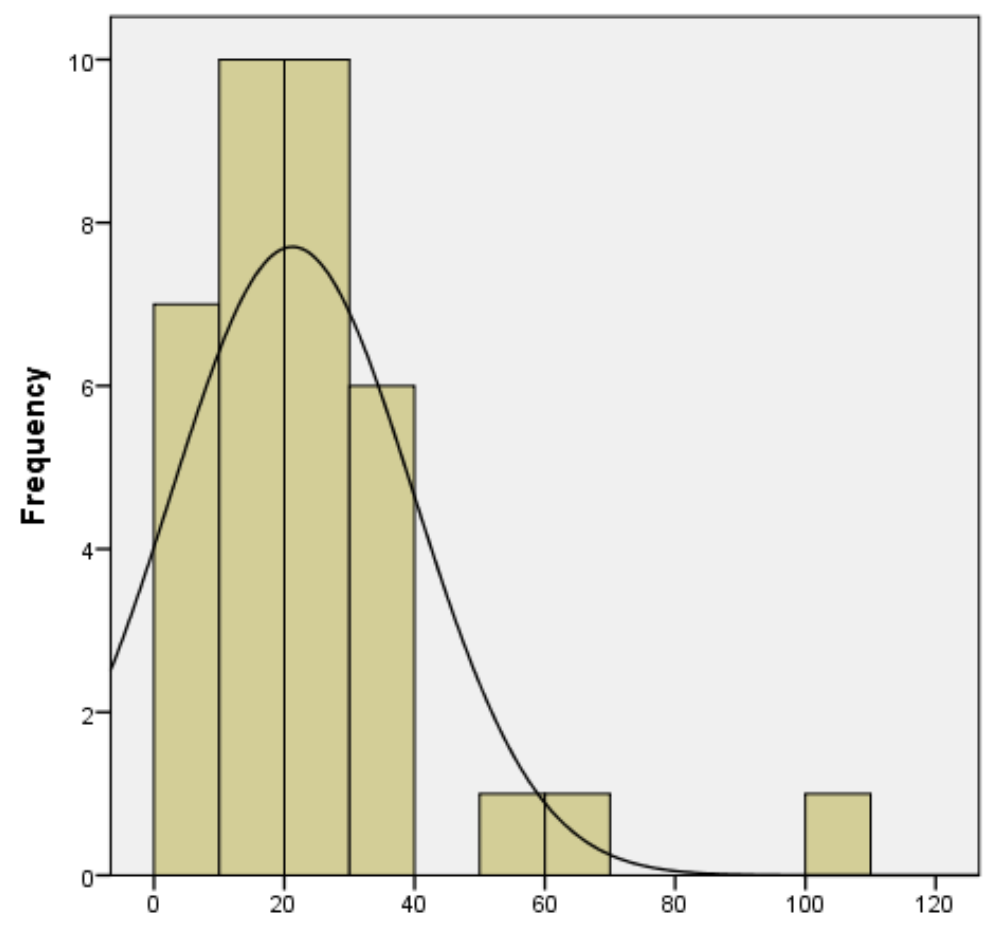

The mean value of the effective protection time is 18 years, with a median of 13 years. This shows that in most of the studied industries the average effective lifetime is well above 10 years.

Figure 47.: Distribution of difference in years between effective and normal lifetime of innovations after eliminating one company with a value of 30 year

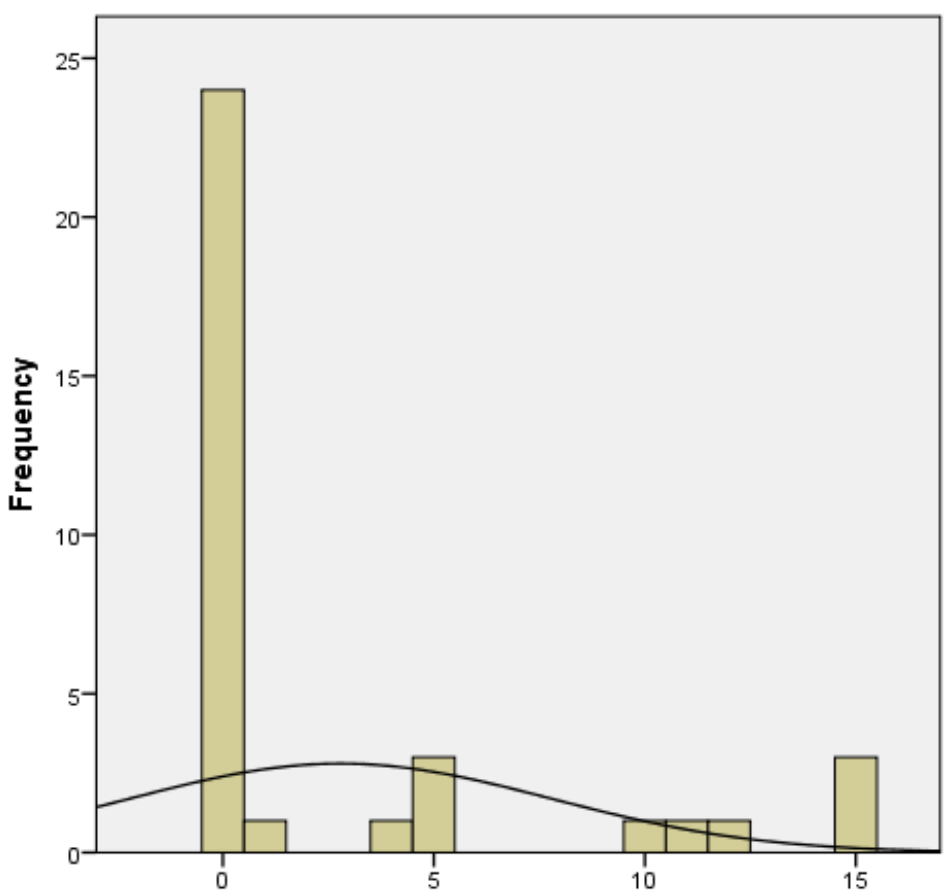


It is surprising that in the case of $65 \%$ of the innovations the effective lifetime is equal to the normal lifetime. In most of the cases where there is a difference the reason was that a new generation or a new type of product/process made the innovation obsolete. Several respondents said that although competitors arise and sometimes even the patent protection time lapses, but they are still able to generate profit from the innovation by maintaining at least some market share.

As both normal and effective lifetimes of innovations are nominal variables, it is possible to calculate the correlation to test the connection between them. As the distributions of both normal and effective lifetime are lognormal and there are relatively obvious outliers, it is recommended to use Spearman's and Kendall's correlation coefficients next to Pearson's. Pearson's and Spearman's correlation coefficients show a very strong connection between the two variables on a $99.9 \%$ significance level, 0.94 and 0.87 respectively. Kendall's correlation coefficient also shows a strong connection, 0.76 . Mean of normal lifetime is 21 years, and 18 years in case of the effective lifetime. In both cases the standard error is about 3 years. The mean values are different on a $99 \%$ significance level, but not different from 20 years on a $95 \%$ significance level. The mean results are sensitive to outlier values. When filtering out the results of the biggest outlier the mean of the effective lifetime decreases to 15 years with a 2 year standard error. The median value of normal lifetime is 20 years, in case of effective lifetime only 10.5 years. On a $95 \%$ significance level the medians of neither variables are different from 20 years. Detailed results of these analyses can be found in Annex 11.

It is interesting to see how the industry of the innovator company influences the effective lifetime of the innovation.

Figure 48.: Average normal and effective innovation lifetime in years in selected industries 


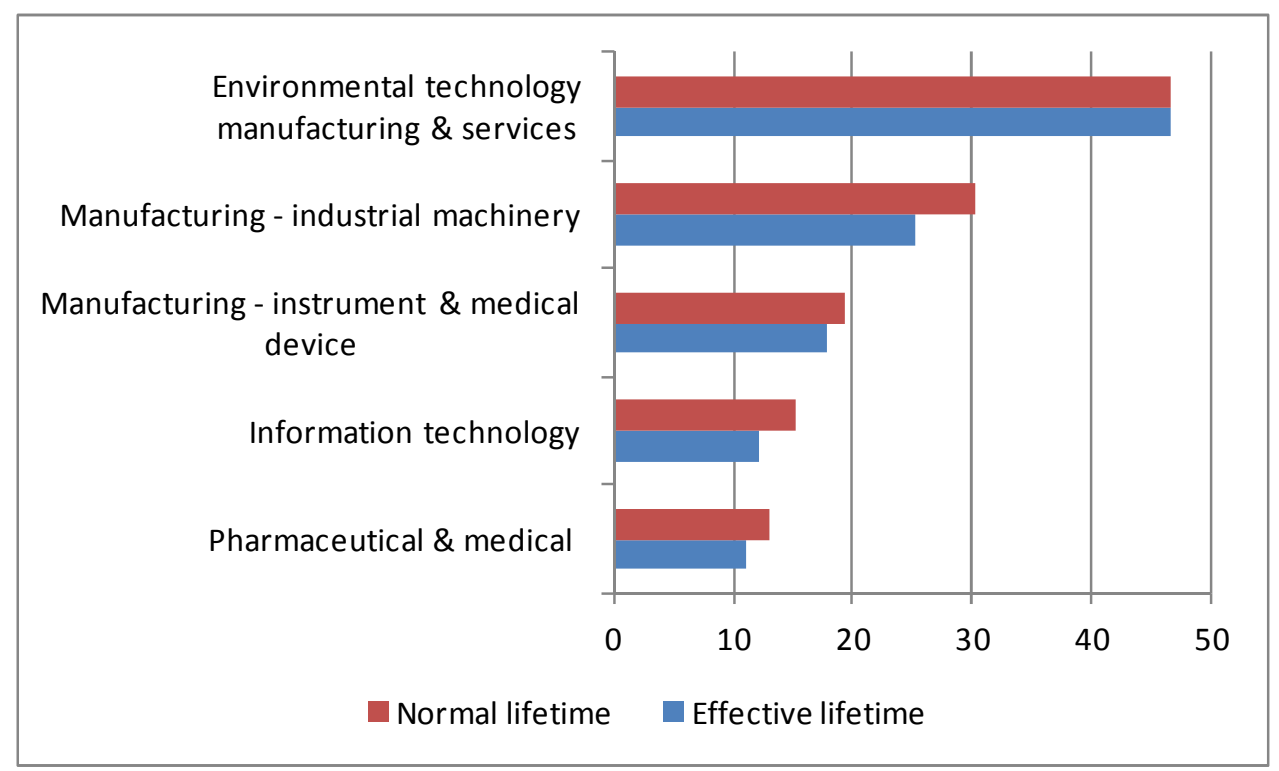

On the figure above industries with the most innovations in the sample were selected. In most industries there were innovations with relatively long lifetimes so the above figure calculated with the mean of industries shows longer lifetimes than the median. The environmental sector has the longest normal and effective lifetime thanks to end-of-pipe innovations with outstanding usability. It is also the only selected industry with no difference between the normal and effective lifetime. Average lifetime of innovations in the manufacturing sector is longer in case of industrial machinery than in the case of instruments \& medical device. In IT innovations average lifetime (more than ten years) is somewhat surprising, one would expect less. The lifetime of innovations in the pharmaceutical and medical sector is the shortest which can be due to the biotech sector represented in this category. Significances of the difference between the normal and effective lifetime can be calculated for the Manufacturing - instrument $\&$ medical device, IT and Pharmaceutical \& medical industries. In the case of the Manufacturing instruments \& medical device industry there is significant difference between normal and effective lifetime on a $99 \%$ significance level. In the case of the pharmaceutical \& medical industry there is difference on an $82 \%$ significance level, while in the case of the IT industry it is only $70 \%$. The relatively low significance level can mostly be due to the relatively small sample size of 5 innovations in both industries. 


\subsubsection{Patent reform}

The survey aimed at exploring the opinion of the innovator companies about the possible reforms of the patent system, and there was also a question about the opinion of companies about the impact of patents on innovation. Respondents could rank their opinion on a 1-5 scale. The statements to be evaluated were as follows:

- Patent system in its current form supports innovative activity

- The setting up of the single European Patent and European Patent Court will support innovative activity

- The current approval time of patents is appropriate.

- Current patenting fees applied by the Hungarian Intellectual Property Office impose a barrier and significantly hinder patenting activity

- Renewal fee of patents should be increased in order to eliminate the numerous relatively valueless patent faster

- If someone else other than the applicant of the patent has independently invented the same innovation, and can prove it, should have the right to use it freely

- Obligatory licensing should be given to those who demand it, in exchange for a fee proportional to $R \& D$ costs

- Instead of patents the incentive of the inventors should be supported by subsidies amounting to $15-35 \%$ of the $R \& D$ costs

- The patent system should be gradually abolished in several steps 
Figure 49.: Distribution of opinion of firms about possible reforms

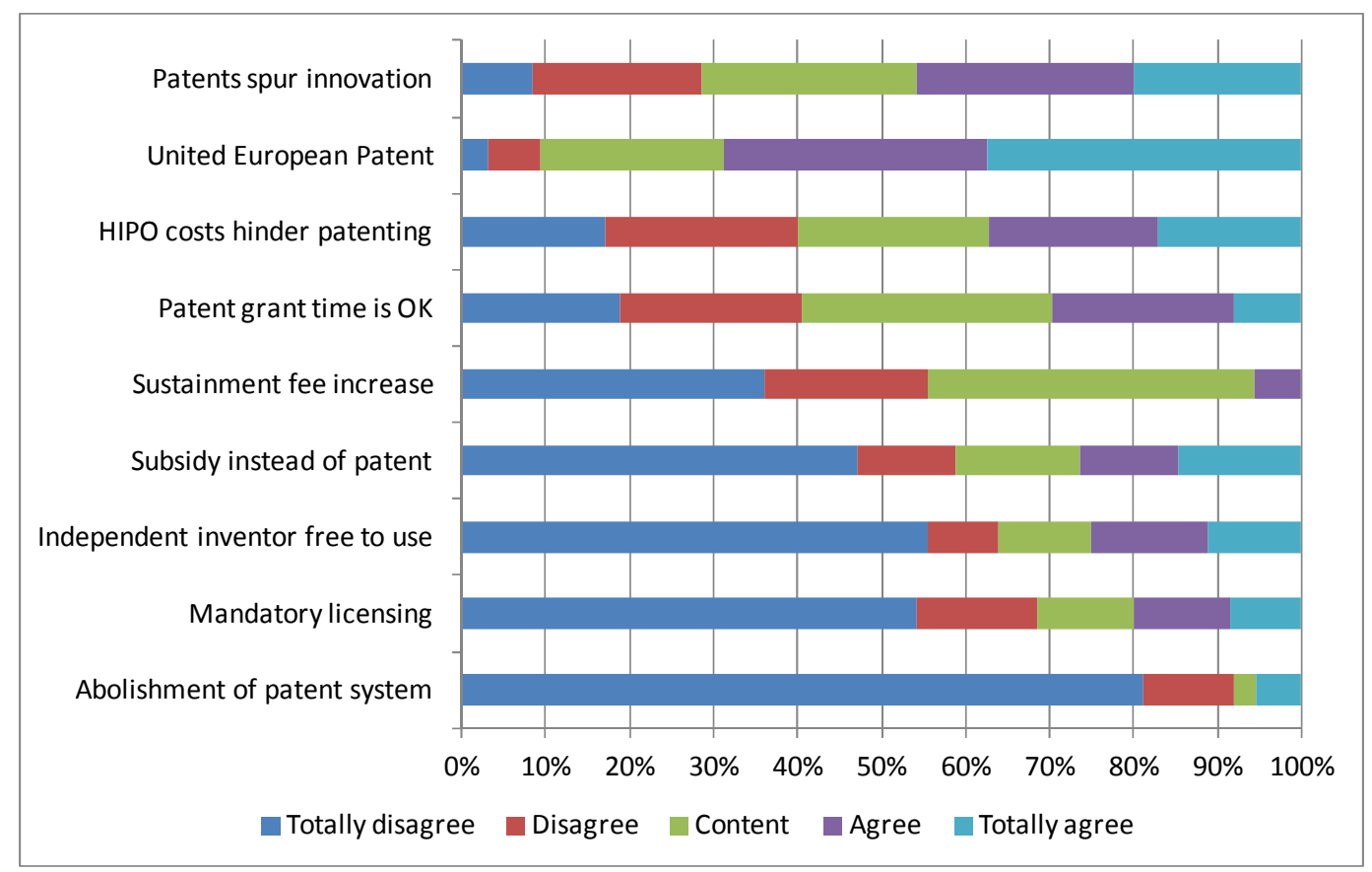

$46 \%$ of the respondents agree or totally agree with the statement that patents spur innovation, while $29 \%$ have the opposite opinion.

Regarding possible future patent reforms, it can generally be said that a number of companies were uncertain about the effects of such reforms. According to dr. Gábor Németh, the director of the HIPO, it is extremely difficult to take into account all aspects of a possible reform. Still, an overview of the opinions of innovator companies is helpful, as most of the respondents were inventors of the innovations and/or top managers of the companies' active in patenting.

The survey included questions about possible incremental as well as radical reforms. Results suggest that the majority of the respondents were against most of the reforms, especially more radical ones. The vast majority of the respondents had a characteristic opinion about the abolishment of the patent system, $81 \%$ totally disagreed with the idea, while $5 \%$ totally agreed with it. This may imply again, that patents can have significant advantages for innovators. $69 \%$ of the respondents agreed or totally agreed with the setting up of a United European Patent System. It is an interesting question how much this picture would change after the implementation of this, possibly in 2015 . 
As Pintz (2014, p.11) pointed out, in the new system "inventors applying for an English or German patent will get one Hungarian for free". Currently, when filing a European patent, applicants can choose in which countries they would like to obtain patent protection. Most of them choose not to pay an extra fee to have patent protection in Hungary. When the United European Patent System comes into force, applicants will automatically get patent protection in all UEPS member states, including Hungary for a fixed fee. This will increase the few thousand yearly new patent applications to about 75 thousand, which will significantly limit the possibilities of Hungarian inventors who will have to search through the increased number of relevant patents and position their patents in a way not to infringe any of them (Pintz, 2014).

Respondents tended to disagree with fundamental changes of the patent system, namely mandatory licensing, the right of an independent inventor to use his innovation freely, and giving subsidies instead of patents. According to the patent law in force independent inventors have some rights even today. Respondents were uncertain about whether the fees of HIPO hinder patenting, and about that the time length of granting a patent is appropriate and that sustainment fees should be increased to swipe out less important patents earlier or not.

These opinions reflect the interests of the companies, but of course do not mean that the listed or other possible reforms, including radical ones, would not be beneficial for the whole society. 


\section{Examination of the research hypotheses}

H1. The realization of patented environmental innovations depends more on the existence of the patent system than in the case of non-environmental innovations.

$18 \%$ of the respondents stated that they would not have created the innovation in the absence of the patent system, which is a relatively low ratio. Taking the sample size of 39 into account there were only a limited number of innovations, the realization of which depended on patent protection. Environmental innovations are more likely to be realized in the absence of patent protection than non-environmental innovations on a $61 \%$ significance level, which is considered significant using the Fisher's Exact Test. The direction of the relation is the opposite as in the hypothesis. Reason for this can be that industry effects influence the results. Innovations from the pharmaceutical sector depend more on the existence of the patent protection and are environmental innovations in a lower proportion than the rest of innovations in the sample. Filtering out innovations from the pharmaceutical sector the realization of environmental innovations depends on the existence of the patent protection as much as non-environmental innovations. Most of the environmental innovations in the sample are realized by companies from other than the environmental sector and the innovations are dominantly cleaner production type. The main reasons for this can be that motivations behind patenting do not differ significantly in case of environmental and nonenvironmental innovations and that often the environmental improvement is not the main driver of the innovation. Based on the above, H1. hypothesis is rejected.

H2. The main motivations behind patenting and the importance of these in case of Hungarian innovators are similar to international innovators, namely: commercial exploitation, protection from imitation, blocking, pure defense (ensuring that the use of the own technology is not hindered by third parties), setting of technical standard, improving reputation, licensing. 
Several studies tried to assess the importance of the motivations behind patenting. The meta-analysis of Blind et al. (2006) summarised six of them, which can be seen in Annex 5. and conducted an own study, the results of which are in Figure 15. Based on these the most important motivations to patent can be grouped into the categories of protection, blockade, reputation, exchange and incentive. PatVal II uses slightly different categories. As PatVal II is more relevant for the comparison with Hungary both in time and location, I decided to use this as a benchmark. The wording of the hypothesis and the questions about this topic in the survey also reflect the structure of PatVal II.

When comparing the results of this research with PatVal II it is important to note that the different methodology of the sampling (most patents in the sample are utilized, smaller ratio of big companies) may influence the results.

Figure 50.: Differences in motivations to patent in PatVal II and the sample

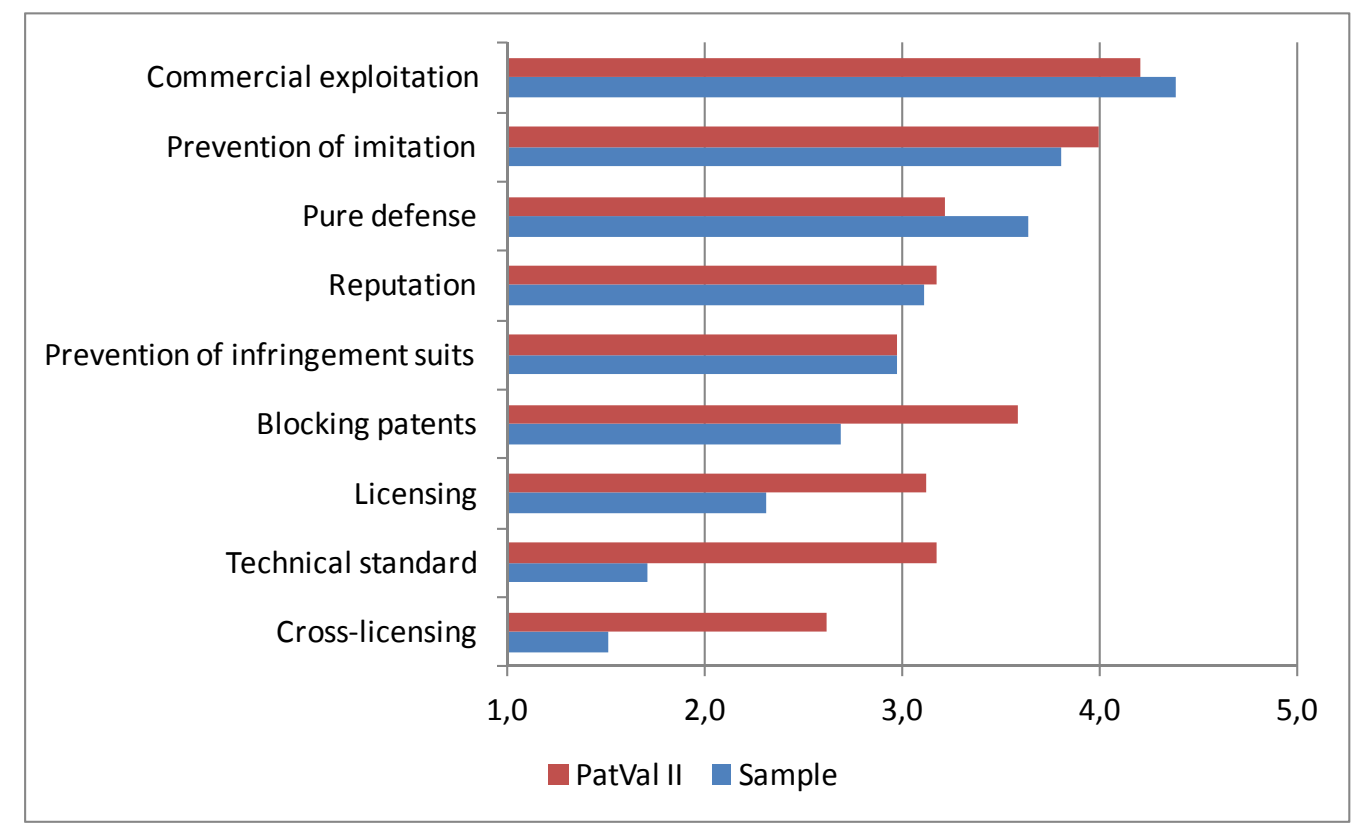

The two most important motivations, namely commercial exploitation and prevention from imitation are the same in both studies. The third most important motivation in PatVal II was blocking, which ranked lower $\left(6^{\text {th }}\right.$ place) in the sample, but this can mostly be attributed to the different sample selection as described previously. Pure defense motivation ranked fourth in the PatVal II and third in the sample which means that they are of the same importance in both studies taking into account the lower rank of blocking in 
the sample. Setting of technical standard ranked lower in the sample as in the PatVal II ( $8^{\text {th }}$ versus $\left.5^{\text {th }}\right)$. This difference again can mainly be attributed to the different size distribution of the two studies. Smaller companies are obviously not as much able to set standards as bigger companies. The sixth most important motivation in PatVal II is to improve reputation. In the sample this motivation was ranked fourth. The difference in the ranks however do not represent a major difference as it can be explained by less importance of blocking and setting technical standard motivations. The correspondence of the importance of this motivation is apparent as the motivation scores in the two surveys are similar. The differences between the licensing motivations can mainly be attributed again to different sample selection. It is also important to note that there are no such differences in the actual licensing activity of the companies in PatVal II and in the sample, as described previously. Although prevention from imitation ranks $8^{\text {th }}$ in PatVal II and $5^{\text {th }}$ in the sample, the motivation scores are almost equal and the difference in the rank can be explained by relatively worse performance of blocking, setting of technical standards and licensing motivations. Cross licensing motivation scores the lowest in both studies but the strength of motivations are significantly different. The difference again can be attributed to the different sample selection. In this case both the lower ratio of bigger size companies and the higher ratio of utilized patents can play a role. Relatively smaller companies with relatively more utilized patents are less active in cross licensing which is typical of companies more active in the strategic usage of patents.

Although the rank correlation between PatVal II and the sample is only 54\%, which shows a medium strength connection, a large part of the difference can be attributed to the different sample selection of the two studies. Based on these H2. hypothesis is accepted.

It is also apparent that motivations behind patenting environmental innovations are similar to motivations behind patenting non-environmental innovations.

H3/A. The patent premium (the added value to the innovation by patent protection) makes up a significant part of the patent value. 
In the sample there are two distinctly separate groups of companies, one group (with $45 \%$ of the innovations) considers the patent protection as less significant (less than 31\%), the other group (with $45 \%$ of the innovations) considers patent protection as very significant (more than 69\%). In this study the ratio of the two groups of innovators is balanced, both the mean and median values are 50\%. Based on these H3/A. hypothesis is accepted.

$H 3 / B$. The value of the patents increases with the size (revenue, employee number) of the innovator.

The size of the innovator is usually measured by the yearly revenue or employee number. Spin off companies can also be filtered out, because they may bias the analysis with non observable variables, like the sales and employee number of the parent company or university, which can have an effect on the patent value.

Based on the analysis the size of the innovator explains at best $13-14 \%$ of the variance on a maximum significance level of $93-94 \%$. The weak explanatory power points to the fact that in line with the literature there are several other factors which can have an effect on the value of patents. Based on these H3/B. hypothesis is rejected on a $95 \%$ significance level.

H4/A. In case of the patented innovations, the effective lifetime of the innovation is shorter than the patent protection period granted by law.

The mean of effective lifetime in the sample is 18 years with a standard error of about 3 years on a $95 \%$ significance level. This means that the mean of effective lifetime is not different from 20 years (the patent protection period granted by law) on a $95 \%$ significance level.

It is important to note that the calculation method of the mean is rather sensitive to outliers (when filtering out the biggest outlier the mean lowers to 15 years and is different from 20 years on a $95 \%$ significance level). So to test the robustness of the analysis the median value was also calculated. Although the median value is 10.5 years, it is also not different from 20 years on a $95 \%$ significance level. 
There are significant differences between the effective lifetimes of innovations in the different industries. There are several industries for which the mean and median values are well above 20 years, for example and the Environmental technology \& manufacturing services, and there are others with lifetimes of about 10 years, like Information Technology and Pharmaceutical \& Medical (including biotechnology). Due to the small sample size the mean values were not significantly different from 20 years in case of any industries with at least 5 observations. Based on these H4/A. hypothesis is rejected.

It is important to note that only few respondents have answered that the lifetime of the innovation came to an end due to the lapse of the patent protection time. Although the average lifetime of the innovations in the sample is not significantly different from 20 years but this can rather be attributed to the average lifetime of the innovations than the lapse of patent protection.

$H 4 / B$. In case of patented innovations, the effective lifetime of the innovation is shorter than the theoretical lifetime.

In the case of $65 \%$ of the innovations the effective lifetime is equal to the normal lifetime. In most of the cases where there is a difference, the reasons were that a new generation or a new type of product/process made the innovation obsolete. Several respondents explained that although competitors arise and sometimes even the patent protection time lapses, but they are still able to generate profit from the innovation by maintaining at least some market share.

Still, due to the dissimilarity of the remaining $35 \%$ of the innovations there is a difference between the mean of normal and effective lifetime of the innovations on a $99.7 \%$ significance level. Due to the small sample size the mean values were not significantly different in case of any industries with at least 5 observations. Based on these H4/B. hypothesis is accepted.

H5. Hungarian innovators with patent applications find the reform of the patent system necessary, in line with the vast majority of researchers. 
As Figure 49. shows, $46 \%$ of the respondents agree or totally agree with the statement that patents spur innovation, while $29 \%$ are on the opposite opinion. Almost half of the respondents think that patent system is useful for them, which shows that patents can have significant advantages for innovators. Regarding the possible future patent reforms, it can generally be said that the majority of the respondents were against most reforms, especially more radical ones and there were several who were uncertain about the effects of such reforms. The vast majority of the respondents had a characteristic opinion about the abolishment of the patent system, $81 \%$ totally disagreed with the idea, while $5 \%$ totally agreed with it. Only the setting up of the United European Patent System and Court was welcomed by $69 \%$ of the respondents, who agreed or totally agreed with this reform. Respondents were uncertain about whether the fees of HIPO hinder patenting, and about that the time length of granting a patent is appropriate and that sustainment fees should be increased to swipe out less important patents earlier or not. Respondents tended to disagree with fundamental changes of the patent system, namely mandatory licensing, the right of an independent inventor to use his innovation freely, and giving subsidies instead of patent protection. The critical view of respondents regarding the reforms can partly be traced back to the fact that they are active in patenting and the majority of them make advantage of the patent system, while social costs are not fully internalized. Based on these H5. hypothesis is rejected.

In connection with the testing of these hypotheses it is important to note the limitations of the research. The survey nature of the study means that the sometimes subjective or (intentionally or accidentally) false information provided by the respondents serve as basic data for the research. In some cases this could be mitigated by the comparison with other relevant studies.

Major limitation of the research is the relatively small sample size, due to which it was harder to come to significant conclusions. The population can be regarded as representative of the Hungarian patenting activity also with limitations. The population contains at least $3.6 \%$ of Hungarian innovations with patent applications, but is biased towards utilized and more valuable 
innovations. This is further affected by the fact that the size and industrial distribution of the sample is different from the population in several aspects due to the unwillingness of several companies to participate in the survey. There were also a couple of companies which ceased to exist, although in most cases it was possible to find a contact to the inventors or the then management of the company. 


\section{Conclusions, recommendations}

The two main goals of the research are the contribution to the more thorough understanding of the advantages and disadvantages of the patent system for innovative companies, and the study of the diversity of these effects in the special case of environmental innovations. In the latter case the selected approach is different from most studies, environmental innovations are not only studied in the environmental sector, but in all industries.

In the literature review several topics and research questions were identified mostly through the review and structuring of the past and current studies. Specific research topics were selected through the synthesis of the main goals of the research and the literature. The research questions selected for in depth analysis related to the difference between environmental and general patents with respect to the realization of the innovations in the absence of the patent system, the main motivations behind patenting, the value of patents with respect to the patent premium, the effect of company size on patent value, the theoretical and normal lifetime of patented innovations and the innovators' opinions about the possible patent reforms.

Respondents regarded $64 \%$ of the studied innovations as environmental innovations, which is a relatively high proportion. Taking into account that companies from the environmental technology \& services represent only $8 \%$ of the studied innovations, this shows that it is extremely important to focus on environmental innovations in other sectors too. Most of these are cleaner production type innovations and are originated from various sectors. This type of environmental innovations share most attributes of non-environmental innovations from the same company or industry. The study has a broader view of the environmental innovation than most studies, as there was no criterion for the environmental innovations to be the aim of the innovation. This is a more holistic approach, as there were numerous innovations in the sample where environmental improvement was only a positive side effect not the main goal of the innovation. Environmental innovations originated from the environmental sector were mainly end-of-pipe technologies as opposed to the 
dominance of cleaner production type innovations in other industries. The latter type of environmental innovation depends heavily on the specific characteristics of the industry of innovation but is not significantly different from the general innovations in most of the studied aspects. The studied environmental innovations depend less on the existence of the patent system, than non-environmental innovations, however, this can mainly be attributed to industrial effects. Taken apart from the pharmaceutical industry, there is no difference between environmental and general patents in this respect. This result is very important because of several reasons. An effective patent system fostering high value innovations in the whole economy can also be able to support environmental innovations. It also seems that the phenomena of double externality do not significantly influences the patenting activity of companies belonging to various sectors, who mostly realize cleaner production type of environmental innovations.

The relatively low ratio of innovations dependent on patent protection is in line with the literature. Innovations that would not have been invented in the lack of patent protection are exaggeratedly typical to the pharmaceutical sector. This again emphasises that patent protection in the modern economy is not what it used to be several centuries ago. The patent protection nowadays is much more than just a way of protection from imitation for the companies. Innovators use the patent system in several other strategically advantageous ways helping the commercial exploitation of the innovation, blocking, ensuring that the use of the own technology is not hindered by third parties, setting of technical standard, improving reputation or licensing. These motivations are similar even with different background settings like the date and country of invention. This together with the studies presented in the literature show that these motivations can be considered robust.

During the study regarding the value of patents, the explanatory power of the Hungarian Innovation Grand Prize was tested. The results show that although there is a significant connection, the explanatory power of the Grand Prize on patent value is rather weak. Great advantage of the study is that next to the assessment of the jury of the Grand Prize the companies have also assessed the value of their patents. As this is likely to be possible in only a limited 
number of future studies, special caution is needed when using the prize or award as a proxy for the value of the patent. Studying the patent premium, two markedly distinct categories of innovators was discovered. Innovators from the first group regarded patent premium to be rather important in contrast with the innovators from the other group who were on the opposite opinion. This can partly explain why several researchers have found significantly different patent propensities in previous studies. Firm size was tested as a factor influencing patent value. Results show that there is no significant connection between the two on a $95 \%$ significance level, but in case of several variables like employee number or yearly sales filtering out spin-off companies, the relation came close to be significant, although with a projected weak explanatory power. The results show that patents of small companies can also be of great value.

In case of the lifetime of the innovations it was unexpected that neither the effective nor the theoretical (normal) lifetimes differ significantly from the patent protection time granted by law. This shows that the social costs arise regarding the delay in follow-on innovations and the deadweight loss during the whole patent protection time. It is important to note that in several cases a superior or imitated innovation reached the market during the lifetime of the innovation. Competition with these has decreased the market share of the innovation, but positive yields were still possible to achieve. This shows that although there are social costs regarding patenting until the lapse of the patent or even further, these costs decrease with time in case of several innovations. It is also important to note that only few respondents have answered that the lifetime of the innovation came to an end due to the lapse of the patent protection time. Although the average lifetime of the innovations in the sample is not significantly different from 20 years but this can rather be attributed to the average lifetime of the innovations than the lapse of patent protection. It was also unexpected that in case of almost two-thirds of the innovations the effective and normal lifetimes of the innovations did not differ. The main reasons for this can be that innovators are able to profit from the innovation until the end of the normal life cycle, although to a decreasing amount in several cases. 
Almost half of the respondents think that the patent system is useful for the companies, which shows that patents can yield significant advantages for innovators. Regarding the possible future reforms of the patent system, it can generally be said that the majority of the respondents were against most reforms, especially more radical ones, like the gradual abolishment of the patent system, and there were several companies who were uncertain about the effects of such reforms. Only the setting up of a United European Patent System and Court was welcomed by most of the respondents. The critical view of respondents regarding the reforms can partly be traced back to the fact that they are active in patenting and the majority of them take advantage of the patent system, while social costs are not fully internalized.

In light of the findings from the thesis it is also possible to make suggestions for further research. Next to the large scale representative studies, research with a more in depth view of the patenting of innovations can give invaluable insights into the characteristically different innovation processes of the companies. The studies based on other innovation prizes, fairs, etc. can provide us with a population of patented innovations with much more valuable information about patents than available in patent registers. These can serve as an excellent base for researching further aspects of the patenting process. The assessments of the effects of possible future reforms are also vital. As most of the researchers and an ever growing part of the companies regard future reforms as necessary, and given the great number of potential reforms, it is important to have relatively accurate preconceptions about the changes in the patent system. 


\title{
Annex
}

\author{
1. Annex
}

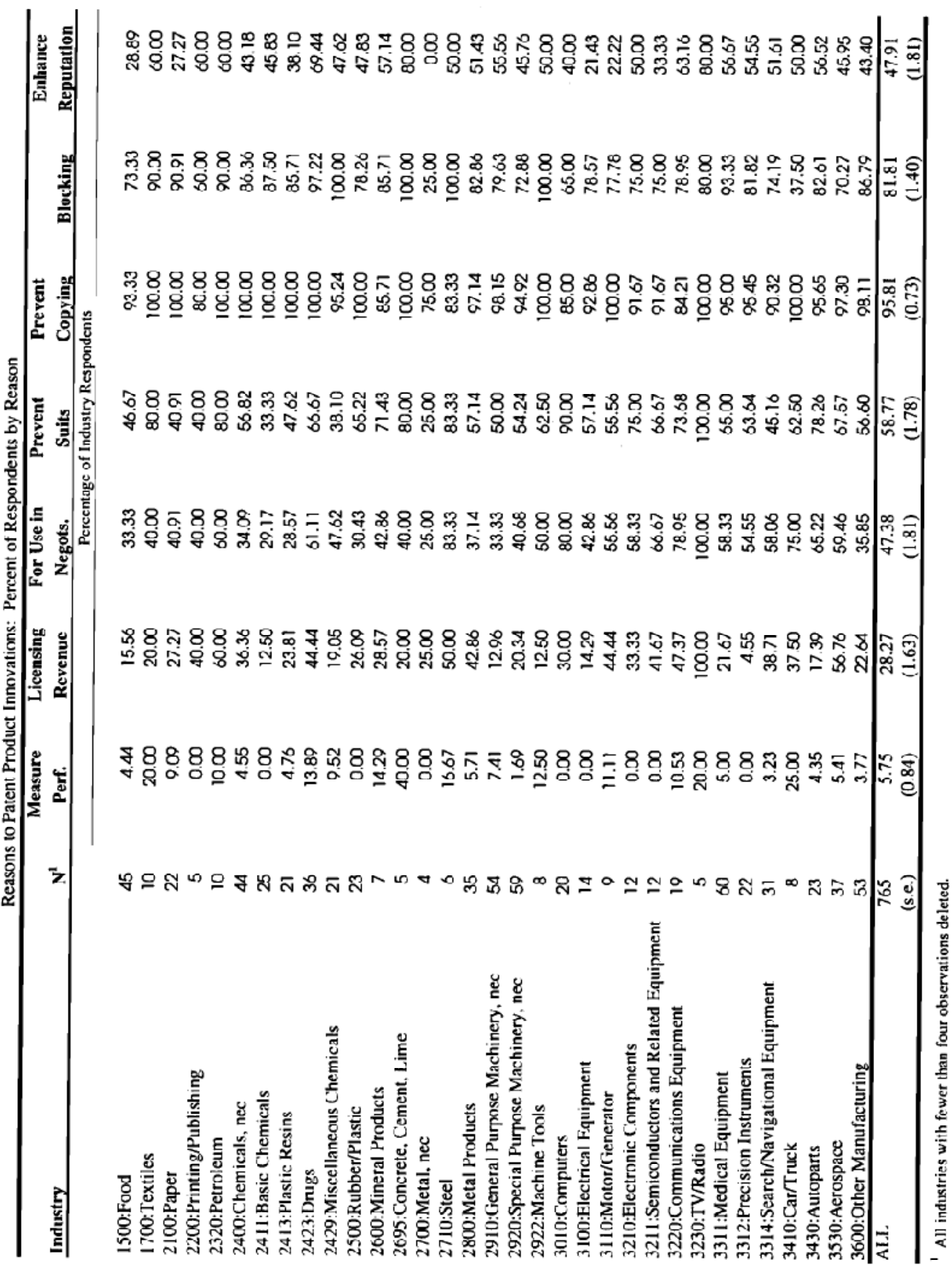

Source: Cohen et al., 2000, p. 38. 


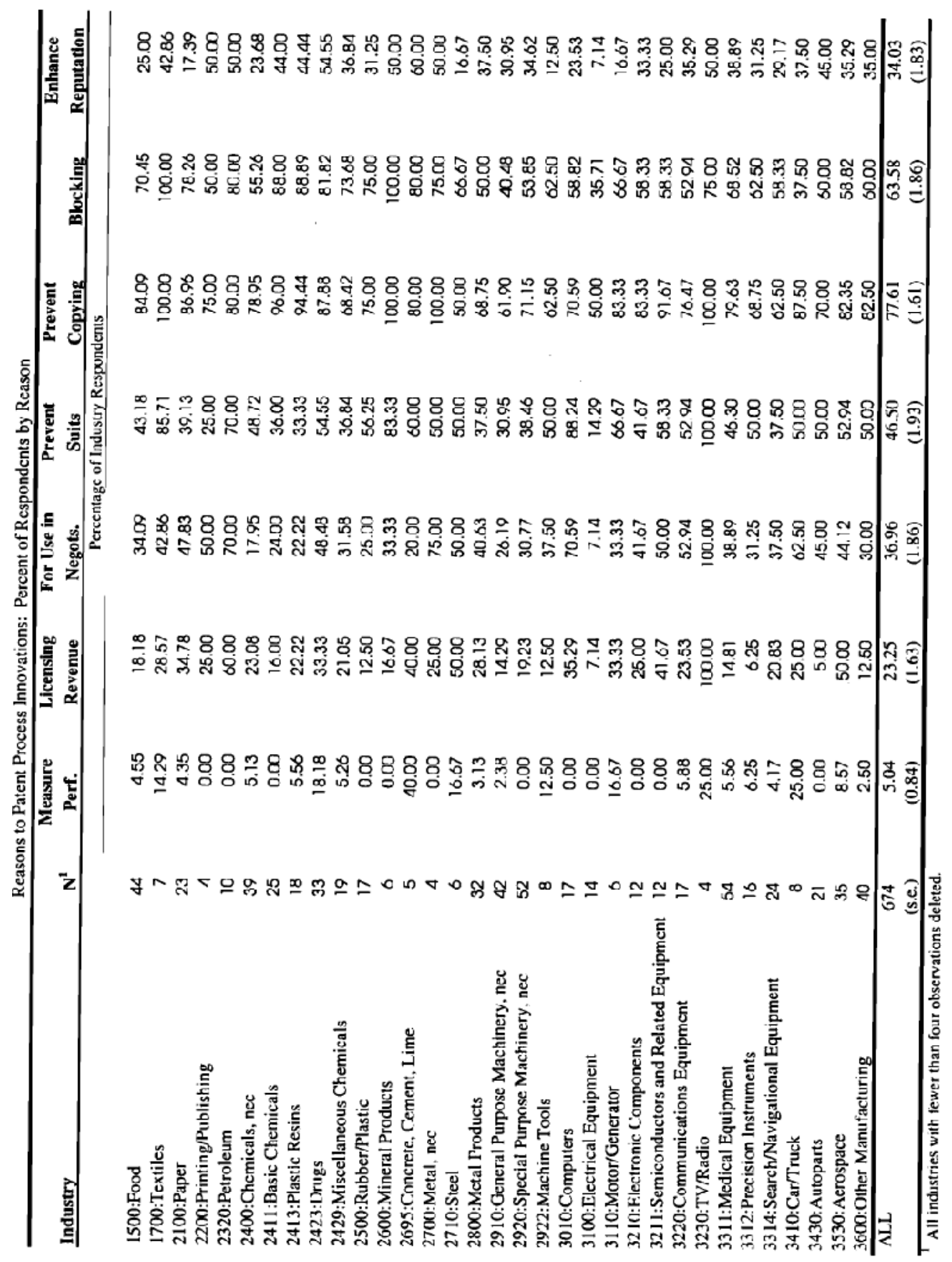

Source: Cohen et al., 2000, p. 39. 
2. Annex

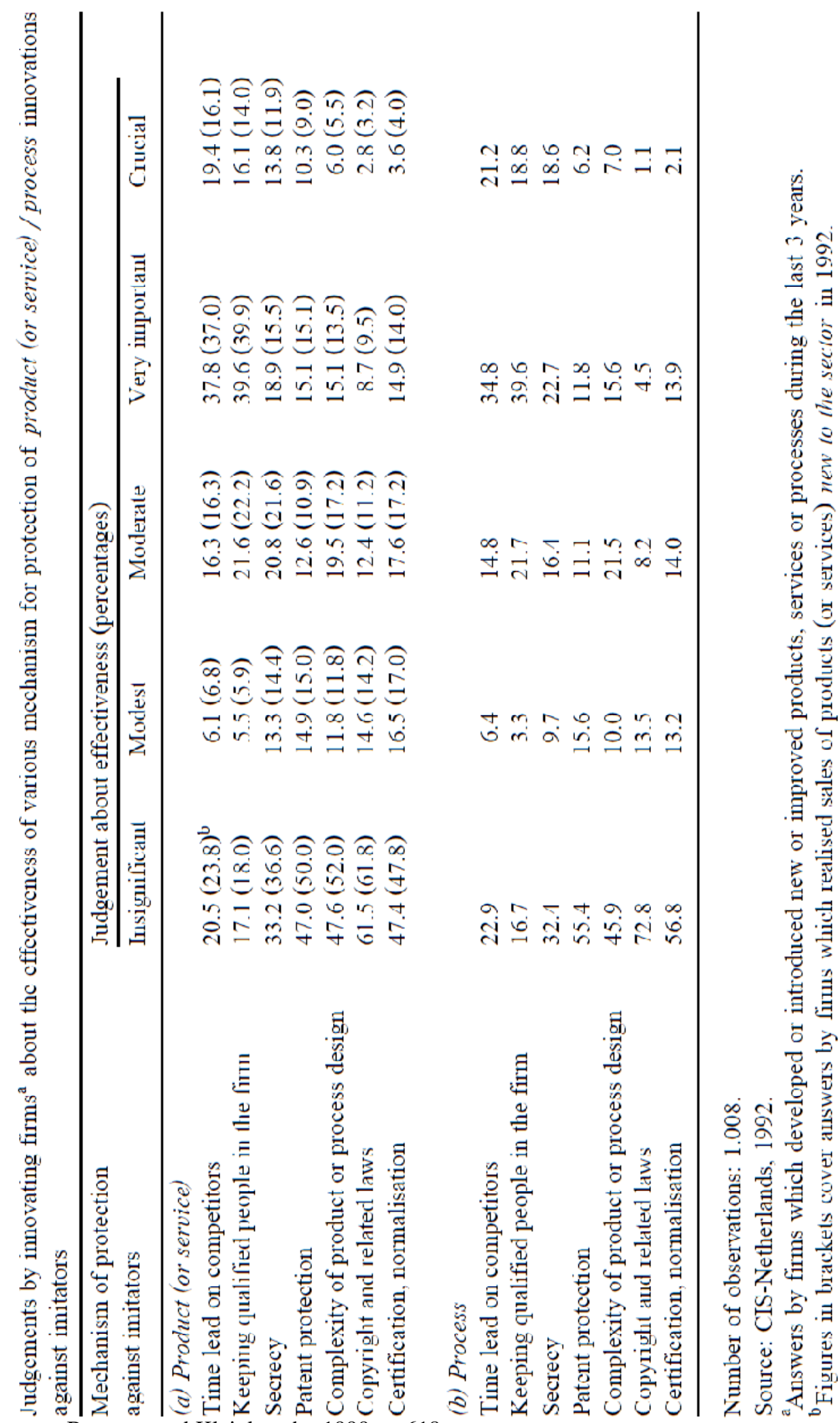

Source: Brouwer and Kleinknecht, 1999, p. 618. 


\section{Annex}

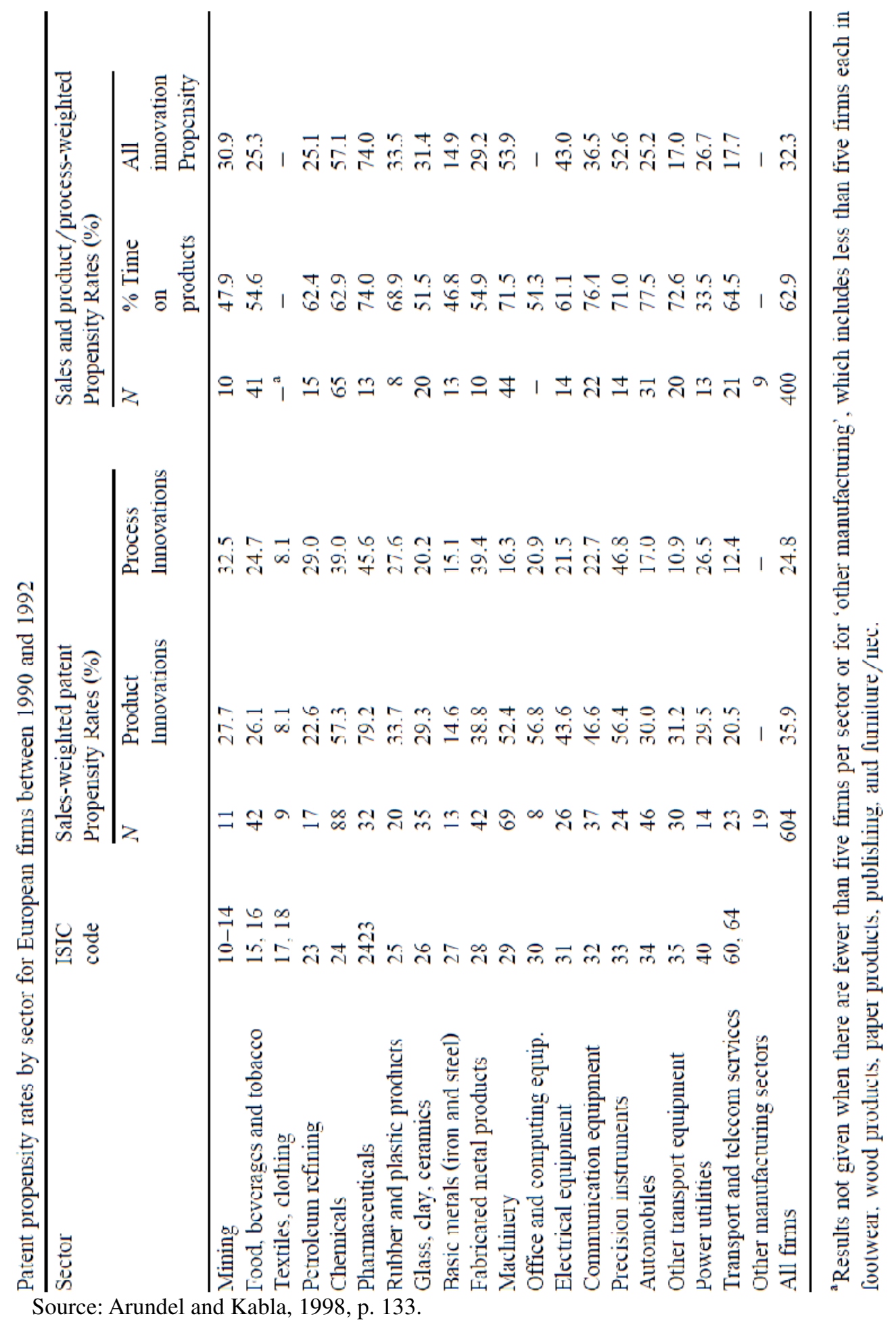




\section{Annex}

The propensity to patent product/process innovations: comparing our results to those of Arundel and Kabla (1998)

\begin{tabular}{|c|c|c|c|c|}
\hline \multirow[t]{2}{*}{ Manufacturing branches } & \multirow[t]{2}{*}{$\begin{array}{l}\text { The propensity to patent } \\
\text { product and process innovations } \\
\text { (Arundel and Kabla, 1998) }\end{array}$} & \multicolumn{3}{|c|}{$\begin{array}{l}\text { Appreciation of the value of patent protection for product } \\
\text { and process innovations in Dutch manufacturing (1992); } \\
\text { patent protection is: }\end{array}$} \\
\hline & & $\begin{array}{l}\text { Insignificant or } \\
\text { modestly important }\end{array}$ & $\begin{array}{l}\text { Moderately } \\
\text { important }\end{array}$ & $\begin{array}{l}\text { Very important } \\
\text { or crucial }\end{array}$ \\
\hline \multicolumn{5}{|l|}{ (a) Product } \\
\hline Food, beverages and tobacco & 26.1 & 65.0 & 10.4 & 24.6 \\
\hline Textiles and clothing & 8.1 & 64.4 & 13.5 & 22.1 \\
\hline Wood, paper and printing & n.a. & 69.1 & 5.8 & 25.1 \\
\hline Petroleum refining & 22.6 & 46.9 & 16.9 & 36.3 \\
\hline Chemicals & 57.3 & 46.9 & 16.9 & 36.3 \\
\hline Pharmaceuticals & 79.2 & 46.9 & 16.9 & 36.3 \\
\hline Rubber and plastics products & 33.7 & 51,9 & 11.7 & 36.4 \\
\hline Class, clay and ceramics & 29.3 & 77.8 & 19.5 & 11.8 \\
\hline Basic metals (iron and steel) & 14.6 & 93.8 & 2.3 & 9.9 \\
\hline Fabricated metal products & 38.8 & 61.9 & 14.5 & 23.6 \\
\hline Mechanical engineering & 52.4 & 51.7 & 21.9 & 26.4 \\
\hline Office and computing equipment & 56.8 & 53.77 & 18.5 & 27.7 \\
\hline Electrical equipment & 43.6 & 53.77 & 18.5 & 27.7 \\
\hline Communication equipment & 46.6 & 53.77 & 18.5 & 27.7 \\
\hline Precision instruments & 56.4 & 44.2 & 19.9 & 35.8 \\
\hline Automobiles & 30.0 & 67.2 & 3.2 & 29.6 \\
\hline Other transport equipment & 31.2 & n.a. & n.a. & n.a. \\
\hline Other manufacturing & n.a. & 82.6 & 11.6 & 5.9 \\
\hline Total manufacturing & 35.9 & 61.9 & 12.8 & 25.4 \\
\hline \multicolumn{5}{|l|}{ (b) Process } \\
\hline Food, beverages and tobacco & 24.7 & 58.7 & 13.9 & 27.4 \\
\hline Textiles and clothing & 8.1 & 78.5 & 5.5 & 16.1 \\
\hline Wood, paper and printing & n.a. & 82.0 & 7.6 & 10.4 \\
\hline Petroleum refining & 29.0 & 54.4 & 9.8 & 35.8 \\
\hline Chemicals & 39.0 & 54.4 & 9.8 & 35.8 \\
\hline Pharmaceuticals & 45.6 & 54.4 & 9.8 & 35.8 \\
\hline Rubber and plastics products & 27.6 & 62.7 & 7.4 & 30.0 \\
\hline Class, clay and ceramics & 20.2 & 74.2 & 20.4 & 5.4 \\
\hline Basic metals (iron and steel) & 15.1 & 93.3 & 3.7 & 3,1 \\
\hline Fabricated metal products & 39.4 & 70.5 & 10.7 & 18.9 \\
\hline Mechanical engineering & 16.3 & 60.3 & 25.3 & 14.4 \\
\hline Office equipment & 20.9 & 79.8 & 6.0 & 14.1 \\
\hline Electrical equipment & 21.5 & 79.8 & 6.0 & 14.1 \\
\hline Communication equipment & 22.7 & 79.8 & 6.0 & 14.1 \\
\hline Precision instruments & 46.8 & 76.2 & 2.5 & 21.3 \\
\hline Automobiles & 17.0 & 75.1 & 5.0 & 19.9 \\
\hline Other transport equipment & 10.9 & n.a. & n.a. & n.a. \\
\hline Other manufacturing & n.a. & 86.7 & 0.0 & 13.3 \\
\hline Total manufacturing & 24,8 & 71.0 & 11.1 & 18,0 \\
\hline
\end{tabular}

Source: Brouwer and Kleinknecht, 1999, p. 619. 
5. Annex

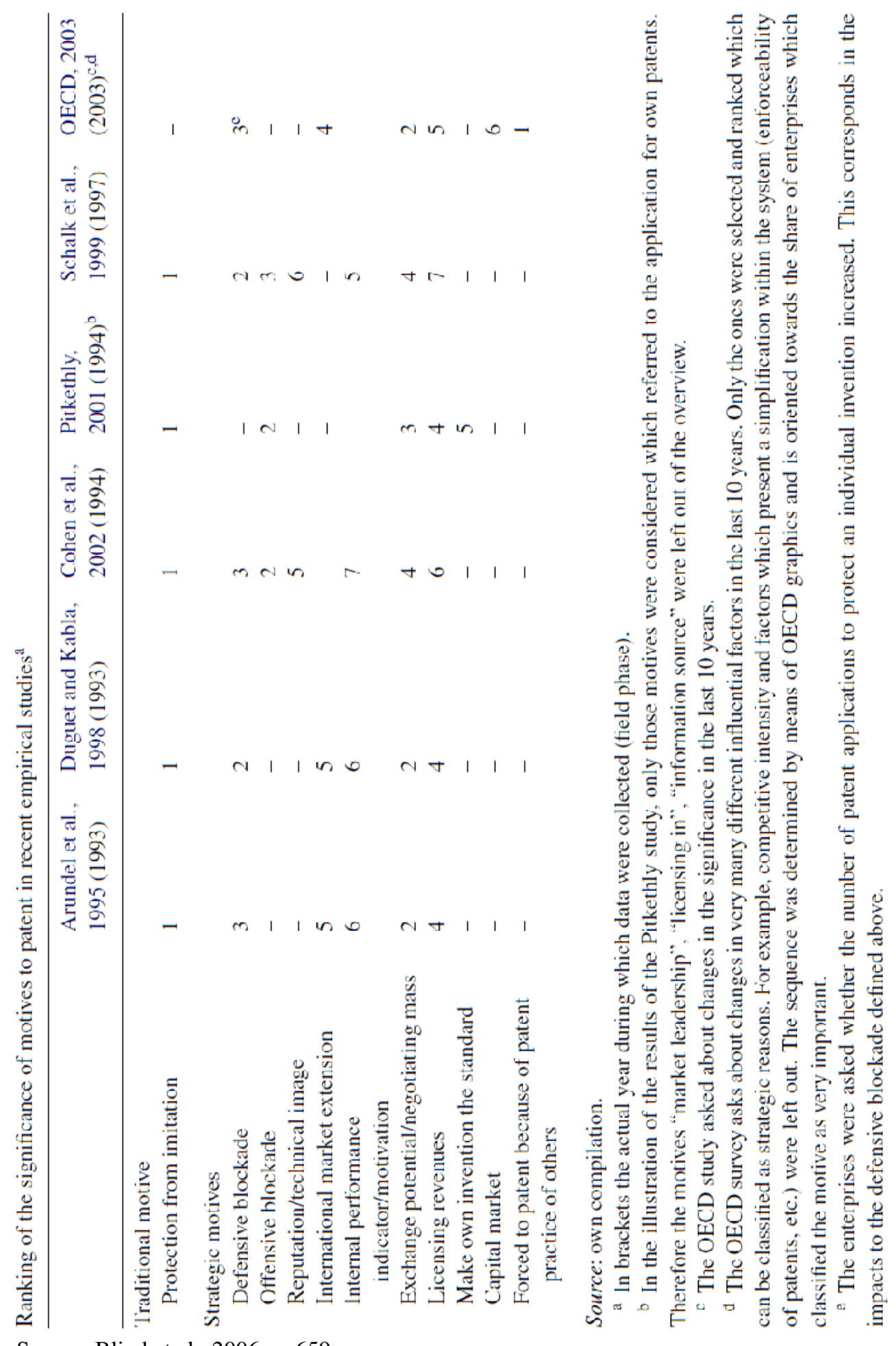

Source: Blind et al., 2006, p. 659. 
6. Annex

\section{Survey about the invention, characteristics and patenting of the significant Hungarian innovations}

This research is a major element of a research exploring the invention, the circumstances of creation, the value and the characteristics of patents of significant Hungarian innovations. These are all extremely important with respect to the modern economy and society. This survey is supported by the Hungarian Association for Innovation and the Hungarian Intellectual Property Office.

We plan to interview all organisations who applied for the Hungarian Grand Prize between 2002 and 2013 and were rewarded with grand prize, prize, honourable mention or mention. The interview is done personally and is planned to be about one hour.

Important remark: Interviewees are obliged by a strict nondisclosure agreement. Strict non-disclosure rules apply also for the handling and processing of the information gathered. Responses will not be disclosed individually or delivered to any third party. Information from the survey can not be published in a way that it could be linked to you to your company or to the inventor. Responses are solely used for the research regarding the patenting of innovations introduced in the first paragraph. Protection of personal and organizational data is regulated by the laws and regulations in effect.

Thank you for your contribution in advance! If you require, the results of the research will be sent to your given email address. 


\section{A. Section - General Information}
A.1.
Name
of
the
applicant
company:

A. 2. Respondent's name and position:

A.3. Title of the innovation and the year of application on the Hungarian Innovation Grand Prize:

The term "patent" in the following is defined as a granted patent or patent application in Hungary or in any other country or region (for example Europe) unless it is explicitly required otherwise is the question.

A.4. How many patents are related to this innovation?

(If the answer is 1, please go to Question A7!)

A.5. What are these patents? (please list the patent or patent application numbers)

A.6. Is a patent among the above more important than the others in a technological, economic or strategic sense?

$\square$ Yes (please enter the patent/application number)

$\square \quad$ No

Please answer the following questions with regard to this most important patent. If the answer for the Question A6 was "No" then select a patent which applicant is your company and about the invention of which you have detailed information. Always refer to this patent unless it is explicitly required otherwise is the question.

A.7. Title of patent:

A.8. Date of application:

A.9. Patent number or patent application number: 
A.10. Name of applicant(s):

A.11. Name of inventor(s):

A.12. List of countries in which the patent was applied for or was granted:

A.13. The respondent's relation to the patent (for example: inventor, top manager of the applicant, employee of the applicant's R\&D division, other employee of the applicant, etc.)

\section{B. Section - General information about the company}

Note:

Information can be gathered about the company from open sources available on the internet about the companies, for example ownership structure, employee number, revenue, etc. It is important that this information refer to the date of the invention of the innovation!

B.1. Is this organisation also (one of) the applicant(s) of the patent or a daughter company of them?

$\square$ Yes $\quad \square \quad$ No

B.2. How many employees were employed in research or development positions at your company at the birth of the invention?

Employees $\square$ None

$\square \quad$ I do not know

B.3. Your company has been established over the last 10 years, during pre-eminence in another organisation (spin-off), or utilizes intellectual property developed in a different organisation?

$\square$ Yes

$\square \quad$ No

(Please go to Question B.5.)

$\square$ I do not know (Please go to Question B.5) 
B.4. Which type of organisation was your company spinned off or utilizes intellectual property developed in which type of organisation?

$\square$ Private firm

$\square$ Government Research Organisation

$\square$ University and education

$\square$ Other Government

$\square$ Hospital, Foundation, or Private Research Organisation

$\square$ Other (please specify)

$\square \quad$ I do not know

B.5. Did your company have foreign daughter-companies or sites at the date of the invention?
$\square$ Yes
$\square$ No
$\square$ I do not know

B.6. In which organisations were the inventors employed at the time of the invention?

$\square$ The only inventor was employed by our company

$\square$ All inventors were employed by our company

$\square$ No inventors were employed by our company, but at (please specify)

organisation

$\square$ At least one of the inventors were employed by our company, but other inventors were employed by (please specify)

organisations.

$\square$ I do not know

(If your answer is 3., 4., or 5., please go to Question C.1.)

B.7. Was any of your co-inventors not employed by (one of) the applicant(s) of

the patent?
$\square$ Yes
$\square \quad$ No
$\square \quad$ I do not know

\section{Section - Process of research and development}

Remark:

During the following questions the respondent should answer in his/her own name is the respondent is the inventor. In other cases try to answer the questions with respect to one 
specific inventor of the patent, if the necessary information is available.

\section{Birth of invention}

C.1. Please enter whose idea served as the base of the invention.

$\square$ Idea of the inventor

$\square$ Idea of another inventor

$\square$ Common idea of a research team

$\square$ Other (please specify)

$\square$ I do not know

C.2. Which of the following scenarios best describes the creative process that led to your invention?

(Check only one box near the relevant answer)

$\square$ The invention was the targeted achievement of a research or development project

$\square$ The invention was an expected by-product of a research or development project, not directly related to the main target of the project

$\square$ The invention was an unexpected by-product of a research or development project, not directly related to the main target of the project

$\square$ The idea for the invention was directly related to your normal job (which is not inventing), and was then further developed in a (research or development) project

$\square$ The idea for the invention was directly related to the normal job of the inventor (which is not inventing), and was then further developed in a (research or development) project

$\square$ The idea for the invention came from the normal job of the inventor (which is not inventing), and was not further developed in a (research or development) project (was patented without further research or development costs)

$\square$ The idea for the invention came from pure inspiration/creativity of the inventor (which is not inventing), and was not further developed in a (research or development) project (was patented without further research or development costs)

$\square$ Other (please specify)

C.3. Did the invention build in a substantial way on other inventions that you knew?

$\square$ Yes 


\section{$\square \quad$ No \\ (Please go to Question C.5. ) \\ $\square \quad$ I do not know \\ (Please go to Question C.5.)}

C.4. Was this previous invention one that had been made in the same organization?

$\square$ Yes $\square$ No $\square$ I do not know

C.5. Does the invention belong to your company's industry or technological field?

- In (one of) the company's main industry or technological field

- In (one of) the company's industries or technological fields but not in the main

- Different from the company's industries or technological fields

- The invention relates to such an industry or technological field which did not exist previously

口 Other (please specify)

C.6. Why was it decided to patent the invention as it was, as opposed to developing it further by devoting additional resources? (can check more than one box below)

$\square$ The invention is good enough as it is

- The aims initially targeted for this invention were satisfied

- Further improvements could have been achieved, but estimated costs were beyond the resources (budget) available

F Further improvements seemed beyond existing technological opportunities

- Further improvements (could have) resulted in another invention that could be patented separately

- The invention had to be patented quickly, because your organisation was aware of other inventors, research groups or firms that were working on inventions in the same field

\section{Sites and competitors}

C.7. We are interested to find out in which region or city the invention was actually made. Please enter the zip code of the location where the invention was made and the name of the town or city and of the state.

Postcode: City Name: County: 
C.8. Where was the strongest competitor in the field of the patented technology at the time of the invention?

$\square$ Same city/region

$\square$ Same country

Another country

$\square$ Competitors are not known

I do not know

C.9. Did you have knowledge about competitors doing parallel research, for the patenting of the invention or similar at the time of the invention?

$\square$ Yes, one competitor

$\square$ Yes, more competitors

No competitors were known (->please go to Question C.13)

I do not know (->please go to Question C.13)

C.10. How intense was the competition for the patenting of the invention?

\begin{tabular}{|c|c|c|c|c|c|}
\hline Not intense & & & & Very intense & $\begin{array}{c}\text { I do not } \\
\text { know }\end{array}$ \\
\hline $\mathbf{1}$ & $\mathbf{2}$ & $\mathbf{3}$ & $\mathbf{4}$ & $\mathbf{5}$ & \\
\hline$\square$ & $\square$ & $\square$ & $\square$ & $\square$ & $\square$ \\
\hline
\end{tabular}

C.11. Did the knowledge about competitors doing parallel research influence your behaviour?

$\square$ Yes, we almost have given up

$\square$ Yes, the project was slowed down

$\square$ Yes, the project was accelerated

$\square$ No effect

$\square$ Cooperation with the related parties

$\square$ Other (please specify):

I do not know

C.12. Please fill out the boxes regarding the branch and site of the competitor(s). (can select more boxes)

\begin{tabular}{|c|c|c|c|c|c|}
\hline & Branch & & Site & & Site \\
\hline$\square$ & Same branch & $\square$ & Same country & $\square$ & Same city/region \\
\hline$\square$ & Other branch & $\square$ & Other country & $\square$ & Other city/region \\
\hline
\end{tabular}




\begin{tabular}{|l|l|l|l|l|l|}
\hline$\square$ & I do not know & $\square$ & I do not know & $\square$ & I do not know \\
\hline
\end{tabular}

Formal and informal communication during the R\&D process

C.13. Is the invention a result of a formal or informal cooperation between your company and a partner? (By formal we mean collaborations involving well defined contracts among the parties) (Please do not include cooperation with co-applicants) (can select more boxes)

\begin{tabular}{|l|c|c|c|c|}
\hline \multicolumn{1}{|c|}{ Type of partner } & No. & $\begin{array}{c}\text { Yes, result } \\
\text { of formal } \\
\text { cooperation. }\end{array}$ & $\begin{array}{c}\text { Yes, result } \\
\text { of informal } \\
\text { cooperation. }\end{array}$ & $\begin{array}{c}\text { I do } \\
\text { not } \\
\text { know }\end{array}$ \\
\hline $\begin{array}{l}\text { Supplier of structural } \\
\text { components, raw materials, } \\
\text { equipment, etc. }\end{array}$ & $\square$ & $\square$ & $\square$ & $\square$ \\
\hline Client(s) or user(s) & $\square$ & $\square$ & $\square$ & $\square$ \\
\hline Competitor & $\square$ & $\square$ & $\square$ & $\square$ \\
\hline Other company & $\square$ & $\square$ & $\square$ & $\square$ \\
\hline University and education & $\square$ & $\square$ & $\square$ & $\square$ \\
\hline $\begin{array}{l}\text { Government } \\
\text { Organisation } \\
\text { Hospital, Foundation, or Private } \\
\text { Research Organisation }\end{array}$ & $\square$ & $\square$ & $\square$ & $\square$ \\
\hline \begin{tabular}{l} 
Other (please specify) \\
\hline
\end{tabular} & $\square$ & $\square$ & $\square$ & $\square$ \\
\hline
\end{tabular}

C.14. What was the importance of the following sources of knowledge for the

research that led to the patented invention?

\begin{tabular}{|l|c|c|c|c|c|c|}
\hline Source of knowledge: & $\begin{array}{l}\text { Not } \\
\text { important }\end{array}$ & & & & $\begin{array}{l}\text { Very } \\
\text { important }\end{array}$ & $\begin{array}{l}\text { Source of } \\
\text { knowledge } \\
\text { was not } \\
\text { used }\end{array}$ \\
\cline { 2 - 7 } & $\mathbf{1}$ & $\mathbf{2}$ & $\mathbf{3}$ & $\mathbf{4}$ & $\mathbf{5}$ & $\square$ \\
\hline $\begin{array}{l}\text { University laboratories and } \\
\text { faculty }\end{array}$ & $\square$ & $\square$ & $\square$ & $\square$ & $\square$ & $\square$ \\
\hline $\begin{array}{l}\text { Non-University public } \\
\text { laboratories }\end{array}$ & $\square$ & $\square$ & $\square$ & $\square$ & $\square$ & $\square$ \\
\hline Customers & $\square$ & $\square$ & $\square$ & $\square$ & $\square$ & $\square$ \\
\hline Product users & $\square$ & $\square$ & $\square$ & $\square$ & $\square$ & $\square$ \\
\hline Suppliers & $\square$ & $\square$ & $\square$ & $\square$ & $\square$ & $\square$ \\
\hline Competitors & $\square$ & $\square$ & $\square$ & $\square$ & $\square$ & $\square$ \\
\hline
\end{tabular}




\begin{tabular}{|l|c|c|c|c|c|c|}
\hline $\begin{array}{l}\text { Consultants or research } \\
\text { companies }\end{array}$ & $\square$ & $\square$ & $\square$ & $\square$ & $\square$ & $\square$ \\
\hline $\begin{array}{l}\text { Other relevant sources } \\
\text { (please specify) }\end{array}$ & $\square$ & $\square$ & $\square$ & $\square$ & $\square$ & $\square$ \\
\hline
\end{tabular}

I do not know

C.15. Please give the scope of activity of the inventor at the time of the invention and the division where the inventor was employed and where the invention was realised.

\begin{tabular}{|l|c|c|}
\hline & $\begin{array}{c}\text { Scope of } \\
\text { activity }\end{array}$ & $\begin{array}{c}\text { Division where } \\
\text { the invention } \\
\text { was realised }\end{array}$ \\
\hline Research and education & $\square$ & $\square$ \\
\hline Logistics & $\square$ & $\square$ \\
\hline Production & $\square$ & $\square$ \\
\hline Marketing / sales & $\square$ & $\square$ \\
\hline Human resources & $\square$ & $\square$ \\
\hline $\begin{array}{l}\text { Top management (including strategic } \\
\text { planning) }\end{array}$ & $\square$ & $\square$ \\
\hline $\begin{array}{l}\text { Other (please } \\
\text { specify)_ }\end{array}$ & $\square$ & $\square$ \\
\hline
\end{tabular}

C.16. How important were the following sources of information at the time of the invention?

\begin{tabular}{|l|c|c|c|c|c|c|}
\hline Source of information & $\begin{array}{l}\text { Not } \\
\text { importa } \\
\text { nt }\end{array}$ & & & & $\begin{array}{l}\text { Very } \\
\text { import } \\
\text { ant }\end{array}$ & $\begin{array}{l}\text { Source was } \\
\text { not used }\end{array}$ \\
\cline { 2 - 6 } & $\mathbf{1}$ & $\mathbf{2}$ & $\mathbf{3}$ & $\mathbf{4}$ & $\mathbf{5}$ & \\
\hline $\begin{array}{l}\text { Disclosures of other } \\
\text { patents }\end{array}$ & $\square$ & $\square$ & $\square$ & $\square$ & $\square$ \\
\hline Scientific publications & $\square$ & $\square$ & $\square$ & $\square$ & $\square$ & $\square$ \\
\hline $\begin{array}{l}\text { Unpublished technological } \\
\text { documentation }\end{array}$ & $\square$ & $\square$ & $\square$ & $\square$ & $\square$ & $\square$ \\
\hline Fairs/expos & $\square$ & $\square$ & $\square$ & $\square$ & $\square$ & $\square$ \\
\hline $\begin{array}{l}\text { Participation on } \\
\text { technological conferences, } \\
\text { courses, etc. }\end{array}$ & $\square$ & $\square$ & $\square$ & $\square$ & $\square$ & $\square$ \\
\hline $\begin{array}{l}\text { Licensed inventions and } \\
\text { know-how }\end{array}$ & $\square$ & $\square$ & $\square$ & $\square$ & $\square$ & $\square$ \\
\hline
\end{tabular}




\begin{tabular}{|l|c|c|c|c|c|c|}
\hline $\begin{array}{l}\text { Communication with } \\
\text { colleagues }\end{array}$ & $\square$ & $\square$ & $\square$ & $\square$ & $\square$ & $\square$ \\
\hline \begin{tabular}{l} 
Other (please specify) \\
\hline
\end{tabular} & $\square$ & $\square$ & $\square$ & $\square$ & $\square$ & $\square$ \\
\hline
\end{tabular}

I I do not know

If disclosures of other patents were not important or the source was not used, please go to Question C.18.

C.17. How important were the disclosures of other patents during the inventive activity. Imagine that the inventor did not have known the patent disclosures which were used during the inventive process.

Please assess how much extra-time would have been needed to invent the innovation without knowing other patent disclosures.

a 0-2 hours

a $>2-5$ hours

口 $>5-10$ hours

a $>10-20$ hours

口 $>20-50$ hours

口 $>50-100$ hours

a More than 100 hours

a The extra time can not be accurately measured, but more than hours.

- The extra time can not be accurately measured, but less than hours.

I do not know

\section{Timing of the invention and necessary resources}

C.18. In which month and year did you start to work on this invention?

Month / Year

C.19. How many man-months did the research leading to the patent require?

(Example: If one inventor committed half of his/her work time for 3 years and another inventor committed one-third of his/her work time for two years on the invention, then the answer is 18 man-months +8 man-months = 26 man-months)

$\square$ There was no need for jobs related to research and development

$\square$ Less than 1 man-month

$\square \quad$ 1-3 man-months

4-6 man-months

ㄱ 7-12 man-months

ㄱ 13-24 man-months

ㄱ 25-48 man-months 
49-72 man-months

$\square$ more than 72 man-

months

$\square \quad$ I do not know

C.20. Which of the following would best describe the financing of the research leading to this patent? (can check more than one box below)

$\square$ Internal funds of the patent applicant (including his subsidiaries)

$\square$ Subsidies from the European Union and the Hungarian State

$\square$ National or regional R\&D supporting programs or other government funds

$\square$ Funds from any other unaffiliated organization joining the project

$\square$ Clients or users

$\square$ Suppliers of structural components, raw materials, equipment, etc.

$\square$ Funds from holding companies (venture capital) or private equity (business angels, etc.)

$\square$ Banks

$\square$ Other (please specify)

\section{Section - Utilization and value of patent}

Companies are not always able to accurately measure the value of their patents, but are usually able to estimate it fairly. Your estimation about the value is perfect for answering the questions in this section. If you are unsure of the answer, you can discuss it with other people from your company. The answers given to these questions serve as a tool to understand the valuation of patents. This information will not be disclosed in a way that would allow anyone to make any conclusion about you or your company's patent applications.

D.1. How important were the following reasons for patenting this invention? (Please refer to the date of patent application)

\begin{tabular}{|l|c|c|c|c|c|c|}
\hline & $\begin{array}{l}\text { Not } \\
\text { import } \\
\text { ant }\end{array}$ & & & & $\begin{array}{l}\text { Very } \\
\text { import } \\
\text { ant }\end{array}$ & $\begin{array}{l}\text { I do not } \\
\text { know }\end{array}$ \\
\cline { 2 - 6 } & $\mathbf{1}$ & $\mathbf{2}$ & $\mathbf{3}$ & $\mathbf{4}$ & $\mathbf{5}$ & \\
\hline $\begin{array}{l}\text { Commercial exploitation } \\
\text { (obtain exclusive rights to exploit } \\
\text { the invention economically) }\end{array}$ & $\square$ & $\square$ & $\square$ & $\square$ & $\square$ & $\square$ \\
\hline $\begin{array}{l}\text { Licensing (obtain exclusive } \\
\text { rights to license the invention in } \\
\text { order to generate licensing }\end{array}$ & $\square$ & $\square$ & $\square$ & $\square$ & $\square$ & $\square$ \\
\hline
\end{tabular}




\begin{tabular}{|l|l|l|l|l|l|l|}
\hline $\begin{array}{l}\text { revenues) } \\
\text { Cross-licensing (improve your } \\
\text { bargaining position in the trading } \\
\text { of your own patent rights in } \\
\text { exchange for other firms' patent } \\
\text { rights) }\end{array}$ & $\square$ & $\square$ & $\square$ & $\square$ & $\square$ & $\square$ \\
\hline $\begin{array}{l}\text { Prevention from imitation } \\
\text { (protect present or future } \\
\text { inventions by patenting the } \\
\text { "findings around") }\end{array}$ & $\square$ & $\square$ & $\square$ & $\square$ & $\square$ & $\square$ \\
\hline $\begin{array}{l}\text { Blocking patents (avoid that } \\
\text { others patent similar inventions) }\end{array}$ & $\square$ & $\square$ & $\square$ & $\square$ & $\square$ & $\square$ \\
\hline $\begin{array}{l}\text { Reputation (patents as an } \\
\text { element of evaluation of the } \\
\text { inventors/research unit) }\end{array}$ & $\square$ & $\square$ & $\square$ & $\square$ & $\square$ & $\square$ \\
\hline $\begin{array}{l}\text { Prevention of infringement } \\
\text { suits (support of a credible } \\
\text { threat, that the organisation can } \\
\text { file a suit if it is sued by third } \\
\text { parties) }\end{array}$ & $\square$ & $\square$ & $\square$ & $\square$ & $\square$ & $\square$ \\
\hline $\begin{array}{l}\text { Pure defense (ensuring that the } \\
\text { use of the own technology is not } \\
\text { hindered by third parties) }\end{array}$ & $\square$ & $\square$ & $\square$ & $\square$ & $\square$ & $\square$ \\
\hline $\begin{array}{l}\text { Technical standard (protection } \\
\text { of an invention which can be } \\
\text { useful as a part of a technical } \\
\text { standard) }\end{array}$ & $\square$ & $\square$ & $\square$ & $\square$ & $\square$ & $\square$ \\
\hline $\begin{array}{l}\text { Other (please specify) } \\
\text { - }\end{array}$ & $\square$ & $\square$ & $\square$ & $\square$ & $\square$ & $\square$ \\
\hline
\end{tabular}

D.2. Has the applicant/owner ever used this patent for commercial or industrial purposes?

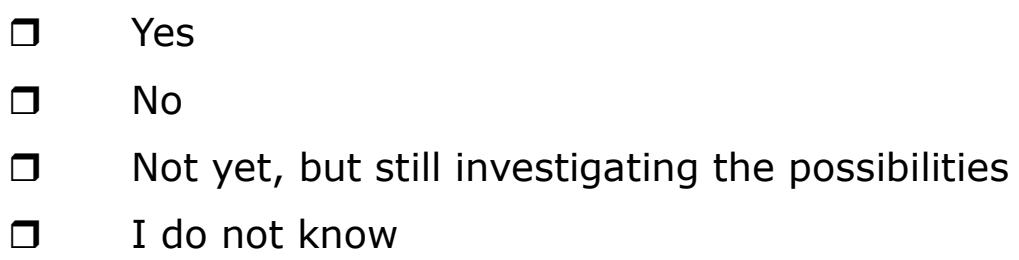

\section{Selling the patent}

D.3. Has this patent been sold by (one of) the patent-holder(s) to an independent party?

$\square \quad$ Yes

$\square \quad$ No

$\square$ No, but willing to sell

$\square$ I do not know

\section{Licensing the patent}


D.4. Has this patent been licensed by (one of) the patent-holder(s) to an independent party?

$\square$ Yes

$\square$ No

$$
\text { (->please go to Question D.7.) }
$$

$\square$ No, but licensing is planned (->please go to Question D.7.)

$\square$ I do not know (->please go to Question D.7.)

D.5. When licensing was it a cross-license agreement?
$\square$ Yes
$\square$ No
$\square$ I do not know

D.6. How many parties got licenses?

$\square$ Only one

ㄱ 2-4

口 5-10

11-50

$\square$ More than 50

口 I do not know

\section{Foundation of a new company}

D.7. Has this patent been exploited commercially by any inventor or your company by starting a new company?

$\square$ Yes, a new company has been founded

$\square$ No yet, but still investigating the possibilities

$\square$ No

(->please go to Question D.11.)

$\square \quad$ I do not know

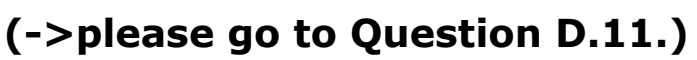

D.8. Who have founded/will found the company? (can check more boxes)

$\square$ The selected inventor

$\square$ Other inventor

ㄱour company

$\square$ Other applicant of the patent

$\square$ Other (please specify)

$\square$ I do not know 
D.9. What is the name of the new company and where is its residence?

Name:

Residence:

$\square$ I do not know

D.10. The new company / the planned company will be ...

\begin{tabular}{|l|l|}
\hline$\square$ & $\ldots$ owned partially by the inventor(s) \\
\hline$\square$ & $\ldots$ owned partially by the applicant(s) \\
\hline$\square$ & $\ldots$ independent (no ownership by the inventor or the applicant) \\
\hline$\square$ & I do not know \\
\hline
\end{tabular}

\section{Company competencies}

D.11. Please give how much are these statements true in case of your company:

\begin{tabular}{|l|c|c|c|c|c|c|}
\hline & $\begin{array}{l}\text { Not } \\
\text { agree }\end{array}$ & & & & $\begin{array}{l}\text { Totally } \\
\text { agree }\end{array}$ & $\begin{array}{l}\text { Not } \\
\text { relevant }\end{array}$ \\
\cline { 2 - 6 } & $\mathbf{1}$ & $\mathbf{2}$ & $\mathbf{3}$ & $\mathbf{4}$ & $\mathbf{5}$ & \\
\hline $\begin{array}{l}\text { The company had sufficient } \\
\text { technological } \\
\text { instruments with respect } \\
\text { to the invention. }\end{array}$ & $\square$ & $\square$ & $\square$ & $\square$ & $\square$ & $\square$ \\
\hline $\begin{array}{l}\text { The budget was enough } \\
\text { for the invention. }\end{array}$ & $\square$ & $\square$ & $\square$ & $\square$ & $\square$ & $\square$ \\
\hline $\begin{array}{l}\text { The company had } \\
\text { supplementary } \\
\text { technological capacities } \\
\text { for making the invention } \\
\text { successul in a } \\
\text { technological sense. }\end{array}$ & $\square$ & $\square$ & $\square$ & $\square$ & $\square$ & $\square$ \\
\hline $\begin{array}{l}\text { The company had } \\
\text { supplementary } \\
\text { resources for making the } \\
\text { invention successful in an } \\
\text { economical sense. (for ex. } \\
\text { in a form of new product or } \\
\text { process or other ways). }\end{array}$ & $\square$ & $\square$ & $\square$ & $\square$ & $\square$ & $\square$ \\
\hline $\begin{array}{l}\text { The company provided a } \\
\text { scientifically and } \\
\text { technologically inspiring } \\
\text { background. }\end{array}$ & $\square$ & $\square$ & $\square$ & $\square$ & $\square$ & $\square$ \\
\hline
\end{tabular}

\section{Technical standards}

D.12. Has technological standards been used during the invention or is the invention based on such standards like ISO or other standards given by industrial associations? 
$\square \quad$ Yes

(please go to Question D.15.)

$\square \quad$ Not yet, but assessing the possibilities (please go to

Question D.15.)

$\square \quad$ I do not know

(please go to Question D.15.)

D.13. Did any inventor cooperate in the elaboration of this technical standard?

$\square$ Yes

$\square \quad$ No

(please go to Question D.15.)

$\square$ I do not know

(please go to Question D.15.)

D.14. Please indicate the name of the organisation providing these technical standards.

Related patents (more patents for one innovation)

We define "related patents" as a group of patents which crucially depend on each other in terms of economical or in a technical way. Related patents can refer to the same priority applications or can be from the same research field.

D.15. Is this patent a related patent?

$\square$ Yes

№

$\square \quad$ I do not know

(->please go to Question D.19.)

(->please go to Question D.19.)

D.16. How many (applied or not applied) related patents exist?
$\square \quad 1$ - 5 patents
$\square \quad 6$ - 10 patents
$\square \quad 11$ - 20 patents
$\square \quad 21$ - 40 patents
$\square \quad 40$ - 80 patents
$\square \quad 81$ or more patents
ㄱ do not know

D.17. Please indicate the significance of this specific patent (application) in relation to the other related patents.

$\square$ This patent is obviously the most important 
$\square$ This patent is one of the more important patents

$\square$ Supporting patent relating to a less significant element of the invention

$\square \quad$ I do not know

D.18. What is your best estimate of the total costs (in Euro) of the research leading to all related patents up to the date of application? (Do not include legal fees or any other fees related to the patent application)

\section{Value of the patent}

D.19. What is your best estimate of the total costs (in Euro) of the research leading to this patent up to the date of application? (Do not include legal fees or any other fees related to the patent application)

D.20. Has the patent application already been granted?
$\square$ Yes
$\square$ No

(Please write the main reason for this)

$\square$ I do not know

From the following four questions (D.21. - D.24.) please answer only one - depending on whether the patent has been granted and whether there are related patents.

\section{D.21. Patent is granted and there are related patents}

This is a hypothetical question. "Suppose that on the day in which this patent was granted, the applicant had all the information about the value of the patent that is available today. In case a potential competitor of the applicant was interested in buying all the related patents, what would be the minimum price (in Euro) the applicant should demand?"

\begin{tabular}{|l|l|}
\hline$\square$ & Less than $30000 €$ \\
\hline$\square$ & $>€ 30.000-€ 100.000$ \\
\hline$\square$ & $>€ 100.000-€ 300.000$ \\
\hline$\square$ & $>300.000 €-1$ Million $€$ \\
\hline$\square$ & $>1$ Million $€-3$ Million $€$ \\
\hline$\square$ & $>3$ Million $€-10$ Million $€$ \\
\hline$\square$ & $>10$ Million $€-30$ Million $€$ \\
\hline$\square$ & $>30$ Million $€-100$ Million $€$ \\
\hline
\end{tabular}




\begin{tabular}{|l|l|}
\hline$\square$ & $>100$ Million $€-300$ Million $€$ \\
\hline$\square$ & More than 300 Million $€$ \\
\hline
\end{tabular}

\section{D.22. Patent is not granted and there are related patents}

This is a hypothetical question. "Suppose that on the day in which this patent was granted, the applicant had all the information about the value of the patent that is available today. In case a potential competitor of the applicant was interested in buying all the related patents, what would be the minimum price (in Euro) the applicant should demand?"

\begin{tabular}{|l|l|}
\hline$\square$ & Less than $30000 €$ \\
\hline$\square$ & $>€ 30.000-€ 100.000$ \\
\hline$\square$ & $>€ 100.000-€ 300.000$ \\
\hline$\square$ & $>300.000 €-1$ Million $€$ \\
\hline$\square$ & $>1$ Million $€-3$ Million $€$ \\
\hline$\square$ & $>10$ Million $€-30$ Million $€$ \\
\hline$\square$ & $>30$ Million $€-100$ Million $€$ \\
\hline$\square$ & $>100$ Million $€-300$ Million $€$ \\
\hline$\square$ & More than 300 Million $€$ \\
\hline$\square$ &
\end{tabular}

\section{D.23. Patent is not granted and there are related patents}

This is a hypothetical question. "Suppose that on the day in which this patent was granted, the applicant had all the information about the value of the patent that is available today. In case a potential competitor of the applicant was interested in buying the patent, what would be the minimum price (in Euro) the applicant should demand?"

\begin{tabular}{|l|l|}
\hline$\square$ & Less than $30000 €$ \\
\hline$\square$ & $>€ 30.000-€ 100.000$ \\
\hline$\square$ & $>€ 100.000-€ 300.000$ \\
\hline$\square$ & $>300.000 €-1$ Million $€$ \\
\hline$\square$ & $>1$ Million $€-3$ Million $€$ \\
\hline$\square$ & $>3$ Million $€-10$ Million $€$ \\
\hline$\square$ & $>10$ Million $€-30$ Million $€$ \\
\hline$\square$ & $>30$ Million $€-100$ Million $€$ \\
\hline$\square$ & More than 300 Million $€$ \\
\hline$\square$ &
\end{tabular}

D.24. Patent is not granted and there are no related patents 
This is a hypothetical question. "Suppose that on the day in which this patent was granted, the applicant had all the information about the value of the patent that is available today. In case a potential competitor of the applicant was interested in buying the patent, what would be the minimum price (in Euro) the applicant should demand?"

\begin{tabular}{|l|l|}
\hline$\square$ & Less than $30000 €$ \\
\hline$\square$ & $>€ 30.000-€ 100.000$ \\
\hline$\square$ & $>€ 100.000-€ 300.000$ \\
\hline$\square$ & $>300.000 €-1$ Million $€$ \\
\hline$\square$ & $>1$ Million $€-3$ Million $€$ \\
\hline$\square$ & $>3$ Million $€-10$ Million $€$ \\
\hline$\square$ & $>10$ Million $€-30$ Million $€$ \\
\hline$\square$ & $>30$ Million $€-100$ Million $€$ \\
\hline$\square$ & $>100$ Million $€-300$ Million $€$ \\
\hline$\square$ & More than 300 Million $€$ \\
\hline
\end{tabular}

D.25. Suppose that all related patent applications are granted. Suppose that only this patent is not granted. What is your estimation, how many percent decrease would this imply with respect to the value given previously.

$\%$

$\square \quad$ No patent family

D.26. In comparison with other patents in your industry or technological field, how would you rate the economic and strategic value of this patent?

Top $10 \%$

ㄱop $25 \%$, but not top $10 \%$

口 Top $50 \%$, but not top $25 \%$

$\square \quad$ Bottom $50 \%$

D.27. Please assess the inventive step of the patent at the date of the application (The invention has an inventive step when it is not obvious for an expert of the relevant technological field.)

\begin{tabular}{|c|c|c|c|c|c|}
\hline \multicolumn{7}{|c|}{ Inventive step with respect to existing inventions } \\
\hline Very big & & Average & & Very small & $\begin{array}{c}\text { I do not } \\
\text { know }\end{array}$ \\
\hline $\mathbf{1}$ & $\mathbf{2}$ & $\mathbf{3}$ & $\mathbf{4}$ & $\mathbf{5}$ & $\square$ \\
\hline$\square$ & $\square$ & $\square$ & $\square$ & $\square$ & $\square$ \\
\hline
\end{tabular}


D.28. Was this patent ever litigated in a court? (By litigation, we mean court proceedings other than opposition or appeal at the Patent Office)

$\square$ Yes $\square$ No

\section{Value of patent protection}

D.29. The value of related patents provided in the Questions D.21D.24. have two components. One is the value of the innovation, the other is the value of the legal protection ensured by the patent protection. What do you think, what is the ratio of the value of the legal protection ensured by the patents is to the whole value of the patents?

(Please provide a percentage)

\section{No related patents (-> please go to Question D.32)}

D.30. If the innovations were not protected by patents but other alternative methods (for example: trade secret, lead time advantage, complementary assets, etc.), how would have this changed the whole value of the patents?

(Please provide a percentage)

D.31. Would all of the related patents have been invented even in the case when patent protection was not available?

$\square$ Yes

$\square$ number of patents, which gives $\%$ of the whole value of would not have been invented.

D.32. The value of the patent provided in the Questions D.21-D.24. have two components. One is the value of the innovation, the other is the value of the legal protection ensured by the patent protection. What do you think, what is the ratio of the value of the legal protection ensured by the patent is to the whole value of the patent?

(Please provide a percentage)

D.33. If the innovation was not protected by patent but other alternative methods (for example: trade secret, lead time advantage, complementary assets, etc.), how would have this changed the whole value of the patent? 
(Please provide a percentage)

D.34 Would the patent have been invented even in the case when patent protection was not available?

Yes $\square$ No

\section{E. Section: Characteristics of the patent}

Patents are very diverse. There are several special attributes which influence heavily the utility of the patents.

\section{Yield production of the innovation}

E.1. How long the period until the applicant is/was could theoretically generate yield from the innovation? (Normal lifetime of the innovation)

(Please provide a lifetime in years)

E.2. How long the period until the applicant is/was could effectively generate yield from the innovation? (Effective lifetime of the innovation)

(Please provide a lifetime in years)

(If the answer provided for Questions E.1. and E.2. please go to Question E.4.)

E.3. What is the main reason for the differing theoretical and effective lifetimes of the innovation? (please check only one box near the relevant answer)

口 Lapse of patent protection time

- Lawful invention of a new, more competitive innovation similar to this innovation, one probably even based on this innovation.

- Unlawful invention of a new, more competitive innovation similar to this innovation, one probably even based on this innovation.

- Invention of a new, more competitive innovation not similar to this innovation

L Lengthening of the lifetime of the innovation in the following way (please specify):

$\square$ Other (please specify)

E.4. Due to the innovation has the environmental impact of a unit product or service during its complete life cycle has decreased 
compared to the relevant alternatives? (independently from the fact whether it was a primary objective of innovation or only its positive side effect)

$\square$ Yes, because (please specify)

$\square$ No

E.5. What is your opinion, has the patenting helped the spread and diffusion of the innovation?

$\square$ Yes, because (please specify):

$\square$ No, because (please specify):

\section{Patent system}

In the following we would like to study how satisfied are you with the current operation of the whole patent system. The Questions refer to the Hungarian and European patent system, including the current legal framework (for example: duration of patent protection, fees, methods of approving a patent, litigation), the subjects available for patenting, the patenting process in the countries and the role of the participating institutions (for example the patent offices).

E.6. Think about the patents where you have applied for a patent. Please assess that in which proportions of these were you or other applicants interested in the faster granting of the patent.

$\%$

E.7. How much you do agree with the following statements?

\begin{tabular}{|l|c|c|c|c|c|c|}
\hline & $\begin{array}{c}\text { Absolutel } \\
\text { y not }\end{array}$ & & & & $\begin{array}{c}\text { Absolutel } \\
\text { y }\end{array}$ & $\begin{array}{c}\text { I do } \\
\text { not } \\
\text { kno } \\
\text { w }\end{array}$ \\
\cline { 2 - 7 } & $\mathbf{1}$ & $\mathbf{2}$ & $\mathbf{3}$ & $\mathbf{4}$ & $\mathbf{5}$ & $\square$ \\
\hline $\begin{array}{l}\text { Patent system in its current } \\
\text { form supports innovative } \\
\text { activity }\end{array}$ & $\square$ & $\square$ & $\square$ & $\square$ & $\square$ & $\square$ \\
\hline $\begin{array}{l}\text { The setting up of the single } \\
\text { European Patent and } \\
\text { European Patent Court will } \\
\text { support innovative activity }\end{array}$ & $\square$ & $\square$ & $\square$ & $\square$ & $\square$ & $\square$ \\
\hline $\begin{array}{l}\text { The current approval time of } \\
\text { patents is appropriate. }\end{array}$ & $\square$ & $\square$ & $\square$ & $\square$ & $\square$ & $\square$ \\
\hline $\begin{array}{l}\text { Current patenting fees applied } \\
\text { by the Hungarian Intellectual } \\
\text { Property Office impose a barrier } \\
\text { and significantly hinder } \\
\text { patenting activity }\end{array}$ & $\square$ & $\square$ & $\square$ & $\square$ & $\square$ & $\square$ \\
\hline
\end{tabular}




\begin{tabular}{|l|l|l|l|l|l|l|}
\hline $\begin{array}{l}\text { Renewal fee of patents } \\
\text { should be increased in order to } \\
\text { eliminate the numerous relatively } \\
\text { valueless patent faster }\end{array}$ & $\square$ & $\square$ & $\square$ & $\square$ & $\square$ & $\square$ \\
\hline $\begin{array}{l}\text { If someone else other than the } \\
\text { applicant of the patent has } \\
\text { independently invented the } \\
\text { same innovation, and can prove } \\
\text { it, should have the right to use it } \\
\text { freely }\end{array}$ & $\square$ & $\square$ & $\square$ & $\square$ & $\square$ & $\square$ \\
\hline $\begin{array}{l}\text { Obligatory licensing should be } \\
\text { given to those who demand it, in } \\
\text { exchange for a fee proportional } \\
\text { to the R\&D costs }\end{array}$ & $\square$ & $\square$ & $\square$ & $\square$ & $\square$ & $\square$ \\
\hline $\begin{array}{l}\text { Instead of patents the } \\
\text { incentive of the inventors should } \\
\text { be supported by subsidies } \\
\text { amounting to 15-35\% of the } \\
\text { R\&D costs }\end{array}$ & $\square$ & $\square$ & $\square$ & $\square$ & $\square$ & $\square$ \\
\hline $\begin{array}{l}\text { The patent system should be } \\
\text { gradually abolished in several } \\
\text { steps }\end{array}$ & $\square$ & $\square$ & $\square$ & $\square$ & $\square$ & $\square$ \\
\hline \begin{tabular}{l} 
Other (please specify): \\
\hline
\end{tabular} & $\square$ & $\square$ & $\square$ & $\square$ & $\square$ & $\square$ \\
\hline
\end{tabular}

\section{F. Section - Inventor}

\section{F.1. Birth country of inventor}

\section{F.2. Birth year of inventor}

F.3. Which language does the inventor speaks at home?

F.4. When the research leading to this patent was conducted, the inventor's highest degree was (Check one box near the relevant answer))

\begin{tabular}{|c|l|}
\hline$\square$ & Secondary School or lower \\
\hline$\square$ & High School Diploma \\
\hline$\square$ & University BA or equivalent \\
\hline$\square$ & University Master or equivalent \\
\hline$\square$ & University PhD or equivalent \\
\hline$\square$ & Habilitation \\
\hline$\square$ & No data (->go to the end) \\
\hline
\end{tabular}


F.5. The year in which this degree was earned:

F.6. The country in which it was earned:

F.7. For University BA or higher, the discipline in which the degree was earned

(e.g. mechanical engineering, biochemistry):

F.8. If the inventor has $B A$ or Masters degree, please enter the name of the institution or the university, where he graduated. (in case of more than one degree, please indicate only the most important for the patent)

F.9. If the inventor has a doctorate, was the Ph.D. acquired in another university or institution, than the university where the Masters degree was acquired?

$\square$ Yes $\square$ No

\section{REMARKS}

Please enter your email address if you would like to be informed about the results of the research: @ 


\section{Annex}

Association between Innovation Without Patent (D34) and Environmental Innovation $(\mathrm{E} 4 / 1)$

\begin{tabular}{|c|c|c|c|c|c|c|}
\hline \multicolumn{7}{|c|}{ Case Processing Summary } \\
\hline & \multicolumn{6}{|c|}{ Cases } \\
\hline & \multicolumn{2}{|c|}{ Valid } & \multicolumn{2}{|c|}{ Missing } & \multicolumn{2}{|c|}{ Total } \\
\hline & $\mathrm{N}$ & Percent & $\mathrm{N}$ & Percent & $\mathrm{N}$ & Percent \\
\hline$E 4 / 1$ * D34 & 38 & $97,4 \%$ & 1 & $2,6 \%$ & 39 & $100,0 \%$ \\
\hline
\end{tabular}

\section{E4/1 * D34 Crosstabulation}

\begin{tabular}{|c|c|c|c|c|c|}
\hline & \multicolumn{2}{|c|}{ D34 } & \multirow[b]{2}{*}{ Total } \\
\hline & & & no & yes & \\
\hline \multirow[t]{12}{*}{ E4/1 } & \multirow[t]{6}{*}{ no } & Count & $4 a$ & $10_{a}$ & 14 \\
\hline & & Expected Count & 2,6 & 11,4 & 14,0 \\
\hline & & $\%$ within E4/1 & $28,6 \%$ & $71,4 \%$ & $100,0 \%$ \\
\hline & & \% within D34 & $57,1 \%$ & $32,3 \%$ & $36,8 \%$ \\
\hline & & $\%$ of Total & $10,5 \%$ & $26,3 \%$ & $36,8 \%$ \\
\hline & & Std. Residual & ,9 &,- 4 & \\
\hline & \multirow[t]{6}{*}{ yes } & Count & $3 a$ & $21_{a}$ & 24 \\
\hline & & Expected Count & 4,4 & 19,6 & 24,0 \\
\hline & & \% within E4/1 & $12,5 \%$ & $87,5 \%$ & $100,0 \%$ \\
\hline & & \% within D34 & $42,9 \%$ & $67,7 \%$ & $63,2 \%$ \\
\hline & & $\%$ of Total & $7,9 \%$ & $55,3 \%$ & $63,2 \%$ \\
\hline & & Std. Residual &,- 7 & 3 & \\
\hline \multirow[t]{5}{*}{ Total } & & Count & 7 & 31 & 38 \\
\hline & & Expected Count & 7,0 & 31,0 & 38,0 \\
\hline & & $\%$ within E4/1 & $18,4 \%$ & $81,6 \%$ & $100,0 \%$ \\
\hline & & \% within D34 & $100,0 \%$ & $100,0 \%$ & $100,0 \%$ \\
\hline & & $\%$ of Total & $18,4 \%$ & $81,6 \%$ & $100,0 \%$ \\
\hline
\end{tabular}

Each subscript letter denotes a subset of D34 categories whose column proportions do not differ significantly from each other at the, 05 level.

Chi-Square Tests

\begin{tabular}{|c|c|c|c|c|c|}
\hline & Value & $\mathrm{df}$ & $\begin{array}{l}\text { Asymp. Sig. } \\
\text { (2-sided) }\end{array}$ & $\begin{array}{l}\text { Exact Sig. } \\
\text { (2-sided) }\end{array}$ & $\begin{array}{l}\text { Exact Sig. } \\
\text { (1-sided) }\end{array}$ \\
\hline Pearson Chi-Square & $1,520^{a}$ & 1 & 218 & \multirow{6}{*}{,387 } & \multirow{6}{*}{,210 } \\
\hline Continuity Correction $^{b}$ & 638 & 1 & ,424 & & \\
\hline Likelihood Ratio & 1,470 & 1 & ,225 & & \\
\hline Fisher's Exact Test & & & & & \\
\hline $\begin{array}{l}\text { Linear-by-Linear } \\
\text { Association }\end{array}$ & 1,480 & 1 & ,224 & & \\
\hline $\mathrm{N}$ of Valid Cases & 38 & & & & \\
\hline
\end{tabular}

a. 2 cells $(50,0 \%)$ have expected count less than 5 . The minimum expected count is 2,58 .

b. Computed only for a $2 \times 2$ table

Directional Measures

\begin{tabular}{|c|c|c|c|c|}
\hline & & & Value & $\begin{array}{l}\text { Asymp. Std. } \\
\text { Error }^{\mathrm{a}}\end{array}$ \\
\hline \multirow{3}{*}{$\begin{array}{l}\text { Nominal } \\
\text { Nominal }\end{array}$} & \multirow[t]{3}{*}{ by Lambda } & Symmetric & ,048 & ,122 \\
\hline & & $\begin{array}{l}\text { E4/1 } \\
\text { Dependent }\end{array}$ & 071 & ,182 \\
\hline & & D34 Dependent &, 000 &, 000 \\
\hline
\end{tabular}




\begin{tabular}{|ll|r|r|}
\hline \begin{tabular}{ll|r|} 
Goodman and Kruskal E4/1 \\
tau
\end{tabular} & Dependent &, 040 &, 066 \\
& D34 Dependent &, 040 &, 067 \\
\hline Uncertainty Coefficient & Symmetric &, 034 &, 056 \\
& E4/1 &, 029 &, 049 \\
& Dependent &, 066 \\
\cline { 2 - 4 } & D34 Dependent &, 040 & .
\end{tabular}

\begin{tabular}{|c|c|c|c|c|c|}
\hline \multicolumn{6}{|c|}{ Directional Measures } \\
\hline & & & & Approx. & $\begin{array}{l}\text { Approx. } \\
\text { Sig. }\end{array}$ \\
\hline \multirow{8}{*}{$\begin{array}{l}\text { Nominal } \\
\text { Nominal }\end{array}$} & \multirow[t]{8}{*}{ by } & Lambda & Symmetric & ,379 & ,705 \\
\hline & & & $\begin{array}{l}\text { E4/1 } \\
\text { Dependent }\end{array}$ & 379 & ,705 \\
\hline & & & D34 Dependent & $c$ &.${ }^{c}$ \\
\hline & & $\begin{array}{l}\text { Goodman and Kruskal } \\
\text { tau }\end{array}$ & $\begin{array}{l}\text { E4/1 } \\
\text { Dependent }\end{array}$ & &, $224^{d}$ \\
\hline & & & D34 Dependent & &, $224^{d}$ \\
\hline & & Uncertainty Coefficient & Symmetric & ,603 &, $225^{\mathrm{e}}$ \\
\hline & & & $\begin{array}{l}\text { E4/1 } \\
\text { Dependent }\end{array}$ & ,603 &, $225^{\mathrm{e}}$ \\
\hline & & & D34 Dependent & ,603 & $225^{\mathrm{e}}$ \\
\hline
\end{tabular}

a. Not assuming the null hypothesis.

b. Using the asymptotic standard error assuming the null hypothesis.

c. Cannot be computed because the asymptotic standard error equals zero.

d. Based on chi-square approximation

e. Likelihood ratio chi-square probability.

\begin{tabular}{|ll|r|r|}
\hline \multicolumn{3}{|c|}{ Symmetric Measures } \\
\hline Nominal by Nominal & Phi & \multicolumn{1}{c|}{ Value } & Approx. Sig. \\
& Cramer's V &, 200 &, 218 \\
& Contingency Coefficient &, 200 &, 218 \\
\cline { 2 - 4 } N of Valid Cases & & 38 &, 218 \\
\hline
\end{tabular}

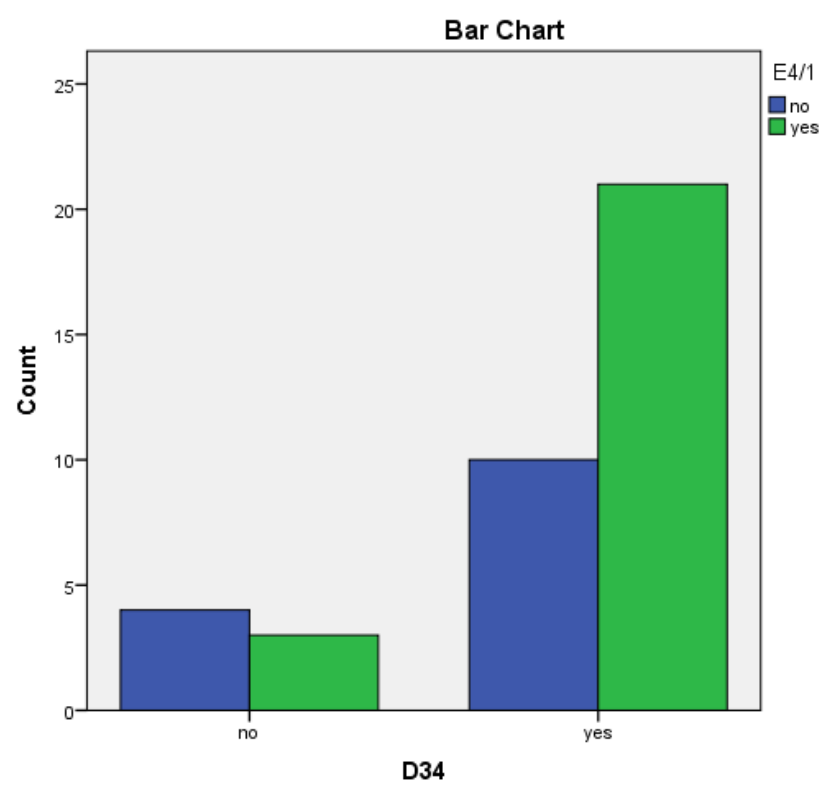

Filtering out innovations from the pharmaceutical industry 
Env_Inn_Wo_Pharma_Real * D34 Crosstabulation

Count

\begin{tabular}{|c|c|c|c|c|}
\hline & & $\mathrm{D}$ & & \\
\hline & & no & yes & Total \\
\hline Env_Inn_Wo_Pharma_Real & ,00 & 1 & 9 & 10 \\
\hline & 1,00 & 3 & 20 & 23 \\
\hline Total & & 4 & 29 & 33 \\
\hline
\end{tabular}

Chi-Square Tests

\begin{tabular}{|c|c|c|c|c|c|}
\hline & Value & df & $\begin{array}{c}\text { Asymp. Sig. } \\
\text { (2-sided) }\end{array}$ & $\begin{array}{c}\text { Exact Sig. (2- } \\
\text { sided) }\end{array}$ & $\begin{array}{c}\text { Exact Sig. (1- } \\
\text { sided) }\end{array}$ \\
\hline $\begin{array}{l}\text { Pearson Chi-Square } \\
\text { Continuity Correction }^{\text {b }} \\
\text { Likelihood Ratio } \\
\text { Fisher's Exact Test } \\
\text { Linear-by-Linear } \\
\text { Association } \\
\mathrm{N} \text { of Valid Cases }\end{array}$ & $\begin{array}{r}, 061^{\mathrm{a}} \\
, 000 \\
, 063 \\
, 059 \\
33\end{array}$ & $\begin{array}{l}1 \\
1 \\
1\end{array}$ & $\begin{array}{r}, 806 \\
1,000 \\
, 802 \\
, 808\end{array}$ & 1,000 & ,649 \\
\hline
\end{tabular}

a. 2 cells $(50,0 \%)$ have expected count less than 5 . The minimum expected count is 1,21 .

b. Computed only for a $2 \times 2$ table

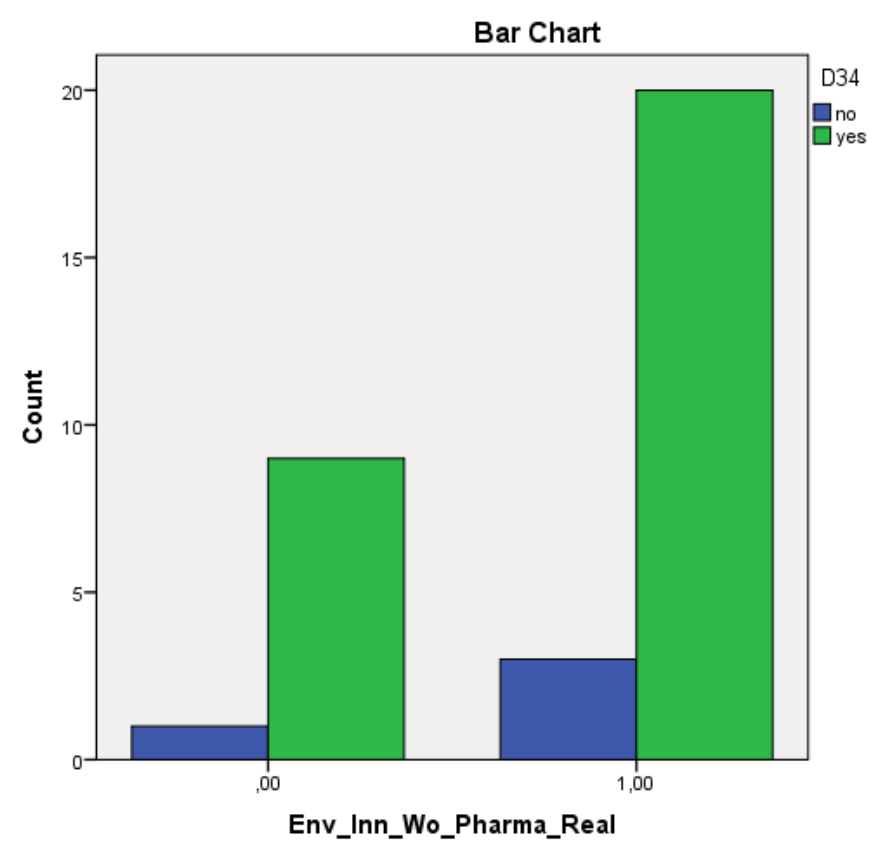


8. Annex

The explanatory power of Innovation Prize on the Patent Value

\begin{tabular}{|ll|r|r|}
\hline \multicolumn{2}{|c|}{ Correlations } \\
\hline Inn_prize & Inn_prize & Pat_Val_EUR \\
& Pearson Correlation & 1 &, 450 \\
& Sig. (2-tailed) & &, 010 \\
& $\mathrm{~N}$ & 39 & 32 \\
\hline Pat_Val_EUR & Pearson Correlation &, 450 & 1 \\
& Sig. (2-tailed) &, 010 & \\
& $\mathrm{~N}$ & 32 & 32 \\
\hline
\end{tabular}

${ }^{\star \star}$. Correlation is significant at the 0.01 level (2-tailed).

Correlations

\begin{tabular}{|c|c|c|c|c|}
\hline & & & Inn_prize & Pat_Val_EUR \\
\hline \multirow[t]{6}{*}{ Kendall's tau_b } & Inn_prize & Correlation Coefficient & 1,000 & ,085 \\
\hline & & Sig. (2-tailed) & &, 562 \\
\hline & & $\mathrm{N}$ & 39 & 32 \\
\hline & Pat_Val_EUR & Correlation Coefficient & ,085 & 1,000 \\
\hline & & Sig. (2-tailed) &, 562 & \\
\hline & & $\mathrm{N}$ & 32 & 32 \\
\hline \multirow[t]{6}{*}{ Spearman's rho } & Inn_prize & Correlation Coefficient & 1,000 & ,101 \\
\hline & & Sig. (2-tailed) & & ,582 \\
\hline & & $\mathrm{N}$ & 39 & 32 \\
\hline & Pat_Val_EUR & Correlation Coefficient & ,101 & 1,000 \\
\hline & & Sig. (2-tailed) &, 582 & \\
\hline & & $\mathrm{N}$ & 32 & 32 \\
\hline
\end{tabular}

With a value of EUR 350 Million for the most valuable patents

\begin{tabular}{|c|c|c|c|}
\hline \multicolumn{4}{|c|}{ Correlations } \\
\hline & & Inn_prize & Pat_Val_EUR2 \\
\hline \multirow[t]{3}{*}{ Inn_prize } & Pearson Correlation & 1 &, 468 \\
\hline & Sig. (2-tailed) & & ,007 \\
\hline & $\mathrm{N}$ & 39 & 32 \\
\hline \multirow[t]{3}{*}{ Pat_Val_EUR2 } & Pearson Correlation & 468 & 1 \\
\hline & Sig. (2-tailed) &, 007 & \\
\hline & $\mathrm{N}$ & 32 & 32 \\
\hline
\end{tabular}

${ }^{* *}$. Correlation is significant at the 0.01 level (2-tailed).

\section{Correlations}

\begin{tabular}{|lll|r|r|}
\hline & & & Inn_prize & Pat_Val_EUR2 \\
\hline Kendall's tau_b & Inn_prize & Correlation Coefficient & 1,000 &, 085 \\
& & Sig. (2-tailed) &. &, 562 \\
& & $\mathrm{~N}$ & 39 & 32 \\
\cline { 2 - 5 } & & Correlation Coefficient &, 085 & 1,000 \\
& & Sat_Val_EUR2 &, 562 &. \\
& & $\mathrm{~N}$ & 32 & 32 \\
\hline Spearman's rho & Inn_prize & Correlation Coefficient & 1,000 &, 101 \\
& & Sig. (2-tailed) &. &, 582
\end{tabular}




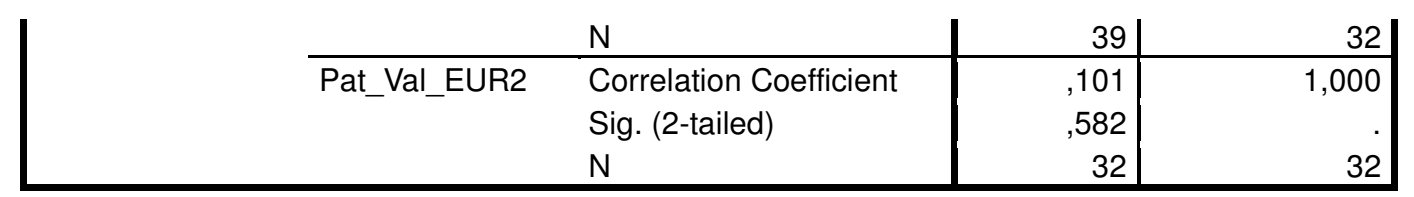


9. Annex

Association between Patent Value and Environmental Innovation (E4/1)

Case Processing Summary

\begin{tabular}{|c|c|c|c|c|c|c|}
\hline & \multicolumn{6}{|c|}{ Cases } \\
\hline & \multicolumn{2}{|c|}{ Valid } & \multicolumn{2}{|c|}{ Missing } & \multicolumn{2}{|c|}{ Total } \\
\hline & $\mathrm{N}$ & Percent & $\mathrm{N}$ & Percent & $\mathrm{N}$ & Percent \\
\hline E4/1 * Pat_Val_EUR & 32 & $82,1 \%$ & 7 & $17,9 \%$ & 39 & $100,0 \%$ \\
\hline
\end{tabular}

Directional Measures

\begin{tabular}{|c|c|c|}
\hline & & Value \\
\hline Nominal by Interval Eta & $\begin{array}{l}\text { E4/1 Dependent } \\
\text { Pat_Val_EUR Dependent }\end{array}$ & $\begin{array}{l}, 468 \\
, 324\end{array}$ \\
\hline
\end{tabular}

ANOVA Table

\begin{tabular}{|ll|r|r|r|r|r|}
\hline & & $\begin{array}{r}\text { Sum of } \\
\text { Squares }\end{array}$ & df & \multicolumn{1}{c|}{$\begin{array}{c}\text { Mean } \\
\text { Square }\end{array}$} & F & Sig. \\
\hline $\begin{array}{l}\text { Pat_Val_EUR } \\
\text { *E4/1 }\end{array}$ & Between (Combin & $\begin{array}{r}45832341 \\
319,219\end{array}$ & 1 & $\begin{array}{r}45832341 \\
319,219\end{array}$ & 3,521 &, 070 \\
& Groups ed) & $\begin{array}{r}39045083 \\
1098,750\end{array}$ & 30 & $\begin{array}{r}13015027 \\
703,292\end{array}$ & & \\
\cline { 2 - 7 } & Within Groups & $\begin{array}{r}43628317 \\
2417,969\end{array}$ & 31 & & & \\
\cline { 2 - 7 } & Total & & & \\
\hline
\end{tabular}

With modified value of highest value patents: EUR 350 Million instead of EUR 650 Million

Directional Measures

\begin{tabular}{|c|c|c|}
\hline & & Value \\
\hline Nominal by Interval Eta & $\begin{array}{l}\text { E4/1 Dependent } \\
\text { Pat_Val_EUR2 Dependent }\end{array}$ & $\begin{array}{l}, 468 \\
, 370\end{array}$ \\
\hline
\end{tabular}

ANOVA Table

\begin{tabular}{|c|c|c|c|c|c|c|c|}
\hline & & & $\begin{array}{l}\text { Sum of } \\
\text { Squares }\end{array}$ & df & $\begin{array}{c}\text { Mean } \\
\text { Square }\end{array}$ & $\mathrm{F}$ & Sig. \\
\hline \multirow[t]{3}{*}{$\begin{array}{l}\text { Pat_Val_EUR2 } \\
{ }^{*} E 4 / 1\end{array}$} & $\begin{array}{l}\text { Between } \\
\text { Groups }\end{array}$ & $\begin{array}{l}\text { (Combin } \\
\text { ed) }\end{array}$ & $\begin{array}{r}21205060 \\
069,219\end{array}$ & 1 & $\begin{array}{r}21205060 \\
069,219\end{array}$ & 4,767 & ,037 \\
\hline & \multicolumn{2}{|c|}{ Within Groups } & $\begin{array}{r}13345733 \\
1098,750\end{array}$ & 30 & $\begin{array}{r}44485777 \\
03,292\end{array}$ & & \\
\hline & \multicolumn{2}{|l|}{ Total } & $\begin{array}{r}15466239 \\
1167,969\end{array}$ & 31 & & & \\
\hline
\end{tabular}


10. Annex

The explanatory power of Firm size on the Patent Value

Model Summary and Parameter Estimates

Dependent Variable: Log_Patval_EUR

\begin{tabular}{|c|c|c|c|c|c|c|c|c|c|}
\hline \multirow[b]{2}{*}{ Equation } & \multicolumn{5}{|c|}{ Model Summary } & \multicolumn{4}{|c|}{ Parameter Estimates } \\
\hline & $\begin{array}{c}\mathrm{R} \\
\text { Square }\end{array}$ & $\mathrm{F}$ & df1 & $\mathrm{df} 2$ & Sig. & $\begin{array}{c}\text { Consta } \\
\text { nt }\end{array}$ & b1 & $\mathrm{b} 2$ & b3 \\
\hline Linear & ,024 & ,703 & 1 & 29 & ,409 & 2,790 & ,089 & & \\
\hline $\begin{array}{l}\text { Logarithmi } \\
c^{\text {a }}\end{array}$ & & & ${ }^{\circ}$ & & & & & & \\
\hline Inverse & ,048 & 1,459 & 1 & 29 & ,237 & 3,677 & $-2,425$ & & \\
\hline Quadratic & , 155 & 2,566 & 2 & 28 & ,095 & 2,741 &,- 205 & ,050 & \\
\hline Cubic & ,156 & 1,659 & 3 & 27 & , 199 & 2,516 &,- 205 & ,070 &,- 002 \\
\hline $\begin{array}{l}\text { Exponenti } \\
\text { al }\end{array}$ & ,018 &, 544 & 1 & 29 & ,467 & 2,678 & ,026 & & \\
\hline Logistic & 018 &, 544 & 1 & 29 & ,467 & ,373 & 975 & & \\
\hline
\end{tabular}

The independent variable is LogSales.

a. The independent variable (LogSales) contains non-positive values. The minimum value is 3,00. The Logarithmic and Power models cannot be calculated.

Model Summary and Parameter Estimates

Dependent Variable: Log_Patval_EUR

\begin{tabular}{|c|c|c|c|c|c|c|c|c|c|}
\hline \multirow[b]{2}{*}{ Equation } & \multicolumn{5}{|c|}{ Model Summary } & \multicolumn{4}{|c|}{ Parameter Estimates } \\
\hline & $\begin{array}{c}\mathrm{R} \\
\text { Square }\end{array}$ & $\mathrm{F}$ & df1 & $\mathrm{df2}$ & Sig. & $\begin{array}{c}\text { Consta } \\
\text { nt }\end{array}$ & b1 & b2 & b3 \\
\hline $\begin{array}{l}\text { Linear } \\
\text { Logarithmi }^{c^{a}} \\
\text { Inverse }^{\text {b }}\end{array}$ & ,116 & 3,553 & 1 & 27 & ,070 & 2,498 & ,458 & & \\
\hline Quadratic & ,121 & 1,796 & 2 & 26 & , 186 & 2,669 & ,157 & ,095 & \\
\hline Cubic & ,123 & 1,166 & 3 & 25 & ,342 & 2,597 & ,463 &,- 144 & ,049 \\
\hline $\begin{array}{l}\text { Exponenti } \\
\text { al }\end{array}$ & ,128 & 3,959 & 1 & 27 & ,057 & 2,357 & ,156 & & \\
\hline Logistic & ,128 & 3,959 & 1 & 27 & ,057 & ,424 & ,855 & & \\
\hline
\end{tabular}

The independent variable is LogEmployee_nr.

a. The independent variable (LogEmployee_nr) contains non-positive values. The minimum value is ,00. The Logarithmic and Power models cannot be calculated.

b. The independent variable (LogEmployee_nr) contains values of zero. The Inverse and $S$ models cannot be calculated.

\section{Model Summary and Parameter Estimates}

Dependent Variable: Log_Patval_EUR

\begin{tabular}{|l|r|r|r|r|r|r|r|r|r|}
\hline \multirow{4}{*}{ Equation } & \multicolumn{4}{|c|}{ Model Summary } & \multicolumn{4}{c|}{ Parameter Estimates } \\
\cline { 2 - 10 } & $\begin{array}{c}\mathrm{R} \\
\text { Square }\end{array}$ & $\mathrm{F}$ & $\mathrm{df1}$ & $\mathrm{df2}$ & $\mathrm{S}$ Sig. & $\begin{array}{c}\text { Consta } \\
\mathrm{nt}\end{array}$ & $\mathrm{b} 1$ & $\mathrm{~b} 2$ & $\mathrm{~b} 3$ \\
\hline Linear &, 136 & 3,605 & 1 & 23 &, 070 & 1,345 &, 341 & & \\
\hline
\end{tabular}




\begin{tabular}{|l|r|r|r|r|r|r|r|r|r|} 
mic &, 121 & 3,158 & 1 & 23 &, 089 &, 264 & 1,763 & & \\
Inverse &, 100 & 2,546 & 1 & 23 &, 124 & 4,799 & $-8,159$ & & \\
Quadrati &, 147 & 1,889 & 2 & 22 &, 175 & 3,441 &,- 419 &, 066 & \\
C &, 151 & 1,246 & 3 & 21 &, 318 & 7,823 & $-2,975$ &, 541 &,- 028 \\
Cubic &, 124 & 3,263 & 1 & 23 &, 084 & 1,694 &, 106 & & \\
Exponent &, 124 & 3,263 & 1 & 23 &, 084 &, 590 &, 900 & & \\
ial & Logistic & & & & & & \\
\hline
\end{tabular}

The independent variable is LogSaleswoSpinoff.

Model Summary and Parameter Estimates

Dependent Variable: Log_Patval_EUR

\begin{tabular}{|c|c|c|c|c|c|c|c|c|c|}
\hline \multirow[b]{2}{*}{ Equation } & \multicolumn{5}{|c|}{ Model Summary } & \multicolumn{4}{|c|}{ Parameter Estimates } \\
\hline & $\begin{array}{c}\mathrm{R} \\
\text { Square }\end{array}$ & $\mathrm{F}$ & df1 & $\mathrm{df} 2$ & Sig. & $\begin{array}{c}\text { Consta } \\
\text { nt }\end{array}$ & b1 & b2 & b3 \\
\hline $\begin{array}{l}\text { Linear } \\
\text { Logarithm } \\
\text { ic }^{\mathrm{a}^{\mathrm{a}}} \\
\text { Inverse }^{\mathrm{b}}\end{array}$ & ,019 & ,451 & 1 & 23 & ,508 & 3,127 &, 126 & & \\
\hline Quadratic & ,131 & 1,656 & 2 & 22 & ,214 & 2,768 & ,025 &, 131 & \\
\hline Cubic & ,132 & 1,067 & 3 & 21 & 384 & 2,874 &,- 068 & , 120 & ,012 \\
\hline $\begin{array}{l}\text { Exponenti } \\
\text { al }\end{array}$ & ,016 & ,365 & 1 & 23 & ,552 & 2,955 & ,037 & & \\
\hline Logistic & ,016 & ,365 & 1 & 23 & ,552 & ,338 & ,964 & & \\
\hline
\end{tabular}

The independent variable is LogEmployee_nr_Wo_spinoff.

a. The independent variable (LogEmployee_nr_Wo_spinoff) contains non-positive values. The minimum value is $-3,00$. The Logarithmic and Power models cannot be calculated.

b. The independent variable (LogEmployee_nr_Wo_spinoff) contains values of zero. The Inverse and S models cannot be calculated.

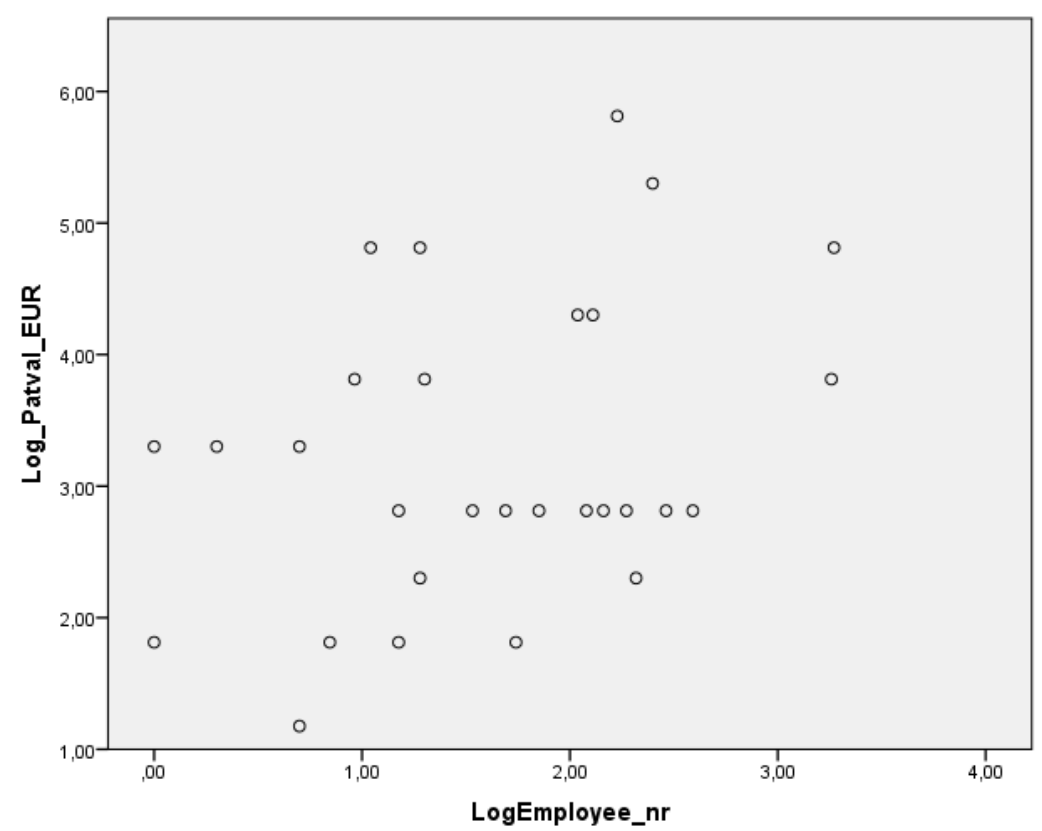




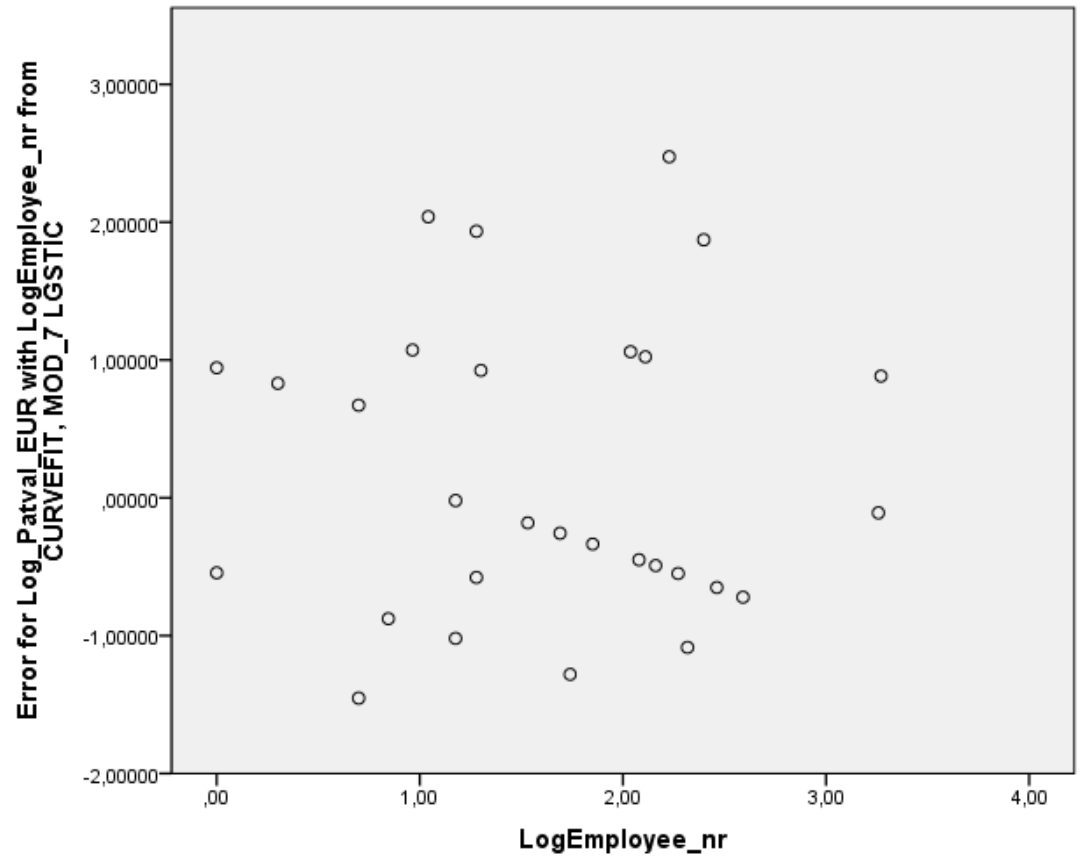


11. Annex

The difference between the normal (E1) and effective lifetime (E2) of the innovations

Descriptive Statistics

\begin{tabular}{|c|c|c|c|c|c|c|c|c|}
\hline & $\mathrm{N}$ & Range & $\begin{array}{c}\begin{array}{c}\text { Minimu } \\
\mathrm{m}\end{array} \\
\end{array}$ & $\begin{array}{c}\text { Maximu } \\
\mathrm{m}\end{array}$ & \multicolumn{2}{|c|}{ Mean } & $\begin{array}{c}\text { Std. } \\
\text { Deviation }\end{array}$ & $\begin{array}{c}\text { Varian } \\
\text { ce }\end{array}$ \\
\hline & $\begin{array}{c}\text { Statisti } \\
\mathrm{C}\end{array}$ & $\begin{array}{c}\text { Statisti } \\
\mathrm{C}\end{array}$ & Statistic & Statistic & $\begin{array}{c}\text { Statisti } \\
\text { C }\end{array}$ & $\begin{array}{l}\text { Std. } \\
\text { Error }\end{array}$ & Statistic & $\begin{array}{c}\text { Statisti } \\
\text { C }\end{array}$ \\
\hline $\begin{array}{l}\mathrm{E} 1 \\
\text { Valid N } \\
\text { (listwise) }\end{array}$ & $\begin{array}{l}36 \\
36\end{array}$ & 100 & 1 & 100 & 21,24 & 3,107 & 18,641 & $\begin{array}{r}347,47 \\
8\end{array}$ \\
\hline
\end{tabular}

Descriptive Statistics

\begin{tabular}{|c|c|c|c|c|c|c|c|c|}
\hline & $\mathrm{N}$ & Range & $\begin{array}{c}\begin{array}{c}\text { Minimu } \\
\mathrm{m}\end{array} \\
\end{array}$ & $\begin{array}{c}\text { Maximu } \\
\mathrm{m}\end{array}$ & \multicolumn{2}{|c|}{ Mean } & $\begin{array}{c}\text { Std. } \\
\text { Deviation }\end{array}$ & $\begin{array}{c}\text { Varian } \\
\text { ce }\end{array}$ \\
\hline & $\begin{array}{c}\text { Statisti } \\
\text { C }\end{array}$ & $\begin{array}{c}\text { Statisti } \\
\text { C }\end{array}$ & Statistic & Statistic & $\begin{array}{l}\text { Statisti } \\
\text { c }\end{array}$ & $\begin{array}{l}\text { Std. } \\
\text { Error }\end{array}$ & Statistic & $\begin{array}{c}\text { Statisti } \\
\text { C }\end{array}$ \\
\hline $\begin{array}{l}\text { E2 } \\
\text { Valid N } \\
\text { (listwise) }\end{array}$ & $\begin{array}{l}36 \\
36\end{array}$ & 100 & 1 & 100 & 17,69 & 3,110 & 18,659 & $\begin{array}{r}348,17 \\
5\end{array}$ \\
\hline
\end{tabular}

Statistics

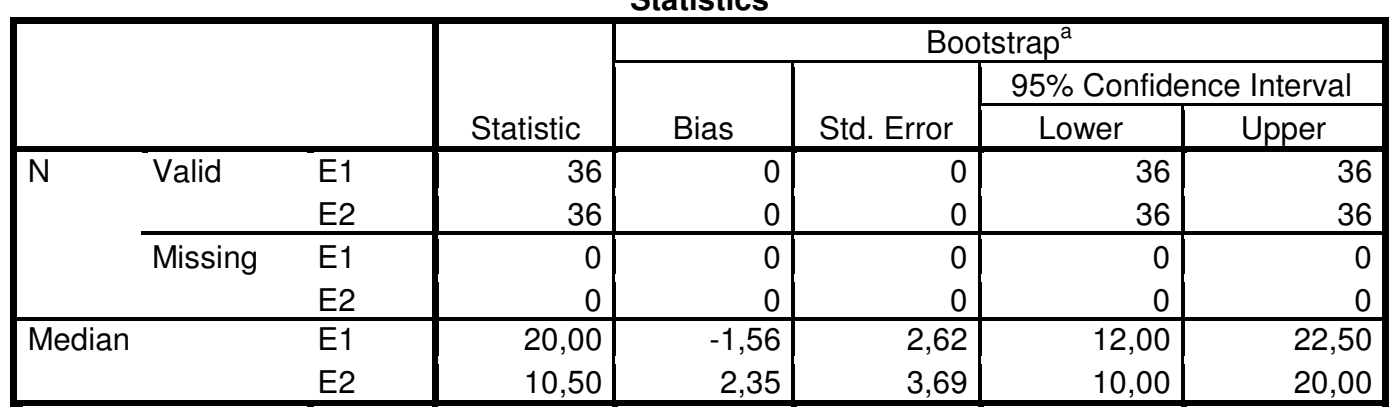

a. Unless otherwise noted, bootstrap results are based on 1000 bootstrap samples

\section{One-Sample Statistics}

\begin{tabular}{|l|r|r|r|r|}
\hline & $\mathrm{N}$ & Mean & Std. Deviation & \multicolumn{1}{c|}{ Std. Error Mean } \\
\hline $\begin{array}{l}\text { E2_wo_ } \\
\text { outlier }\end{array}$ & 35 & 15,34 & 12,389 & 2,094 \\
\hline
\end{tabular}

\section{Correlations}

\begin{tabular}{|ll|r|r|}
\hline & & E1 & \multicolumn{1}{|c|}{ E2 } \\
\hline E1 & Pearson Correlation & 1 &, 936 \\
& Sig. (2-tailed) & &, 000 \\
& $\mathrm{~N}$ & 36 & 36 \\
\hline E2 & Pearson Correlation &, 936 & 1 \\
& Sig. (2-tailed) &, 000 & \\
& $\mathrm{~N}$ & 36 & 36 \\
\hline
\end{tabular}

\section{Correlations}

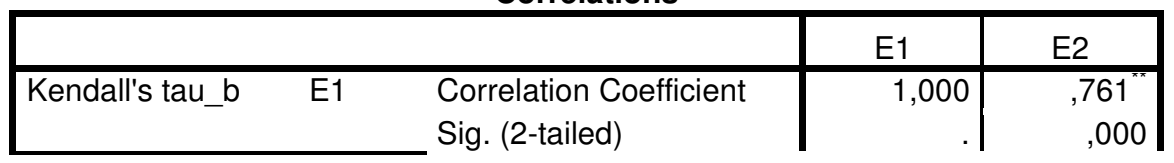




\begin{tabular}{|c|c|c|c|c|}
\hline & & $\mathrm{N}$ & 36 & 36 \\
\hline & E2 & $\begin{array}{l}\text { Correlation Coefficient } \\
\text { Sig. (2-tailed) } \\
\mathrm{N}\end{array}$ & $\begin{array}{r}, 761^{\pi \times} \\
, 000 \\
36\end{array}$ & $\begin{array}{r}1,000 \\
36\end{array}$ \\
\hline Spearman's rho & $\mathrm{E} 1$ & $\begin{array}{l}\text { Correlation Coefficient } \\
\text { Sig. (2-tailed) } \\
\mathrm{N}\end{array}$ & $\begin{array}{r}1,000 \\
. \\
36 \\
\end{array}$ & $\begin{array}{r}, 868 \\
, 000 \\
36 \\
\end{array}$ \\
\hline & E2 & $\begin{array}{l}\text { Correlation Coefficient } \\
\text { Sig. (2-tailed) } \\
\mathrm{N}\end{array}$ & $\begin{array}{r}, 868^{\pi \pi} \\
, 000 \\
36\end{array}$ & $\begin{array}{r}1,000 \\
. \\
36\end{array}$ \\
\hline
\end{tabular}

${ }^{* *}$. Correlation is significant at the 0.01 level (2-tailed).

ANOVA Table

\begin{tabular}{|c|c|c|c|c|c|c|c|}
\hline & & & $\begin{array}{l}\text { Sum of } \\
\text { Squares }\end{array}$ & $d f$ & $\begin{array}{l}\text { Mean } \\
\text { Square }\end{array}$ & $\mathrm{F}$ & Sig. \\
\hline \multirow{5}{*}{$\begin{array}{l}\text { E1 } \\
\text { E2 }\end{array}$} & \multirow{3}{*}{$\begin{array}{l}\text { Between } \\
\text { Groups }\end{array}$} & (Combined) & 11062,023 & 16 & 691,376 & 11,945 & ,000 \\
\hline & & Linearity & 10647,925 & 1 & $\begin{array}{r}10647,92 \\
5\end{array}$ & $\begin{array}{r}183,96 \\
5\end{array}$ &, 000 \\
\hline & & $\begin{array}{l}\text { Deviation from } \\
\text { Linearity }\end{array}$ & 414,098 & 15 & 27,607 & ,477 & ,925 \\
\hline & \multicolumn{2}{|c|}{ Within Groups } & 1099,720 & 19 & 57,880 & & \\
\hline & \multicolumn{2}{|l|}{ Total } & 12161,743 & 35 & & & \\
\hline
\end{tabular}

Paired Samples Test

\begin{tabular}{|c|c|c|c|c|c|c|c|c|}
\hline & \multicolumn{5}{|c|}{ Paired Differences } & \multirow[b]{3}{*}{$\mathrm{t}$} & \multirow[b]{3}{*}{ df } & \multirow{3}{*}{$\begin{array}{l}\text { Sig. (2- } \\
\text { tailed) }\end{array}$} \\
\hline & \multirow[b]{2}{*}{ Mean } & \multirow{2}{*}{$\begin{array}{c}\text { Std. } \\
\text { Deviation }\end{array}$} & \multirow{2}{*}{$\begin{array}{c}\text { Std. Error } \\
\text { Mean }\end{array}$} & \multicolumn{2}{|c|}{$\begin{array}{l}95 \% \text { Confidence } \\
\text { Interval of the } \\
\text { Difference }\end{array}$} & & & \\
\hline & & & & Lower & Upper & & & \\
\hline $\begin{array}{ll}\text { Pair } & \text { E1 - } \\
1 & \text { E2 }\end{array}$ & 3,542 & 6,688 & 1,115 & 1,279 & 5,805 & 3,177 & 35 & ,003 \\
\hline
\end{tabular}




\section{References}

Ács, Z.J. and Audretsch, D.B. [1988]: "Innovation in Large and Small Firms: An Empirical Analysis." American Economic Review 78. p. 678-90.

Administrative Office of the U.S. Courts. [1997]: “Judicial Business of the United States Courts”. Washington, D.C.

Aho, Esko, Cornu, Jozef, Georghiou, Luke and Subira, Antoni. [2006]: "Creating an Innovative Europe." Report of the Independent Expert Group on $R \& D$ and Innovation appointed following the Hampton Court Summit.

Arora, A. [1997]: "Patents, Licensing, and Market Structure in Chemicals." Research Policy 26. p. 391-403. http://dx.doi.org/10.1016/S00487333[97]00014-0

Arora, A., Ceccagnoli, M and Cohen, W. [2008]: "R\&D and the Patent Premium." International Journal of Industrial Organization 26. p. 1153-79. http://dx.doi.org/10.1016/j.ijindorg.2007.11.004

Arora, A., Ceccagnoli, M. and Cohen, W. [2003]: "R\&D and the Patent Premium." In NBER working paper.

Arundel, A. [2001]: "Patents in the Knowledge-Based Economy." Beleidsstudies Technologie Economie 37. p. 67-88.

Arundel, A. and Kabla, I. [1998]: "What Percentage of Innovations Is Patented?". Research Policy 27. p. 127-41. http://dx.doi.org/10.1016/S0048-7333[98]00033-X

Arundel, A. and Patel, P. [2003]: "Strategic Patenting. Background Report for the Trend Chart Policy Benchmarking Workshop." In New Trends in IPR Policy.

Arundel, A., van de Paal, G. and Soete, L. [1995]: "Innovation Strategies of Europe's Largest Industrial Firms. Results of the Pace Survey for Information Sources, Public Research, Protection of Innovations and Government Programmes. In: Pace Report, Final Report." edited by M. MERIT, European, Commission/GD., Telecommunication, I., u.N., d.F. [Eds.]. Brussels, GD XIII.: European Commission. 
Bajmócy, Zoltán and Málovics, György. [2011]: "Az Ökológiai Hatékonyságot Növelö Innovációk Hatása a Fenntarthatóságra. Az Ipat Formula Dinamizálása." Közgazdasági Szemle LVIII. évf., 2011. október. p. 890-904.

Baldwin, J.M. and Hanel, P. [2003]: "Innovation and Knowledge Creation in an Open Economy: Canadian Industry and International Implications”. Cambridge: University Press. http://dx.doi.org/10.1017/CBO9780511510847

Balogh, Tamás. [2012]: "Innováció És Versenyképesség." A kutatás-fejlesztési tevékenység rejtelmei. Munkácsy27 Oktatóközpont (1063 Budapest, $\begin{array}{lllll}\text { Munkácsy } & \text { Mihály } & \text { u. } & \text { I/3). }\end{array}$ http://dev.seed.hu/files/attachments/konferencia-a-kutatas-fejlesztesitevekenyseg-rejtelmei/innovacio-es-versenykepesseg-balog-tamas.pdf.

Bánfi, Tamás, Boros, Áron and Lovas, Anita. [2012]: "Vállalati Vezetők Innovációs Érzékenysége, Szemlélete És Szándékaik-Egy Felmérés Tapasztalatai [Managers' Innovation Sensivity, Approach, and Purposes-Experience of a Survey]." Vezetéstudomány/Budapest Management Review 43, no. 3. p. 2-18.

Barlow, John Perry. [1994]: "Rethinking Patents and Copyrights in the Digital Age." The Framework for Economy of Ideas. p. 83-97.

Barysch, Katinka, Tilford, Simon and Whyte, Philip. [2008]: "The Lisbon Scorecard Viii: Is Europe Ready for an Economic Storm?”. Centre for European Reform.

Barzel, Y. [1968]: "Review of Economics and Statistics." Optimal Timing of Innovations 50. p. 348-55.

Basberg, B. [1987]: "Patents and the Measurement of Technological Change: A Survey of the Literature." Research Policy 2-4. p. 131-41. http://dx.doi.org/10.1016/0048-7333[87]90027-8

Beck, U. [2003]: “A Kockázat-Társadalom. Út Egy Másik Modernitásba”. Budapest: Századvég Kiadó. 
Beckerman-Rodau, Andrew. [2010]: "The Problem with Intellectual Property Rights: Subject Matter Expansion." YALE J.L. \&TECH. 13 (35). p. 3689.

Bendzsel, M. [2006]: "Fátyoltánc a Szabadalmi Titok Körül." Iparjogvédelmi és Szerzői Jogi Szemle 1. (111.) évfolyam 1. szám, 2006. február p. 820.

Bentham, Jeremy. [1839]: “A Manual of Political Economy”. New York: G.P. Putnam.

Bessen, J. and Hunt, R. M. [2003]: "An Empirical Look at Software Patents." Journal of Economics \& Management Strategy 16(1). p. 157-89.

Bessen, J. and Meurer, M.J. [2008]: Patent Failure. How Judges, Bureaucrats, and Lawyers Put Innovators at Risk. Princeton University Press.

Bessen, James. [2008]: "The Value of Us Patents by Owner and Patent Characteristics." Research Policy 37, no. 5. p. 932-45. http://dx.doi.org/10.1016/j.respol.2008.02.005

Bessen, James and Maskin, Eric S. [2006]: "Sequential Innovation, Patents, and Innovation." www.najecon.org.

Blind, K., Edler, J., Frietsch, R. and Schmoch, U. [2006]: "Motives to Patent: Empirical Evidence from Germany." Research Policy 35(5) p. 655-72. http://dx.doi.org/10.1016/j.respol.2006.03.002

Blind, K. and Thumm, N . [2004]: "Interrelation between Patenting and Standardisation Strategies: Empirical Evidence and Policy Implications." Research Policy 33 (10). p. 1583-98. http://dx.doi.org/10.1016/j.respol.2004.08.007

Bobrovszky, Jenő. [2008]: "Az Enyém, a Tied És a Miénk a Szellemi Tulajdonban.". http://mta.hu/mta_hirei/az-enyem-a-tied-es-a-mienk-aszellemi-tulajdonban-58601/ Downloaded: 24.09.2012.

Boldrin, M. and Levine, D. K. [2009 December]: "Does Intellectual Monopoly Help Innovation? ." Review of Law \& Economics 5, no. 3. p. 4-37. http://dx.doi.org/10.2202/1555-5879.1438 
Borsi, Balázs and Bajmócy, Zoltán. [2009]: "Kvantitatív Leszakadás, Kvalitatív Felzárkózás? A Hazai Regionális Innovációpolitika Kihívásai." Közgazdasági Szemle LVI., no. 2009. október. p. 933-54.

Branstetter, L. and Sakakibara, M. [2001]: "Do Stronger Patents Induce More Innovation? Evidence from the 1988 Japanese Patent Law Reforms." Rand Journal of Economics 32. p. 77-100.

Braungart, M., McDonough, W. and Bollinger, A. [2007]: "Cradle-to-Cradle Design: Creating Healthy Emissions - a Strategy for Eco-Effective Product and System Design." Journal Of Cleaner Production 15(13/14). p. 1337-48. http://dx.doi.org/10.1016/j.jclepro.2006.08.003

Brezet, H. [1997]: "Dynamics in Ecodesign Practice.". Industry and Environment Vol. 20 N. 1-2, January-June. p. 21-24.

Bronwyn, H. H. [2006]: "Innovation and Diffusion." In The Oxford Handbook of Innovation. New York: Oxford University Press.

Brouwer, E. and Kleinknecht, A. [1999]: "Innovative Output and a Firms Propensity to Patent. An Empirical Investigation." Research Policy 28. p. 615-24. http://dx.doi.org/10.1016/S0048-7333(99)00003-7

Brunt, Liam, Josh Lerner, and Nicholas, Tom. [2012]: "Inducement prizes and innovation." The Journal of Industrial Economics 60.4. p. 657-696. http://dx.doi.org/10.1111/joie.12002

Buday-Sántha, Attila. [2009]: “Környezetgazdálkodás”. Dialog Campus.

Chesbrough, H. [2006]: “Open Business Models”. Cambridge, MA: Harvard Business School Press.

Chesbrough, Henry. [2012]: "Open Innovation. Where We've Been and Where We're Going." Research-Technology Management Special Issue: Open Innovation Revisited July_August 2012. p. 20-27.

Chien, Colleen V. [2011]: "Predicting Patent Litigation." Texas Law Review Vol. 90:283. p. 283-329.

Chikán, A. [2009]: "A Vállalati Versenyképesség És a Társadalmi Felelősség." Harvard Business Review 2008. november. p. 6 - 13. 
Chikán, Attila, Czakó, Erzsébet and Zoltayné Paprika, Zita. [2010]: "Vállalati Versenyképesség Válsághelyzetben. Gyorsjelentés a 2009. Évi Kérdőives Felmérés Eredményeiről.": Budapesti Corvinus Egyetem.

Chok, Nian Shong. [2010]: „Pearson's Versus Spearman's and Kendall's Correlation Coefficients for Continuous Data.” Doctoral Dissertation. University of Pittsburgh.

Clark, John Bates. [1927]: "Essential of Economic Theory”. New York: Macmillan.

Clay, Andrew. [June 2012]: "A Unified European Patent Process and a Unified Way of Enforcing It." Intellectual Property \& Technology Law Journal 24, no. 6 .

Cohen, W., Nelson, R.R. and Walsh, J. [2000]: " Protecting Their Intellectual Assets: Appropriability Conditions and Why U.S. Manufacturing Firms Patent (or Not)." edited by National Bureau of Economic Research. Cambridge, MA.

Cohen, W.M., Goto, A., Nagata, A., Nelson, R.R. and Walsh, J.P. [2002]: "R\&D Spillovers, Patents and the Incentives to Innovate in Japan and the United States." Research Policy 31. p. 1349-67. http://dx.doi.org/10.1016/S0048-7333(02)00068-9

Cornelli, F. and Schankerman, M.D. [1999]: "Patent Renewal and R\&D Incentives." RAND Journal of Economics 30. p. 197-213. http://dx.doi.org/10.2307/2556077

Csutora, M. and Kerekes, S. [2004]: “A Környezetbarát Vállalatirányítás Eszközei”. Budapest: Jogi és Üzleti Kiadó.

Csutora, Mária. [2008]: "Fenntartható Fogyasztás: Közösségi, Vállalati És Egyéni Kibúvó Stratégiák." Budapesti Corvinus Egyetem Környezetgazdaságtani és Technológiai Tanszék Mühelytanulmány.

Danguy, J., de Rassenfosse, G. and van Pottelsberghe de la Potterie, M. [2010]: "The R\&D-Patent Relationship: An Industry Perspective." In ECARES working paper 2010-038. 
David, Paul A. [1993]: “Intellectual Property and the Panda's Thumb: Patents, Copyrights and Trade Secrets in Economic Theory and History in Global Dimensions of Intellectual Property Rights in Science and Technology”. Washington: National Academy Press.

—. [1985]: "New Technology, Diffusion, Public Policy and Industrial Competitiveness." Stanford University, Center for Economic Policy Research.

de Rassenfosse, G. [2010]: "Essays on the Propensity to Patent: Measurement and Determinants." Ph.D. thesis, Université libre de Bruxelles.

Demsetz, Harold. [1969]: "Information and Efficiency: Another Viewpoint." Law and Economics 12. p. 1-22. http://dx.doi.org/10.1086/466657

Demsetz, Harold [1970]: "The Private Production of Public Goods." Law and Economics 13. p. 293-306. http://dx.doi.org/10.1086/466695

Dodgson, M., Gann, D. and Salter, A. [2008]: The Management of Technological Innovation. Oxford: Oxford University Press.

Dosi, G. [1988]: "Sources, Procedures and Microeconomic Effects of Innovation." Journal of Economic Literature 26. p. 1120-71.

Drucker, Peter F. [1985]: "Innovation and entrepreneurship." New York: Practice and Principles.

Duguet, E. and Kabla, I. [1998]: "Appropriation Strategy and the Motivations to Use the Patent System: An Econometric Analysis at the Firm Level in French Manufacturing. Annales D." Economie et de Statistique 49/50 p. 289-327.

Dutta, S. and Lanvin, B. (eds). [2013]: „Global Innovation Index 2013: The Dynamics of Innovation” Cornell University, INSEAD WIPO.

Ehrlich, Paul R. [1968]: “The Population Bomb”. New York: Ballantine Books.

Eisenberg, Rebecca S. [2011]: "Patent Costs and Unlicensed Use of Patented Inventions.". University Of Chicago Law Review 78(1). p. 53-69. 
Ekins, Paul. [2010]: "Eco-Innovation for Environmental Sustainability:Concepts, Progress and Policies." Int Econ Econ Policy 7. p. 267-90. http://dx.doi.org/10.1007/s10368-010-0162-Z

Enos, John L. [1958]: "A Measure of the Rate of Technological Progress in the Petroleum Refining Industry." Industrial Economics 6. p. 180-97. http://dx.doi.org/10.2307/2097628

EPO. [1994]: Utilisation of Patent Protection in Europe. Eposcript. Vol. 3., Munich: European Patent Office.

EPO. [2014]: „Annual Report 2013 - European patent applications.” European Patent Office. http://documents.epo.org/projects/babylon/eponet.nsf/0/340EC0DE935 5BD60C1257C8D0048645E/\$File/european_patent_applications_en.p df

European Commission. [2014]: "The Innovation Union Scoreboard 2014." European Union.

Fontana, R. , Nuvolari, A., Shimitzu, H. and Vezzulli, A. [June 21-24, 2010]: "The Nature of Inventive Activities. Evidence from a Data-Set of R\&D Awards." In International Schumpeter Society Conference 2010 on INNOVATION, ORGANISATION, SUSTAINABILITY AND CRISES. Aalborg.

Frietsch, Rainer, Schmoch, U, Van Looy, B, Walsh, JP, Devroede, R, Du Plessis, M, Jung, T. et al. [2010]: The Value and Indicator Function of Patents. ISI.

Fromer, Jeanne. [2009]: "Claiming Intellectual Property." University of Chicago Law Review 76. p. 719.

Frosch, R.A. and Gallopoulos, N.E. [1989]: "Strategies for Manufacturing." Scientific American 261, no. 3. p. 144-52. http://dx.doi.org/10.1038/scientificamerican0989-144

Galasso, Alberto and Schankerman, Mark. [2010]: "Patent Thickets, Courts, and the Market for Innovation." RAND Journal of Economics Vol. 41, 
No. 3, Autumn 2010 p. 472-503. http://dx.doi.org/10.1111/j.17562171.2010.00108.x

Gallini, N. [2002]: "The Economics of Patents: Lessons from Recent U.S. Patent Reform." Economic Perspective 16. p. 131-54.

Gallini, N. and Scotchmer, S. [2001]: Intellectual Property: When Is It the Best Incentive System? Innovation Policy and the Economy. Vol. 2, Cambridge: MIT Press.

Gambardella, A., Harho, D. and Verspagen, B. [2008]: "The Value of European Patents." European Management Review 5. p. 69-84.

Gambardella, Alfonso, Giuri, Paola and Luzzi, Alessandra. [2008]: "The Market for Patents in Europe." Research Policy 36, no. 8. p. 1163-83. http://dx.doi.org/10.1016/j.respol.2007.07.006

Gambardella, Alfonso, Giuri, Paola and Mariani, Myriam. [2005]: "The Value of European Patents Evidence from a Survey of European Inventors. Final Report of the Patval Eu Project." Contract HPV2-CT-2001-00013.

Gambardella, Alfonso and Hall, Bronwyn H. [2006]: "Proprietary Versus Public Domain Licensing of Software and Research Products." Research Policy 35, no. 6. p. 875-92. http://dx.doi.org/10.1016/j.respol.2006.04.004

Gambardella, A., Girui, P., Harhoff, D., Mariani, M., and Torrisi, S. [2010]. "Innovative S\&T indicators combining patent data and surveys: Empirical models and policy analyses." Final report of PatVal-EU II survey methods and results. http://bcmmntyqp.unibocconi.it/QuickPlace/innovativest/Main.nsf/\$defaultview/74EA 6A33919C1E4BC125775800683221/\$File/D_2_5.pdf?OpenElement

Gambardella, A., Harhoff, D. and Verspagen, B. [2011]: “The determinants of the private value of patented inventions." Mimeo, Bocconi University.

Gazdasági Versenyhivatal. [2003]: "A Gyógyszerpiac Szabályozásának Versenypolitikai Kérdései." In Versenyhivatali Füzetek, edited by Gazdasági Versenyhivatal. Budapest. 
Gilbert, Richard J. and Newberry, David M.G. [1982]: "Preemptive Patenting and the Persistence of Monopoly." American Economic Review 72. p. $514-26$.

Giuri, Paola, Mariani, Myriam, Brusoni, Stefano, Crespi, Gustavo, Francoz, Dominique, Gambardella, Alfonso, Garcia-Fontes, Walter, et al. [2007]: "Inventors and Invention Processes in Europe: Results from the PatvalEu Survey." Research Policy 36, no. 8. p. 1107-27. http://dx.doi.org/10.1016/j.respol.2007.07.007 http://dx.doi.org/10.1016/j.respol.2007.07.008

Griliches, Zvi. [1990]: "Patent Statistics as Economic Indicators: A Survey." Journal of Economic Literature XXVIII. p. 1661-707.

Guellec, D. and van Pottelsberghe, B. de la Potterie. [2001]: "R\&D and Productivity Growth: Panel Data Analysis of 16 Oecd Countries.". OECD Economic Studies (33). p. 103-25.

Hall, B.H, and Ham, R.-M. [April 1999] "The Patents Paradox Revisited: Determinants of Patenting in the U.S. Semiconductor Industry, 198094." University of California at Berkley.

Hall, B.H. and Ziedonis, R.M. [2001]: "The Patent Paradox Revisited: An Empirical Study of Patenting in the Us Semiconductor Industry, 19791995." The Rand Journal of Economics 32 (1). p. 101-28. http://dx.doi.org/10.2307/2696400

Hall, Bronwyn H and Harhoff, Dietmar. [2012]: "Recent Research on the Economics of Patents." National Bureau of Economic Research.

Hall, Bronwyn H. and Helmers, Christian. [2010]: „The role of patent protection in (clean/green) technology transfer." No. w16323. National Bureau of Economic Research. http://dx.doi.org/10.3386/w16323

Hámori, Balázs, Szabó, Katalin, Derecskei, Anita, Hlédik, Erika, Rosta, Miklós and Tóth, László. [2012]: "Innovációs Verseny-Esélyek És Korlátok.". Aula Kiadó. 
Hanula, Zsolt. "Jöhet a Szabadalmi Háború Vége." http://index.hu/tech/2012/08/26/johet_a_szabadalmi_haboru_vegel Downloaded: 27.08.2012.

Harangozó, G. [2007]: "Mitől Zöld Egy Vállalat? A Termelö Vállalatok Környezeti Teljesítménye." Ph.D. Értekezés, Budapesti Corvinus Egyetem.

Havas, A. [2009]: "Hungarian Paradox? Possible Reasons of the Weak Innovative Performance." Külgazdaság. LIII., no. 9-10. p. 74-112.

Heller, M. and Eisenberg, R. [1998]: "Can Patents Deter Innovation? The Anticommons in Biomedical Researc ". Science 28 May 1St. p. 698701.

Hirshleifer, Jack. [1971]: "The Private and Social Value of Information and the Reward to Innovative Activity." American Economic Review 61. p. 56174.

Hoffer, Ilona and Katona, Viktória. [2012]: "Fogalmi Kapaszkodók a Kkv-K Innovációs Gyakorlatában." Vezetéstudomány/Budapest Management Review 43, no. 9. p. 46-58.

Hoorebeek, Mark Van and Onzivu, William. [2010]: "The Eco-Patent Commons and Environmental Technology Transfer: Implications for Efforts to Tackle Climate Change." Carbon \& Climate Law Review 1. p. 13-29.

Hottenrott, Hanna and Lopes Bento, Cindy. [2012]: "Quantity or Quality? Collaboration Strategies in Research and Development and Incentives to Patent." Collaboration Strategies in Research and Development and Incentives to Patent. p. 12-047.

Hounshell, D.A. and Smith, J.K. [1988]: Science and Corporate Strategy. Cambridge: Cambridge University Press.

Hronszky, Imre. [2002]: "Kockázat És Innováció. A Technika Fejlődése Társadalmi Kontextusban.", $\quad$ http://mek.oszk.hu/01500/01548/ . Downloaded: 29.09.2012. 
Hungarian Association for Innovation. [2014]: "Innovációs Nagydíj 2013." Budapest.

Hungarian Intellectual Property Office. [2013]: “Glossary of Industrial Property Terms".

http://www.sztnh.gov.hu/English/kerdesek/ertelmezo/szt.html downloaded: 29.12.2013.

Hungarian Intellectual Property Office. [2014]: "Patent". http://www.sztnh.gov.hu/English/szabadalom/ downloaded: 02.04.2014. Hunyadi, László, Mundruczó, Gy., and Vita, L. [1997]: "Statisztika. II., hibajegyzékkel kiegészített kiadás" AULA kiadó, Budapest

Huppes, G, Kleijn, R, Huele, R, Ekins, P, Shaw, B, Esders, M and Schaltegger, S. [2008]: "Measuring Eco-Innovation:Framework and Typology of Indicators Based on Causal Chains. Final Report of the Ecodrive Project." University of Leiden.

Inzelt, A. [2010]: "Külföldi Részvétel Az Egyetemek És Az Ipar Közötti Együttmüködésben.". Közgazdasági Szemle LVII. évf., 5. sz. p. 431-56.

Inzelt, Annamária. [2011]: "Innováció - Határok Nélkül. Bevezető a Tematikus Számhoz." Külgazdaság LV. évf. 2011. szeptember-október p. 3-21.

—. [2011a] "Innováció És Nemzetköziesedés a Kicsik Világában. Bevezető a Tematikus Számhoz." Külgazdaság LV., no. 2011. szeptember-október. p. 3-21.

—_. [2011b]: "Innováció És Nemzetköziesedés a Kicsik Világában. Egy EFelvétel Eredményei." Külgazdaság LV., no. 2011. szeptember-október. p. $122-54$.

Iványi, Attila Szilárd and Hoffer, Ilona. [2010]: Innováció a Vállalkozásfejlesztésben. Budapest: Aula Kiadó.

Jaffe, A.B. [2000]: "The U.S. Patent System in Transition: Policy Innovation and the Innovation Process." Research Policy 29. p. 531-57. 
Jaffe, Adam B and Lerner, Josh. [2004]: "Innovation and Its Discontents: How Our Broken Patent System Is Endangering Innovation and Progress, and What to Do About It." Princeton University Press.

Japan Institute of Intellectual Property. [1994]: "Report on the Basic Issues Concerning Economic Effects of Intellectual Property." Japan: Japan Institute of Intellectual Property.

Jensen, Paul H., Thomson, Russell and Yong, Jongsay. [2009]: "Estimating the Patent Premium: Evidence from the Australian Inventor Survey." Melbourne: Intellectual Property Research Institute of Australia.

Kani, Masayo and Motohashi, Kazuyuki. [2012]: "Understanding the Technology Market for Patents: New Insights from a Licensing Survey of Japanese Firms." Research Policy 41, no. 1. p. 226-35. http://dx.doi.org/10.1016/j.respol.2011.08.002

Kanwar, S. and Evenson, R. [2003]: "Does Intellectual Property Protection Spur Technological Change?". Oxford Economic Papers 55. p. 235-64. http://dx.doi.org/10.1093/oep/55.2.235

Kemp, R and Foxon, T. [2007]: "Typology of Eco-Innovation.". Maastricht: UNU-MERIT.

Kemp, R., Schot, J. and Hoogma, R. [1998]: "Regime Shifts to Sustainability through Processes of Niche Formation: The Approach of Strategic Niche Management.". Technology Analysis and Strategic Management 10 (2). p. 175-95. http://dx.doi.org/10.1080/09537329808524310

Kerekes, S. [2006]: "A Fenntartható Fejlődés Közgazdasági Értelmezése.". In Fenntartható Fejlődés Magyarországon - Jövőképek És Forgatókönyvek., 196-211. Budapest: ÚMK.

Kerekes, S. and Wetzker, K. [2007]: "Keletre Tart a "Társadalmilag Felelős Vállalat" Koncepció [the Concept of Csr Going East]." Harvard Businessmanager 2007/04. p. 37-47.

Kica, Evisa and Groenendijk, Nico. [2011]: "The European Patent System: Dealing with Emerging Technologies." Innovation - The European 
Journal of Social Science Research Vol. 24, Nos. 1-2, March-June 2011. p. 85-105.

Kingston, W. [2001]: "Innovation Needs Patents Reform." Research Policy 30. p. 403-23. http://dx.doi.org/10.1016/S0048-7333(00)00090-1

Kiss, János. [2009]: "A Magyar Innovációs Rendszer Helyzete Vállalati NézIpontból." Budapesti Corvinus Egyetem.

—. [2004]: "A Technológiai Innováció Szerepe a Magyar Vállalatok Versenyképességében." Ph.D. Értekezés, Budapesti Corvinus Egyetem.

Kiss, Károly. [2009]: "Zöld Gazdaságpolitika." Aula.

Kitch, E.W. [1977]: "The Nature and Function of the Patent System." Journal of Law and Economics 20. p. 265-90. http://dx.doi.org/10.1086/466903

Kleinknecht, A. and van der Panne, G. [2009]: "The Propensity to Patent an Innovation: Comparing Entrepreneurial to Routinized Innovators." TU Delft.

Kocsis, Tamás. [2010]: "„Hajózni Muszáj!” a Gdp, Az Ökológiai Lábnyom És a Szubjektív Jóllét Stratégiai Összefüggései." Közgazdasági Szemle LVII. évf., 2010. június. p. 536-54.

Kortum, S. and Lerner, J. [1998]: "Stronger Protection or Technological Revolution: What Is Behind the Recent Surge in Patenting?". CarnegieRochester Conference Series on Public Policy 48. p. 247-304. http://dx.doi.org/10.1016/S0167-2231(98)00023-2

_. [1999]: "What Is Behind the Recent Surge in Patenting?". Research Policy 28. p. 1-22. http://dx.doi.org/10.1016/S0048-7333(98)00082-1

Kortum, S. and Putnam, J. [1989]: "Estimating Patenting by Industry: Parts I and II ". New Haven: Yale University.

Krakovsky, Marina. [2012]: "Patently Inadequate." Communications of the ACM. Vol. 55 No. 7, p. 18-20.

Kremer, Michael, and Williams, Heidi. [2010]: "Incentivizing innovation: Adding to the tool kit." Innovation Policy and the Economy, Volume 10. University of Chicago Press. p. 1-17. 
Hungarian Central Statistical Office. [2012]: Statistical reflections. Issue 30., Volume 6., 2012.09.13.

Lampe, Ryan L., and Moser, Petra. [2012]: „Do patent pools encourage innovation? Evidence from 20 US Industries under the New Deal." No. w18316. National Bureau of Economic Research. http://dx.doi.org/10.3386/w18316

Lanjouw, J. and Cockburn, I. [2002]: "New Pills for Poor People? Empirical Evidence after Gatt." World Development 29. p. 265-89. http://dx.doi.org/10.1016/S0305-750X(00)00099-1

Lanjouw, J. O. [1997]: "The Introduction of Pharmaceutical Product Patents in India: Heartless Exploitation of the Poor and Suffering?" In NBER Working Paper.

Lanjouw, J.O. and Lerner, J. [1997]: "The Enforcement of Intellectual Property Rights: A Survey of the Empirical Literature." In NBER, Working Paper.

Lanjouw, J.O. and Mody, A. [1996]: "Innovation and the International Diffusion of Environmentally Responsive Technology." Research Policy 25. p. 549-71. http://dx.doi.org/10.1016/0048-7333(95)00853-5

Lanjouw, Jean O. and Schankerman, Mark [2004]: "Protecting Intellectual Property Rights: Are Small Firms Handicapped?". Law and economics 47 (1). p.45-74.

Leger, A. [June 2004]: "Strenghtening of Intellectual Property Rights in Mexico: A Case Study of Maize Breeding." In working paper. Unisfera International Center.

Lehota, József. [2001]: „Marketingkutatás az Agrárgazdaságban.” Mezőgazda Kiadó. ISBN: 9639358258

Lemley, Mark A. [2008]: "Ignoring Patents." Michigan State Law Review Vol. 2008:19. p. 19-34.

Lengyel, I. [2001]: " Iparági És Regionális Klaszterek: Tipizálásuk, Térbeliségük És Fejlesztésük Főbb Kérdései.". Vezetéstudomány 10. p. 64-89. 
Lerner, J. [2002]: "Patent Protection and Innovation over 150 Years." The American Economic Review Papers and Proceedings 92. p. 221-25. http://dx.doi.org/10.1257/000282802320189294

_. [1995 October]: "Patenting in the Shadow of Competitors." Law and Economics 01.38, no. NO.2. p. 463-95.

Levin, R., Kievorick, A., Nelson, R.R. and Winter, S.G. [1987]: "Appropriating the Returns from Industrial R\&D." Brookings Papers on Economic Activity. p. 783-820. http://dx.doi.org/10.2307/2534454

Levine, Dan. "Judge Who Shelved Apple Trial Says Patent System out of Sync." http://www.reuters.com/article/2012/07/05/us-apple-google-judgeidUSBRE8640IQ20120705 Downloaded: 28.08.2012.

Levine, L. and Saunders, K.M. [2004]: "Software Patents: Innovation or Litigation?" In IFIP 8.6 Working Conference: IT Innovation for Adaptiveness and Competitive Advantage. Leixlip, Ireland.

Licht, G. and Zoz, K. [June 1996]: "Patents and R\&D. An Econometric Investigation Using Applications for German, European and Us Patents by German Companies." ZEW-Mannheim.

Lifset, R. and Graedel, T. [2002]: "A Handbook of Industrial Ecology." Cheltenham: Edward Elgar.

Lo, S-T. [2004]: "Strenghtening Intellectual Property Rights: Experience from the 1986 Taiwanese Patent Reforms." UCLA, Dept. of Economics.

Losoncz, Miklós. [2008]: "Az Eu-Csatlakozás És a Magyar Kutatás-Fejlesztési És Technológiai Innovációs Stratégia." Közgazdasági Szemle, LV. évf., 2008. február. p. 169-82.

Lőrincz, László. [2007]: "A Járadékszerzés Elmélete." Kormányzás, Közpénzügyek, Szabályozás II., no. 1. p. 105-25.

Machlup, Fritz. [1958]: "An Economic Review of the Patent System." In Study of the Sub-Committee on Patents, Trademarks, and Copyrights of the Committee on the Judiciary 85th Congress, Second Session. 
—. [1968]: "Patents." In International Encyclopedia of the Social Sciences, New York: Macmillian. p. 461-72.

Mak, James and Walton, Gary M. [1972]: "Steamboats and the Great Productivity Surge in River Transportation." Economic History 32. p. 619-40. http://dx.doi.org/10.1017/S0022050700077159

Mäkinen, Iiro. [September 20-21. 2007]: "The Propensity to Patent: An Empirical Analysis at the Innovation Level." In EPIP-2007 Conference. Lund, Sweden.

Mandel, G.N. [2005]: "Promoting Environmental Innovation with Intellectual Property Innovation: A New Basis for Patent Rewards." In 24 TEMP. ENVT'L L. \& TECH. J. 51. [symposium] Environmental Technology and Innovation. Temple Law School.

Mann, R. [February 2004]: "The Myth of the Software Patent Thicket: An Empirical Investigation of the Relationship between Intellectual Property and Innovation in Software Firms." The University of Texas School of Law, Law and Economics.

Mansfield, E., Schwartz, M. and Wagner, S. [1981]: "Imitation Costs and Patents: An Empirical Study." Economic Perspective 91. p. 907-18.

Mansfield, Edwin [1986]: "Patents and Innovation: An Empirical Study." Management $\quad$ Science $32 . \quad$ p. 173-81. http://dx.doi.org/10.1287/mnsc.32.2.173

Marinova, D. and McAleer, M. [2003]: "Modelling Trends and Volatility in Ecological Patents in the USA." Environmental Modelling \& Software 18. p. 195-203. http://dx.doi.org/10.1016/S1364-8152(02)00079-8

Maskus, Keith. [2010]: „Differentiated intellectual property regimes for environmental and climate technologies." No. 17. OECD Publishing. http://dx.doi.org/10.1787/5kmfwjvc83vk-en

Masnick, Mike. [2010]: "Meet the Patent Thicket: Who's Suing Who for Smartphone

Patents.". http://www.techdirt.com/blog/wireless/articles/20101007/22591311328/ 
meet-the-patent-thicket-who-s-suing-who-for-smartphonepatents.shtml. Downladed: 25.09.2012.

Mazzoleni, Roberto and Nelson, Richard R. [1998]: "The Benefits and Costs of Strong Patent Protection: A Contribution to the Current Debate." Research Policy 27, no. 3. p. 273-84. http://dx.doi.org/10.1016/S0048$\underline{7333(98) 00048-1}$

McDonough, W. and Braungart, M. [2002]: Cradle to Cradle: Remaking the Way We Make Things. New York: North Point Press.

Menell, Peter S. [1989]: "An Analysis of the Scope of Copyright Protection for Application Programs." Stanford Law Review 41. p. 1045-104. http://dx.doi.org/10.2307/1228751

_. [1998]: "An Epitaph for Traditional Copyright Protection of Network Features of Computer Software." The Antitrust Bulletin 43. p. 651-713.

—. [1999]: "Intellectual Property: General Theories." In Encyclopedia of Law \& Economics.

_. [1987]: "Tailoring Legal Protection for Computer Software." Stanford Law Review 39. p. 1329-72. http://dx.doi.org/10.2307/1228849

Merges, R.P. and Nelson, R.R. [1990]: "On the Complex Economics of Patent Scope." Columbia Law Review 90. p. 839-916. $\underline{\text { http://dx.doi.org/10.2307/1122920 }}$

Merges, Robert P. [1995]: "The Economic Impact of Intellectual Property Rights: An Overview and Guide." Cultural Economics 19. p. 103-17. http://dx.doi.org/10.1007/BF01074200

Merz, J. and Pace, R. [1994]: "Trends in Patent Litigation: The Apparent Influence of Strengthened Patents Attributable to the Court of Appeals for the Federal Circuit." Journal of the Patent and Trademark Office Society 76.

Mill, John Stuart. [1862]: Principles of Political Economy [5th Edn]. New York: Appleton. 
Ministry of National Economy. [2013]: "Befektetés a Jövőbe Nemzeti KutatásFejlesztési És Innovációs Stratégia 2013-2020". Budapest: Nemzetgazdasági Minisztérium.

Moser, Petra. [2005]: "How Do Patent Laws Influence Innovation? Evidence from Nineteenth-Century World's Fairs." American Economic Review 94.4. p. 1214-36. http://dx.doi.org/10.1257/0002828054825501

—. [August 2007]: "Why Don't Inventors Patent?" In NBER Working Paper.

Motohashi, Kazuyuki. [2008]: "Licensing or Not Licensing? An Empirical Analysis of the Strategic Use of Patents by Japanese Firms." Research $\begin{array}{lllll}\text { Policy } & 37, & \text { no. } & \text { 9. } & \text { 1548-55. }\end{array}$ http://dx.doi.org/10.1016/j.respol.2007.12.014

Musk, Elon. [12 June 2014]: „All Our Patent Are Belong To You”. http://www.teslamotors.com/blog/all-our-patent-are-belong-you Downloaded: 16.06.2014.

Myhrvold, Nathan. [2010]: "The Big Idea Funding Eureka!". Harvard Business Review March 2010. p. 40-50.

Nameroff, T.J., Garant, R.J. and Albert, M.B. [2004]: "Adoption of Green Chemistry: An Analysis Based on Us Patents." Research Policy 33. p. 959-74. http://dx.doi.org/10.1016/j.respol.2004.03.001

Nelson, Richard R. and Winter, Sidney G. [1982]: An Evolutionary Theory of Economic Change. Cambridge, MA: Belknap of Harvard University Press.

Némethné Pál, Katalin. [2010]: "Innovációs Tevékenység Mérése a Magyar Vállalatoknál." Ph.D. Értekezés, Budapesti CORVINUS Egyetem.

Network, Global Footprint. [2009]: "Ecological Footprint Standards 2009. Oakland: $\quad$ Global $\quad$ Footprint $\quad$ Network.". http://www.footprintnetwork.org/images/uploads/Ecological_Footprint Standards_2009.pdf

Nicholas, Tom. [2013a]: "Hybrid Innovation in Meiji, Japan." International Economic Review 54.2. p. 575-600. 
Nicholas, Tom. [2013b]: „Are Patents Creative or Destructive?” Harvard Business School Working Paper.

Nordhaus, William D. [1969]: Invention, Growth and Welfare: A Theoretical Trea. Cambridge, MA: MIT Press.

North, D.C. [1981]: "Structure and Change in Economic History”. Norton.

OECD. [2005]: The Measurement of Scientific and Technological Activities, Oslo Manual: Guidelines for Collecting and Interpreting Innovation Data. Organisation for Economic Co-operation and Development.

—. [2009]: "Oecd Innovációpolitikai Országtanulmányok: Magyarország." Budapest: Nemzeti Kutatási és Technológiai Hivatal.

_. [June, 2003]: "Preliminary Results of Oecd/Biac Survey on the Use and Perception of Patents in the Business Community." In Working Party on Innovation and Policy, edited by Committee for Scientific and Technological Policy.

—. [2011]: "Science, Technology and Industry Scoreboard 2011."

—. [2001]: "Using Patent Counts for Cross-Country Comparisons of Technology Output." In Science Technology Industry, 129-46. Paris: OECD.

OECD Patent Database and US Patent and Trademark Office. [2011]: "The Uspto Trademark Casefile Dataset [1884-2010], Ohim Community Trademark Database, Jpo Annual Reports 2008-2010, Ctm Download, April 2011.". http://dx.doi.org/10.1787/888932485386

Oppenlander, K.H. [1984]: "Patentwesen, Technischer Fortschritt and Wettbewerb." Berlin: Schriftenreihe des Instituts für Oekologische Wirtschaftsforschung.

Osman, Péter. [2006]: "Fórum. Tegyük Végre Tisztába Nézeteinket Az Innovációról.". Iparjogvédelmi és Szerzői Jogi Szemle. p. 108-30.

—. [2012]: "Könyv És Folyóiratszemle. Iparjogvédelem. Szellemi Tulajdon Nemzeti Hivatala 2012.". Iparjogvédelmi és Szerzői Szemle 7. (117.) Évfolyam 2. szám 2012. április. p. 174-80. 
Pakucs, J and Papanek, G. [2006]: Innováció Menedzsment. Budapest: Magyar Innovációs Szövetség.

Pakucs, János. [2003]: "Az Innováció Hatása a Nemzeti Jövedelem Növekedésére (a Gdp Növekedés Részarányából Az Innováció Hatása) Nemzetközi És Hazai Elemzés Alkalmazásával." Magyar Innovációs Szövetség.

Palmer, K., Oates, W.E. and Portney, P.R. [1995]: "“Tightening Environmental Standards: The Benefit-Cost or No-Cost Paradigm?" ". Journal of Economic Perspectives 9 (Fall 1995). p. 119-32. http://dx.doi.org/10.1257/jep.9.4.119

Palmer, Tom G. [1990]: "Are Patents and Copyrights Morally Justified? The Philosophy of Property Rights and Ideal Objects." Harvard Law and Public Policy 13. p. 817-65.

_. [1989]: "Intellectual Property: A Non-Posnerian Law and Economics Approach." Hamline Law Review 12. p. 261-304.

Palugyai, I. [2004]: "Szabadalomra Oktatnak." Népszabadság.

Park, W.G. [December 2001]: "R\&D, Spillovers, and Intellectual Property Rights." Dept. of Economics, American University.

Pigou, A.C. [1924]: The Economics of Welfare (2nd Edn). London: Macmillan. Pintz, György. [2014]: „Találd fel magad - avagy a siker szabadalma.” Pintz és Társai Kft. Budapest.

Pitkethly, R.H. [2001]: "Intellectual Property in Japanese and Uk Companies: Patent Licensing Decisions and Learning Opportunities." Research Policy $30 \quad$ (3). $\quad$ p. $\quad 425-42 . \quad$ http://dx.doi.org/10.1016/S0048$\underline{7333(00) 00084-6}$

Pitti, Zoltán. [2008]: "'A Hazai Vállalkozások Demográfiai, Teljesítményi És Eredményességi Jellemzői a 2000-2007. Évi Innovációs Gyakorlat És K+F Teljesítmények Tükrében” [Kutatási Összefoglaló]." Budapest.

Plant, Arnold [1934]: "The Economic Theory Concerning Patents for Inventions." Economica 1. p. 30-51. http://dx.doi.org/10.2307/2548573 
Porter, M. E and Kramer, M. R. [2007]: "Stratégia És Társadalom: A Versenyelőny És a Vállalatok Társadalmi Felelőssége." Harvard Businessmanager 2007/2. p. 6-20.

Porter, M. E. and Van der Linde, C. [1995]: "Toward a New Conception of the Environment-Competitiveness Relationship. " Journal of Economic Perspectives 9 (4) Fall. p. 97-118. http://dx.doi.org/10.1257/jep.9.4.97

Prager, Frank D. [1946]: "Brunelleschi's Patent." Journal of Patent Office Society 28. p. 109.

Qian, Y. [2007]: "Do National Patent Laws Stimulate Domestic Innovation in a Global Patenting Environment? A Cross-Country Analysis of Pharmaceutical Patent Protection, 1978-2002." Review of Economics and Statistics 89. p. 436-53.

Rakusz, Lajos. [2008]: "Az Innováció Intézményrendszere.". http://teszt.ipe.hu/wp-content/uploads/Az-innovaciointezmenyrendszere.pdf Downloaded: 07.06.2012.

Ransburg, Beatrix. [2011]: "A Fenntartható Fejlödés Vállalati Integrációja a Kommunikáció Tükrében. A Hazai Nagyvállalati Gyakorlat Vizsgálata." Ph.D. Értekezés, Budapesti Műszaki és Gazdaságtudományi Egyetem.

Raymond, Michel, and Rousset, Francois. [1995]: "An exact test for population differentiation." Evolution. p. 1280-1283.

Reitzig, Markus. [2004]: "Improving Patent Valuations for Management Purposes-Validating New Indicators by Analyzing Application Rationales." Research Policy 33, no. 6. p. 939-57. http://dx.doi.org/10.1016/j.respol.2004.02.004

Rennings, K. [2000]: "Redefining Innovation - Eco-Innovation Research and the Contribution from Ecological Economics." Ecological Economics 32. p. 319-32. http://dx.doi.org/10.1016/S0921-8009(99)00112-3

Roberts, B. [1999]: "A Tale of Two Patent Strategies." Electronic Business 10 (25). p. 79-84. 
Romer, P. [1996]: "Science, Economic Growth and Public Policy." edited by B. Smith and C. Barfield: Technology, R\&D, and the Economy, Brookings Institution and American Enterprise Institute.

Rosenberg, Nathan. [1972]: "Factors Affecting the Diffusion of Technology." Explorations in Economic History 10. p. 3-33. http://dx.doi.org/10.1016/0014-4983(72)90001-0

RPX, Corporation. [2011]: "Securities Registration Statement." http://files.shareholder.com/downloads/ABEA$\underline{\text { 5XYKB4/3439507040x0xS1193125-11-116066/1509432/filing.pdf }}$

Ryan, C. [2003]: "Learning from a Decade [or So] of Eco-Design Experience." $\begin{array}{llllll}\text { Journal } & \text { of } & \text { Industrial } & \text { Ecology } & 7 & \text { (2). }\end{array}$ http://dx.doi.org/10.1162/108819803322564316

Sakakibara, M. and Branstetter, L. [2001]: "Do Stronger Patents Induce More Innovation? Evidence from the 1988 Japanese Patent Law Reforms." RAND Economics 32. p. 77-100.

Schalk, H.J., Täger, U.C. and Brander, S. [1999]: "Wissensverbreitung Und Diffusionsdynamik Im Spannungsfeld Zwischen Innovierenden Und Imitierenden Unternehmen." München: Ifo-Institut für Wirtschaftsforschung.

Schankerman, M. [1998]: "How Valuable Is Patent Protection? Estimates by Technology Field." RAND Economics 29. p. 77-107. http://dx.doi.org/10.2307/2555817

Scherer, F. and Harhoff, D. [2000]: "Technology Policy for a World of SkewDistributed Outcomes." Research Policy 29, no. 4-5. p. 559-66. http://dx.doi.org/10.1016/S0048-7333(99)00089-X

Scherer, F.M. [1965]: "Firm Size, Market Structure, Opportunity, and the Output of Patented Inventions." American Economic Review. p. 1097125.

[1980]: Industrial Market Structure and Economic Performance (2nd Edn). Chicago: Rand McNally \& Co.. 
Scherer, F.M. and Weisbrod, S. [1995]: "Economic Effects of Strengthening Pharmaceutical Patent Protection in Italy." International Review of Industrial Property and Copyright Law 26. p. 1009-24.

Schumpeter, J. A. [1980]: A Gazdasági Fejlődés Elmélete: Vizsgálódás a Vállalkozói Profitról, a Tökéről, a Hitelről, a Kamatról És a Konjunktúraciklusról. Budapest: Közgazdasági és Jogi Könyvkiadó.

Schumpeter, J. A. [1934]: The Theory of Economic Development. Cambridge, Mass.: Harvard University Press.

Schwartzmann, D. [1976]: Innovation in the Pharmaceutical Industry. Baltimore, MD: John Hopkins University Press.

Scotchmer, S. [1999]: "On the Optimality of the Patent Renewal System." RAND Economics 30. p. 181-96. http://dx.doi.org/10.2307/2556076

_ [1991]: "Standing on the Shoulders of Giants: Cumulative Research and Patent Law." Economic Perspectives 5. p. 29-41. http://dx.doi.org/10.1257/jep.5.1.29

Senftleben, Martin. [2010]: "Overprotection and Protection Overlaps in Intellectual Property Law - the Need for Horizontal Fair Use Defences . , , Eds., Cheltenham: E." In The Structure of Intellectual Property Law: Can One Size Fit All? 2011. Cheltenham: Edward Elgar Publishing.

Sirilli, G. [1987]: "Patents and Inventors: An Empirical Study." Research Policy 16. p. 157-74. http://dx.doi.org/10.1016/0048-7333(87)90029-1

Smahó, M. [2005]: "Szabadalmi Bejelentések És Területi Innovativitás Magyarországon ". Tér és Társadalom 19. évf. , no. 3-4. p. 61-79.

Smith, Adam. [1776]: The Wealth of Nations [Cannan, E. Ed. 1976]. Oxford: Clarendon.

Smith, Kim and Petersen, Julie. [2011]: "Steering Capital: Optimizing Financial Support for Innovation in Public Education." Bellwether Education Partners. http://files.eric.ed.gov/fulltext/ED522063.pdf 
Sommer, T., Gaines S.E. and Olsen, B.E. [2010] "Guest editorial note.” Nordic Environmental Law Journal. 2. Special Issue Climate Change and Intellectual Property Rights. p. 105-110.

Stoneman, Paul. [1987]: The Economic Analysis of Technology Policy. New York, NY: Oxford University Press.

Szabó, Katalin. [2009]: "Innováció Magyarországon: Felülnézetben És Földközelben." Vezetéstudomány 4. p. 2-15.

Széchy, Anna. [2011]: "Környezeti Innovációk a Hazai Feldolgozóiparban." Ph.D. Értekezés, Budapesti Corvinus Egyetem.

—. [2012]: "Környezeti Innovációk a Hazai Feldolgozóiparban." Vezetéstudomány XLIII., no. 11. p. 60-73.

SZTNH. [2013. III. negyedév]: In „Hírlevél a Szellemi Tulajdon Védelméről” 10. évfolyam 3. szám.

Szűcs, Gergely. [2011]: "Az 1990-2000 között benyújtott magyar szabadalmi bejelentések környezeti hatásának idősoros elemzése." Vezetéstudomány. 42.10. pp. 44-52.

Taylor, C. and Silberston, Z.A. [1973]: The Economic Impact of the Patent System. London: Cambridge University Press.

Teece, D.J. [1986]: "Profiting from Technological Innovation: Implications for Integration, Collaboration, Licensing and Public Policy." Research Policy 15. p. 286-305. http://dx.doi.org/10.1016/0048-7333(86)90027-2

Török, Ádám. [2006]: Stratégiai Ágazat Stratégia Nélkül? A Magyar KutatásFejlesztés Teljesítménye És Versenyképessége Nemzetközi Összehasonlításban. Savaria University Press. Szombathely.

Trajtenberg, Manuel. [1990]: "A Penny for Your Quotes: Patent Citations and the Value of Innovations." The Rand Journal of Economics. p. 172-87. http://dx.doi.org/10.2307/2555502

Turner, Julie S. [1998]: "The Nonmanufacturing Patent Owner: Toward a Theory of Efficient Infringement." California Law Review 86, no. 1. http://dx.doi.org/10.2307/3481149 
Tzeng, Cheng-Hua. [2009]: "A Review of Contemporary Innovation Literature: A Schumpeterian Perspective.". Innovation: Management, Policy \& Practice. Dec2009, Vol. 11 Issue 3. p. 373-94. http://dx.doi.org/10.5172/impp.11.3.373

UNCTAD. [1994]: "The Outcome of the Uruguay Round: An Initial Assessment". New York, NY: United Nations.

UNEP, EPO and ICTSD. [2010]."Patents and Clean Energy: Bridging the Gap Between Evidence and Policy: Final Report." Geneva, Munich.

Valente, T. W. [1995]: “Network Models of the Diffusion of Innovations.” New Jersey: Hampton Press.

Van Ark, Bart and Piatkowski, Marcin. [2004]: "Productivity, Innovation and Ict in Old and New Europe." International Economics and Economic Policy 1, no. 2. p. 215-46. http://dx.doi.org/10.1007/s10368-004-0012-y

Vardi, Nathan. [2011]: "Trolling for Suckers." Forbes 8/8/2011, Vol. 188, Issue 2.

Venulex, Legal Summaries. [2011]: "The 2011 Patent Reform Act." In Jones Day Commentary.

Von Hippel, Eike. [1988]: “The Sources of Innovation.” New York, NY: Oxford University Press.

Von Weizsäcker, Ernst U., Lovins, Amory B. and Lovins, L. H. [1995]: „Faktor Vier. Doppelter Wohlstand - Halbierter Naturverbrauch.“. München: Droemer-Knaur.

Wackernagel, Mathis and Rees, William. [2001]: "Ökológiai Lábnyomunk.": Föld Napja Alapítvány.

Wagner, Marcus. [2007]: "On the Relationship between Environmental Management, Environmental Innovation and Patenting: Evidence from German Manufacturing Firms." Research Policy 36. p. 1587-602. http://dx.doi.org/10.1016/j.respol.2007.08.004

Walley, N. and Whitehead, B. [May-June 1994]: "It's Not Easy Being Green." Harvard Business Review. p. 46-52. 
Walsh, John P and Nagaoka, Sadao. [2009]: "How" Open" Is Innovation in the Us and Japan?: Evidence from the Rieti-Georgia Tech Inventor Survey,". No. 09022.

WBCSD. [1998]: "Cleaner Production and Eco-Efficiency - Complementary Approaches to Sustainable Development.".

WBSCD. [1996]: "Eco-Efficient Leadership - for Improved Economic and Environmantal Performance.".

World Commission on Environment and Development [WCED]. [1987]: Our Common Future. Oxford: Oxford University Press.

Yin, R. [1994]: Case Study Research: Design and Methods, 2nd Edition. London: SAGE Publishing.

Yin, R.K. [2008]: Case Study Research: Design and Methods, 4th Edition. London: SAGE Publishing.

Zilahy, G. [2004]: "Organisational Factors Determining the Implementation of Cleaner Production Measures in the Corporate Sector." Journal of Cleaner Production 12. p. 311-19. http://dx.doi.org/10.1016/S0959$\underline{6526(03) 00016-7}$

Zilahy, Gyula. [2000]: "A Tisztább Termeléstől Az Ipari Ökológiáig." http://www.ipariokologia.hu/ie_pres /gyulacikk.htm. Downloaded: 12.09.2012.

Zilahy, Gyula and Széchy, Anna. [2010]: "Eco-Innovations in the Chemical Industry: Motivation Factors and Barriers." In Knowledge Collaboration \& Learning for Sustainable Innovation ERSCP-EMSU conference. Delft, The Netherlands.

Zivkovic, Jelena. [2012]: "Strengths and Weaknesses of Business Research Methodologies: Two Disparate Case Studies." Business Studies Journal 4, no. 2. p. 91-99. 


\section{The author's own publications related to the topic}

Szücs, Gergely. (under publication): „A Szabadalmak Megkérdőjeleződött Hasznossága (Query about the Usefulness of Patents)" Vezetéstudomány/Budapest Management Review

Szűcs, Gergely. (under publication): „Mikor Érdemes az Innovációt Szabadalmaztatni? (When is it Worth to Patent an Innovation?)" Értékelemzési Szemle

Szűcs, Gergely. [2011]: „Az 1990-2000 Között Benyújtott Magyar Szabadalmi Bejelentések Környezeti Hatásának Idősoros Elemzése.” (Time series analysis of environmental effects of submitted Hungarian patents between 1990 and 2000)." Vezetéstudomány/Budapest Management Review 42.10. p. 44-52.

Szücs, Gergely. [2010]: „Overview of Hungarian Technological Innovations with Positive Environmental Effect” p. 15-25 in „Towards a Green Economy: Young Researcher Perspective” edited by J. Hlaváček, P. Šauer and J. Šauerová et al. Litomysl: Litomysl Seminar Publishing.

Szücs, Gergely. [2011]: „Drivers and Drawbacks of Environmental Innovation: Empirical Analysis of the Hungarian Chemical Sector" 3rd International Conference of Economic Sciences, Sustainable economics-community strategies, Kaposvár, 2011. május 19-20.

Szücs, Gergely. [2011]: „Empirical Analysis of Environmentally Innovative Approaches in the Hungarian Chemical Sector" 14th EMAN Conference, Budapest, 2011. január 24-25.

Szűcs, Gergely. [2010]: „Environmental Innovations - Empirical Study of the Hungarian Chemical Sector" International Conference on the occasion of the Hungarian Science Festival, Sopron, 2010. november 3.

Szücs, Gergely. [2010]: „Trend Analysis of Environmental Effects of Hungarian Patents Between 1990-2006" M I D - T E R M " International Conference, Pécs, 2010. október 8-9. 